\title{
Building and Sustaining Innovation Ecosystems
}

A Research on New Ventures' Strategies and Capabilities

\section{Jin Han}

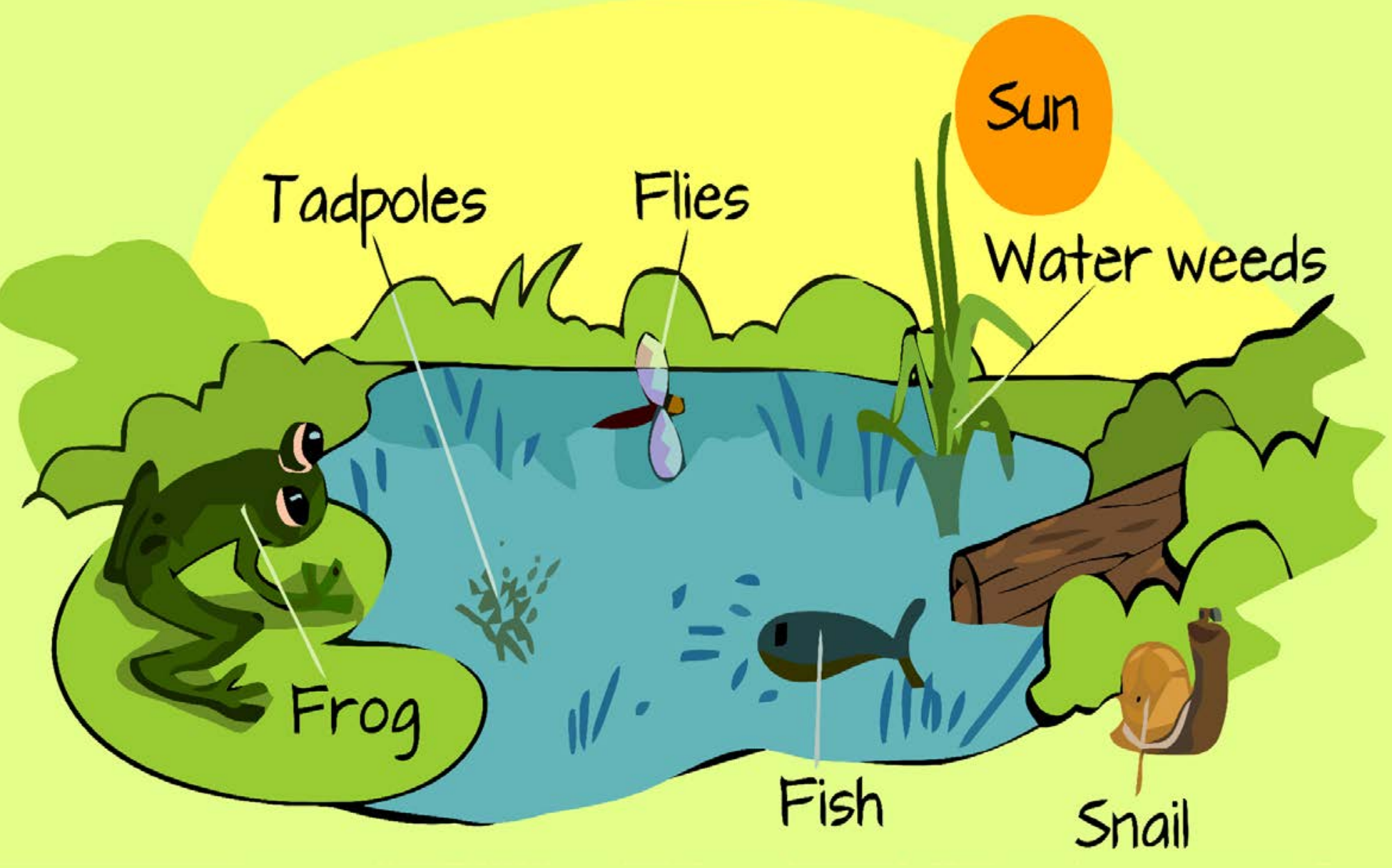



BUILDING AND SUSTAINING INNOVATION ECOSYSTEMS

A RESEARCH ON NEW VENTURES' STRATEGIES AND CAPABILITIES

\author{
Jin Han
}





\title{
BUILDING AND SUSTAINING INNOVATION ECOSYSTEMS
}

\section{A RESEARCH ON NEW VENTURES’ STRATEGIES AND CAPABILITIES}

\author{
DISSERTATION
}

to obtain

the degree of doctor at the Universiteit Twente, on the authority of the rector magnificus, prof. dr. ir. A. Veldkamp, on account of the decision of the Doctorate Board to be publicly defended on Thursday 9 September 2021 at 12.45 hours

by

\section{Jin Han}

born on the $11^{\text {th }}$ of August, 1990 in Hunan, China 
This dissertation has been approved by:

Supervisor

prof. dr. ir. P.C. de Weerd-Nederhof

Co-supervisors

dr. ir. S.J.A. Löwik

dr. H. Zhou

Cover design: Jin Han

Printed by: Ipskamp Printing Enschede

Lay-out: Jin Han

ISBN: 978-90-365-5221-9

DOI: $10.3990 / 1.9789036552219$

(C) 2021 Jin Han, The Netherlands. All rights reserved. No parts of this thesis may be reproduced, stored in a retrieval system or transmitted in any form or by any means without permission of the author. Alle rechten voorbehouden. Niets uit deze uitgave mag worden vermenigvuldigd, in enige vorm of op enige wijze, zonder voorafgaande schriftelijke toestemming van de auteur. 


\section{Graduation Committee:}

Chair / secretary:

prof. dr. T.A.J. Toonen

Supervisor:

prof. dr. ir. P.C. de Weerd-Nederhof

Co-supervisors:

dr. ir. S.J.A. Löwik

dr. H. Zhou

Committee Members: $\quad$ prof. dr. ir. J. Henseler

University of Twente

prof. dr. H. Schiele University of Twente

prof. dr. A.G.L. Romme

prof. dr. I.R. Hatak

Eindhoven University of Technology

dr. K. Rong

University of St. Gallen

dr. ir. K. Visscher

Tsinghua University

University of Twente 



\section{TABLE OF CONTENTS}

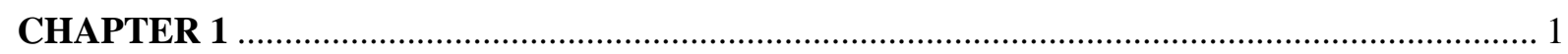

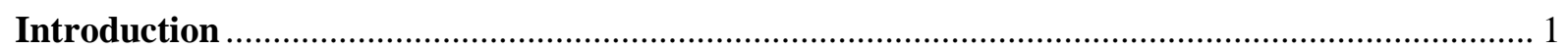

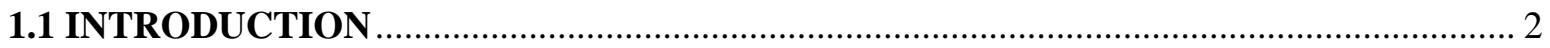

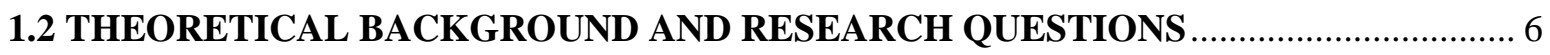

1.2.1 Defining new focal ventures and early-stage innovation ecosystems ................................... 6

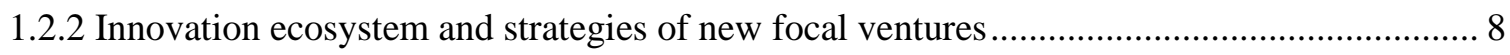

1.2.3 Innovation ecosystem and capabilities in new focal ventures ................................................ 11

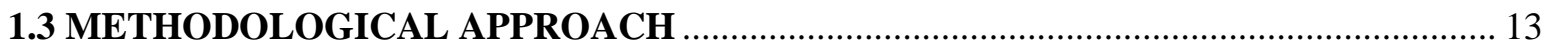

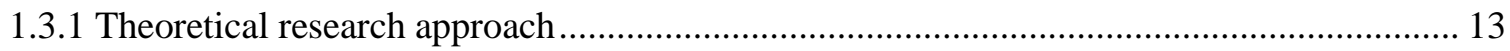

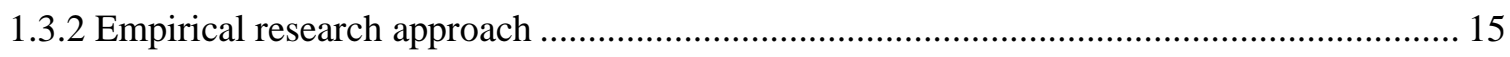

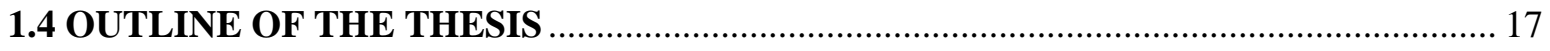

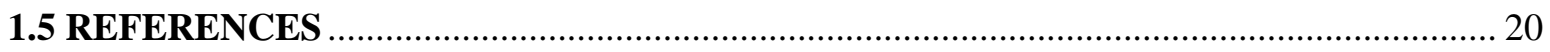

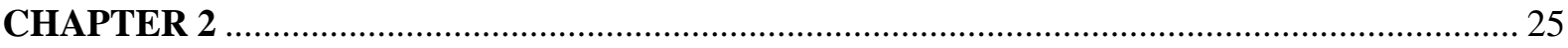

Enhancing the Understanding of Small Firms with Regard to Innovation Ecosystems: Aggregation in the Conceptual Boundaries of Ecosystems ....................................................... 25

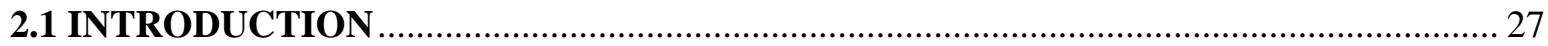

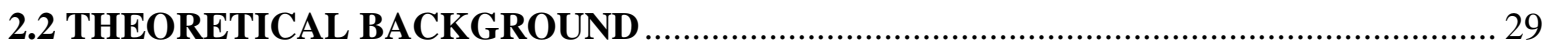

2.2.1 Current understanding of the conceptual boundaries of ecosystems.................................... 30

2.2.2 Aggregation in the conceptual boundaries of ecosystems.................................................. 31

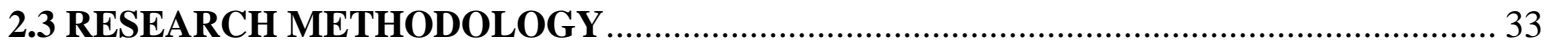

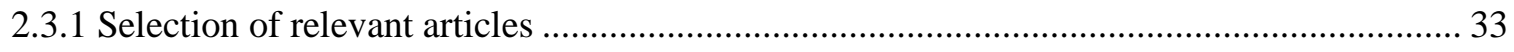

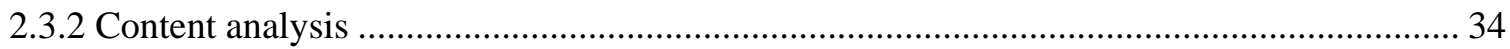

2.4 TOWARDS A THEORETICAL FRAMEWORK FOR THE CONCEPTUAL

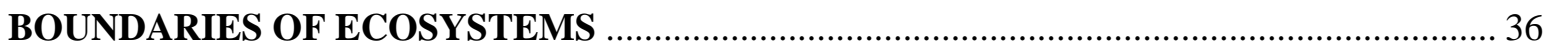

2.4.1 Building blocks: Roles, structures, and processes ................................................................. 36

2.4.2 Dimensions of the conceptual boundaries of ecosystems restructure throughout the lifecycle of an ecosystem, from birth and expansion to maturity ............................................................... 44

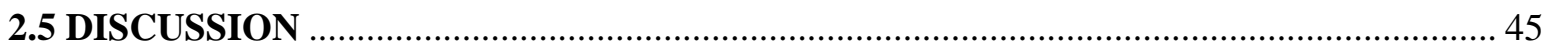

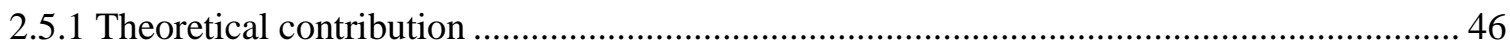

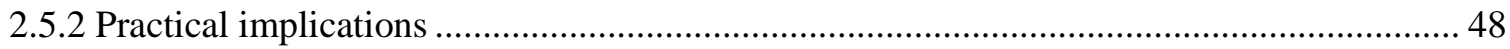

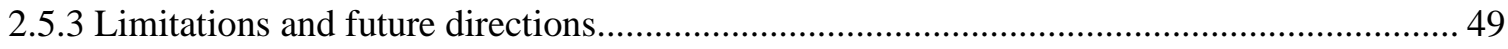

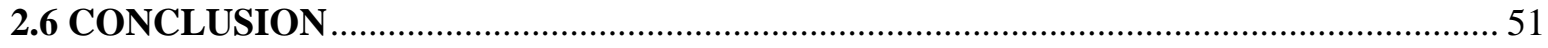

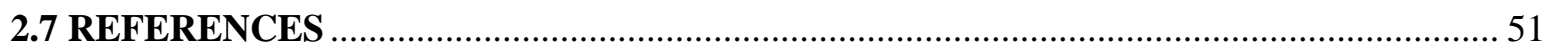


Building and Sustaining Emerging Ecosystems through New Focal Ventures: Evidence from

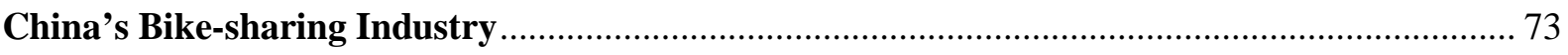

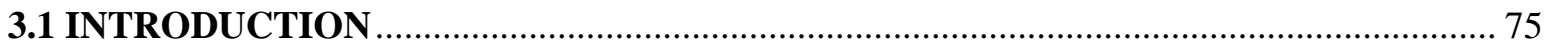

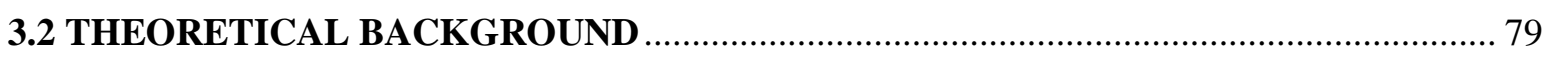

3.2.1 Repositioning the sociopolitical environment in emerging ecosystems.............................. 79

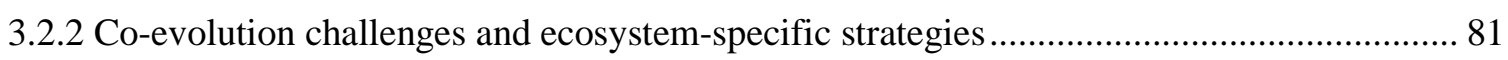

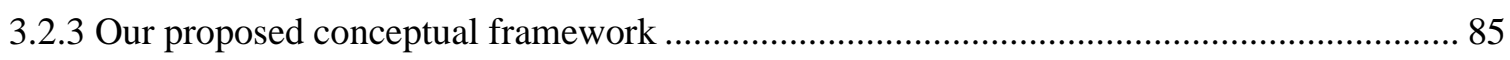

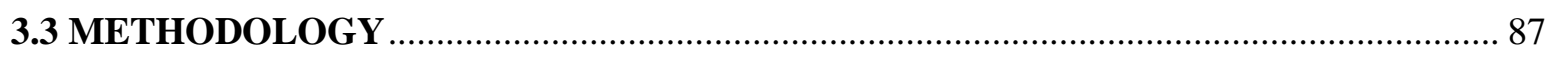

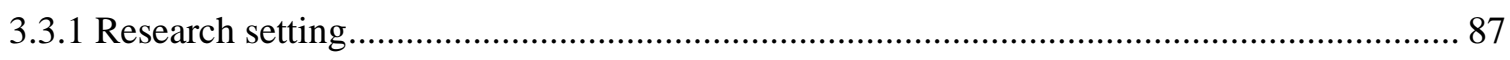

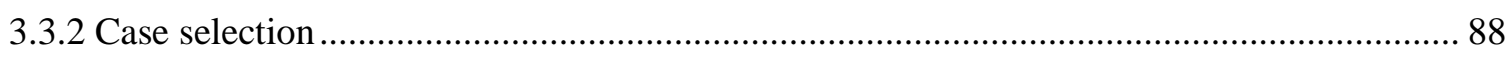

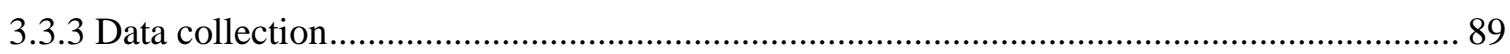

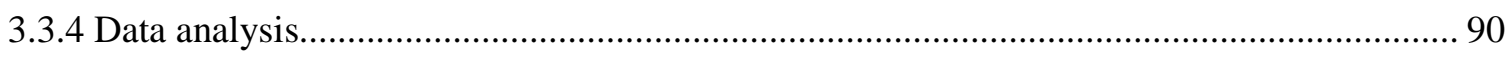

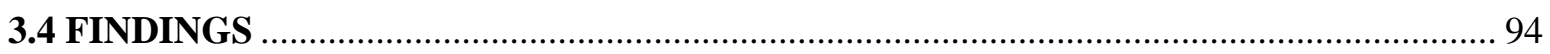

3.4.1 Recognizing co-evolution challenges from two ecosystem environments: niche

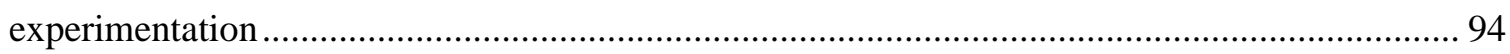

3.4.2 Overcoming co-evolution challenges: strategic versatility and strategic suboptimality ...... 98

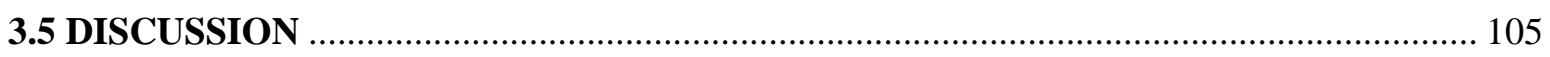

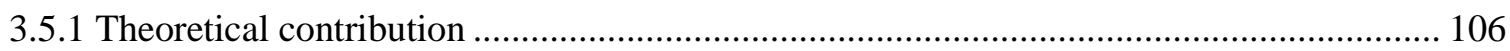

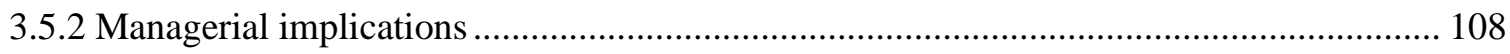

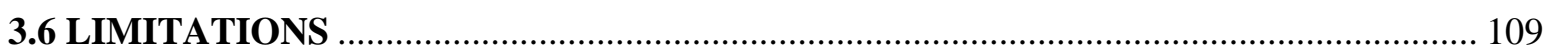

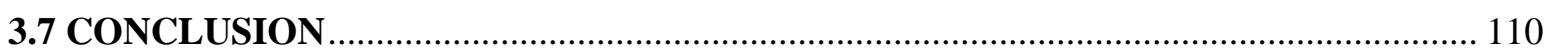

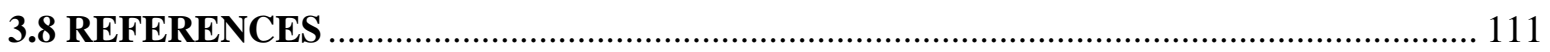

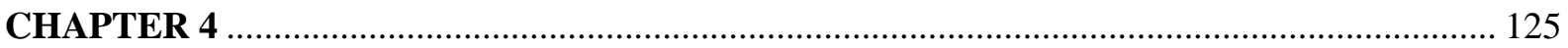

Learning to Swim in the Pool Before Surfing in the Sea: A Study of Local Innovation

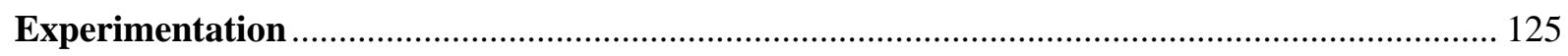

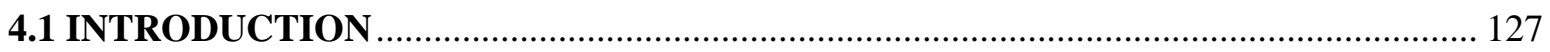

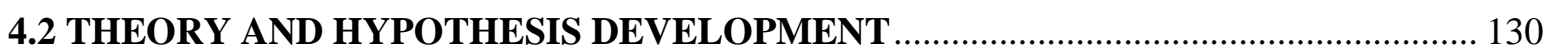

4.2.1 A model of the LIE: from an innovation ecosystem perspective .................................... 130

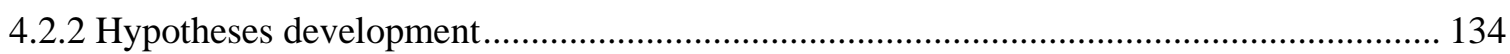

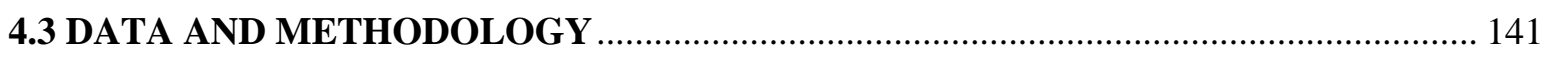

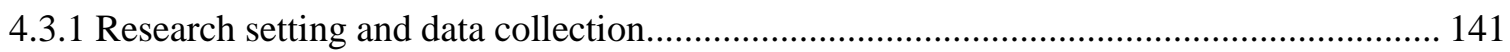

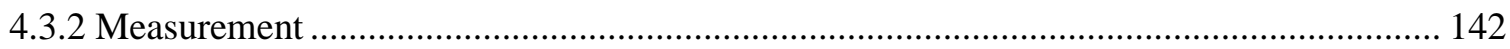

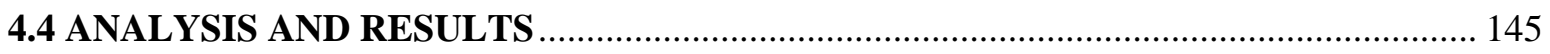

4.4.1 Assessment of overall goodness of model....................................................................... 146 


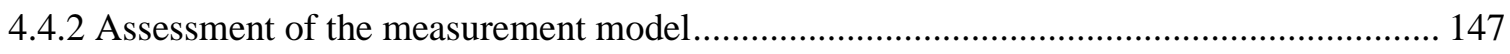

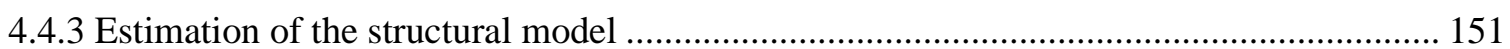

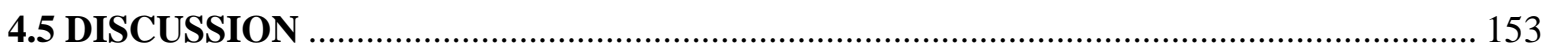

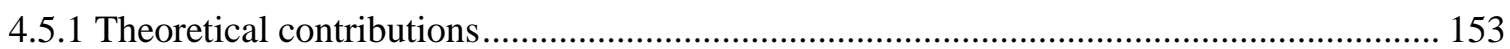

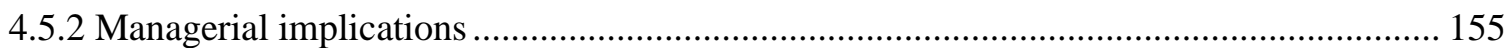

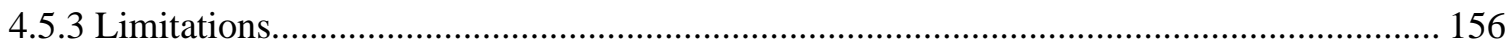

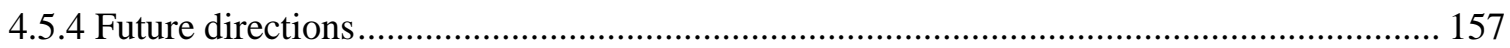

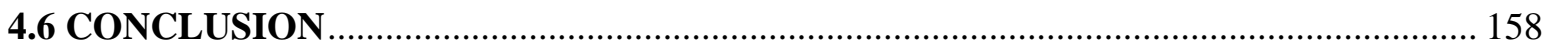

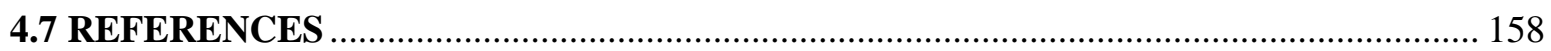

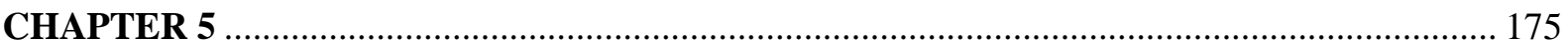

Toward a Complex Adaptive System: The Case of the Zhongguancun Entrepreneurship

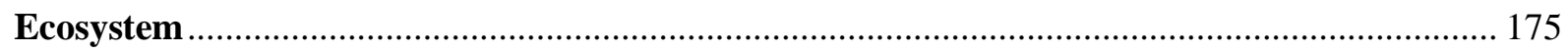

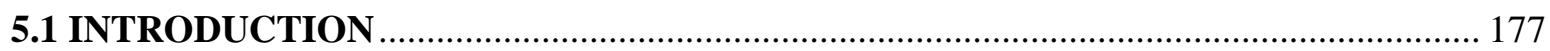

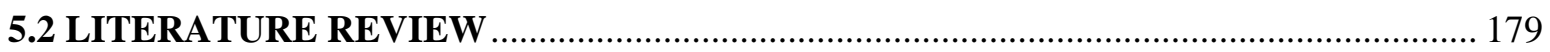

5.2.1 Overview of EEs: main ideas and the challenges of complexity........................................ 179

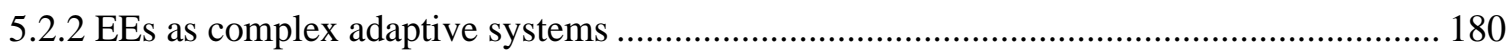

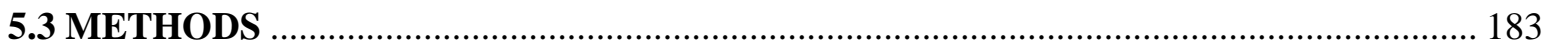

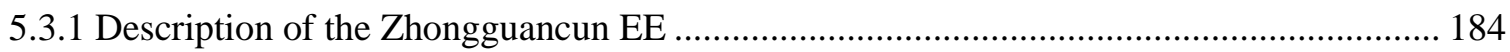

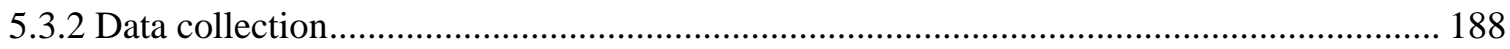

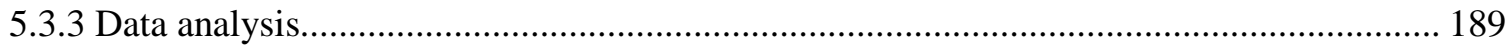

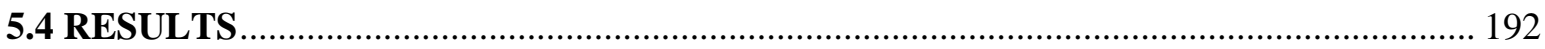

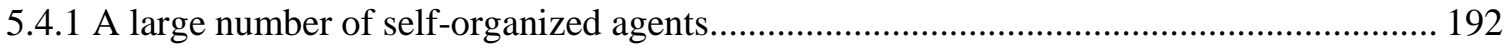

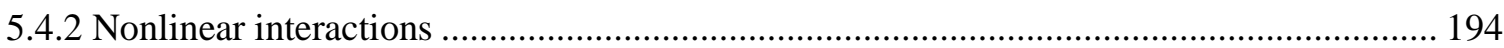

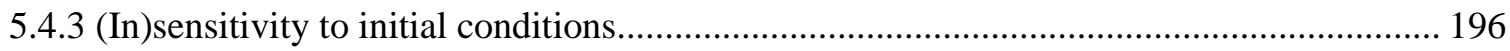

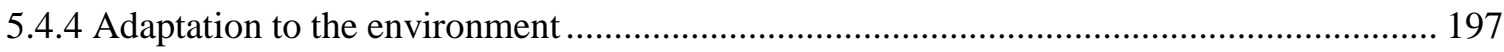

5.4.5 Emergence of successful entrepreneurial firms................................................................. 198

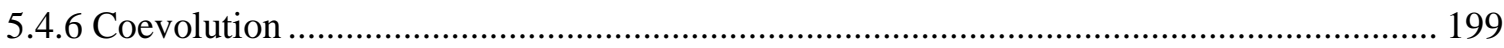

5.4.7 A complexity-based framework for the Zhongguancun EE ................................................ 201

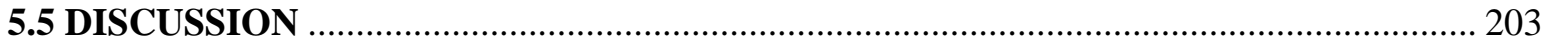

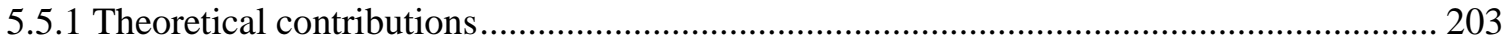

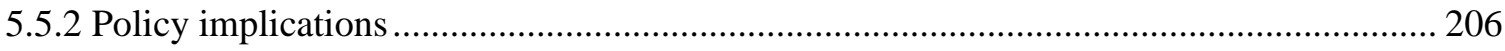

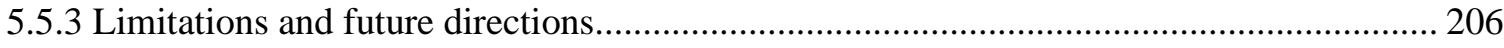

5.6 CONCLUSION

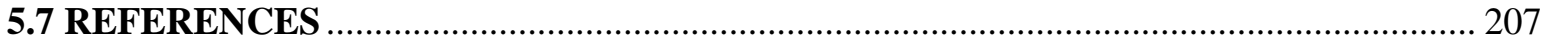

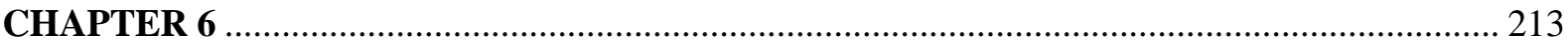




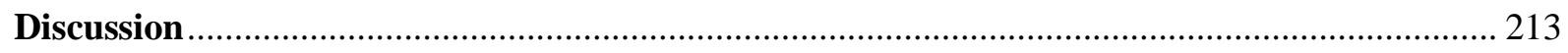

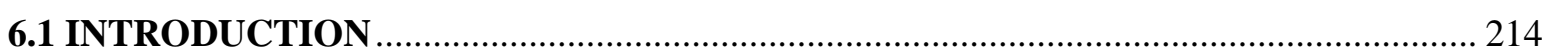

6.2 ANSWERING THE OVERARCHING RESEARCH QUESTION .................................. 214

6.2.1 Strategy mechanisms: how to develop ecosystem-specific strategies .................................. 214

6.2.2 Capability mechanisms: how to exploit ecosystem-related capabilities............................... 217

6.2.3 Additional cross-level mechanisms: how a viable EE matters........................................... 219

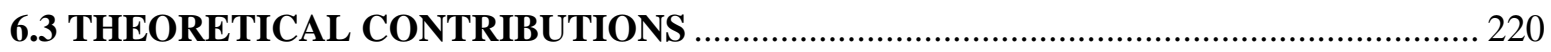

6.3.1 Theoretical contributions to the innovation ecosystem field............................................. 220

6.3.2 Theoretical contributions to the complexity management literature ................................... 224

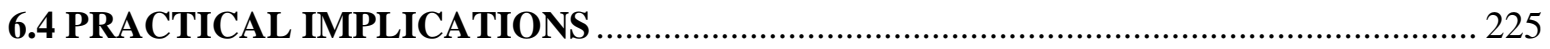

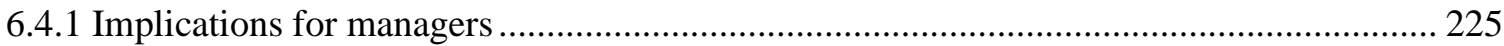

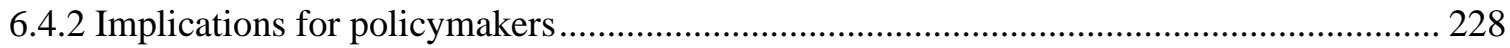

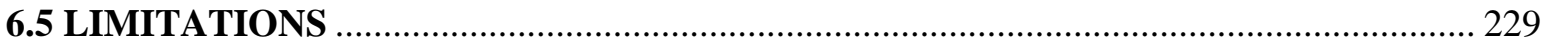

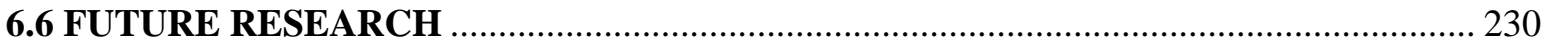

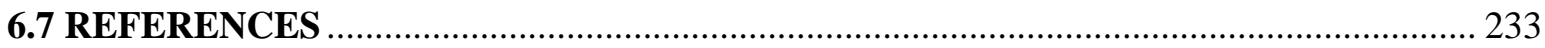

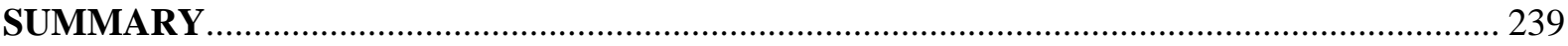

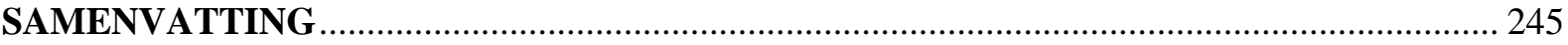

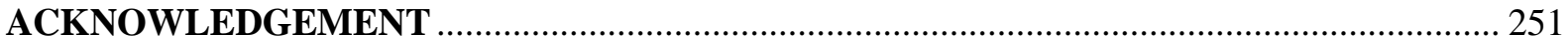


CHAPTER 1

Introduction 


\subsection{INTRODUCTION}

Building and sustaining an innovation ecosystem has been a strategic choice for firms wishing to gain sustainable competitive advantage. As Figure 1.1 shows, an innovation ecosystem includes a community of organizations (e.g., suppliers, lead producers, competitors, and other sociopolitical stakeholders) and individuals (e.g., end-users and analysts), who are organized around the focal firms to offer a coherent innovation to mass societies (Adner, 2006; Moore, 1996). The essential tenet behind the innovation ecosystem phenomenon lies in that it becomes difficult for any single firm to develop and commercialize an innovative offering from the start to finish because complementary assets needed for innovations are dispersed among heterogeneous organizations and individuals (Adner, 2012, 2017; Jacobides et al., 2018). Typical cases are the Samsung smart digital-health ecosystem, the Amazon autonomous robotaxi ecosystem, Bosch electric vehicle ecosystem, and the Airbnb online housing-rental ecosystem, certifying that such focal firms could only deliver innovative offerings by aligning strategic resources residing in a wide range of actors.

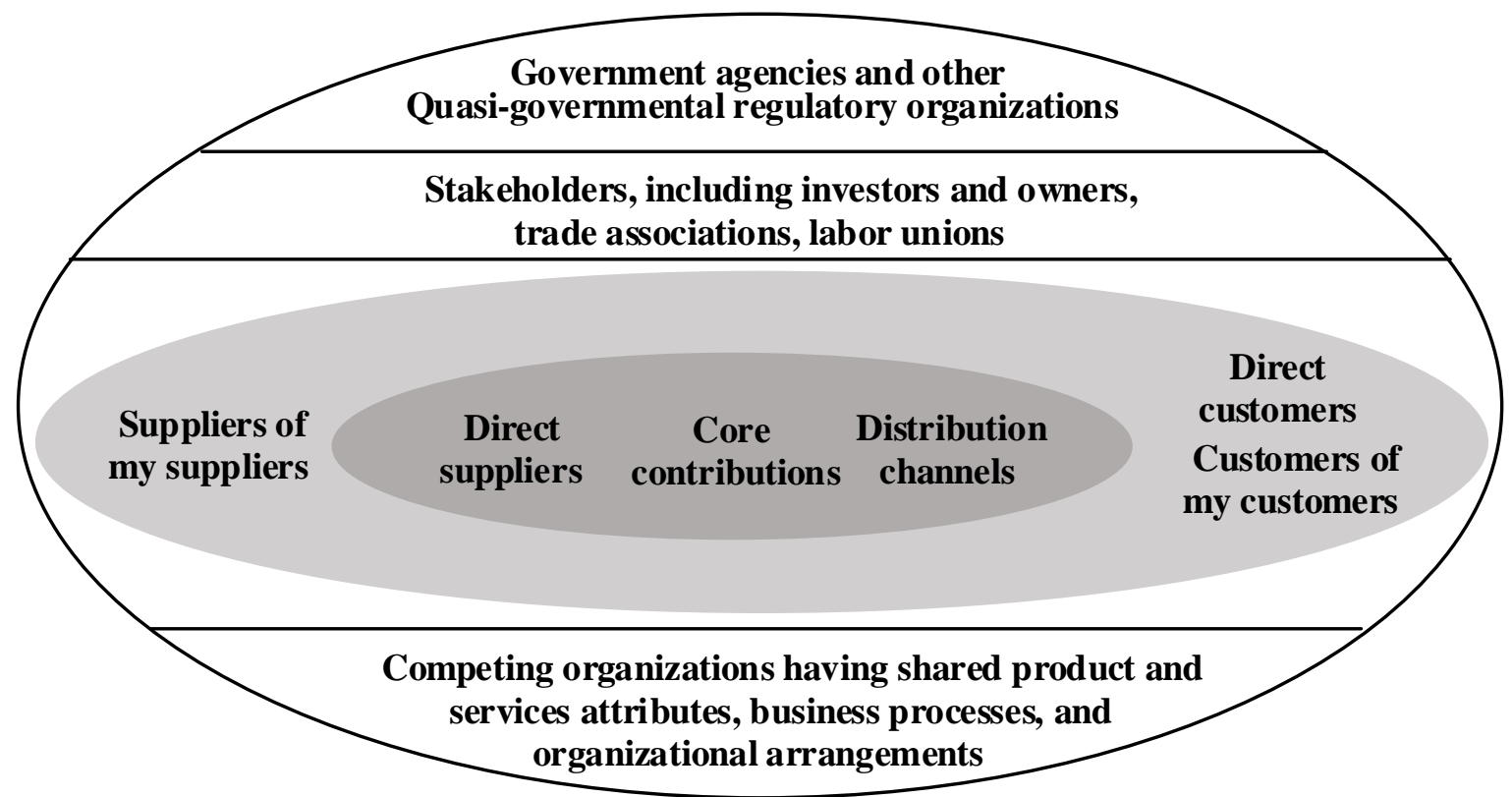

Figure 1.1: A viable innovation ecosystem (Moore, 1996).

Strategically crucial for those large firms given as examples above, new ventures also need to pay strategic attention to developing a viable innovation ecosystem (Dattée et al., 2018; Hannah and Eisenhardt, 2018). Congruent with big firms, a viable innovation ecosystem also requires new ventures as focal actors (hereafter: new focal ventures) to successfully align key- 
value complementors and co-evolve toward shared vision(s). Successful co-evolution processes bring new focal ventures ecosystem-specific advantages ( $\mathrm{Li}$ et al., 2019), such as more accessible innovation resources (Williamson and De Meyer, 2012), more entrepreneurial opportunities (Overholm, 2015), and enhanced resilience to technological disruptions (Adner and Kapoor, 2016).

Despite new focal ventures' increasing interests in developing innovation ecosystems, they typically suffer a high failure rate in building a viable ecosystem due to the newness liabilities. First, building a viable innovation ecosystem is time-consuming. Unlike large firms with power and rich resources, new focal ventures lack comprehensive sets of strategic resources and capabilities. Resource limitation usually prevents them from aligning a large number of diverse ecosystem actors in a short time. Second, even if new focal ventures, together with some key complementors, could kick-start ecosystems by co-creating innovations, the lack of legitimacy and formal power poses difficulties in aligning competitors and socio-political actors (e.g., regulators). Although such actors do not contribute directly to co-creating innovation, they do indirectly impose restrictions on the proposed innovations' final success. Third, new focal ventures have limited ecosystem management experience. Such experience deficiency can make them feel laborious to sustain a newly-built innovation ecosystem since they cannot properly manage the dynamics and complexities caused by interconnected ecosystem actors, activities, and institutions. Two new focal ventures - Anki (a domestic robotics firm) and Aria (a commercial drone firm) as examples can illustrate the challenges discussed above. Various press releases indicated that both firms' innovation ecosystems had developed well since around 2010, but both failed abruptly in 2019. Several reasons caused the failures. Anki's domestic robotics ecosystem failed since the firm lost a strategic partnership and seemed not to conform to social fitness. ${ }^{(1)}$ Aria's commercial drone ecosystem was unable to overcome regulatory problems and to align technology partners effectively. ${ }^{2}$

Extant literature offers some insights into how new focal ventures build and sustain innovation ecosystems by addressing the challenges they face. By integrating the organization (focal firm) and ecosystem levels, researchers argued that focal firms shoulder the primary responsibilities of and benefit the most from viable innovation ecosystems (Iansiti and Levien, 2004). Focal firms’ dynamic capabilities (e.g., Cao et al., 2020; Feng et al., 2019; Thomas and Autio, 2020; Velu, 2015; Walrave et al., 2018) and ecosystem-specific strategies (e.g., Dattée

\footnotetext{
(1) See more information from https://www.failory.com/cemetery/anki (Accessed 12 December 2020);

(2) See more information from https://www.failory.com/cemetery/aria-insights (Accessed 12 December 2020).
} 
et al., 2018; Hannah and Eisenhardt, 2018; Visscher et al., 2021) strongly determine the viability of innovation ecosystems.

Though these insights from the literature are useful, several assumptions related to this line of inquiry need reconsideration. Considering focal firms' dynamic capabilities, scholars have argued that a single type of dynamic capability serves as a key antecedent to an innovation ecosystem's birth and viability. For example, focal firms’ knowledge management capabilities positively influence a newly-built innovation ecosystem (e.g., Dougherty and Dunne, 2011; Kashan and Mohannak, 2017; Velu, 2015). However, these types of dynamic capabilities are intended to pursue economic objectives. As indicated by Anki and Aria's ecosystem failures, it is expected that focal firms need other types of ecosystem-related dynamic capabilities to overcome, for example, emergent regulatory challenges dictated by political imperatives. Thus, the inclusion of multiple dynamic capabilities into the innovation ecosystem model is more proper.

Further, most of the literature posits that ecosystem-related dynamic capabilities should directly enable an innovation ecosystem's birth and viability. Nevertheless, scholars provide little explanation of why some newly built innovation ecosystems, as the two cases mentioned above suggest, still fail even though those focal firms have developed superior dynamic capabilities. Theoretical nuances between focal firms' dynamic capabilities and the innovation ecosystem's birth and viability need to be further explored.

Finally, focal firms' dynamic capabilities are thought to be formed endogenously (Walrave et al., 2018), indicating that the internal top management team members determine the level of ecosystem-related dynamic capabilities. However, when new focal ventures begin to initiate an innovation ecosystem, they typically have only limited resources and capabilities. Anki and Aria's innovation ecosystems gained developmental momentum from external innovation regions in which they started their new businesses. Hence, when examining an innovation ecosystem's birth and viability, the exogenous view of how new focal ventures improved capabilities and resources is warranted.

Considering ecosystem-specific strategies, researchers have shown that focal firms' strategies are also crucial determinants of the success of an innovation ecosystem's birth and viability. Ecosystem-specific strategies refer to "the way in which a focal firm approaches the alignment of partners and secures its role in a competitive ecosystem” Adner (2017, p. 47). As most non-focal actors are bounded together with limited hierarchical control, they leave and stop contributing to the innovation ecosystems, which causes the co-evolution challenges for 
focal firms (Kapoor, 2018). Accordingly, to build and sustain a viable innovation ecosystem, effective ecosystem-specific strategies need to be precisely developed and implemented to overcome multiple co-evolution challenges posed by non-focal actors.

Yet the scale of aligned non-focal actors needs broader consideration. Most studies have assumed that socio-political actors favor an innovation ecosystem's birth and viability, so focal firms just need to keep economically viable and retain competitive actors' commitment to the innovation ecosystems. However, the two failed cases mentioned before suggest socio-political actors' restricting role in the innovation ecosystem's birth and viability. Therefore, focal firms should execute strategies to align economic, competitive, and socio-political actors within innovation ecosystems. Besides, an innovation ecosystem in its early stage is fraught with many uncertainties resulting from non-focal actors being highly interdependent (Adner, 2012). Less often studied is how inexperienced managers in new focal ventures combine different strategies and implement them effectively.

Overall, the above incomplete understandings might originate from an insufficient investigation into the cross-level mechanisms that underlie the innovation ecosystem's birth and viability. Here, birth and viability denote that an innovation ecosystem remains stuck in its early developmental stages (Moore, 1996). More specifically, birth suggests that though immature and fragile, the newly-built innovation ecosystem includes all non-focal actors; the viability suggests all actors co-evolve toward the shared visions (Hannah and Eisenhardt, 2018). According to the ecosystem theorists, the cross-level mechanisms revolve around the effects of focal firms' capabilities and strategies (lower firm-level) on an innovation ecosystem (higher system-level), and the other way around. Delving into such cross-level mechanisms could open the black-box of how focal firms' ecosystem-related dynamic capabilities form and deliver impacts, how focal firms' ecosystem-specific strategies are implemented and yield ecosystemlevel effects, and even how the capabilities and strategies are related to each other. It is thus hypothesized that more complete cross-level mechanisms on the innovation ecosystem birth and viability will offer practitioners and scholars insights into how new focal ventures use capabilities and strategies to develop innovation ecosystems successfully. Hence, the overarching research question of this $\mathrm{PhD}$ research is:

\section{How can new focal ventures develop capabilities and strategies to build and sustain a} viable innovation ecosystem? 
In response to this overarching research question, the rest of this chapter is organized as follows. Next, the PhD research's theoretical background is described, which leads to four subresearch questions integrated to address the overarching research question. Then, it continues with the elaboration on research approaches adopted in this $\mathrm{PhD}$ research. Finally, this chapter ends with a brief outline of the remaining five chapters of this thesis.

\subsection{THEORETICAL BACKGROUND AND RESEARCH QUESTIONS}

This section first defines new focal ventures and illustrates innovation ecosystems' characteristics during their early developmental stages. It then reviews how the extant literature relates focal actors' strategies, capabilities, and regional innovation contexts, to an innovation ecosystem's birth and viability. Consequently, four individual research questions are formulated on these theoretical foundations to answer the overarching research question posed in Section 1.1.

\subsubsection{Defining new focal ventures and early-stage innovation ecosystems}

Since the ecosystem concept was first introduced in the management literature (Moore, 1993), scholars have shown enthusiasm for studying how new ventures can capture value from established ecosystems. Generally, a "new venture” refers to an organization that is in its early years of existence. In contrast to their bigger counterparts, such a venture lacks mature practices, experiences, and systems, lacks a rich bundle of capabilities and resources, and also lacks trustbased relationships and legitimacy due to its short operation history (Zimmerman and Zeitz, 2002). Such "liabilities of newness" are even more pronounced when they are founded in the initial several years (Zhou et al., 2018). As such, studies offer managers of new ventures insightful pathways to strive for survival and organic growth (see reviews e.g., Gilbert et al., 2006; Soto-Simeone et al., 2020). A salient body of literature on innovation management indicates that new ventures can overcome newness problems through ecosystem thinking (Zahra and Nambisan, 2012). For example, they should shape business models to connect with other actors' business models to form an ecosystem-level business model (Hellström et al., 2015); they should transform strategic resources to align with an established organization or platform's strategic purposes (Pierce, 2009); they need to balance coopetitive dynamics with peer ventures and big incumbents (Ansari et al., 2016).

Yet scholars have considered new ventures to be non-focal actors constrained by the focal incumbents (Nambisan and Baron, 2013; Zahra and Nambisan, 2011), which is at odds with 
observations in the contemporary industrial world. As mentioned earlier, two new ventures Anki and Aria, ambitiously take the roles of leading actors in innovation ecosystems. On the contrary, some big firms are actually non-focal actors. Being ambitious means that this new venture group is high-growth-oriented, unlike other ventures that are satisfied with the status quo (Czarnitzki and Delanote, 2013). More specifically, managers of ambitious new ventures will exhibit greater vigorous entrepreneurial intensity, greater intentions of market expansion and technological change, use a broader range of venture capitals, show greater willingness to incur opportunity costs, and seek leadership in terms of market reputation and image (Gundry and Welsch, 2001). Based on this literature, a new focal venture is defined as follows:

A new focal venture is an organization in its early years of existence, venture capitalbacked, technology-based, and founded to achieve high growth goals by developing a viable innovation ecosystem.

Despite the ambitious intention, it is not easy for new focal ventures to develop a viable innovation ecosystem to gain high-growth goals because of two features regarding early-stage innovation ecosystems. First, an innovation ecosystem in its early stage is likely to be more fuzzy, iterative, and chaotic than during later stages (Dedehayir et al., 2018). This feature suggests that the innovation ecosystem-building process will cost managers many resources, time, and attention. New focal ventures possess fewer resources and capabilities, which heavily restricts the speed of innovation ecosystem building process. This is different from those big firms that can exploit rich capabilities and resources to build an innovation ecosystem quickly. So resource-strapped new focal ventures are usually forced to develop innovation ecosystems in a slow, staged process. As a result, they face a tension. On the one hand, they could build a viable innovation ecosystem through trial and error (Lynn et al., 1996). On the other hand, trials and errors result in a loss of first-mover advantage due to the possible emergence of a competitive ecosystem (Hannah and Eisenhardt, 2018).

Second, early-stage innovation ecosystems tend to be fragile. Such fragility suggests that participatory non-focal actors and new entrants are poorly synchronized owing to heterogeneous capabilities, resources, and conflicting motives (Rong and Shi, 2014). As a result, newly-built innovation ecosystems are vulnerable to the tension between value co-creation and value co-capture (Letaifa, 2014; Oskam et al., 2020). In other words, non-focal actors could not expect to profit from co-created innovations, but they do need to invest continuously. They would leave and stop their unique contribution to the proposed innovations, resulting in co- 
evolution challenges. Therefore, managers need to create effective strategies to align all participants into an integrated whole to achieve ecosystem-level competitiveness (Visscher et al., 2021). But their leadership in innovation ecosystems suffers threats when big incumbents play a dominant role in an ecosystem. In such a circumstance, they face another tension. On the one hand, the loss of critical non-focal participants keeps the leadership, but the ecosystemlevel competitiveness becomes less achievable. On the other hand, engaging with big incumbents ensures ecosystem-level competitiveness. Yet, the increased likelihood of losing leadership would deliver a smaller share of value captured from the commercialized innovations.

In conclusion, (1) the iterative development process of an early-stage innovation ecosystem requires rich resources and robust capabilities of new focal ventures to overcome the tension between the slow ecosystem building process and losing first-mover advantages. Besides, (2) the fragility of an early-stage innovation ecosystem requires new focal ventures to formulate effective strategies to solve the tension between individual leadership and ecosystemlevel competitiveness. Overall, an innovation ecosystem's birth and viability seem to be closely associated with new focal ventures’ core capabilities, resources, and strategies. In the following sections, based on the review of previous literature, four sub-research questions are formulated. Taken together, these four sub-research questions are intended to address the overarching research question.

\subsubsection{Innovation ecosystem and strategies of new focal ventures}

The current literature has demonstrated that the innovation ecosystem's birth and viability are closely related to focal firms' ecosystem-specific strategies. The ecosystem-specific strategy complements, rather than being identical to, a conventional corporate strategy that is usually thought to maximize individual competitive advantage (Mintzberg and Waters, 1985). Its key is to ensure non-focal actors' long-term commitment to ensure ecosystem-level competitiveness (Fuller et al., 2019). In the literature, investors, technology partners, and competitors are frequently mentioned as indispensable non-focal actors. For instance, to ensure venture capitalists' contributions, vision diffusion strategies are useful (Rong et al., 2017). The intellectual property strategy is purposefully constructed to ensure technological partners' continuous investment (Holgersson et al., 2018). The offensive and defensive strategies are implemented to cope with various competitors (Hedman and Henningsson, 2015). Altogether, this set of ecosystem-specific strategies needs to be performed effectively so that both focal firms and non-focal actors can co-capture value successfully from the proposed innovations. 
However, the existing knowledge about the relationship between focal firms' ecosystemspecific strategies and the innovation ecosystem birth and viability needs further development. Managers are more likely to design effective ecosystem-specific strategies if they can make better sense of the ecosystem conceptual boundaries. The aggregated conceptual boundaries consist of key distinguishing features of the innovation ecosystem and interactions between such features. In a nutshell, the conceptual boundaries stipulate how a viable innovation ecosystem operates (Phillips and Ritala, 2019). Yet, in the extant literature the aggregated conceptual boundaries of innovation ecosystems remain underexplored. From an epistemological view, the key distinguishing features exhibited from the value co-creation to co-capture process demarcate it from other system phenomena, such as strategic networks and supply chains (Kapoor, 2018). The existing literature merely presents what distinguishing features should be included in the conceptual boundaries. Typically, Li (2009, p. 380) explicitly described innovation ecosystems as "having three major characteristics: symbiosis, platform, and co-evolution”. Through a structural lens, the platform provided by focal actors is the tool for non-focal actors to interact to co-create value, based on which they co-evolve capabilities collectively. Through the temporal lens, the probability of successful co-evolution of all actors is lower during an innovation ecosystem's birth stage than in later stages. In all, the structural and time-dependent understandings of the conceptual boundaries should be further explored so that managers of new focal ventures could perform ecosystem-specific strategies more effectively (see Figure 1.2). Hence, the first research sub-question is:

\section{RQ1: What are the aggregated conceptual boundaries related to an innovation ecosystem?}

Second, the scope of ecosystem-specific strategies should be broadened. The majority of previous studies assumed that some non-focal, peripheral actors (regulators and social media) would naturally support an innovation ecosystem (Snihur et al., 2018). Hence, ecosystem-level competitiveness relies on focal firms' economic or coopetitive strategies being directly linked to the value co-creation process. The strategic objects of economic strategies mainly include technological partners, key suppliers, investors, and customers; the coopetitive strategies primarily target competitors (see Figure 1.1). However, when the co-created innovations relate to public goods (e.g., commercial drones and urban waste disposal services), new focal ventures should also consider socio-political strategies. This is because some non-focal actors, such as 
regulators, would pose restrictions on an innovation ecosystem's birth and growth by inhibiting the value co-capture process (Peltola et al., 2016).

Third, the different ecosystem-specific strategies must be effectively combined for them to act successfully. Current literature posits that focal firms implement strategies separately and sequentially so as to align non-focal actors into shared visions (Guo and Bouwman, 2016; Zhang and Liang, 2011). This one-to-one strategy execution does not fully consider those interactions among non-focal actors that are highly interdependent (Adner, 2017). Besides, scholars focus their analysis on the short-term effects of focal firms' strategies. As mentioned previously, the innovation ecosystem-building process is a long haul, necessitating that managers manage the implemented strategies' temporal effects effectively. Despite the importance of that, it appears challenging for new focal ventures' managers to combine different strategies.

Therefore, as shown in Figure 1.2, the above two paragraphs' arguments lead to the first cross-level mechanism of innovation ecosystem birth and viability (a: firm-level $\rightarrow$ systemlevel): various ecosystem-specific strategies should be executed effectively to lead to ecosystem-level competitiveness. Hence, the second sub-research question is formulated as follows:

\section{RQ2: How can new focal ventures integrate different strategies effectively to build and sustain innovation ecosystem development?}

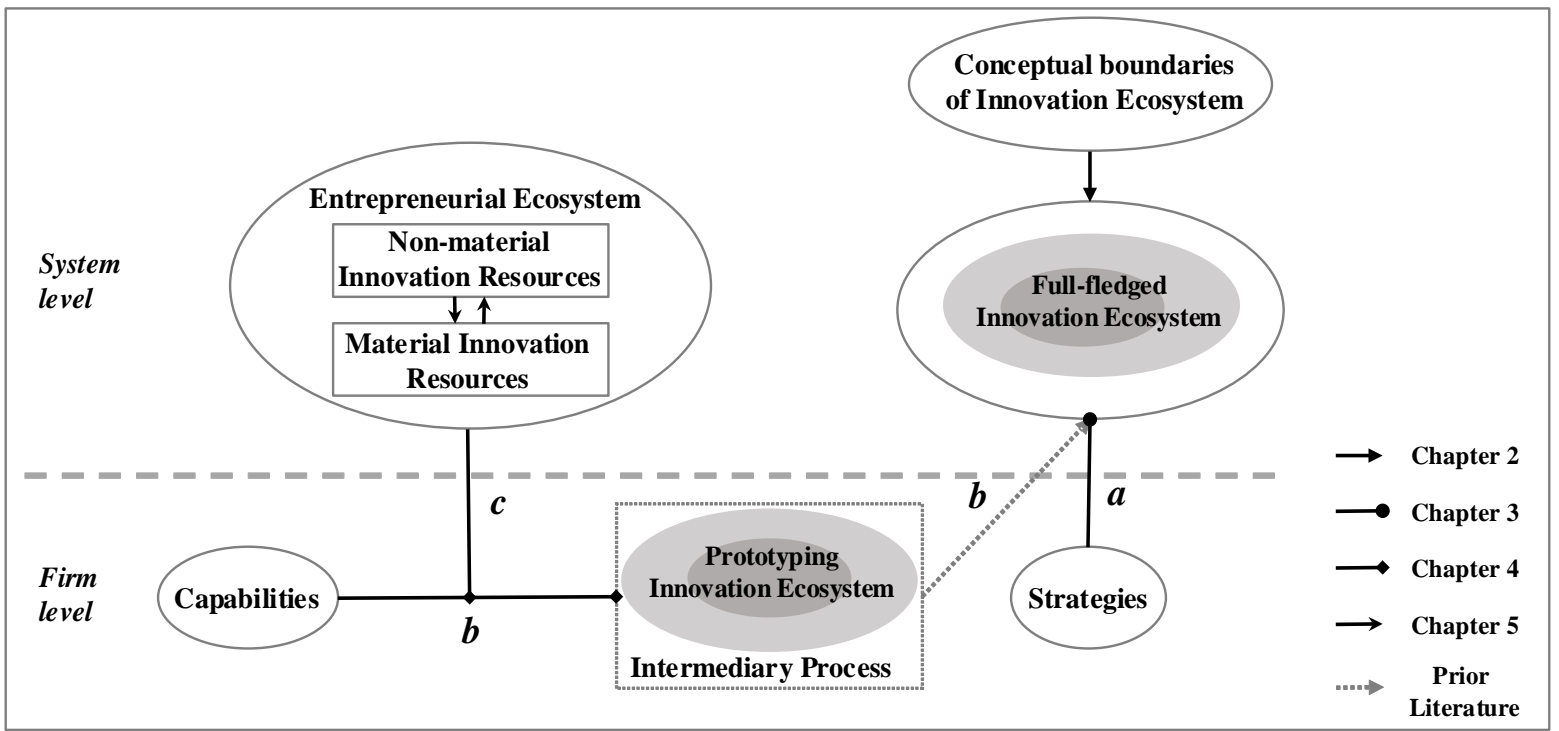

Figure 1.2: Cross-level mechanisms of the innovation ecosystem's birth and viability. 


\subsubsection{Innovation ecosystem and capabilities in new focal ventures}

The current literature has further documented that the innovation ecosystem birth and viability depend mainly on focal firms" key capabilities, given that "[t]he capabilities of the lead firm to orchestrate the partner firms lie at the heart of the innovation performance of the ecosystem" (Velu, 2015, p. 125). Core dynamic capabilities are rooted in unique, inimitable resources, thereby resulting in competitive advantage (Adner and Helfat, 2003). For instance, researchers suggest that due to the fragmented knowledge and motives among non-focal actors, the focal firms’ cognitive capabilities (Cao et al., 2020), knowledge management capabilities (Kashan and Mohannak, 2017), platform management capabilities (Liu and Rong, 2015), and framing capabilities (Snihur et al., 2018) are essential to the successful birth and viability of innovation ecosystems.

However, the theorizing from dynamic capabilities to innovation ecosystem's birth and viability needs reconsideration. First, it would be problematic for focal firms to rely on single specific capabilities. In fact, they need strong networking capabilities to approach and orchestrate capable partners to co-develop innovations. Besides, they should be sufficiently agile to respond effectively to different problems during the innovation co-development process. They might also need superior cognitive skills to have the foresight to manage the relations between the present and future benefits, and between the whole ecosystem and individual benefits (Zahra and Nambisan, 2012). To summarize, new focal ventures need a portfolio of dynamic capabilities to help develop the innovation ecosystems.

Second, the direct link from dynamic capabilities to innovation ecosystem birth is problematic. This is because though two new focal ventures may have similar dynamic capabilities when building ecosystems, they are finally destined to obtain divergent results. Capability scholars claim that dynamic capabilities need to be deployed offensively to gain competitive advantages (Helfat et al., 2009). That implies that theoretical nuances between dynamic capabilities and the innovation ecosystem's birth and viability need further clarification. As argued before, the limited resources force new focal ventures to select a slowstaged ecosystem-building process. As Figure 1.2 shows, new focal ventures typically construct a "minimum viable ecosystem” (Adner, 2012) or a "prototyping ecosystem” (Marcocchia and Maniak, 2018) before their innovation ecosystems become fully-fledged and undergo a wild expansion. For example, Better Place, a new focal venture founded in 2007, experimented with novel full EV cars in two city regions: Copenhagen and Tel Aviv (Noel and Sovacool, 2016). 
Based on such an experimentation process, they reduced multiple uncertainties related to the revolutionary electric cars (Dougherty and Dunne, 2011). Finally, Better Place, together with its key partners, made its proposed innovations mature enough to diffuse into mass societies. In line with the current literature (see Mahmoud-Jouini and Charue-Duboc, 2017), such an experimentation process is framed as "local innovation experimentation" (LIE) in the present $\mathrm{PhD}$ research. Hence, the high performance of LIE leads to a prototyping ecosystem, which acts as one of the crucial intermediations between dynamic capabilities and the full-fledged innovation ecosystem.

As Figure 1.2 shows, the above arguments lead to the second cross-level mechanism (b: firm-level $\rightarrow$ system-level): a portfolio of dynamic capabilities that seems to enable the viability of the prototyping innovation ecosystem, which leads to a viable full-fledged innovation ecosystem. As such, the third main research sub-question is:

\section{RQ3: What organizational dynamic capabilities can lead new focal ventures to deliver}

\section{high LIE performance?}

Third, the firm-internal view of focal firms' dynamic capabilities is insufficient to explicate the innovation ecosystem's birth and viability. Two discussed examples - Anki and Aria - were established into regions regarded as having well-functioning entrepreneurial ecosystems (EE) (i.e., Silicon Valley and Massachusetts Boston, respectively), in which the rich, systemic regional innovation resources (e.g., talents, finance, technologies, and services) could overcome resource shortages and complement existing organizational capabilities. In this respect, the local contexts matter for new ventures (Autio et al., 2014; Visscher and de WeerdNederhof, 2006). A firm-external view of how new focal firms develop ecosystem-related dynamic capabilities by tapping into regional innovation resources is necessary to examine innovation ecosystems' birth and viability (see Figure 1.2).

The third cross-level mechanism is then concluded as follows (c: system-level $\rightarrow$ firmlevel): the regional systemic innovation resources in an EE impact on new focal ventures' capabilities and resources. Likewise, the fourth sub-research question is proposed to explore such cross-level mechanisms:

RQ4: How can regional innovation resources in an $\mathrm{EE}$ interact to affect new focal ventures? 
Thus far, it is concluded that though previous ecosystem literature has acknowledged the critical effects of focal firms' capabilities and strategies on an innovation ecosystem's birth and viability, the understandings of the three cross-level mechanisms have received insufficient scholarly attention. Due to this reason, this $\mathrm{PhD}$ research is going to expand on this discourse through four studies, briefly introduced in the following sections.

\subsection{METHODOLOGICAL APPROACH}

Reflecting to the four sub-research questions, this $\mathrm{PhD}$ research conducted one conceptual study and three empirical studies. This section describes the research approaches taken for these four studies, which are summarized in Table 1.1. A more detailed description of each of the applied research methods is found in the corresponding chapters.

\subsubsection{Theoretical research approach}

Chapter 2 is a systematic literature review intended to help address the first research subquestion: What are the aggregated conceptual boundaries related to an innovation ecosystem? A systematic literature review method is appropriate to aggregate innovation ecosystems' conceptual boundaries (namely, the structural interrelationships and temporal differences), for several reasons. First, through the guidelines of a systematic literature review (Tranfield et al., 2003), the exact number of key distinguishing features can be identified since the innovation ecosystem concept has been widely (but fragmentedly) researched by massive academics (Bogers et al., 2019). Second, through content analysis and inductive clarification techniques (Duriau et al., 2007), the inter-relationships among the distinguishing features into higher-level wisdom could be therefore extracted and synthesized. As a result, Chapter 2 captured 171 publications dealing with the innovation ecosystem that highlighted nine key distinguishing features of innovation ecosystems. 
Table 1.1: An overview of four studies in the PhD thesis.

\begin{tabular}{|c|c|c|c|}
\hline Chapter & Research Question & Research Approach & Research Results \\
\hline 2 & $\begin{array}{l}\text { What are the aggregated } \\
\text { conceptual boundaries } \\
\text { related to an innovation } \\
\text { ecosystem? }\end{array}$ & $\begin{array}{l}\text { Systematic literature review } \\
\text { - Data collection: } 171 \text { publications } \\
\text { on innovation/business } \\
\text { ecosystems } \\
\text { - Data analysis: content analysis }\end{array}$ & $\begin{array}{l}\text { 1. Structural relationships of conceptual boundaries refer to that nine } \\
\text { (lower-order) key distinguishing features of innovations could be } \\
\text { aggregated into three higher-order dimensions: roles (self- } \\
\text { organization, non-linearity, shared vision), structures } \\
\text { (complementarity, modularity, coupling) and processes (emergence, } \\
\text { co-opetition, coevolution); } \\
\text { 2. Temporal dynamics of conceptual boundaries refer to that three } \\
\text { higher-order dimensions as a whole exhibit difference along with an } \\
\text { innovation ecosystem's birth, expansion, and mature stages. }\end{array}$ \\
\hline 3 & $\begin{array}{l}\text { How can new focal ventures } \\
\text { integrate different } \\
\text { strategies effectively to } \\
\text { build and sustain } \\
\text { innovation ecosystem } \\
\text { development? }\end{array}$ & $\begin{array}{l}\text { Multiple-case study } \\
\text { - Case collection: two failed and } \\
\text { two survived bike-sharing } \\
\text { ecosystems } \\
\text { - Data collection: } 33 \text { interviews } \\
\text { (based on critical incident } \\
\text { interviewing method) and } \\
\text { secondary data } \\
\text { - Data analysis: Langley process } \\
\text { analysis }\end{array}$ & $\begin{array}{l}\text { 1. "Local innovation experimentation” as the strategic innovation process } \\
\text { enables new focal ventures to obtain a more holistic understanding of } \\
\text { the newly-built innovation ecosystems; } \\
\text { 2. "Strategy versatility” suggests that new focal ventures combine } \\
\text { strategies to overcome the co-evolution challenges; } \\
\text { 3. "Strategic suboptimality” suggests that new focal ventures sacrifice } \\
\text { specific strategies' short-term effects to enhance other implemented } \\
\text { strategies' long-term effects. }\end{array}$ \\
\hline 4 & $\begin{array}{l}\text { What organizational } \\
\text { dynamic capabilities can } \\
\text { lead new focal ventures to } \\
\text { deliver high LIE } \\
\text { performance? }\end{array}$ & $\begin{array}{l}\text { Survey-based study } \\
\text { - Data resources: two Beijing- } \\
\text { based innovation platforms } \\
\text { - Data collection: } 111 \text { respondents } \\
\text { based on the web-based Qualtrics } \\
\text { - Data analysis: PLS-SEM method }\end{array}$ & $\begin{array}{l}\text { 1. The high-level performance of the LIE depends on the high levels of } \\
\text { TMT-based metacognitive capability, networking capability, and } \\
\text { learning agility; } \\
\text { 2. Frequent attending local networking events and networking capability } \\
\text { result in the higher-level performance of the LIE. Frequent use of } \\
\text { innovation facilities and learning agility result in the higher-level } \\
\text { performance of the LIE. }\end{array}$ \\
\hline 5 & $\begin{array}{l}\text { How can regional innovation } \\
\text { resources in an EE interact } \\
\text { to affect new focal } \\
\text { ventures? }\end{array}$ & $\begin{array}{l}\text { Single-case study } \\
\text { - Case selection: Zhongguancun } \\
\text { EE located in Beijing } \\
\text { - Data collection: } 23 \text { group } \\
\text { interviews and secondary data } \\
\text { - Data analysis: grounded theory } \\
\text { based on Gioia method }\end{array}$ & $\begin{array}{l}\text { 1. Diverse innovation agencies interact in a viable EE and thus show six } \\
\text { complexity properties: a large number of self-organized agents, } \\
\text { nonlinear interactions, (in)sensitivity to initial conditions, adaptation to } \\
\text { the environment, emergence of successful entrepreneurial firms, and } \\
\text { coevolution; } \\
\text { 2. The effects of well-integrated regional innovation resources on new } \\
\text { venture creation and innovation ecosystem development are nonlinear, } \\
\text { persistent, and far-reaching. }\end{array}$ \\
\hline
\end{tabular}




\subsubsection{Empirical research approach}

Chapters 3, 4, and 5 describe empirical studies. All three empirical studies have a research context of mainland China. This overall research setting is opportune to study the birth and viability of innovation ecosystems. First, the particular institutional context in China suggests that new ventures might face challenges from socio-political actors. For those untouched areas of innovation, the Chinese government encourages new start-ups' innovation activities since in most cases, no legislation is available for them to regulate such newly emerging innovations. Yet the institutional voids (especially legal systems and customs) cause ambitious entrepreneurs to face high regulatory uncertainty (Meyer and Peng, 2016). As a result, this specialty would allow the observation of new focal ventures' sets of strategic actions to cope with co-evolution challenges from particularly socio-political actors, who are generally regarded as peripheral actors in the innovation ecosystems.

Second, well-developed regional innovation hubs have been spawning many high-growth new start-ups, leading in critical innovation areas such as biotech/life science, big data, 5G, and artificial intelligence. According to recent reports from CB Insights (2020) and Deloitte (2019), around one-quarter of high-growth start-ups globally are from three major innovation hubs (Beijing, Shanghai, Shenzhen) in mainland China. New start-ups' resources and capability bases, and their innovation ecosystem development, might benefit from the presence of various investment agencies, innovation-oriented platforms and incubators, rich talent, integrated social entrepreneurial networks, and diverse innovation infrastructures in these hubs.

To be specific, the qualitative case study in Chapter 3 aims to answer the research subquestion: How can new focal ventures integrate different strategies effectively to build and sustain innovation ecosystem development? Multiple cases are purposefully selected to help address the research question. Using multiple, extreme cases has advantages in terms of increasing the external validity of theorization, facilitating theory replication, and yielding a more generalizable theory (de Weerd-Nederhof, 2001; Eisenhardt, 1989). In Chapter 3, four innovation ecosystems (two surviving and two failed) developed by bike-sharing new ventures were selected. A selection of the bike-sharing industry in China as the research setting fits our research purposes. First of all, novel dockless bike-sharing services require new focal ventures to build innovation ecosystems by integrating multiple technologies that they could not themselves own, such as mobile payment, GPS tracking, solar energy, and narrow-band Internet of Things (NB-IoT). Second, they encountered significant co-evolution challenges from 
economic, coopetitive, socio-political actors. Particularly, they received some socio-political criticisms about being e-waste makers and being a capital-driven game during its early exposure. Therefore, it is expected that the integration between ecosystem-specific strategies and their effects on early-stage innovation ecosystems will be identified.

As to data collection, the critical incident interviewing technique is applied (Flanagan, 1954). This approach has merits in terms of obtaining procedural reports about managerial decision-making about strategic issues. Adopting this technique allows capture of the timebased integration of ecosystem-specific strategies, fitting well with the research purpose.

In total, together with rich secondary data, 33 interviews were conducted to present comparable insights into how four new focal ventures built and sustained innovation ecosystems. The qualitative data covers 2015 to 2018, during which the bike-sharing ecosystems were born and gradually become viable.

The survey-based study in Chapter 4 takes a further step to look into the dimensions, antecedents, and contingencies of local innovation experiments (LIE), answering the research sub-question: What organizational capabilities can lead new focal ventures to deliver LIE high performance? Adopting a quantitative survey method for this study is suitable since no public dataset offers all of the information needed to test the hypothesized relationships between capabilities, contingencies, and LIE. The survey-based data were analyzed by the structural equation method of Partial Least Squares (PLS) (Henseler et al., 2016). The PLS data analysis technique has advantages in simultaneously processing latent reflective and formative variables, samples in small size, and less distributional assumptions. The sample described in Chapter 4 includes 111 top managers of innovative firms from two Beijing-based innovation platforms. Respondents from these two innovation platforms were involved in developing innovations by allying cross-industry partners, which favors capturing information on the LIE.

The third empirical study, described in Chapter 5, is a single case study to answer the research sub-question: How can regional innovation resources in an entrepreneurship ecosystem interact to affect new focal ventures? Note that literature on entrepreneurship ecosystem (EE) and literature on traditional Marshallian districts (including "knowledge/innovation clusters”, “entrepreneurial infrastructure”, "innovative milieus”, and “regional systems of innovation”) agree on the spatial affordance effects (such as economies of scale, economies of scope, and knowledge spillovers) of systemic resources on agglomerate industry organizations in regions. While at the core of EE (1) is the explicit complexity nature arising from digitally-intermingled entrepreneurial agents beyond purposeful design and 
regional boundaries, and (2) is the focus on bottom-up elements (e.g., business model experimentation) related exclusively to high-growth ventures (Autio et al., 2018). EE thus departs from the traditional top-down policy approaches common to traditional Marshallian approaches (Spigel and Harrison, 2018). Given that an EE consists of massive intermingled innovation agencies, resources, and dimensions, using a single case provides a more finegrained insight into the dynamics and complexities in an EE. In this way, the Zhongguancun EE located in Beijing was deliberately selected for this study. First, it has been one of the most viable EEs globally because an increasing number of high-growth new ventures were born there from 2012 to 2018 (Dong et al., 2019). These high-growth new ventures belong to various emerging industries, such as biomedicine, new energy, new materials, advanced intelligent manufacturing, and aerospace engineering. Hence, new ventures and their newly-created innovation ecosystems are probably promoted by the inclusive entrepreneurship culture, highquality human resources, supportive innovation policies, emerging markets, various financial agencies, and integrated digital infrastructures (Dong et al., 2019). Considering the specialties of the Zhongguancun EE are thus beneficial to addressing the research question.

Together with six secondary data types (websites, newspapers, magazines, videos, books, and academic papers), 23 group interviews (multiple interviewers and one interviewee) covering six domains of a viable EE are conducted (Isenberg, 2011). Multiple interviewers, including the principal investigators, senior ecosystem scholars, and industrial practitioners, made it possible to collect in-depth answers from both academic and practical angles.

As a result, following the grounded theory (Gioia et al., 2013), in Chapter 5 the qualitative data from the 1980s to 2018 are analyzed to elucidate how regional innovation resources in an EE interact to influence new ventures and their innovation ecosystems.

\subsection{OUTLINE OF THE THESIS}

Building on the brief introduction about methodological approaches, this final section will highlight key findings in Chapters 2, 3, 4, and 5 (see Table 1.1). Drawing on them, it also sheds light on how four chapters relate to each other. With a logical outline of four chapters, this section ends with a short introduction of Chapter 6, the final Chapter of this $\mathrm{PhD}$ thesis.

Chapter 2 as a systematic literature review focuses on the aggregation of an innovation ecosystem's conceptual boundaries. As discussed in Section 1.2.3, the conceptual boundaries refer to the aggregation of a number of key distinguishing features of an innovation ecosystem. Furthermore, such aggregation is reflected in two related aspects: structural relationships and 
temporal dynamics. Based on the review, (1) all nine of the key distinguishing features are abstracted into three dimensions: roles (self-organization, non-linearity, shared vision), structures (complementarity, modularity, coupling), and processes (emergence, co-opetition, co-evolution); (2) also, the three dimensions as a whole take on differing appearances in different stages of the innovation ecosystem development, from birth, expansion, to maturity. The chapter concludes with proposing three practical implications for designing and implementing strategies, for CEOs who are ambitious to develop the innovation ecosystems but often encounter a high rate of ecosystem failure.

Chapter 3 presents empirical insights into how CEOs of new focal ventures integrate ecosystem-specific strategies to lead to the innovation ecosystem's birth and viability. This chapter expands on Chapter 2, which uncovers the general insights into the execution of ecosystem-specific strategies. Based on four comparative cases, results show that new focal ventures adopt two typical strategizing forms: "strategy versatility" and "strategy suboptimality”. Strategy versatility suggests that resource-constrained new focal ventures typically leverage the interactions between executed strategies, thus developing innovation ecosystems more effectively. In comparison, strategy suboptimality indicates that outperformed new focal ventures will sacrifice specific strategies' short-term effects to enhance other implemented strategies’ long-term effects. Two interactive strategizing forms are successful due to the execution of an effective strategic innovation process - framed as LIE. The LIE refers to that new focal ventures and key partners will purposely experiment with imperfect innovations in local small-scale societies (e.g., campus, hospital, urban district) before they become mature to go to mass societies. Such an intermediary experimentation process helps managers grasp an innovation ecosystem's actual boundaries, including its ecosystem structures, actor dynamics, and interaction relationships. To some extent, these actual boundaries lay the preconditions for the effective integration of ecosystem-specific strategies.

Chapter 4 takes a further step to examine the LIE, considering its strategic roles in forming effective ecosystem-specific strategies. Chapter 4 shows that three high levels of top management teams (TMT)-based dynamic capabilities - that is, metacognitive capability, networking capability, learning agility are associated with the high-level performance of the LIE. Furthermore, results show that (1) networking capability predicts the higher level performance of LIE when managers exploit regional networking resources in an EE more frequently than others; (2) likewise, learning agility produces a higher-level performance of LIE if managers utilize more systemic innovation facilities in an EE than others. In other words, 
Chapter 4 validates that material-related resources in EEs have significant effects on new ventures’ capabilities and innovation activities.

Chapter 5 takes the "top-down" approach to look into how an EE impacts new focal ventures and their newly-created innovation ecosystems. This is complementary to the "bottomup” approach adopted by the Chapter 4 where new focal ventures use regional material-related resources to complement the dynamic capabilities levels. An EE refers to "a set of interdependent actors and factors coordinated in such a way that they enable productive entrepreneurship within a particular territory” (Stam, 2015, p. 1765). A viable EE includes various regional innovation resources divided into material and nonmaterial parts (Spigel, 2017). The material part mainly involves innovation resources such as support services, physical infrastructures, universities, and so on. The nonmaterial part mainly involves intangible resources like supportive culture, social networks, worker talents, mentors, and role models. Since regional innovation resources in a viable EE are numerous and highly connected, they exhibit distinctive complexity properties because of intricate interactions among agencies over time (Mitleton-Kelly, 2003). Hence, detecting how various regional innovation resources exhibit complexity properties could better determine how they influence (positively or negatively) new focal ventures and their innovation ecosystems.

Results in Chapter 5 show that diverse, integrated regional innovation resources in a viable EE exhibit six complexity properties: a large number of self-organized agents, nonlinear interactions, (in)sensitivity to initial conditions, adaptation to the environment, the emergence of successful entrepreneurial firms, and co-evolution. These six complexity properties indicate that the effects of well-integrated regional innovation resources on new venture creation and innovation ecosystem development are nonlinear, persistent, and far-reaching.

Chapter 6 as the summarizing chapter integrates the research results from Chapter 2, 3, 4 and 5, in order to address the research question of how new focal ventures can build and sustain their innovation ecosystems. From this $\mathrm{PhD}$ research, well-developed ecosystem-specific strategies and well-exploited dynamic capabilities will help inexperienced and resourceconstraint new focal ventures to build and sustain a viable innovation ecosystem. Integrating these new insights, a research framework is constructed to show the relationships between the studies within this $\mathrm{PhD}$ research. The theoretical contributions, as well as practical implications, are described. Finally, research limitations and avenues for future studies are discussed. 


\subsection{REFERENCES}

Adner, R. (2006). Match your innovation strategy to your innovation ecosystem. Harvard Business Review, 84(4), 98-108.

Adner, R. (2012). The wide lens: A new strategy for innovation. London: Penguin.

Adner, R. (2017). Ecosystem as structure: An actionable construct for strategy. Journal of Management, 43(1), 39-58.

Adner, R., \& Helfat, C. E. (2003). Corporate effects and dynamic managerial capabilities. Strategic Management Journal, 24(10), 1011-1025.

Adner, R., \& Kapoor, R. (2016). Innovation ecosystems and the pace of substitution: Re-examining technology S-curves. Strategic Management Journal, 37(4), 625-648.

Ansari, S., Garud, R., \& Kumaraswamy, A. (2016). The disruptor's dilemma: TiVo and the US television ecosystem. Strategic Management Journal, 37(9), 1829-1853.

Autio, E., Kenney, M., Mustar, P., Siegel, D., \& Wright, M. (2014). Entrepreneurial innovation: The importance of context. Research Policy, 43(7), 1097-1108.

Autio, E., Nambisan, S., Thomas, L. D., \& Wright, M. (2018). Digital affordances, spatial affordances, and the genesis of entrepreneurial ecosystems. Strategic Entrepreneurship Journal, 12(1), 72-95.

Autio, E., \& Thomas, L. (2014). Innovation ecosystems: Implication for innovation management. In M. Dodgson, D. M. Gann, \& N. Phillips (Eds.), The Oxford handbook of innovation management (pp. 204-288). Oxford: Oxford University Press.

Bogers, M., Sims, J., \& West, J. (2019). What is an ecosystem? Incorporating 25 years of ecosystem research. Academy of Management Proceedings. Available at: https://ssrn.com/abstract $=3437014$.

Cao, X., Ouyang, T., Balozian, P., \& Zhang, S. (2020). The Role of Managerial Cognitive Capability in Developing a Sustainable Innovation Ecosystem: A Case Study of Xiaomi. Sustainability, 12(17), 71-76.

CB Insights (December, 2020). Retrieved from https://www.cbinsights.com/research-unicorncompanies. Assessed 12 December 2020

Czarnitzki, D., \& Delanote, J. (2013). Young Innovative Companies: The New High-Growth Firms? Industrial and Corporate Change, 22, 1315-1340.

Dattée, B., Alexy, O., \& Autio, E. (2018). Maneuvering in poor visibility: How firms play the ecosystem game when uncertainty is high. Academy of Management Journal, 61(2), 466498.

de Weerd-Nederhof, P. C. (2001). Qualitative case study research. The case of a $\mathrm{PhD}$ research project on organising and managing new product development systems. Management Decision, 39(7), 513-538.

Dedehayir, O., Mäkinen, S. J., \& Ortt, J. R. (2018). Roles during innovation ecosystem genesis: A literature review. Technological Forecasting and Social Change, 136, 18-29.

Deloitte (December, 2019). Retrieved from https://www2.deloitte.com/content/dam/Deloitte/cn/Documents/innovation/deloitte-cninnovation-china-innovation-ecosystem-report-en-191101.pdf. Assessed 12 December 2020

Dong, X., Hu, Y., Yin, W., \& Kuo, E. (2019). Zhongguancun model: Driving the dual engines of science \& technology and capital. Berlin, Germany: Springer. 
Dougherty, D., \& Dunne, D. (2011). Organizing Ecologies of Complex Innovation. Organization Science, 22, 1214-1223.

Duriau, V. J., Reger, R. K., \& Pfarrer, M. D. (2007). A content analysis of the content analysis literature in organization studies: Research themes, data sources, and methodological refinements. Organizational Research Methods, 10(1), 5-34.

Eisenhardt, K. M. (1989). Building theories from case study research. Academy of Management Review, 14(4), 532-550.

Feng, N., Fu, C., Wei, F., Peng, Z., Zhang, Q., \& Zhang, K. H. (2019). The key role of dynamic capabilities in the evolutionary process for a startup to develop into an innovation ecosystem leader: An indepth case study. Journal of Engineering and Technology Management, 54, 81-96.

Fuller, J., Jacobides, M. G., \& Reeves, M. (2019). The myths and realities of business ecosystems. MIT Sloan Management Review, 60(3), 1-9.

Gilbert, B., McDougall, P.P., \& Audretsch, D. (2006). New Venture Growth: A Review and Extension. Journal of Management, 32, 926 - 950.

Gioia, D. A., Corley, K. G., \& Hamilton, A. L. (2013). Seeking qualitative rigor in inductive research: Notes on the gioia methodology. Organizational Research Methods, 16(1), 15-31.

Gulati, R., Puranam, P., \& Tushman, M. (2012). Meta-organization design: Rethinking design in interorganizational and community contexts. Strategic Management Journal, 33(6), 571586.

Gundry, L., \& Welsch, H. (2001). The Ambitious Entrepreneur: High Growth Strategies of WomenOwned Enterprises. Journal of Business Venturing, 16, 453-470.

Guo, J., \& Bouwman, H. (2016). An analytical framework for an m-payment ecosystem: A merchants' perspective. Telecommunications Policy, 40(2-3), 147-167.

Hannah, D. P., \& Eisenhardt, K. M. (2018). How firms navigate cooperation and competition in nascent ecosystems. Strategic Management Journal, 39(12), 3163-3192.

Hedman, J., \& Henningsson, S. (2015). The new normal: Market cooperation in the mobile payments ecosystem. Electronic Commerce Research and Applications, 14(5), 305-318.

Helfat, C. E., Finkelstein, S., Mitchell, W., Peteraf, M. A., Singh, H., Teece, D. J., \& Winter, S. G. (2007). Dynamic capabilities: Understanding strategic change in organizations. London: Blackwell.

Hellström, M., Tsvetkova, A., Gustafsson, M., \& Wikström, K. (2015). Collaboration mechanisms for business models in distributed energy ecosystems. Journal of Cleaner Production, 102, 226-236.

Henseler, J., Hubona, G., \& Ray, P. A. (2016). Using PLS path modeling in new technology research: updated guidelines. Industrial Management \& Data Systems, 116, 2-20.

Holgersson, M., Granstrand, O., \& Bogers, M. (2018). The evolution of intellectual property strategy in innovation ecosystems: Uncovering complementary and substitute appropriability regimes. Long Range Planning, 51(2), 303-319.

Iansiti, M., \& Levien, R. (2004). The keystone advantage: What the new dynamics of business ecosystems mean for strategy, innovation, and sustainability. Boston: Harvard Business School Press. 
Isenberg, D. J. (2011). The entrepreneurship ecosystem strategy as a new paradigm for economic policy: Principles for cultivating entrepreneurship. In Paper presented at the institute of international and European affairs. Dublin, Ireland.

Jacobides, M. G., Cennamo, C., \& Gawer, A. (2018). Towards a theory of ecosystems. Strategic Management Journal, 39(18), 2255-2276.

Kapoor, R. (2018). Ecosystems: broadening the locus of value creation. Journal of Organization Design, 7(1), 1-16. https://doi.org/10.1186/s41469-018-0035-4.

Kashan, A. J., \& Mohannak, K. (2017). The Role of Knowledge Integration in Capability Development and Emergence of Innovation Ecosystem. International Journal of Innovation and Technology Management, 14(5), 1-18.

Letaifa, S. B. (2014). The uneasy transition from supply chains to ecosystems: the value creation/ value-capture dilemma. Management Decision, 52(2), 278-295.

Li, Y.-R. (2009). The technological roadmap of Cisco's business ecosystem. Technovation, 29(5), 379-386.

Li, J., Chen, L., Yi, J., Mao, J., \& Liao, J. (2019). Ecosystem-specific advantages in international digital commerce. Journal of International Business Studies, 50(9), 1448-1463.

Liu, G., \& Rong, K. (2015). The nature of the co-evolutionary process: Complex product development in the mobile computing industry's business ecosystem. Group \& Organization Management, 40(6), 809-842.

Lynn, G. S., Morone, J. G., \& Paulson, A. S. (1996). Marketing and discontinuous innovation: the probe and learn process. California Management Review, 38(3), 8-37.

Mahmoud-Jouini, S. B., \& Charue-Duboc, F. (2017). Experimentations in emerging innovation ecosystems: specificities and roles. The case of the hydrogen energy fuel cell. International Journal of Technology Management, 75(1-4), 28-54.

Marcocchia, G., \& Maniak, R. (2018). Managing 'proto-ecosystems' - two smart mobility case studies. International Journal of Automotive Technology and Management, 18, 209-228.

Meyer, K. E., \& Peng, M. W. (2016). Theoretical foundations of emerging economy business research. Journal of International Business Studies, 47(1), 3-22.

Mintzberg, H., \& Waters, J. A. (1985). Of strategies, deliberate and emergent. Strategic Management Journal, 6(3), 257-272.

Mitleton-Kelly, E. (2003). Ten principles of complexity and enabling infrastructures. In E. Mitleton-Kelly (Ed.), Complex systems and evolutionary perspectives on organizations: The application of complexity theory to organizations (pp. 23-50). London, England: Elsevier.

Moore, J. F. (1993). Predators and prey: a new ecology of competition. Harvard Business Review, 71(3), 75-86.

Morretta, V., Syrett, S., \& Ramirez, L. S. (2020). Territorial capital as a source of firm competitive advantage: evidence from the North and South of Italy. European Planning Studies, 28(12), 2390-2408.

Nambisan, S., \& Baron, R. A. (2013). Entrepreneurship in innovation ecosystems: Entrepreneurs' self-regulatory processes and their implications for new venture success. Entrepreneurship Theory and Practice, 37(5), 1071-1097. 
Noel, L., \& Sovacool, B.K. (2016). Why Did Better Place Fail?: Range anxiety, interpretive flexibility, and electric vehicle promotion in Denmark and Israel. Energy Policy, 94, 377386.

Oskam, I., Bossink, B., \& Man, A.D. (2020). Valuing Value in Innovation Ecosystems: How CrossSector Actors Overcome Tensions in Collaborative Sustainable Business Model Development. Business \& Society, 1-33.

Overholm, H. (2015). Collectively created opportunities in emerging ecosystems: the case of solar service ventures. Technovation, 39, 14-25.

Peltola, T., Aarikka-Stenroos, L., Viana, E., \& Mäkinen, S. (2016). Value capture in business ecosystems for municipal solid waste management: Comparison between two local environments. Journal of Cleaner Production, 137, 1270-1279.

Phillips, M. A., \& Ritala, P. (2019). A complex adaptive systems agenda for ecosystem research methodology. Technological Forecasting and Social Change, 148, 119739. https://doi.org/10.1016/j.techfore.2019.119739.

Pierce, L. (2009). Big losses in ecosystem niches: How core firm decisions drive complementary product shakeouts. Strategic Management Journal, 30(3), 323-347.

Rong, K., \& Shi, Y. (2014). Business Ecosystems: Constructs, Configurations, and the Nurturing Process. London: Palgrave Macmillan.

Rong, K., Shi, Y., Shang, T., Chen, Y., \& Hao, H. (2017). Organizing business ecosystems in emerging electric vehicle industry: Structure, mechanism, and integrated configuration. Energy Policy, 107, 234-247.

Soto-Simeone, A., Sirén, C., \& Antretter, T. (2020). New Venture Survival: A Review and Extension. International Journal of Management Reviews, 22, 378-407.

Spigel, B. (2017). The Relational Organization of Entrepreneurial Ecosystems. Entrepreneurship Theory and Practice, 41(1), 49-72.

Spigel, B., \& Harrison, R. (2018). Toward a process theory of entrepreneurial ecosystems. Strategic Entrepreneurship Journal, 12(1), 151-168.

Snihur, Y., Thomas, L. D., \& Burgelman, R. A. (2018). An ecosystem-level process model of business model disruption: The disruptor's gambit. Journal of Management Studies, 55(7), 1278-1316.

Stam, E. (2015). Entrepreneurial ecosystems and regional policy: a sympathetic critique. European Planning Studies, 23(9), 1759-1769.

Thomas, L. D. W., \& Autio, E. (2020). Innovation ecosystems in management: An organizing typology. In Oxford Encyclopedia of Business and Management. Oxford University Press.

Thomke, S. (2003). Experimentation Matters: Unlocking the Potential of New Technologies for Innovation. Cambridge: Harvard Business School Press.

Tranfield, D., Denyer, D., \& Smart, P. (2003). Towards a methodology for developing evidence informed management knowledge by means of systematic review. British Journal of Management, 14(3), 207-222.

Velu, C. (2015). Knowledge management capabilities of lead firms in innovation ecosystems. AMS Review, 5(3-4), 123-141.

Visscher, K., \& de Weerd-Nederhof, P. C. (2006). Rise and fall of an innovative organisation: the innovation journey of Ericsson Enschede. International Journal of Innovation Management, 10(03), 217-235. 
Visscher, K., Hahn, K., \& Konrad, K. (2021). Innovation ecosystem strategies of industrial firms: A multilayered approach to alignment and strategic positioning. Creativity and Innovation Management, 1-13, In Press. https://doi.org/10.1111/caim.12429.

Walrave, B., Talmar, M., Podoynitsyna, K. S., Romme, A. G. L., \& Verbong, G. P. (2018). A multilevel perspective on innovation ecosystems for path-breaking innovation. Technological Forecasting and Social Change, 136, 103-113.

Williamson, P. J., \& De Meyer, A. (2012). Ecosystem advantage: How to successfully harness the power of partners. California Management Review, 55(1), 24-46.

Zahra, S. A., \& Nambisan, S. (2011). Entrepreneurship in global innovation ecosystems. AMS Review, 1(1), 4-17.

Zahra, S. A., \& Nambisan, S. (2012). Entrepreneurship and strategic thinking in business ecosystems. Business Horizons, 55(3), 219-229.

Zhang, J., \& Liang, X. J. (2011). Business ecosystem strategies of mobile network operators in the 3G era: The case of China Mobile. Telecommunications Policy, 35(2), 156-171.

Zhou, H., Huang, L., \& Kuo, T.-K. (2018). Determinants of small firm growth: An exhaustive analysis using conceptual and statistical approaches. International Review of Entrepreneurship, 16(4), 525-564.

Zimmerman, M. A., \& Zeitz, G. J. (2002). Beyond survival: Achieving new venture growth by building legitimacy. Academy of Management Review, 27(3), 414-431. 


\section{CHAPTER 2}

\section{Enhancing the Understanding of Small Firms with Regard to Innovation Ecosystems: Aggregation in the Conceptual Boundaries of Ecosystems}

\section{Based on:}

1. Han, J. Lowik, S. \& de Weerd-Nederhof, P. (2017). Uncovering the conceptual boundaries of the ecosystems: origins, evolution and future directions. Paper presented at the 2017 R\&D Management Conference, Leuven, Belgium.

2. Han, J. Lowik, S. \& de Weerd-Nederhof, P. (2017). Uncovering the conceptual boundaries of the ecosystems: origins, evolution and future directions. Paper presented at the $25^{\text {th }}$ Annual High Technology Small Firms Conference, Amsterdam, Netherlands.

3. This manuscript of this chapter is currently under review $\left(1^{\text {st }}\right.$ round of revision \& resubmission) at Industrial Marketing Management. 
ABSTRACT: Although small firms are increasingly building new innovation ecosystems, mortality amongst such ecosystems tends to be high during the early-growth stage. Nevertheless, the current ecosystems literature provides limited knowledge concerning the conceptual boundaries of ecosystems - the aggregation of ecosystems' key distinguishing features. Such knowledge could help managers to improve their understanding of how such systemic, dynamic and complex organisational arrangements produce complex value. To address this gap, the current study involved developing a theoretical framework indicating that the complex structural interactions of the nine key lower-order distinguishing features of ecosystems can be aggregated into three higher-order dimensions: roles (self-organisation, non-linearity, shared vision), structures (complementarity, modularity, coupling) and processes (emergence, coopetition, co-evolution). As a whole, these higher-order dimensions exhibit time-based differences across the process of ecosystem development. This study provides a comprehensive, general framework of the aggregated conceptual boundaries of ecosystems that highlights the basic guiding principles of any ecosystem approach. It can thereby be used to moderate the debate on differences between innovation and business ecosystems, allowing the explanation of differences in the developmental stages of innovation ecosystems, from birth to maturity. For the managers of small firms, the study provides guidelines for the successful construction of new innovation ecosystems. 


\subsection{INTRODUCTION}

Defined as a set of perfectly integrated value contributors who bring new innovative offerings to modern society (Adner, 2006, 2012), successful innovation ecosystems are an important source of competitive advantages for industrial firms. In recent years, there has been a tendency for many small industrial firms (especially younger ones) to invest ambitious efforts to start their own ecosystems (Dattée et al., 2018; de Vasconcelos Gomes et al., 2018b; Hannah and Eisenhardt, 2018; Oskam et al., 2020; Pekkarinen et al., 2019; Walrave et al., 2018). As increasing evidence has demonstrated, however, this group of small firms has suffered a high rate of ecosystem mortality (cf. Furr and Shipilov, 2018). This is not surprising. In comparison to their larger counterparts (see Masucci et al., 2020; Parente et al., 2019; Ritala et al., 2013; Velu, 2015), small firms often struggle to create successful ecosystems, due to a scarcity of strategic resources and asset-specific knowledge.

In addition to the liabilities of smallness and newness, the high mortality rate of innovation ecosystems has been attributed to the tendency of small firms to lack a holistic, in-depth understanding of the key distinguishing features of ecosystems (Aarikka-Stenroos and Ritala, 2017; Adner, 2017; Fuller et al., 2019; Granstrand and Holgersson, 2020; Phillips and Ritala, 2019; Sako, 2018). As observed by Pidun et al. (2020b, p. 1), “designing an ecosystem is more like developing a whole residential district: more complex, more players to coordinate, more layers of interaction and unintended emergent outcomes”. From this perspective, inexperienced CEOs of small firms could be expected to be more capable of building such strategic but demanding 'residential districts' after they have developed a better grasp of ecosystems as a whole, as well as of their key distinguishing features (Jacobides et al., 2018; Li et al., 2019; Shipilov and Gawer, 2020; Valkokari, 2015). In this study, we refer to these key distinguishing features and the interactions among them as the conceptual boundaries of ecosystems.

To date, scholars have devoted extensive discussion to identifying which key distinguishing features (e.g., non-linearity, modularity and co-opetition) are to be included in the conceptual boundaries of ecosystems (e.g., Autio and Thomas, 2014; Iansiti and Levien, 2004b; Letaifa, 2014; Li, 2009; Nambisan and Baron, 2013; Pidun et al., 2020a). According to existing literature, however, the current understanding of the aggregated inter-relationships within these networks remains limited, based on two issues. First, scholars have proposed a distinction between two seminal ecosystem concepts - the business ecosystem (Iansiti and Levien, 2004a; Moore, 1993) and the innovation ecosystem (Adner, 2006). The former relates 
more to the co-capture of value, while the latter relates more to the co-creation of value (e.g., Aarikka-Stenroos and Ritala, 2017; de Vasconcelos Gomes et al., 2018a). This distinction is likely to confuse managers, who must combine the features of both business and innovation ecosystems in order to co-create, deliver, and co-capture new complex value with complementors (Hannah and Eisenhardt, 2018; Leten et al., 2013; Liu and Rong, 2015; Wareham et al., 2014). Although the two approaches to ecosystems apparently share the same key distinguishing features (Thomas and Autio, 2020), their aggregated integration might be different.

A second issue pointing to a lack of knowledge concerning the inter-relationships within ecosystems has to do with the increasing number of studies searching for system-level knowledge of ecosystems (e.g., Adner and Feiler, 2019; Basole et al., 2015; Kapoor and Agarwal, 2017; Mei et al., 2019). Most studies proceed from the premise that the actual boundaries of an innovation ecosystem (i.e., the constitutive agents that are and are not present in ecosystems) should be relatively stable (Li, 2009; Phillips and Srai, 2018), with interactions between actors arising from certainties (Adner and Kapoor, 2010; Ganco et al., 2020; Luo, 2018). Although this premise corresponds to the reality of mature ecosystems, it runs counter to the dynamic, complex nature of innovation ecosystems in the nascent stages, when small firms must cope with fluid boundaries resulting from the frequent entrance, exit, and roletransition of ecosystem participants (Dedehayir et al., 2018; Lu et al., 2014). Such uncertainties lead to unpredictable outcomes in terms of ecosystem growth (Mars et al., 2012; Peltoniemi, 2006). This suggests that, although the distinguishing features may seem stable, the dynamic and temporal behaviour of innovation ecosystems cannot be explained adequately without taking aggregation into account.

The existing body of knowledge says little about the aggregated conceptual boundaries of ecosystems, as particularly reflected in two aspects: internal structures and temporal variances. Addressing these issues could be beneficial to scholars of ecosystems, as well as to small firms. To this end, we explore the following research question: What are the aggregated conceptual boundaries of ecosystems that small firms can use to capture value sustainably by building their own new innovation ecosystems?

To answer this research question, we developed a new theoretical framework that highlights nine lower-order distinguishing features of innovation ecosystems, which can be aggregated into three higher-order dimensions: roles (self-organisation, non-linearity, shared vision), structures (complementarity, modularity, coupling) and processes (emergence, co- 
opetition, co-evolution). Additionally, these three dimensions exhibits complex, time-related interactions, thus explaining differences in the developmental lifecycles of innovation ecosystems from birth to maturity.

Our work contributes to the current ecosystem literature in three major ways. First, it presents an aggregated perspective on the conceptual boundaries of ecosystems involving nine lower-order distinguishing features and three higher-order dimensions. This constitutes an explicit response to recent calls for the conceptualisation of innovation ecosystems from a metatheoretical perspective (Granstrand and Holgersson, 2020; Phillips and Ritala, 2019; Thomas and Autio, 2020), which could help both scholars and practitioners to understand the special characteristics of ecosystems with regard to producing complex value. Second, our theoretical model highlights the coherent structural aggregation within the three dimensions. In doing so, it moderates the current debate on the conceptual proximity between the two seminal concepts of innovation ecosystems and business ecosystems. Our work suggests that scholars should be explicit about the focal areas of their research by considering the structural aggregation of the conceptual boundaries of ecosystems. Our third contribution is the dynamic characteristic of aggregation of the conceptual boundaries of ecosystems. This draws the attention of ecosystem researchers to time-based differences in the three dimensions and their underlying features, thereby enhancing the understanding of scholars and practitioners with regard to the true boundaries of the innovation ecosystems that they are investigating.

\subsection{THEORETICAL BACKGROUND}

First introduced by scholars of innovation (Adner, 2006, 2012; Iansiti and Levien, 2004a, 2004b; Moore, 1993, 1996), the concept of innovation ecosystems has been a topic of considerable theoretical and practical interest in the past five years (Bogers et al., 2019). The increasing popularity of the concept reflects a fundamental change in the industry, in which many complex innovations (e.g. renewable energy and biomedicine) are being accomplished not by individuals, but by networks of actors with complementary resources (Dougherty and Dunne, 2011; Williamson and De Meyer, 2012). Scholars have reached consensus on the uniqueness of the innovation ecosystem as a type of multi-agent phenomenon. This consensus concerns three prominent aspects. (1) An ecosystem includes various 'uncommon' cross-industry actors brought together around common innovation goals (Furr and Shipilov, 2018; Zahra and Nambisan, 2011). (2) The interactions of actors are not subject to formal power; they are complex, and they cannot be simply decomposed into single direct or indirect ties (Adner, 2017). 
(3) The systemic performance of an ecosystem both depends on and affects the performance of individual actors. A virtuous circle between these two different but closely related levels of performance enables ecosystem growth (Rong et al., 2018). Overall, innovation ecosystems are systemic, complex and dynamic in nature. They emphasise that it is important for firms to devote serious consideration to the key distinguishing features of ecosystems and to take effective strategic decisions in order to obtain competitive advantages through and within ecosystems (Oh et al., 2016; Ritala and Almpanopoulou, 2017).

\subsubsection{Current understanding of the conceptual boundaries of ecosystems}

In this study, we define the conceptual boundaries of ecosystems as an aggregation of key distinguishing features possessed by a general ecosystem of interest. The basic thinking is that these boundaries comprise the combination of key features that allow the distinction-at least conceptually_ of what does and does not constitute the essential definition of an ecosystem (Autio and Thomas, 2014; Gibbert and Välikangas, 2004). The notion and importance of the conceptual boundaries of ecosystems has been addressed by other scholars as well, using a variety of terms, including 'differentiators' (Oh et al., 2016), ‘conceptual underpinnings' (Ritala and Almpanopoulou, 2017), 'key invariants' (Scaringella and Radziwon, 2018) and 'theoretical primers' (Jacobides et al., 2018).

To date, most studies have focused on single parts of the conceptual boundaries of ecosystems, including self-organisation (e.g., Dedehayir et al., 2018; Weber and Hine, 2015), multilateralism (e.g., Adner, 2017), complementarity (e.g., Pierce, 2009), modularity (Jacobides et al., 2018) and co-evolution (Basole, 2009; Luo, 2018). These observations acknowledge that an ecosystem is clearly a self-standing concept (Ritala and Almpanopoulou, 2017), a distinct multi-agent paradigm of value co-creation (Kapoor, 2018), layered within the environment of a broader societal system (Aarikka-Stenroos and Ritala, 2017). At the same time, however, the attention that has been paid to partial features of the conceptual boundaries of ecosystems could lead to contradictory conclusions concerning such issues as whether the governance of an ecosystem does or does not require orchestration by focal actors (Autio and Thomas, 2014; Isenberg, 2016; Leten et al., 2013; Oskam et al., 2020; Zahra and Nambisan, 2012).

Scholars have listed a relatively wide range of key features of the conceptual boundaries of ecosystems. For example, Li (2009, p. 380) describes ecosystems as "having three major characteristics: symbiosis, platform, and co-evolution”. Similarly, Autio and Thomas (2014) 
propose that the conceptual underpinnings of an ecosystem are composed of three features: shared assets, a complex-value process and non-linearity. Nambisan and Baron (2013) portray ecosystems as being characterised by features including actor interdependency, shared goals and complementarity. Despite the proliferation of lists of defining features, however, little is known about the distinctiveness of these characteristics or about their theoretical interrelationships. This is unfortunate, given that such inter-relationships constitute a primary criteria for the assessment of clear, researchable concepts (Corley and Gioia, 2011; Podsakoff et al., 2016). Further endeavours are needed in order to provide an aggregated understanding (Thomas and Autio, 2020).

\subsubsection{Aggregation in the conceptual boundaries of ecosystems}

In general, the term 'aggregation' is used to refer to "the systematic accumulation, analysis and reflective interpretation of the full body of relevant empirical evidence related to a question” (Rousseau et al., 2008, p. 475). For example, the chapters in a textbook have different functions. Without the chapters, the textbook has no context and loses its meaning. In addition, the textbook would be unreadable unless these distinct, independent chapters were to form a logical whole. As suggested by this simple example, aggregation does not become viable until the underlying principles of a mass (book chapters) are sufficiently elaborated. Likewise, the aggregation of the conceptual boundaries of ecosystems is not viable unless the coherent interrelationships of the mass of key distinguishing features are well articulated.

In the theory of ecosystems, the aggregated conceptual boundaries of ecosystems are critical for two important reasons. First, the clarified, aggregated conceptual boundaries of ecosystems can help researchers to demarcate the categorical boundaries archetypal ecosystems. Categorical boundaries refer to the elements that allow the conceptual differentiation of one ecosystem approach from the others. The existing literature contains ambiguities regarding to the conceptual proximity between two seminal ecosystem approaches: the business ecosystem and the innovation ecosystem. According to one prominent stream of literature, innovation ecosystems emphasise the co-creation of value and collaborations amongst the participants in an ecosystem. This is in contrast to the focal areas of the business-ecosystems approach, which emphasises value co-capture and competition (e.g., Aarikka-Stenroos and Ritala, 2017; Clarysse et al., 2014; de Vasconcelos Gomes et al., 2018a; Ritala et al., 2013).

The distinctions outlined above are problematic, given that the co-creation of value is ultimately intended to co-capture value, even as the fairness of value-capture amongst the actors 
in an ecosystem determines the likelihood that all value contributors will co-evolve towards subsequent rounds of activities aimed at the co-creation of value, thus providing a salient indicator of productive ecosystems (Adner, 2017; Leten et al., 2013; Peltola et al., 2016). As noted by Granstrand and Holgersson (2020), such a strict demarcation between innovation and business ecosystems sacrifices too much accuracy in conceptual understanding in the interest of simplicity. Based on this argument, we propose that clarification of the conceptual boundaries of ecosystems might provide more nuanced insight into why two types of ecosystems possess the same features for the conceptual boundaries of ecosystems, while differing in the emphasis placed on the value processes. Such knowledge could guide inexperienced managers in making better choices regarding appropriate types of ecosystems to develop.

Another benefit of the aggregation in the conceptual boundaries of ecosystems is that it can help to cope with the actual boundary issue. This issue concerns how to locate the boundaries that can best "identify the perimeter and constituent parts of the ecosystem" (Battistella et al., 2013, p. 1197), thereby generating system-level knowledge concerning the governance and growth of ecosystems. Although they are important in research, the various operationalisations of boundaries appear to be problematic. Based on a variety of methods (e.g. surveys, experiments and agent-based modelling), an insightful body of literature arguably selects either merger and acquisition activities (Li, 2009), related patents (Basole et al., 2015), technological modularity (Kolloch and Dellermann, 2018) or digital platforms (Tiwana, 2015) as proxies for the delineation of actual boundaries.

The authors of the aforementioned studies assume that the boundaries they set should appear to be relatively stable and the dynamics of interactions between actors should be linked to certainties (Phillips and Srai, 2018). This runs counter to the dynamic understanding of ecosystems in the nascent stages, when the frequent entrance, exit and role-transitions of participants render the actual boundaries of the ecosystem relatively unpredictable (Dedehayir et al., 2018). In a reductionist approach, some researchers select research boundaries as involving 'minimum viable' actors (Adner, 2012; Adner and Kapoor, 2010; Kapoor and Lee, 2013; Pierce, 2009). Such choices nevertheless restrict these authors from capturing systemic information on the complexity and dynamics of ecosystems (Autio and Thomas, 2014; Battistella et al., 2013). The clarification of the conceptual boundaries of ecosystems could thus help researchers to be explicit about their boundary choices and, more importantly, inform them about the extent to which their research findings can be generalised and applied (Bogers et al., 
2019). From the perspective of management, if they are guided by the time-related differences of the conceptual boundaries of ecosystems, new ecosystems of small firms are likely to thrive, due to the implementation of more effective strategies.

We therefore ask: What are the aggregated conceptual boundaries of ecosystems that small firms can use to capture value sustainably by building their own new ecosystems?

\subsection{RESEARCH METHODOLOGY}

Our research question (i.e., a 'what' question) demands collective insight through theoretical synthesis. To answer it, we developed a coherent theoretical framework. One advantage of a theoretical synthesis is that it produces new, higher-order understanding by seeking to integrate the fragmented existing scholarly wisdom on the conceptual boundaries of ecosystems into a manageable whole (Rousseau et al., 2008; Cornelissen, 2017). Based on recent suggestions by Jaakkola (2020), our synthesis work involved three phases: (1) conducting a systematic literature review capturing relevant articles on ecosystems; (2) extracting and grouping clear, specific claims concerning the key features of ecosystems in these articles; and (3) inductively forming an integrated view of the aggregation of conceptual boundaries of ecosystems by building on the compatible relationships across the key features of ecosystems.

\subsubsection{Selection of relevant articles}

Following the guidelines for systematic literature-review methods (Boell and CecezKecmanovic, 2015; Tranfield et al., 2003), we captured 171 ecosystem publications in a fouryear longitudinal process (additional details are provided in Figure 2.1, which tracks the relevant ecosystem studies from the popular research engines, including Scopus, Web of Science, and ScienceDirect).

Several measures were used to consolidate the reliability and validity of data (Boell and Cecez-Kecmanovic, 2015). With regard to data reliability, we examined 16 literature reviews published in a variety of journals (see Appendix 2.1), in which the appendices and open-access online supplements about ecosystem literature facilitated cross-checking the publications we identified. We further relied on seminal works on ecosystems (see the bibliometric results in de Vasconcelos Gomes et al., 2018a), in order to identify where and by whom these seminal works have been cited. This allowed us to determine whether the publications that we extracted were published between 1993 and 2020. To avoid serious research bias in the selection of target articles, we invited senior researchers to review our selection for completeness and precision. 


\subsubsection{Content analysis}

Given the fragmented nature of existing knowledge on the conceptual boundaries of ecosystems, we adopted the technique of inductive content analysis (Duriau et al., 2007; Potter and LevineDonnerstein, 1999; Short and Palmer, 2008). Our objective is to extract key distinguishing features from the textual data. To this end, we followed the model of 'human-scored approaches', in which researchers intentionally develop coding units. Our coding units are narratives (e.g., sentences) that explicitly mention key distinguishing features of ecosystems (e.g., features, characteristics, traits, particularity, distinction, peculiarity, property, primacy, cornerstone, pillars, difference, builds on, differentiates with, key tenets, or key logic). Our focus is on manifest (as opposed to latent) narratives, which are regarded as objective in nature, thereby enhancing the reliability of our results without excessive personal interpretation (Short and Palmer, 2008). Following a complete review of the collection of 171 papers, we identified 172 key features that were extracted from specific sentences in 84 publications (see the emphasis in Appendix 2.1).

\subsubsection{Inductive classification}

Our final step consisted of the inductive development of these 172 key features into categories. We started by grouping features containing the same words into categories, with the decisive limit defined as a count of more than five (e.g. 'self-organisation' appeared eight times). This initially resulted in six categories. We then supplemented these six categories with key features having semantically equivalent meanings (e.g. 'significant autonomy' and 'volunteerism' were grouped into the self-organisation category). In this process, we frequently returned to the original discourse in publications in order to ensure that the different terms were actually used to refer to the same conceptual meanings. After the initial classification of 96 features into six categories, the remaining 76 key features were further grouped in another round of classification. We repeated these steps, using three similar codes as the benchmark for a discrete category. Each category is identified by a key distinguishing feature. In the interest of reliability and consistency, we circulated the results of this classification amongst our colleagues (i.e., junior and senior ecosystems scholars). After incorporating several rounds of academic comments, we ultimately retained nine key distinguishing features for further analysis and aggregation (the full set is provided in Appendix 2.2). 


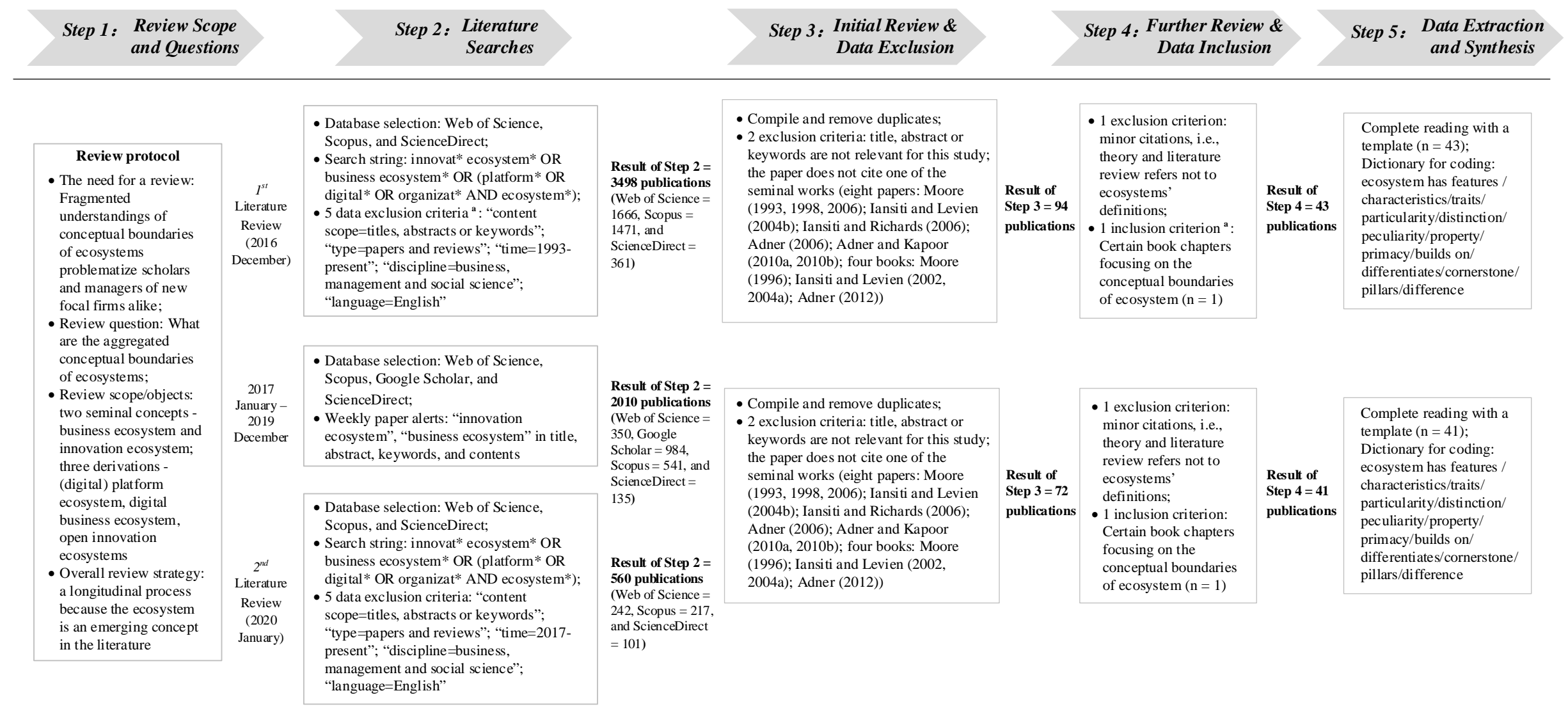

Note: $a$ = After serious consideration, we included two book chapters by Autio and Thomas (2014) and Thomas and Autio (2020) as two works contribute explicitly to ecosystem conceptual boundary.

\section{Figure. 2.1: Process of selection of relevant articles.}




\subsection{TOWARDS A THEORETICAL FRAMEWORK FOR THE CONCEPTUAL BOUNDARIES OF ECOSYSTEMS}

According to our analysis, the aggregated conceptual boundaries of ecosystems are reflected in two typical ways: (1) all nine of the key distinguishing features are abstracted into three dimensions: roles, structures, and processes; (2) in addition, the three dimensions as a whole take on different appearances in different stages of ecosystem development, from birth to maturity. A graphic presentation of these two aggregations is presented in Figure 2.2. In the following sections, we elaborate the aggregations in greater detail.

\subsubsection{Building blocks: Roles, structures, and processes}

From the ecosystem literature, we abstracted nine key distinguishing features of ecosystems, and we aggregated them into three dimensions. More specifically, the 'roles' dimension includes three key distinguishing features: self-organisation, non-linearity, and shared vision; the 'structures' dimension consists of three features: complementarity, modularity and coupling; and the 'processes' dimension comprises emergence, co-opetition and co-evolution (Table 2.1).

\subsubsection{The 'roles' dimension}

According to general systems theory, an innovation ecosystem is a complex system in which the number and diversity of agents, interactions between agents and their environment are the basic elements of system-level structures and behaviours (Anderson, 1999; Peltoniemi, 2006). For example, according to studies by Aarikka-Stenroos and Ritala (2017) and by Granstrand and Holgersson (2020), an innovation ecosystem should include at least some of the following basic elements: harmonious actors, artefacts, activities and institutions.

The roles dimension and its three constituent features illustrate the traits of individual ecosystem actors: each actor is self-organised and interacts with others free of formal controls. Specific actors occupy their respective niches within ecosystems and move towards the shared goals. Overall, the roles dimension and its three constituent features relate to individual ecosystem actors, indicating how different ecosystems roles come into being in the first place (Dedehayir et al., 2018; Iansiti and Levien, 2004b; Rong and Shi, 2014). 


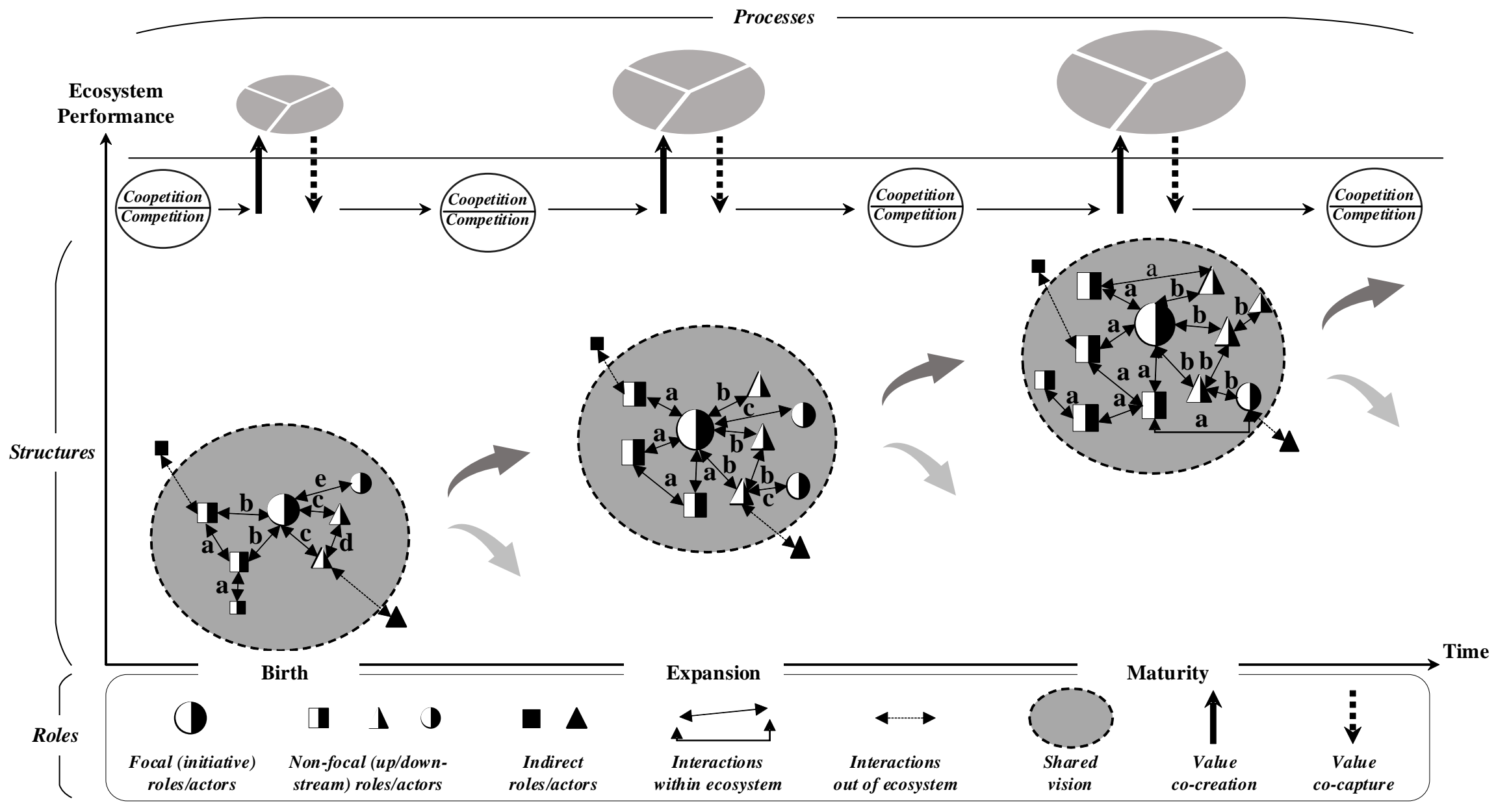

Figure. 2.2: Schematic framework for the conceptual boundaries of ecosystems (source: authors). 
Table 2.1: Key distinguishing features.

\begin{tabular}{|c|c|c|c|}
\hline Dimension & Feature & Definition & Representative Quote \\
\hline \multirow{3}{*}{$\begin{array}{l}\text { Roles } \\
\text { "the involved } \\
\text { actors in } \\
\text { ecosystems and } \\
\text { their } \\
\text { characteristics } \\
\text { " }\end{array}$} & $\begin{array}{l}\text { Self- } \\
\text { organization }\end{array}$ & $\begin{array}{l}\text { Self-organization signals that } \\
\text { hierarchical, formal control is } \\
\text { invisible in ecosystems. }\end{array}$ & $\begin{array}{l}\text { - m11: "It can be useful to think of a loosely coupled network as a } \\
\text { business ecosystem (Iansity and Levien, 2002); they share some } \\
\text { key properties: complexity, self-organization and adaptation." } \\
\text { (p122); a } \\
\text { - n46: "The main characteristics of DBEs are platform, symbiosis, } \\
\text { co-evolution and self-organization." (p53) b }\end{array}$ \\
\hline & Non-linearity & $\begin{array}{l}\text { Non-linearity indicates that } \\
\text { communications/interactions } \\
\text { happen without certainties } \\
\text { among actors. }\end{array}$ & $\begin{array}{l}\text { - m43: "Business ecosystems, on the other hand, are } \\
\text { characterized by a non-linear value creation process as groups } \\
\text { of firms deliver integrated solutions to end users." (p1174); } \\
\text { - } \mathrm{n} 41 \text { : "what differentiates the business ecosystem perspective } \\
\text { from the networks and value chain constructs is its nonlinear, } \\
\text { multisided, coevolutionary characteristic." (p277) }\end{array}$ \\
\hline & $\begin{array}{l}\text { Shared } \\
\text { vision }\end{array}$ & $\begin{array}{l}\text { Shared vision describes what } \\
\text { a possible future of the } \\
\text { ecosystem looks like. }\end{array}$ & $\begin{array}{l}\text { - m32: "The three defining characteristics of an innovation } \\
\text { ecosystem then are the dependencies established among the } \\
\text { members (members' performance and survival are closely linked } \\
\text { to those of the ecosystem itself ), a common set of goals and } \\
\text { objectives (shaped by the ecosystem-level focus on a unique } \\
\text { customer value proposition), and a shared set of knowledge and } \\
\text { skills."(p1071); } \\
\text { - n23: "Business ecosystems are characterized by a functional } \\
\text { goal to enable technological development and innovation." (p2) }\end{array}$ \\
\hline \multirow{4}{*}{$\begin{array}{l}\text { Structures } \\
\text { "how } \\
\text { ecosystem } \\
\text { actors are } \\
\text { coordinated } \\
\text { and linked as a } \\
\text { whole" }\end{array}$} & $\begin{array}{l}\text { Complement } \\
\text { arity }\end{array}$ & $\begin{array}{l}\text { Complementarity refers to } \\
\text { potential synergies (higher } \\
\text { value benefits and lower }\end{array}$ & $\begin{array}{l}\text { - m28: "the access to resources and the complementarity in } \\
\text { innovation processes appear to be unique characteristics of this } \\
\text { business ecosystems." (p20); }\end{array}$ \\
\hline & & $\begin{array}{l}\text { coordination costs) as a result } \\
\text { of diverse actors who are co- } \\
\text { specialized in unique assets. }\end{array}$ & $\begin{array}{l}\text { - n34: “This encapsulates three crucial attributes of an } \\
\text { ecosystem... First, “multilateral, nongeneric } \\
\text { complementarities...” (p2264) }\end{array}$ \\
\hline & Modularity & $\begin{array}{l}\text { Modularity refers to the } \\
\text { extent to which actors' } \\
\text { unique inputs can be } \\
\text { separated and recombined } \\
\text { into independent yet } \\
\text { connected units. }\end{array}$ & $\begin{array}{l}\text { - m65: "The modularity of an ecosystem organizational form and, } \\
\text { by extension, the type of knowledge attached to the selection, } \\
\text { inter-connection, combination and integration of its various } \\
\text { components are thus central to its very definition as an } \\
\text { ecosystem." (p12); } \\
\text { - n34: "What makes ecosystems unique is that the } \\
\text { interdependencies tend to be standardized within each role, } \\
\text { which creates the need for a new set of skills in terms of } \\
\text { designing ecosystems..." (p2264-2265) }\end{array}$ \\
\hline & Coupling & $\begin{array}{l}\text { Coupling is about the overall } \\
\text { intensity of actors' linkages } \\
\text { when they co-create new } \\
\text { value. }\end{array}$ & $\begin{array}{l}\text { - m3: " "ecosystems" are characterized by a large number of } \\
\text { loosely interconnected participants who depend on each other } \\
\text { for their mutual effectiveness and survival." (p10); } \\
\text { - n59: "The network logic of the ecosystem is usually aligned with } \\
\text { a keystone and is characterized by a large number of loosely } \\
\text { connected actors (niches) that depend on each other for their } \\
\text { mutual benefit and, through interdependence, can co-create } \\
\text { value that no single actor can." (p319) }\end{array}$ \\
\hline \multirow{3}{*}{$\begin{array}{l}\text { Processes } \\
\text { "how the } \\
\text { ecosystem as a } \\
\text { collective } \\
\text { develops over } \\
\text { time" }\end{array}$} & Emergence & $\begin{array}{l}\text { Emergence is an intrinsic, } \\
\text { system-level property } \\
\text { describing the ecosystem } \\
\text { overall trends from one state } \\
\text { to the other. }\end{array}$ & $\begin{array}{l}\text { - m26: “both biological and organizational ecosystems share } \\
\text { similar emergent properties.” (p278); } \\
\text { - } \mathrm{n} 57 \text { : “The danger of this myth is that it leads us to adopt static, } \\
\text { deductive approaches that are at odds with the dynamic, } \\
\text { emergent character of ecosystems.” (p5) }\end{array}$ \\
\hline & Co-opetition & $\begin{array}{l}\text { Co-opetition refers to the } \\
\text { overall condition of various } \\
\text { ecosystem actors' } \\
\text { engagement in collaborative } \\
\text { and competitive actions } \\
\text { aiming to materialize } \\
\text { ecosystem value propositions. }\end{array}$ & $\begin{array}{l}\text { - m51: "Ecosystems are characterized by coopetition." (p281); } \\
\text { - n25: "Cooperation and competition can also unfold } \\
\text { simultaneously and differently at multiple ecosystem levels: } \\
\text { within components; across firms in a focal ecosystem; and } \\
\text { among rival ecosystems. These characteristics increase the } \\
\text { complexity of balancing cooperation and competition by firms } \\
\text { within ecosystems." (p3163) }\end{array}$ \\
\hline & Co-evolution & $\begin{array}{l}\text { Co-evolution refers to overall } \\
\text { conditions of innovation } \\
\text { ecosystem which evolves all } \\
\text { actors into a new landscape } \\
\text { by avoiding the system inertia }\end{array}$ & $\begin{array}{l}\text { - m63: "co-evolution in different stages of a lifecycle is an } \\
\text { essential feature of the business ecosystem." (p44); } \\
\text { - n39: "co-evolution remains a widely referred topic and is a } \\
\text { central feature of ecosystems." (p10) }\end{array}$ \\
\hline
\end{tabular}

Note: a, " $m 11$ " and " $p 122$ " denote respectively code literature captured from the $1^{\text {st }}$ SLR and the page; $b$, " $n 46$ " and " $p 53$ " denote respectively code literature captured from the $2^{\text {nd }}$ SLR and the page. 
As depicted at the bottom of Figure 2.2, a set of innovation actors in various shapes and sizes exists within an innovation ecosystem. The element of self-organisation reflects the absence of formal, hierarchical control amongst the actors in an ecosystem (Isenberg, 2016; Sako, 2018). Regardless of size, newness or form, each ecosystem actor has full autonomy to decide how to use, when to deploy, and with whom to exchange critical resources that are valuable for new innovative offerings (Gulati et al., 2012).

Without purposeful interventions from others, non-linearity relates to the interactions of individual actors, which do not occur in a simple, linear fashion (Kapoor, 2018), instead exhibiting increasing complexity as the number and diversity of actors increase within ecosystems (Kim et al., 2010; Lu et al., 2014; Mars et al., 2012). With our framework, the interactions (see the double-sided arrows in Figure 2.2) connect various ecosystem actors. Beyond the dyads, actor interactions linked by flows of resources and information take on such forms as co-design, negotiations, learning, and innovation experimentations (Davis, 2016).

The non-linear interactions of the self-organised actors often generate outcomes-shared visions - which are untraceable, due to their multi-directional causalities (Aarikka-Stenroos and Ritala, 2017). The shared vision, also known as a ‘focal value proposition' (Adner, 2017) or 'battlefield' (Furr and Shipilov, 2018), is regarded either as a focal statement to be performed or as the promised performance to be achieved by ecosystem actors (Adner, 2017; Moore, 1996; Walrave et al., 2018). Shared visions emerge out of the non-linear interactions of self-organised actors. Through frequent non-linear interactions, current actors gradually learn how they can contribute to the collective offering, thus leading them to occupy beneficial niches within ecosystems (Liu and Rong, 2015). Moreover, as a form of socialisation, high-quality interactions breed shared values, working norms and common language, thereby facilitating the formation of a shared vision (Dhanaraj and Parkhe, 2006). In their turn, shared visions are subject to modifications or replacement based on non-linear interactions, which subsequently influence the decisions (e.g., regarding entry and exit) of existing/potential ecosystem actors. Nevertheless, the decisions of actors concerning whether to accept/reject ecosystem membership due to changes in shared visions are free of any intervention from controllers (Peltoniemi, 2006).

\subsubsection{The 'structures' dimension}

An innovation ecosystem is a kind of social system in which the interactions of system agents cannot be decomposed into single agents, thus illustrating why system agents are able to act 
collectively (Baldwin, 2012; Callon, 1986; Whittington, 1992). Likewise, expanding on the ecosystem-as-component school, which focuses primarily on individual actors, Adner (2017) adopts a structuralist perspective to suggest that researchers should also know the links and positions existing amongst ecosystem actors. Adner further argues that actors in innovation ecosystems are embedded within complex multilateral structures that "are not decomposable to an aggregation of bilateral interactions” (Adner, 2017, p. 42). Such multilateral structures also suggest the shared fate that, if any actors delay contributing to new value propositions required by the tasks of their roles, the overall performance of the ecosystem will suffer, and vice versa (Iansiti and Levien, 2004b; Rong et al., 2015).

Informed by these arguments, the structures dimension and its three constituent features relate to structural relationships amongst the actors in an ecosystem. More specifically, the respective contributions that actors make to the final offerings of an ecosystem should be complementary. To achieve this goal effectively, modularity and coupling are two underlying mechanisms for developing the complementary contributions into a coherent whole for endusers. We propose that the structures dimension and its three constituent features relate to the mutuality of ecosystem actors, thereby indicating how actors are linked to one another and coordinated as a whole.

Guided by shared visions, actors are interdependent on each other in the co-creation of new value (Autio and Thomas, 2014). Note that the value in ecosystem settings is multidimensional, including economic, cultural, social, and other values that are in use (Letaifa, 2014). Ecosystem value can take a variety of forms, including efficiency, innovativeness, usefulness, and new experiences (Lepak et al., 2007).

Complementarity refers to potential synergies (higher value benefits and lower coordination costs) as a result of diverse actors who are co-specialised in unique assets. From a value-chain perspective, the complementarity of actors reveals differences in up-stream (production) and down-stream (consumption) aspects. More specifically, the up-stream side ensures that 'the total benefits of use of A and B exceed using each separately', whereas the down-stream side can be summarised as 'more A making B more valuable' (Jacobides et al., 2018). An innovation ecosystem is thus a mixture of co-specialised actors who are embedded within varying degrees of asset complementarities (Ganco et al., 2020; Kapoor, 2018; Shipilov and Gawer, 2020).

Modularity refers to the extent to which the unique, complementary contributions that actors make to final offerings can be separated and recombined into independent yet connected 
units (Bayliss and Clark, 1997; Sanchez and Mahoney, 1996). As illustrated in Figure 2.2, as innovation ecosystems grow, the number and diversity of actors increase, and the discrete technology interfaces, standards, and rules become incompatible (see the representations of a, b, c, and d in the framework). Ecosystems are deemed to be low in modularity if the interfaces, standards, and rules that are necessary in order to promote the coordination of value activities proliferate and are incompatible. As a result, when one key customisation for the final offerings is delayed or fails, this leads to high costs of coordination and adjustment for other actors. Conversely, high ecosystem modularity suggests that components of the overall offering are easily combined and integrated, with low costs of coordination (Schilling, 2000; Tiwana, 2015).

Coupling has to do with the overall intensity of the linkages between actors as they cocreate new value. Theories of organisation have long reasoned that, by absorbing environmental cues, any organisational form will exhibit two distinct structures: responsiveness and distinctiveness (Orton and Weick, 1990). In our framework, responsiveness (white) reflects the extent to which actors need to align consistently with the innovation actions/activities of others, whereas distinctiveness (black) signifies the extent to which actors need to remain separate from others in terms of innovation activities. On these grounds, innovation ecosystems exhibit three overall conditions: decoupling (most actors are in black), tight coupling (most actors are in white) and loose coupling (actors are balanced between black and white) (cf. Brusoni and Prencipe 2001, 2013).

In summary, actor complementarity is regarded as the basis for modularity and coupling. In other words, greater heterogeneity amongst the complementary inputs that are used to compose the final offering is associated with an increased need on the part of the ecosystem to accumulate modularity (specificity), as well as with loose (or tight) coupling within the ecosystem (Brusoni and Prencipe, 2013).

\subsubsection{The 'processes' dimension}

An innovation ecosystem is an open value system consisting of groups of members who are highly influenced by environments, thereby explicating the non-linear dynamics that system agents are likely to ignite (Autio and Thomas, 2014; Kast and Rosenzweig, 1972). In addition to roles (individual actors) and structures (amongst actors), the ecosystem literature has laid fertile foundations for explaining how innovation ecosystems change over time (e.g., Moore, 1996; Phillips and Ritala, 2019; Rong et al., 2015). The rationale is that "any ecosystem examination should pay close attention to where the dynamics are, and to which extent the 
ecosystem pursues retention of stability or instigates change” (Phillips and Ritala, 2019, p. 9). In line with this thinking, we argue that the processes dimension and its three constituent features relate to the time-related dynamics of ecosystems, thereby indicating how the innovation ecosystem develops as a collective over time. More specifically, the features of emergence and co-opetition characterise the dynamics of innovation ecosystems, which the coevolution of all actors with respect to capability, knowledge and skills, need to adapt to.

Based on the innovative offerings that have been co-created, the fair distribution of value amongst the actors in an ecosystem and the appropriation of a portion of the total value by each of these actors determines whether the innovation ecosystem will be able to develop as a collective. Emergence is a system-level property describing the overall ecosystem trend from one state to the other. According to Peltoniemi (2006, p. 13), "the key to emergence is the link between the micro and macro behavior”. Emergence is a consistent feature, given that, throughout their development, innovation ecosystems always end up with two unforeseeable states: mutation (positive evolution; see the dark arrows in Figure 2.2) and degeneration (negative evolution; see the light arrows in Figure 2.2) (Anderson, 1999). In this regard, scholars have argued that ecosystem growth should not be regarded as linear and stable, with deterministic velocity. Instead, it fluctuates, with rapid shifts, abrupt reversals, unintended crashes or some combination of these movements (Fuller et al., 2019; Lu et al., 2014).

Co-opetition refers to the overall condition of the engagement of ecosystem actors in collaborative and competitive actions aimed at materialising and benefitting from co-created innovative offerings. In general, collaborative actions relate primarily to the co-creation of value ('how to make a big pie'), while competitive actions are aimed more at the co-capture of value ('how to share the pie') (Ritala et al., 2013). Co-opetition varies throughout the stages of ecosystem development: low/high collaboration and low/high competition. As demonstrated by Hannah and Eisenhardt (2018), ecosystems with high market performance benefit from a continuous, delicate balance between competition and collaboration (see the combination of arrows and graphic symbols at the top of Figure 2.2). In contrast, tipping towards either collaboration or competition would lead ecosystem actors to attain inferior advantages.

Co-evolution arises from actor interdependence (Peltoniemi, 2006; Phillips and Ritala, 2019) and "proceeds by competition and coopetition" (Moore, 1996, p. 82). Co-evolution refers to the overall conditions of an innovation ecosystem, which lead all ecosystem actors towards a new landscape by avoiding system inertia (Li, 2009; Luo, 2018). In more substantive terms, Aarikka-Stenroos and Ritala (2017, p. 25) suggest that a hallmark of the co-evolution of 
ecosystems centres on the boundaries and composition of an ecosystem, defined as "the contextual breadth within which the relevant set of actors, technologies, and institutions is situated”, along with their temporal, system-wide changes. In our framework, therefore, the low (or high) level of ecosystem co-evolution suggests a small (or large) size of ecosystem boundaries and composition.

In conclusion, the general principle of ecosystem development is characterised by emergence, with the balance of ecosystem-level collaboration and competition determining whether ecosystem actors will be able to evolve sustainably as a collective over time. Furthermore, as indicated by the unforeseeable mutation and the balanced level of co-opetition, all ecosystem actors could potentially co-evolve successfully in terms of their capabilities, skills and knowledge.

\subsubsection{Aggregating lower-order features into higher-order dimensions}

Thus far, we have demonstrated in detail that the nine distinguishing features of ecosystems are grouped together due to higher-order similarities, as well as in response to their complex interactions within the dimensions. More specifically, the formation of a shared vision within an ecosystem depends on the individual ecosystem actors, which are self-organised and interact in a non-linear manner. These three distinguishing features are aggregated into the roles dimension, as they inform the manner in which innovation ecosystems actors come into being in the first place. Furthermore, actor complementarity is regarded as the premise for the modularity and coupling condition of an ecosystem. These three distinguishing features are aggregated into the structures dimension, as they collectively characterise the ways in which ecosystem actors are coordinated in order to co-create value. Finally, the ability of ecosystem actors to co-evolve collectively depends on the dynamism of ecosystem development, which is characterised by emergence and co-opetition. They are combined into the processes dimension, as they point primarily to the ways in which ecosystem actors co-create and, more importantly, co-capture complex value, thereby indicating how innovation ecosystems develop over time. Based on these observations, we propose the following:

Proposition 1: In general, the aggregation of the conceptual boundaries of ecosystems is understood from three major, inter-related higher-order dimensions-roles, structures and processes-within which the distinctive features reveal complex, dynamic lowerorder interactions. 


\subsubsection{Dimensions of the conceptual boundaries of ecosystems restructure throughout the lifecycle of an ecosystem, from birth and expansion to maturity}

Our theoretical framework also suggests that the three dimensions and underlying features exhibit aggregate differences throughout the growth of an ecosystem. In this vein, the aggregation of three dimensions is closely associated with the overall level of the complexity and dynamics of an ecosystem throughout its lifecycle, from birth to maturity (Dedehayir et al., 2018; Phillips and Ritala, 2019; Reeves et al., 2019).

In the nascent (birth) stage, an ecosystem is characterised by an increasing level of complexity and dynamics, due to the increasing heterogeneity of the actors in the ecosystem (Moore, 1996). First, due to the different cognitive frames, decision modes and participative motives of the self-organised actors, the process of forming shared visions is iterative, possibly proceeding through competitions or compromises amongst ecosystem actors. To establish the shared vision, that the initiators of the ecosystem often exercise forms of 'soft' influence (e.g., framing and dialogues) on followers, rallying around a collective 'ecosystem life' (Liu and Rong, 2015; Snihur et al., 2018). Second, as illustrated in Figure 2.2, the number and diversity of actors increase during this stage, along with the incompatible discrete interfaces, standards and rules. Ecosystems are far from modular. To co-create complex value efficiently, therefore, nascent ecosystems occasionally require tightly coupled coordination mechanisms, due to their vulnerability to market uncertainties and competitive ecosystem pressures. Third, nascent ecosystems require more collaboration than competition, due to their fragility and immaturity. The co-evolution that occurs amongst the actors in the ecosystem is relatively limited, given the low rate of monetisation of new offerings in this early developmental stage.

In the expansion stage, the rapid increase of ecosystem actors leads to a higher level of complexity and dynamics within the ecosystem (Rong and Shi, 2014). In this stage, (1) the shared vision, although it has undergone modifications and refinements, is quite stable and acceptable to the self-organised actors. (2) Ecosystems gradually become modular, facilitated by basic-level interaction mechanisms (e.g., digital platforms, standardised protocols, dominant design processes) (Moore, 2006; Pidun et al., 2020a; Tiwana, 2015). Key complements to the final offerings become highly inter-operable, due to integrated communication interfaces that allow for quick coordination and adjustments at lower costs. At the same time, ecosystems need structures that are less tightly coupled than before, as excessive emphasis on collective actions results in slowing the ecosystem's reactions to environmental shocks (Brusoni and Prencipe, 
2013). (3) Expanding ecosystems shift towards a higher intensity of collaboration and competition, as the new offerings attain a great deal of popularity in various markets (Letaifa, 2014). This leads to rapid co-evolution amongst the actors in the ecosystem.

In the maturity stage, innovation ecosystems have an optimal level of complexity and dynamics, as the number and diversity of actors remain fairly stable (Moore, 1996). During this stage, (1) shared visions continue to be highly attractive and become very clear to all participants. The ecosystem identity is completely clear (Rong and Shi, 2014). (2) With various compatible interaction mechanisms remaining in place, actors (whether existing or new) are able to design/re-design and develop/re-develop their contributions independently, while they continue to function as an integrated whole, with minimal bureaucratic orders (Moore, 2006; Pidun et al., 2020b; Schilling, 2000). In this way, innovation ecosystems become highly modular (Jacobides et al., 2018). Correspondingly, mature ecosystems resemble looselycoupled systems, which are characterised by a balance between individual innovativeness and collective concerted actions, as maintained by the actors (Brusoni and Prencipe 2013). (3) Further, ecosystem actors benefit from ecosystem-level competitiveness, with a salient pattern of high collaboration and high competition (cf. Letaifa, 2014). In this stage, all actors co-evolve successfully at a stable pace.

In summary, instead of viewing the key features and the three related higher-order dimensions in a static way, we propose that the conceptual boundaries of ecosystems exhibit time-related characteristics. Each developmental stage is characterised by a coherent one-toone co-relationship amongst key distinguishing features. In addition, these co-relationships are closely associated with the overall level of complexity and dynamics in the ecosystem. Based on these insights, we propose:

Proposition 2: In general, the conceptual boundaries of ecosystems exhibit different timerelated interactions between higher-order dimensions, due to the changing, lower-order key distinguishing features.

\subsection{DISCUSSION}

Despite the popularity of the innovation-ecosystem approach in the literature (Bogers et al., 2019; Hakala et al., 2020; Möller and Halinen, 2017; Scaringella and Radziwon, 2018), the aggregation aspect of the conceptual boundaries-which is framed by a set of key distinguishing features that stipulate the uniqueness of how multiple innovation actors produce new innovative offerings - has been relatively under-investigated. We argue that insight into 
this issue could generate benefits for both scholars of innovation ecosystems and managers of small firms (Fuller et al., 2019; Phillips and Ritala, 2019; Thomas and Autio, 2020). We have developed a theoretical framework by aggregating nine key distinguishing features (i.e., selforganisation, non-linearity, shared vision, complementarity, modularity, coupling, emergence, co-opetition, and co-evolution) into three higher-order dimensions (roles, structures, and processes) that are possessed by all innovation ecosystems. These aggregations become manifest in two ways: (1) the internal coherent interrelationships within each dimension and the interactions between the dimensions, and (2) the three dimensions (and their underlying features) together exhibit time-related differences during the development processes of ecosystems. Our findings make three theoretical contributions to the ecosystem literature and provide useful implications for managers.

\subsubsection{Theoretical contribution}

Our first contribution to ecosystem literature is related to the theoretical framework that we have developed, which provides a more comprehensive and general perspective on the conceptual boundaries of ecosystems. Our framework is more comprehensive than existing models, in that it encompasses nine key distinguishing features derived from an extensive systematic literature review and content analysis. To date, ecosystem scholars have focused on one or a few key features in their studies, possibly leading to conflicting research conclusions. Building and expanding on these works, we offer a more complete understanding of the conceptual boundaries of ecosystems. In addition, and in line with recent theoretical guidelines that advocate the conceptualisation of innovation ecosystems from a metatheoretical perspective (Granstrand and Holgersson, 2020; Phillips and Ritala, 2019; Thomas and Autio, 2020), our framework provides a general description of the conceptual boundaries of ecosystems from three distinct higher-order dimensions: roles, structures, and processes. The framework allows scholars to focus on the distinctive features to explain the basic principles of any ecosystems and to distinguish them from domain-specific concepts (e.g., IT ecosystems, entrepreneurial ecosystems, service ecosystems, knowledge ecosystems). Our conceptual boundaries of ecosystems support the current trend in which scholars are increasingly adopting the ecosystem concept without adding any prefixes (Adner, 2017; Kapoor, 2018; Shipilov and Gawer, 2020; Thomas and Autio, 2020).

The second contribution that this study makes to the literature on innovation ecosystems is that it moderates the current debates on conceptual proximity between two seminal 
archetypes: the business ecosystem and the innovation ecosystem. Some researchers argue that these two concepts are different and clearly demarcated, as "[b]usiness ecosystems introduce the customer (demand) side which is mainly absent in innovation ecosystems” (Clarysse et al., 2014, p. 1166). Scholars tend to concur that business ecosystems relate more to actor competition and the co-capture of value, while innovation ecosystems relate more to actor collaboration and the co-creation of value (de Vasconcelos Gomes et al., 2018a; Jacobides et al., 2018; Ritala and Almpanopoulou, 2017). In contrast, other scholars maintain that the two seminal concepts are the same, and that they can be applied interchangeably, without distinction. Based on our conceptualisation, we argue that the two approaches to ecosystem share the same key distinguishing features (Thomas and Autio, 2020), although the difference between innovation and business ecosystems could be explained according to differences in the aggregation of these features. For innovation ecosystems, the key features are aimed at the dimensions of roles and structures, which characterise the ways in which self-organised ecosystem actors are coordinated in order to co-create value. Relatedly, the key features of business ecosystems point to the dimensions of roles and processes, emphasising the ways in which self-organised actors co-capture value. The course and appearance of an ecosystem are thus determined by the relative importance of the features and the extent to which they interact. For this reason, researchers in the field of ecosystem management should be explicit about their conceptual areas of focus.

Our third contribution is the time-related understanding of the conceptual boundaries of ecosystems, which has relevant implications for research on ecosystems. Scholars of innovation ecosystems have experienced and acknowledged the difficulty of capturing the full 'actual' boundaries of ecosystems, given their complex, dynamic nature. Nevertheless, the time-related aggregation aspect of the key features of innovation ecosystems suggests that the stabilityand therefore the generalisability — of research findings differ according to the lifecycle stage of the ecosystem under investigation. For example, compared to the nascent stage, empirical inquiries focusing on the maturity stage could assume that the actual boundaries of ecosystems are relatively stable. This is because, in this stage, ecosystems have stable shared visions, welldeveloped actor-coordination mechanisms (high modularity and loose coupling) and wellbalanced collaboration and competition amongst actors. In the nascent and expansion stages, however, the aggregation of the distinguishing features of ecosystems develops in a more dynamic and less predictable manner, forcing researchers to make clearer delineations and be more aware of the ecosystem contexts under study. It is thus arguably fair to say that qualitative 
methods, including longitudinal process studies, are more appropriate for identifying the actual boundaries of ecosystems (Phillips and Ritala, 2019; Ritala and Almpanopoulou, 2017). In any case, researchers should always consider the developmental stage of an ecosystem and the unique aggregation aspects of its distinguishing features.

\subsubsection{Practical implications}

Our study has three important implications for the CEOs of small firms that are seeking to develop new innovation ecosystems but that often encounter a high rate of failure during the early growth stage of ecosystems. As such, our two aggregated understandings of the distinguishing key features of ecosystems offer several implications to increase their success rate, by learning how to align key complementors with shared visions (roles), how to motivate complementors to contribute to the final innovations (structures) and how to achieve a sustainable rate of growth (processes).

First, with regard to the roles dimension, as leaders of innovation ecosystems, small firms need to formulate effective strategies for aligning key complementors into the new ecosystems. In doing so, they should pay more attention to formulating emergent strategies than to developing deliberate 'plan-and-execute' strategies, as most self-regulating complementors are just as free to exit ecosystems as they are to enter them. The non-linear character of interactions amongst the actors in an ecosystem suggests a need to inspect the strategies that they have implemented, as even one poorly implemented strategy aimed at affecting one actor could generate systemic effects on other actors, possibly leading to the rapid failure of the ecosystem. More importantly, shared visions that cannot be settled directly might be subject to competition or compromise amongst ecosystem actors, particularly if large commercial entities or noneconomic actors (e.g., regulators) play an important role in the shared vision. This suggests that, when formulating (or re-formulating) relevant strategies, CEOs should shift their focus away from maximising benefits for their own companies and towards broader competitiveness at the level of the ecosystem.

Second, from the perspective of the structures dimension, the CEOs of focal firms should orchestrate non-focal actors in the customisation of special complements to the innovative offering of the ecosystem. In most cases, however, CEOs are faced with few incentives from complementors to make upfront investments in unproven market needs. For this reason, instead of starting the ecosystem on a large scale, which would require a substantial amount of resources, small firms should aim for early, small-scale success by optimising the use of their 
limited resources. For example, CEOs could develop prototypes of proposed innovations and then strive to test their market potential in niche markets (Ozcan and Eisenhardt, 2009; Pidun et al., 2020b). This could motivate complementors to kick-start innovation ecosystems successfully. In addition, unlike large commercial entities, whose established platforms or legitimacy can contribute to the co-creation of highly modular ecosystem offerings by easily uniting a variety of technological standards, designs and requirements, small firms are advised either to undertake open innovation activities (e.g., technology conferences, co-designing, collective experiments) (Davis, 2016; Pera et al., 2016) or to rely on intermediary actors (e.g., anti-trust commissions and patent unions) (Moore, 2006). In the course of such orchestration activities, small firms should inform all complementors within the ecosystem concerning the fact that the ecosystem is continuously exposed to fragility, thereby emphasising the need for consistent cohesive innovation actions in response to external disruptors.

Third, our findings with regard to the processes dimension suggest that small firms should balance the developmental momentum of innovation ecosystems with stability. They should enhance the attractiveness of the innovative offerings, making it more attractive for new actors to participate into the 'game'. At the same time, however, small firms should be aware of the risks of moving too quickly with new ecosystems. More specifically, introducing a large number of new participants within a short period might make it more difficult to achieve the relative schemes for co-capturing fair value, thereby triggering competitive tensions amongst ecosystem actors, that could be detrimental to ecosystem growth. To avoid this situation and realise organic scaling within the ecosystem, inexperienced small firms should be more proactive in analysing the possible influences of the newly introduced ecosystem elements (e.g., new and uncommon actors, technologies, or institutions) or the modified core-value propositions concerning the overall development of the ecosystem. This could help small firms to translate small changes stemming from the non-linear interactions of ecosystem actors into valuable information, giving them a head start in converting these proactive understandings into high-quality ideas or creative solutions. At the same time, however, such proactiveness and agility can pose considerable challenges for small firms with regard to strengthening their cognitive and learning capabilities.

\subsubsection{Limitations and future directions}

As is the case with all studies, our study is subject to several limitations. First, in our systematic literature review, we selected only peer-reviewed articles and two specially-edited book 
chapters. It is important to note, however, that issues relating to the conceptual boundaries of ecosystems have also been discussed in conference proceedings, working papers and consultancy reports. Future studies could seek to capture these sources by combing the bibliometric method and text-mining algorithms, which would allow for the expansion of data resources and the effective processing of large volumes of data, thereby generating more complete research results.

In our study, we applied inductive content analysis in order to derive a comprehensive, detailed understanding of the conceptual boundaries of ecosystems. Further steps are needed in order to advance understanding of these boundaries. We encourage future research to include empirical tests of the usability of the concepts we have developed. Integration with domainspecific features would be particularly helpful in enhancing understanding concerning the principle building blocks of any ecosystem. For example, empirical evidence has demonstrated that knowledge ecosystems could potentially transform themselves into business ecosystems (Attour and Lazaric, 2020; Clarysse et al., 2014) and that possible interactions exist between entrepreneurial ecosystems and innovation ecosystems (Thomas et al., 2018). These studies support our suggestions that more complex structural aggregations could unveil the transitions and interactions occurring amongst various types of ecosystems. Building on our framework, future conceptual endeavours are likely to generate robust structurally aggregated understandings of the conceptual boundaries of ecosystems by accommodating other types of ecosystems.

Our aggregated understanding of the conceptual boundaries of ecosystems, which builds on a linear life-cycle perspective from birth to maturity, might be an oversimplification, which is incapable of exposing the highly fluid view on the growth of ecosystems. Our interpretative analysis generated the notion of differences in the relevance and stability of the distinguishing features of ecosystems and their interactions within the various dimensions. Our nine key distinguishing features are actually either 'generic' or 'variant' in nature. 'Generic' features are unlikely to change throughout the development of innovation ecosystems. For example, the actors in an ecosystem are always self-organised, and their interactions are non-linear (roles dimension) throughout the lifecycle of ecosystem development. In contrast, 'variant' features suggest a continuum of degrees or levels corresponding to the management and development of ecosystems. For example, the shared vision (roles dimension) varies from ambiguity to clarity within the development process of an ecosystem. This suggests an aggregated insight that the interpretation of the fluid/dynamic growth of an ecosystem is directly dependent on 
such 'variant' features within three dimensions, as well as in the complex interactions between them. In this regard, we encourage ecosystem scholars to test this relatively complex aggregation according to longitudinal qualitative data at the level of the ecosystem, thereby providing nuanced guidelines for small firms concerning the relevant features that should receive special attention in order to enable the sustainable growth of ecosystems.

\subsection{CONCLUSION}

This study is intended to highlight ways in which small firms can enhance their understanding of innovation ecosystems by making sense of their key distinguishing features and interactions (i.e., the conceptual boundaries of innovation ecosystems). According to our theoretical framework, in addition to devoting serious consideration to the complex interactions of key distinguishing features within the dimensions of roles, structures, and processes, the CEOs of small firms should pay special attention to time-related changes in the combination of these three dimensions. These two aggregated understandings provide implications for scholars with regard to incorporating business and innovation ecosystems into studies with improved conceptual rigour, thereby arriving at a proper specification of the temporal boundaries of the ecosystems they investigate.

\subsection{REFERENCES}

Aarikka-Stenroos, L., \& Ritala, P. (2017). Network management in the era of ecosystems: Systematic review and management framework. Industrial Marketing Management, 67, 2336.

Adner, R. (2006). Match your innovation strategy to your innovation ecosystem. Harvard Business Review, 84(4), 98-108.

Adner, R. (2012). The wide lens: A new strategy for innovation. London: Penguin.

Adner, R. (2017). Ecosystem as structure: An actionable construct for strategy. Journal of Management, 43(1), 39-58.

Adner, R., \& Feiler, D. (2019). Interdependence, perception, and investment choices: An experimental approach to decision making in innovation ecosystems. Organization Science, 30(1), 109-125.

Adner, R., \& Kapoor, R. (2010). Value creation in innovation ecosystems: How the structure of technological interdependence affects firm performance in new technology generations. Strategic Management Journal, 31(3), 306-333.

Anderson, P. (1999). Perspective: Complexity theory and organization science. Organization Science, 10(3), 216-232.

Attour, A., \& Lazaric, N. (2020). From knowledge to business ecosystems: emergence of an entrepreneurial activity during knowledge replication. Small Business Economics, 54(2), 575-587. 
Autio, E., \& Thomas, L. (2014). Innovation ecosystems: Implication for innovation management. In M. Dodgson, D. M. Gann, \& N. Phillips (Eds.), The Oxford handbook of innovation management (pp. 204-288). Oxford: Oxford University Press.

Baldwin, C. Y. (2012). Organization design for business ecosystems. Journal of Organization Design, 1(1), 20-23.

Basole, R. C. (2009). Visualization of interfirm relations in a converging mobile ecosystem. Journal of Information Technology, 24(2), 144-159.

Basole, R. C., Park, H., \& Barnett, B. C. (2015). Coopetition and convergence in the ICT ecosystem. Telecommunications Policy, 39(7), 537-552.

Battistella, C., Colucci, K., De Toni, A. F., \& Nonino, F. (2013). Methodology of business ecosystems network analysis: A case study in Telecom Italia Future Centre. Technological Forecasting and Social Change, 80(6), 1194-1210.

Bayliss, C., \& Clark, K. B. (1997). Managing in an age of modularity. Harvard Business Review, 75(5), 84-93.

Boell, S. K., \& Cecez-Kecmanovic, D. (2015). On being 'systematic' in literature reviews in IS. Journal of Information Technology, 30(2), 161-173.

Bogers, M., Sims, J., \& West, J. (2019). What is an ecosystem? Incorporating 25 years of ecosystem research. Academy of Management Proceedings. Available at: https://ssrn.com/abstract=3437014.

Brusoni, S., \& Prencipe, A. (2001). Managing knowledge in loosely coupled networks: Exploring the links between product and knowledge dynamics. Journal of Management Studies, 38(7), 1019-1035.

Brusoni, S., \& Prencipe, A. (2013). The organization of innovation in ecosystems: problem framing, problem solving, and patterns of coupling. In Collaboration and competition in business ecosystems (pp. 167-194): Emerald Group Publishing Limited.

Callon, M. (1986). The sociology of an actor-network: The case of the electric vehicle. In Mapping the dynamics of science and technology (pp. 19-34). London: Palgrave Macmillan.

Clarysse, B., Wright, M., Bruneel, J., \& Mahajan, A. (2014). Creating value in ecosystems: Crossing the chasm between knowledge and business ecosystems. Research Policy, 43(7), 1164-1176.

Corallo, A., Passiante, G., \& Prencipe, A. (2007). The digital business ecosystem. London: Edward Elgar Publishing.

Corley, K. G., \& Gioia, D. A. (2011). Building theory about theory building: what constitutes a theoretical contribution? Academy of Management Review, 36(1), 12-32.

Cornelissen, J. (2017). Editor's comments: Developing propositions, a process model, or a typology? Addressing the challenges of writing theory without a boilerplate. Academy of Management Review, 42(1), 1-9.

Dattée, B., Alexy, O., \& Autio, E. (2018). Maneuvering in poor visibility: How firms play the ecosystem game when uncertainty is high. Academy of Management Journal, 61(2), 466498.

Davis, J. P. (2016). The group dynamics of interorganizational relationships collaborating with multiple partners in innovation ecosystems. Administrative Science Quarterly, 64, 621-661. 
de Vasconcelos Gomes, L. A., Facin, A. L. F., Salerno, M. S., \& Ikenami, R. K. (2018a). Unpacking the innovation ecosystem construct: Evolution, gaps and trends. Technological Forecasting and Social Change, 136, 30-48.

de Vasconcelos Gomes, L. A., Salerno, M. S., Phaal, R., \& Probert, D. R. (2018b). How entrepreneurs manage collective uncertainties in innovation ecosystems. Technological Forecasting and Social Change, 128, 164-185.

Dedehayir, O., Mäkinen, S. J., \& Ortt, J. R. (2018). Roles during innovation ecosystem genesis: A literature review. Technological Forecasting and Social Change, 136, 18-29.

Dhanaraj, C., \& Parkhe, A. (2006). Orchestrating innovation networks. Academy of Management Review, 31(3), 659-669.

Dougherty, D., \& Dunne, D. D. (2011). Organizing ecologies of complex innovation. Organization Science, 22(5), 1214-1223.

Duriau, V. J., Reger, R. K., \& Pfarrer, M. D. (2007). A content analysis of the content analysis literature in organization studies: Research themes, data sources, and methodological refinements. Organizational Research Methods, 10(1), 5-34.

Fuller, J., Jacobides, M. G., \& Reeves, M. (2019). The myths and realities of business ecosystems. MIT Sloan Management Review, 60(3), 1-9.

Furr, N., \& Shipilov, A. (2018). Building the right ecosystem for innovation. MIT Sloan Management Review, 59(4), 59-64.

Ganco, M., Kapoor, R., \& Lee, G. K. (2020). From rugged landscapes to rugged ecosystems: Structure of interdependencies and firms' innovative search. Academy of Management Review, 45(3), 646-674.

Gawer, A., \& Cusumano, M. A. (2014). Industry platforms and ecosystem innovation. Journal of Product Innovation Management, 31(3), 417-433.

Gibbert, M., \& Välikangas, L. (2004). Boundaries and innovation: special issue introduction by the guest editors. Long Range Planning, 37(6), 495-504.

Granstrand, O., \& Holgersson, M. (2020). Innovation ecosystems: A conceptual review and a new definition. Technovation, 90, 10298. https: //doi.org/10.1016/j.technovation.2019.102098.

Gulati, R., Puranam, P., \& Tushman, M. (2012). Meta-organization design: Rethinking design in interorganizational and community contexts. Strategic Management Journal, 33(6), 571586.

Hakala, H., O'Shea, G., Farny, S., \& Luoto, S. (2020). Re-storying the Business, Innovation and Entrepreneurial Ecosystem Concepts: The Model-Narrative Review Method. International Journal of Management Reviews, 22(1), 10-32.

Hannah, D. P., \& Eisenhardt, K. M. (2018). How firms navigate cooperation and competition in nascent ecosystems. Strategic Management Journal, 39(12), 3163-3192.

Iansiti, M., \& Levien, R. (2004a). Strategy as ecology. Harvard Business Review, 82(3), 68-81.

Iansiti, M., \& Levien, R. (2004b). The keystone advantage: What the new dynamics of business ecosystems mean for strategy, innovation, and sustainability. Boston: Harvard Business School Press.

Isenberg, D. J. (2016). Applying the ecosystem metaphor to entrepreneurship: uses and abuses. The Antitrust Bulletin, 61(4), 564-573.

Jaakkola, E. (2020). Designing conceptual articles: four approaches. AMS Review, 10, 18-26. 
Jacobides, M. G., Cennamo, C., \& Gawer, A. (2018). Towards a theory of ecosystems. Strategic Management Journal, 39(18), 2255-2276.

Kapoor, R. (2018). Ecosystems: broadening the locus of value creation. Journal of Organization Design, 7(1), 1-16. https://doi.org/10.1186/s41469-018-0035-4.

Kapoor, R., \& Agarwal, S. (2017). Sustaining superior performance in business ecosystems: Evidence from application software developers in the iOS and Android smartphone ecosystems. Organization Science, 28(3), 531-551.

Kapoor, R., \& Lee, J. M. (2013). Coordinating and competing in ecosystems: How organizational forms shape new technology investments. Strategic Management Journal, 34(3), 274-296.

Kast, F. E., \& Rosenzweig, J. E. (1972). General systems theory: Applications for organization and management. Academy of Management Journal, 15(4), 447-465.

Kim, H., Lee, J. N., \& Han, J. (2010). The role of IT in business ecosystems. Communications of the ACM, 53(5), 151-156.

Kolloch, M., \& Dellermann, D. (2018). Digital innovation in the energy industry: the impact of controversies on the evolution of innovation ecosystems. Technological Forecasting and Social Change, 136, 254-264.

Lepak, D. P., Smith, K. G., \& Taylor, M. S. (2007). Value creation and value capture: a multilevel perspective. Academy of Management Review, 32(1), 180-194.

Letaifa, S. B. (2014). The uneasy transition from supply chains to ecosystems: the valuecreation/value-capture dilemma. Management Decision, 52(2), 278-295.

Leten, B., Vanhaverbeke, W., Roijakkers, N., Clerix, A., \& Van Helleputte, J. (2013). IP Models to Orchestrate Innovation Ecosystems. California Management Review, 55(4), 51-64.

Li, Y.-R. (2009). The technological roadmap of Cisco's business ecosystem. Technovation, 29(5), 379-386.

Li, J., Chen, L., Yi, J., Mao, J., \& Liao, J. (2019). Ecosystem-specific advantages in international digital commerce. Journal of International Business Studies, 50(9), 1448-1463.

Liu, G., \& Rong, K. (2015). The nature of the co-evolutionary process: Complex product development in the mobile computing industry's business ecosystem. Group \& Organization Management, 40(6), 809-842.

Lu, C., Rong, K., You, J., \& Shi, Y. (2014). Business ecosystem and stakeholders' role transformation: Evidence from Chinese emerging electric vehicle industry. Expert Systems with Applications, 41(10), 4579-4595.

Luo, J. (2018). Architecture and evolvability of innovation ecosystems. Technological Forecasting and Social Change, 136, 132-144.

Mars, M. M., Bronstein, J. L., \& Lusch, R. F. (2012). The value of a metaphor: Organizations and ecosystems. Organizational Dynamics, 41(4), 271-280.

Masucci, M., Brusoni, S., \& Cennamo, C. (2020). Removing bottlenecks in business ecosystems: The strategic role of outbound open innovation. Research Policy, 49(1), 103823. https://doi.org/10.1016/j.respol.2019.103823.

Mei, L., Zhang, T., \& Chen, J. (2019). Exploring the effects of inter-firm linkages on SMEs' open innovation from an ecosystem perspective: An empirical study of Chinese manufacturing SMEs. Technological Forecasting and Social Change, 144, 118-128.

Möller, K., \& Halinen, A. (2017). Managing business and innovation networks - from strategic nets to business fields and ecosystems. Industrial Marketing Management, 67, 5-22. 
Moore, J. F. (1993). Predators and prey: a new ecology of competition. Harvard Business Review, 71(3), 75-86.

Moore, J. F. (1996). The death of competition: Leadership and strategy in the age of business ecosystems. New York: HarperBusiness.

Moore, J. F. (2006). Business ecosystems and the view from the firm. Antitrust Bull, 51, 31-75.

Nambisan, S., \& Baron, R. A. (2013). Entrepreneurship in innovation ecosystems: Entrepreneurs' self-regulatory processes and their implications for new venture success. Entrepreneurship Theory and Practice, 37(5), 1071-1097.

Oh, D.-S., Phillips, F., Park, S., \& Lee, E. (2016). Innovation ecosystems: A critical examination. Technovation, 54, 1-6.

Orton, J. D., \& Weick, K. E. (1990). Loosely coupled systems: A reconceptualization. Academy of Management Review, 15(2), 203-223.

Oskam, I., Bossink, B., \& de Man, A.-P. (2020). Valuing value in innovation ecosystems: How cross-sector actors overcome tensions in collaborative sustainable business model development. Business \& Society, 1-33. https://doi.org/10.1177/0007650320907145.

Ozcan, P., \& Eisenhardt, K. M. (2009). Origin of alliance portfolios: Entrepreneurs, network strategies, and firm performance. Academy of Management Journal, 52(2), 246-279.

Parente, R., Rong, K., Geleilate, J.-M. G., \& Misati, E. (2019). Adapting and sustaining operations in weak institutional environments: A business ecosystem assessment of a Chinese MNE in Central Africa. Journal of International Business Studies, 50(2), 275-291.

Pekkarinen, S., Tuisku, O., Hennala, L., \& Melkas, H. (2019). Robotics in Finnish welfare services: dynamics in an emerging innovation ecosystem. European Planning Studies, 1-21. https://doi.org/10.1080/09654313.2019.1693980.

Peltola, T., Aarikka-Stenroos, L., Viana, E., \& Mäkinen, S. (2016). Value capture in business ecosystems for municipal solid waste management: Comparison between two local environments. Journal of Cleaner Production, 137, 1270-1279.

Peltoniemi, M. (2006). Preliminary theoretical framework for the study of business ecosystems. Emergence: Complexity and Organization, 8(1), 10-19.

Pera, R., Occhiocupo, N., \& Clarke, J. (2016). Motives and resources for value co-creation in a multi-stakeholder ecosystem: A managerial perspective. Journal of Business Research, 69(10), 4033-4041.

Phillips, M. A., \& Ritala, P. (2019). A complex adaptive systems agenda for ecosystem research methodology. Technological Forecasting and Social Change, 148, 119739. https://doi.org/10.1016/j.techfore.2019.119739.

Phillips, M. A., \& Srai, J. S. (2018). Exploring emerging ecosystem boundaries: defining 'the game’. International Journal of Innovation Management, 22(08), 1840012. https://doi.org/10.1142/S1363919618400121.

Pidun, U., Reeves, M., \& Schuessler, M. (2020a). Do You Need a Business Ecosystem? Retrieved 12 March 2020 from https://www.bcg.com/en-us/publications/2019/do-you-need-businessecosystem.aspx.

Pidun, U., Reeves, M., \& Schüssler, M. (2020b). How Do You “Design” a Business Ecosystem? Retrieved 12 March 2020 from https://www.bcg.com/publications/2020/how-do-you-designa-business-ecosystem.aspx. 
Pierce, L. (2009). Big losses in ecosystem niches: How core firm decisions drive complementary product shakeouts. Strategic Management Journal, 30(3), 323-347.

Podsakoff, P. M., MacKenzie, S. B., \& Podsakoff, N. P. (2016). Recommendations for creating better concept definitions in the organizational, behavioral, and social sciences. Organizational Research Methods, 19(2), 159-203.

Potter, W. J., \& Levine-Donnerstein, D. (1999). Rethinking Validity and Reliability in Content Analysis. Journal of Applied Communication Research, 27, 258-284.

Reeves, M., Lotan, H., Legrand, J., \& Jacobides, M. G. (2019). How Business Ecosystems Rise (and Often Fall). MIT Sloan Management Review, 60(4), 1-6.

Ritala, P., Agouridas, V., Assimakopoulos, D., \& Gies, O. (2013). Value creation and capture mechanisms in innovation ecosystems: a comparative case study. International Journal of Technology Management, 63(3-4), 244-267.

Ritala, P., \& Almpanopoulou, A. (2017). In defense of 'eco' in innovation ecosystem. Technovation, 60, 39-42.

Rohrbeck, R., Hölzle, K., \& Gemünden, H. G. (2009). Opening up for competitive advantage-How Deutsche Telekom creates an open innovation ecosystem. R\&D Management, 39(4), 420430.

Rong, K., Hu, G., Lin, Y., Shi, Y., \& Guo, L. (2015). Understanding business ecosystem using a 6C framework in Internet-of-Things-based sectors. International Journal of Production Economics, 159, 41-55.

Rong, K., Lin, Y., Li, B., Burström, T., Butel, L., \& Yu, J. (2018). Business ecosystem research agenda: more dynamic, more embedded, and more internationalized. Asian Business \& Management, 17(3), 167-182.

Rong, K., \& Shi, Y. (2014). Business ecosystems: Constructs, configurations, and the nurturing process. London: Palgrave Macmillan.

Rousseau, D. M., Manning, J., \& Denyer, D. (2008). 11 Evidence in management and organizational science: assembling the field's full weight of scientific knowledge through syntheses. Academy of Management Annals, 2(1), 475-515.

Sako, M. (2018). Business ecosystems: how do they matter for innovation?. Communications of the ACM, 61(4), 20-22.

Sanchez, R., \& Mahoney, J. T. (1996). Modularity, flexibility, and knowledge management in product and organization design. Strategic Management Journal, 17(S2), 63-76.

Scaringella, L., \& Radziwon, A. (2018). Innovation, entrepreneurial, knowledge, and business ecosystems: Old wine in new bottles? Technological Forecasting and Social Change, 136, 59-87.

Schilling, M. A. (2000). Toward a general modular systems theory and its application to interfirm product modularity. Academy of Management Review, 25(2), 312-334.

Short, J. C., \& Palmer, T. B. (2008). The application of DICTION to content analysis research in strategic management. Organizational Research Methods, 11(4), 727-752.

Shipilov, A., \& Gawer, A. (2020). Integrating Research on Interorganizational Networks and Ecosystems. Academy of Management Annals, 14(1), 92-121.

Snihur, Y., Thomas, L. D., \& Burgelman, R. A. (2018). An ecosystem-level process model of business model disruption: The disruptor's gambit. Journal of Management Studies, 55(7), 1278-1316. 
Stam, E. (2015). Entrepreneurial ecosystems and regional policy: a sympathetic critique. European Planning Studies, 23(9), 1759-1769.

Thomas, L. D. W., \& Autio, E. (2020). Innovation ecosystems in management: An organizing typology. In Oxford Encyclopedia of Business and Management. Oxford University Press.

Thomas, L.D., Sharapov, D. and Autio, E. (2018). Linking entrepreneurial and innovation ecosystems: The case of appcampus. In Alvarez, S., Carayannis, E.G., Dagnino, G. and Faraci, R. (eds), Entrepreneurial Ecosystems and the Diffusion of Startups. Cheltenham: Edward Elgar Publishing.

Tiwana, A. (2015). Evolutionary competition in platform ecosystems. Information Systems Research, 26(2), 266-281.

Tranfield, D., Denyer, D., \& Smart, P. (2003). Towards a methodology for developing evidenceinformed management knowledge by means of systematic review. British Journal of Management, 14(3), 207-222.

Valkokari, K. (2015). Business, innovation, and knowledge ecosystems: How they differ and how to survive and thrive within them. Technology Innovation Management Review, 5(8), 1724.

van der Borgh, M., Cloodt, M., \& Romme, A. G. L. (2012). Value creation by knowledge-based ecosystems: evidence from a field study. $\boldsymbol{R} \& \boldsymbol{D}$ Management, 42(2), 150-169.

Vargo, S. L., Wieland, H., \& Akaka, M. A. (2015). Innovation through institutionalization: A service ecosystems perspective. Industrial Marketing Management, 44, 63-72.

Velu, C. (2015). Knowledge management capabilities of lead firms in innovation ecosystems. AMS Review, 5(3-4), 123-141.

Walrave, B., Talmar, M., Podoynitsyna, K. S., Romme, A. G. L., \& Verbong, G. P. (2018). A multilevel perspective on innovation ecosystems for path-breaking innovation. Technological Forecasting and Social Change, 136, 103-113.

Wareham, J., Fox, P. B., \& Cano Giner, J. L. (2014). Technology ecosystem governance. Organization Science, 25(4), 1195-1215.

Weber, M. L., \& Hine, M. J. (2015). Who inhabits a business ecosystem? the technospecies as a unifying concept. Technology Innovation Management Review, 5(5), 31-44.

Whittington, R. (1992). Putting Giddens into action: social systems and managerial agency. Journal of Management Studies, 29(6), 693-712.

Williamson, P. J., \& De Meyer, A. (2012). Ecosystem advantage: How to successfully harness the power of partners. California Management Review, 55(1), 24-46.

Zahra, S. A., \& Nambisan, S. (2011). Entrepreneurship in global innovation ecosystems. AMS Review, 1(1), 4-17.

Zahra, S. A., \& Nambisan, S. (2012). Entrepreneurship and strategic thinking in business ecosystems. Business Horizons, 55(3), 219-229. 
Appendix 2.1: Chronology of selected articles (1993-2020).

\begin{tabular}{|c|c|c|c|c|c|c|}
\hline Code & Author & Title & Type & Year & Publisher & Quotes and Page (Emphasis Added) \\
\hline m3 & $\begin{array}{l}\text { Iansiti and } \\
\text { Levien }\end{array}$ & $\begin{array}{l}\text { The new operational dynamics of } \\
\text { business ecosystems: Implications } \\
\text { for policy, operations and } \\
\text { technology strategy. Boston, MA: } \\
\text { Division of Research. }\end{array}$ & & 2002 & $\begin{array}{l}\text { Harvard Business } \\
\text { School }\end{array}$ & $\begin{array}{l}\text { "'ecosystems" are characterized by a large number of loosely } \\
\text { interconnected participants who depend on each other for their mutual } \\
\text { effectiveness and survival." (p10) }\end{array}$ \\
\hline $\mathrm{m} 4$ & $\begin{array}{l}\text { Iansiti and } \\
\text { Levien }\end{array}$ & Strategy as ecology. & & 2004 & $\begin{array}{l}\text { Harvard Business } \\
\text { Review }\end{array}$ & $\begin{array}{l}\text { "Both are characterized by a large number of loosely interconnected } \\
\text { participants that depend on one another for their effectiveness and } \\
\text { survival. ... also are characterized by the presence of crucial hubs that } \\
\text { assume the keystone function of regulating ecosystem health." (p73) }\end{array}$ \\
\hline m5 & Moore & $\begin{array}{l}\text { Business ecosystems and the view } \\
\text { from the firm. }\end{array}$ & & 2006 & The Antitrust Bulletin & $\begin{array}{l}\text { "Volunteerism is part of every business ecosystem..."(p45)"A business } \\
\text { ecosystem definition is at its core a plan for how the contributions in the } \\
\text { proposed system will be modularized, and what sorts of firms will provide } \\
\text { which element." (p56) }\end{array}$ \\
\hline m6 & Adner & $\begin{array}{l}\text { Match your innovation strategy to } \\
\text { your innovation ecosystem. }\end{array}$ & & 2006 & $\begin{array}{l}\text { Harvard Business } \\
\text { Review }\end{array}$ & $\begin{array}{l}\text { "Innovation ecosystems are characterized by three fundamental types of } \\
\text { risk: initiative risks-the familiar uncertainties of managing a project; } \\
\text { interdependence risks - the uncertainties of coordinating with } \\
\text { complementary innovators; and integration risks - the uncertainties } \\
\text { presented by the adoption process across the value chain." (p101) }\end{array}$ \\
\hline $\mathrm{m} 7$ & Peltoniemi & $\begin{array}{l}\text { Preliminary theoretical } \\
\text { framework for the study of } \\
\text { business ecosystems. }\end{array}$ & & 2006 & $\begin{array}{l}\text { Emergence: } \\
\text { Complexity \& } \\
\text { Organisation }\end{array}$ & $\begin{array}{l}\text { "First of all, interconnectedness is an important feature...coevolution } \\
\text { takes place between an organization and its environment...In a business } \\
\text { ecosystem context, self-organization implies the absence of a central or } \\
\text { outside controller...The key to emergence is the link between micro and } \\
\text { macro behavior." (p10-19) }\end{array}$ \\
\hline m8 & $\begin{array}{l}\text { Iansiti and } \\
\text { Richards }\end{array}$ & $\begin{array}{l}\text { The information technology } \\
\text { ecosystem: Structure, health, and } \\
\text { performance. }\end{array}$ & & 2006 & The Antitrust Bulletin & $\begin{array}{l}\text { "the IT ecosystem is characterized by a large number of participants who } \\
\text { depend on each other for their mutual effectiveness and survival." ( } p 79)\end{array}$ \\
\hline $\mathrm{m} 11$ & $\begin{array}{l}\text { Le and } \\
\text { Tarafdar }\end{array}$ & $\begin{array}{l}\text { Business ecosystem perspective } \\
\text { on value co-creation in the Web } \\
2.0 \text { era: implications for } \\
\text { entrepreneurial opportunities. }\end{array}$ & & 2009 & $\begin{array}{l}\text { International Journal } \\
\text { of Entrepreneurial } \\
\text { Venturing }\end{array}$ & $\begin{array}{l}\text { "It can be useful to think of a loosely coupled network as a business } \\
\text { ecosystem (Iansity and Levien, 2002); they share some key properties: } \\
\text { complexity, self-organisation and adaptation." (p122) }\end{array}$ \\
\hline $\mathrm{m} 14$ & $\mathrm{Li}$ & $\begin{array}{l}\text { The technological roadmap of } \\
\text { Cisco's business ecosystem. }\end{array}$ & & 2009 & Technovation & $\begin{array}{l}\text { "Business ecosystems move beyond market positioning and industrial } \\
\text { structure by having three major characteristics: symbiosis, platform, and } \\
\text { co-evolution." (p381) }\end{array}$ \\
\hline m15 & Basole & $\begin{array}{l}\text { Visualization of interfirm } \\
\text { relations in a converging mobile } \\
\text { ecosystem. }\end{array}$ & & 2009 & $\begin{array}{l}\text { Journal of } \\
\text { Information } \\
\text { Technology }\end{array}$ & $\begin{array}{l}\text { "A key characteristic of an ecosystem is its ability to continuously adapt } \\
\text { and evolve to changes inside and outside of it." (p147) }\end{array}$ \\
\hline
\end{tabular}




\begin{tabular}{|c|c|c|c|c|c|c|}
\hline Code & Author & Title & Type & Year & Publisher & Quotes and Page (Emphasis Added) \\
\hline m17 & $\begin{array}{l}\text { Adner and } \\
\text { Kapoor }\end{array}$ & $\begin{array}{l}\text { Value creation in innovation } \\
\text { ecosystems: How the structure of } \\
\text { technological interdependence } \\
\text { affects firm performance in new } \\
\text { technology generations. }\end{array}$ & & 2010 & $\begin{array}{l}\text { Strategic Management } \\
\text { Journal }\end{array}$ & $\begin{array}{l}\text { "These approaches have focused on understanding coordination among } \\
\text { partners in exchange networks that are characterized by simultaneous } \\
\text { cooperation and competition .. although the very imagery of a value chain } \\
\text { (at the level of both firms and industries) suggests interdependencies } \\
\text { characterized as an ordered arrangement of activities." (p309) }\end{array}$ \\
\hline m18 & $\begin{array}{l}\text { Zhang and } \\
\text { Liang }\end{array}$ & $\begin{array}{l}\text { Business ecosystem strategies of } \\
\text { mobile network operators in the } \\
3 G \text { era: The case of China } \\
\text { Mobile. }\end{array}$ & & 2011 & $\begin{array}{l}\text { Telecommunications } \\
\text { Policy }\end{array}$ & $\begin{array}{l}\text { "some of its common features can be summarized, including: (a) } \\
\text { consisting of a large number of organizations; }(b) \text { interconnectedness } \\
\text { and interdependency; and (c) dynamic co-evolution" (p158) }\end{array}$ \\
\hline $\mathrm{m} 20$ & $\begin{array}{l}\text { Zahra and } \\
\text { Nambisan }\end{array}$ & $\begin{array}{l}\text { Entrepreneurship in global } \\
\text { innovation ecosystems. }\end{array}$ & & 2011 & AMS Review & $\begin{array}{l}\text { "two key features of innovation ecosystems have become more prominent } \\
\text { in recent years, first, Innovation platforms have become widespread in } \\
\text { other sectors including consumer electronics... has led to the participation } \\
\text { of new ventures not a criterion for ecosystem membership... second, } \\
\text { physical proximity is no longer a criterion for ecosystem membership." } \\
\text { (p6-7) }\end{array}$ \\
\hline $\mathrm{m} 22$ & $\begin{array}{l}\text { Williamson } \\
\text { and De Meyer }\end{array}$ & $\begin{array}{l}\text { Ecosystem advantage: How to } \\
\text { successfully harness the power of } \\
\text { partners. }\end{array}$ & & 2012 & $\begin{array}{l}\text { California } \\
\text { Management Review }\end{array}$ & $\begin{array}{l}\text { "as we have already noted, one of the attractions of an ecosystem } \\
\text { compared to a vertical integrated organization is its potential for dynamic } \\
\text { re configuration-sometimes even on the basis of "self-organization"-- } \\
\text { and for accelerated learning by bringing together a diversity of partners } \\
\text { with different capabilities and experiences; joint venture agreement might } \\
\text { be characterized by saying that: "the various parties share a common } \\
\text { goal, will make best endeavors to contribute to the achievement of that } \\
\text { goal, and will share the resulting (uncertain) profits." (p40) }\end{array}$ \\
\hline $\mathrm{m} 26$ & Mars et al. & $\begin{array}{l}\text { The value of a metaphor: } \\
\text { Organizations and ecosystems. }\end{array}$ & & 2012 & $\begin{array}{l}\text { Organizational } \\
\text { Dynamics }\end{array}$ & $\begin{array}{l}\text { "both biological and organizational ecosystems share similar emergent } \\
\text { properties." (p278) }\end{array}$ \\
\hline $\mathrm{m} 28$ & Baldwin & $\begin{array}{l}\text { Organization design for business } \\
\text { ecosystems. }\end{array}$ & & 2012 & $\begin{array}{l}\text { Journal of } \\
\text { Organization Design }\end{array}$ & $\begin{array}{l}\text { "the access to resources and the complementarity in innovation processes } \\
\text { appear to be unique characteristics of this business ecosystem." (p20) }\end{array}$ \\
\hline m29 & Rong et al. & $\begin{array}{l}\text { Business ecosystem extension: } \\
\text { facilitating the technology } \\
\text { substitution. }\end{array}$ & & 2013 & $\begin{array}{l}\text { International Journal } \\
\text { of Technology } \\
\text { Management }\end{array}$ & $\begin{array}{l}\text { "Symbiotic relationship was a common type in the evolving ecosystem." } \\
\text { (p275) }\end{array}$ \\
\hline m30 & Selander et al. & $\begin{array}{l}\text { Capability search and redeem } \\
\text { across digital ecosystems. }\end{array}$ & & 2013 & $\begin{array}{l}\text { Journal of } \\
\text { Information } \\
\text { Technology }\end{array}$ & $\begin{array}{l}\text { "This co-evolution between the technology and ecosystem participants } \\
\text { creates self-reinforcing feedback loops that can affect the ecosystem either } \\
\text { positively or negatively." ( } 185)\end{array}$ \\
\hline m32 & $\begin{array}{l}\text { Nambisan and } \\
\text { Baron }\end{array}$ & $\begin{array}{l}\text { Entrepreneurship in innovation } \\
\text { ecosystems: Entrepreneurs' self- } \\
\text { regulatory processes and their } \\
\text { implications for new venture } \\
\text { success. }\end{array}$ & & 2013 & $\begin{array}{l}\text { Entrepreneurship } \\
\text { Theory and Practice }\end{array}$ & $\begin{array}{l}\text { "The three defining characteristics of an innovation ecosystem then are the } \\
\text { dependencies established among the members (members' performance and } \\
\text { survival are closely linked to those of the ecosystem itself), a common set } \\
\text { of goals and objectives (shaped by the ecosystem-level focus on a unique } \\
\text { customer value proposition), and a shared set of knowledge and skills." } \\
\text { (p1071) }\end{array}$ \\
\hline
\end{tabular}




\begin{tabular}{|c|c|c|c|c|c|c|}
\hline Code & Author & Title & Type & Year & Publisher & Quotes and Page (Emphasis Added) \\
\hline $\mathrm{m} 38$ & $\begin{array}{l}\text { Brusoni and } \\
\text { Prencipe }\end{array}$ & $\begin{array}{l}\text { The organization of innovation in } \\
\text { ecosystems: Problem framing, } \\
\text { problem solving, and patterns of } \\
\text { coupling. }\end{array}$ & & 2013 & $\begin{array}{l}\text { Advances in Strategic } \\
\text { Management }\end{array}$ & $\begin{array}{l}\text { "tight coupling is a temporary feature of ecosystems." (P184) "new } \\
\text { innovation ecosystems characterized by both distinctiveness and } \\
\text { responsiveness, that is, loosely coupled systems." (p178) }\end{array}$ \\
\hline m39 & Ritala et al. & $\begin{array}{l}\text { Value creation and capture } \\
\text { mechanisms in innovation } \\
\text { ecosystems: a comparative case } \\
\text { study. }\end{array}$ & & 2013 & $\begin{array}{l}\text { International Journal } \\
\text { of Technology } \\
\text { Management }\end{array}$ & $\begin{array}{l}\text { "The already existing innovation ecosystems of this case are characterised } \\
\text { as 'emerged'. This is opposed to 'purposely-built', as these ecosystems } \\
\text { have been predominately formed and evolved around established." (p255) }\end{array}$ \\
\hline $\mathrm{m} 43$ & Clarysse et al. & $\begin{array}{l}\text { Creating value in ecosystems: } \\
\text { Crossing the chasm between } \\
\text { knowledge and business } \\
\text { ecosystems. }\end{array}$ & & 2014 & Research Policy & $\begin{array}{l}\text { "First, business ecosystems are characterized by a large number of loosely } \\
\text { interconnected participants dependent on each other for their mutual } \\
\text { performance..."(p1166) "Business ecosystems, on the other hand, are } \\
\text { characterized by a non-linear value creation process as groups of firms } \\
\text { deliver integrated solutions to end users." (p1174) }\end{array}$ \\
\hline $\mathrm{m} 44$ & $\begin{array}{l}\text { Autio and } \\
\text { Thomas }\end{array}$ & $\begin{array}{l}\text { Innovation ecosystems: } \\
\text { Implications for Innovation } \\
\text { Management? }\end{array}$ & & 2014 & $\begin{array}{l}\text { Oxford University } \\
\text { Press }\end{array}$ & $\begin{array}{l}\text { "We noted earlier that this is one of the few constructs that explicitly } \\
\text { covers conceptually both upstream (production side) and downstream } \\
\text { (user side) activities. This 'whole-system' view echoes the original } \\
\text { biological meaning of the term. The ecosystem construct is distinguished } \\
\text { from value chain and supply chain constructs by its non-linear aspect, as it } \\
\text { includes both vertical and horizontal relationships between actors. The } \\
\text { ecosystem construct is also distinguished from -value creation oriented } \\
\text { constructs such as value networks and value constellations by its focus on } \\
\text { value appropriation and use. A distinctive-although not universally } \\
\text { applied-aspect associated with this construct relates to its focus on the } \\
\text { evolution of networks of interconnected actors towards new states, rather } \\
\text { than emphasizing the optimization of the output potential of the an existing } \\
\text { and unchanging network configuration." (p207-208) }\end{array}$ \\
\hline $\mathrm{m} 48$ & Siqueira et al. & $\begin{array}{l}\text { Supporting innovation } \\
\text { ecosystems with microfinance: } \\
\text { Evidence from Brazil and } \\
\text { implications for social } \\
\text { entrepreneurship. }\end{array}$ & & 2014 & $\begin{array}{l}\text { Journal of Social } \\
\text { Entrepreneurship }\end{array}$ & $\begin{array}{l}\text { "Collaboration and interdependence among organizations are typical } \\
\text { features of innovation ecosystems." (p319) }\end{array}$ \\
\hline $\mathrm{m} 49$ & Hienerth et al. & $\begin{array}{l}\text { Synergies among producer firms, } \\
\text { lead users, and user communities: } \\
\text { The case of the LEGO producer- } \\
\text { user ecosystem. }\end{array}$ & & 2014 & $\begin{array}{l}\text { Journal of Product } \\
\text { Innovation } \\
\text { Management }\end{array}$ & $\begin{array}{l}\text { "One of the key characteristics of the symbiotic ecosystem observed is that } \\
\text { risks usually carried by a single actor are distributed among all } \\
\text { participating actors." (p858) }\end{array}$ \\
\hline m51 & Ben Letaifa & $\begin{array}{l}\text { The uneasy transition from supply } \\
\text { chains to ecosystems The value- } \\
\text { creation/value-capture dilemma. }\end{array}$ & & 2014 & Management Decision & "Ecosystems are characterized by coopetition." (p281) \\
\hline
\end{tabular}




\begin{tabular}{|c|c|c|c|c|c|c|}
\hline Code & Author & Title & Type & Year & Publisher & Quotes and Page (Emphasis Added) \\
\hline m52 & Valkokari & $\begin{array}{l}\text { Business, innovation, and } \\
\text { knowledge ecosystems: How they } \\
\text { differ and how to survive and } \\
\text { thrive within them. }\end{array}$ & SLR & 2015 & $\begin{array}{l}\text { Technology } \\
\text { Innovation } \\
\text { Management Review }\end{array}$ & $\begin{array}{l}\text { "an ecosystem always induces both competition and cooperation, which } \\
\text { leads to the selection and adaption of species...ecosystems is not a trivial } \\
\text { machine, with a defined input-output ratio." (p20-21) }\end{array}$ \\
\hline m55 & Basole et al. & $\begin{array}{l}\text { Coopetition and convergence in } \\
\text { the ICT ecosystem. }\end{array}$ & & 2015 & $\begin{array}{l}\text { Telecommunications } \\
\text { Policy }\end{array}$ & $\begin{array}{l}\text { "Early on the ecosystem was primarily characterized by a growth in } \\
\text { convergence; more recently we are seeing a growing coopetition." (p544) }\end{array}$ \\
\hline m58 & $\begin{array}{l}\text { Bosch- } \\
\text { Sijtsema, and } \\
\text { Bosch }\end{array}$ & $\begin{array}{l}\text { Plays nice with others? Multiple } \\
\text { ecosystems, various roles and } \\
\text { divergent engagement models. }\end{array}$ & & 2015 & $\begin{array}{l}\text { Technology Analysis } \\
\text { \& Strategic } \\
\text { Management }\end{array}$ & $\begin{array}{l}\text { "has the following characteristics: (1) symbiosis: the survival of all } \\
\text { members is built on the benefit of an overall ecosystem (Li 2009). (2) Co- } \\
\text { evolution: firms co-evolve capabilities around new innovation (Moore } \\
\text { 1993). (3) Platform:..." (p961) }\end{array}$ \\
\hline m59 & Russell et al. & $\begin{array}{l}\text { Relational capital for shared } \\
\text { vision in innovation ecosystems. }\end{array}$ & & 2015 & Triple Helix & $\begin{array}{l}\text { "A dynamic innovation ecosystem is characterized by a continual } \\
\text { realignment of synergistic relationships that promote growth of the } \\
\text { system." (p3) }\end{array}$ \\
\hline m61 & $\begin{array}{l}\text { Hedman and } \\
\text { Henningsson }\end{array}$ & $\begin{array}{l}\text { The new normal: Market } \\
\text { cooperation in the mobile } \\
\text { payments ecosystem. }\end{array}$ & & 2015 & $\begin{array}{l}\text { Electronic Commerce } \\
\text { Research and } \\
\text { Applications }\end{array}$ & $\begin{array}{l}\text { "In the literature, four features of ecosystems stand out. First, an } \\
\text { ecosystem is characterized by simultaneous competition and cooperation, } \\
\text { so called co-opetition...second, a matter of managing resource } \\
\text { dependencies...third, tan organization can be a stakeholder in many } \\
\text { ecosystems... fourth, The fourth typical characteristic of ecosystems is that } \\
\text { they are not stable, but are constantly evolving." (p308) }\end{array}$ \\
\hline m62 & Basole et al. & $\begin{array}{l}\text { Understanding business } \\
\text { ecosystem dynamics: A data- } \\
\text { driven approach. }\end{array}$ & & 2015 & $\begin{array}{l}\text { ACM Transactions on } \\
\text { Management } \\
\text { Information Systems }\end{array}$ & "Cocreation is hence an essential ecosystem characteristic." (p62) \\
\hline m63 & Rong et al. & $\begin{array}{l}\text { Understanding business } \\
\text { ecosystem using a } 6 \mathrm{C} \text { framework } \\
\text { in Internet-of-Things-based } \\
\text { sectors. }\end{array}$ & & 2015 & $\begin{array}{l}\text { International Journal } \\
\text { of Production } \\
\text { Economics }\end{array}$ & $\begin{array}{l}\text { "co-evolution in different stages of a lifecycle is an essential feature of the } \\
\text { business ecosystem." (p44) }\end{array}$ \\
\hline m64 & $\begin{array}{l}\text { Weber and } \\
\text { Hine }\end{array}$ & $\begin{array}{l}\text { Who inhabits a business } \\
\text { ecosystem? The technospecies as } \\
\text { a unifying concept. }\end{array}$ & & 2015 & $\begin{array}{l}\text { Technology } \\
\text { Innovation } \\
\text { Management Review }\end{array}$ & $\begin{array}{l}\text { "As ecosystems are considered to be self-organizing and scale-free, they } \\
\text { consist of an interconnected, complex, assemblage of members having } \\
\text { resource and information flows and some level of productivity where each } \\
\text { ecosystem affects and is affected by the inhabitants of that ecosystem } \\
\text { resulting in evolution or adaptation with emergence or emergent } \\
\text { features." (p33) }\end{array}$ \\
\hline m65 & $\begin{array}{l}\text { Attour and } \\
\text { Barbaroux }\end{array}$ & $\begin{array}{l}\text { Architectural knowledge and the } \\
\text { birth of a platform ecosystem: a } \\
\text { case study. }\end{array}$ & & 2016 & $\begin{array}{l}\text { Journal of Innovation } \\
\text { Economics } \\
\text { Management }\end{array}$ & $\begin{array}{l}\text { "The modularity of an ecosystem organizational form and, by extension, } \\
\text { the type of knowledge attached to the selection, inter-connection, } \\
\text { combination and integration of its various components are thus central to } \\
\text { its very definition as an ecosystem." (p12) }\end{array}$ \\
\hline
\end{tabular}




\begin{tabular}{|c|c|c|c|c|c|c|}
\hline Code & Author & Title & Type & Year & Publisher & Quotes and Page (Emphasis Added) \\
\hline m66 & $\begin{array}{l}\text { Mantovani } \\
\text { and Ruiz- } \\
\text { Aliseda }\end{array}$ & $\begin{array}{l}\text { Equilibrium innovation } \\
\text { ecosystems: the dark side of } \\
\text { collaborating with } \\
\text { complementors. }\end{array}$ & & 2016 & Management Science & $\begin{array}{l}\text { "Building such innovation ecosystems...seems to be the key competitive } \\
\text { weapon in most high-tech industries, in which the notion of competition } \\
\text { has been displaced by that of coopetition (Brandenburger and Nalebuff } \\
\text { 1996). A noteworthy feature of collaboration with complementors ...is that } \\
\text { it is not unusual for firms to collaborate with several complementors that } \\
\text { sell substitutes of each other." (p534) }\end{array}$ \\
\hline m67 & Song & $\begin{array}{l}\text { Innovation ecosystem: impact of } \\
\text { interactive patterns, member } \\
\text { location and member } \\
\text { heterogeneity on cooperative } \\
\text { innovation performance. }\end{array}$ & & 2016 & $\begin{array}{l}\text { Innovation: } \\
\text { Management, Policy } \\
\text { \& Practice }\end{array}$ & $\begin{array}{l}\text { "Therefore, when considering the characteristics of interaction behaviour } \\
\text { for members of an innovation ecosystem, this paper uses the computer } \\
\text { simulation method to simulate the self-organisation process of member } \\
\text { interactions." (p15) }\end{array}$ \\
\hline $\mathrm{m} 71$ & $\begin{array}{l}\text { Pellikka and } \\
\text { Ali-Vehmas }\end{array}$ & $\begin{array}{l}\text { Managing Innovation Ecosystems } \\
\text { to Create and Capture Value in } \\
\text { ICT Industries. }\end{array}$ & & 2016 & $\begin{array}{l}\text { Technology } \\
\text { Innovation } \\
\text { Management Review }\end{array}$ & $\begin{array}{l}\text { "Continuous forming, re-forming, and dissolving are characteristic of the } \\
\text { innovation ecosystems." (p19) }\end{array}$ \\
\hline $\mathrm{m} 72$ & Pera et al. & $\begin{array}{l}\text { Motives and resources for value } \\
\text { co-creation in a multi-stakeholder } \\
\text { ecosystem: A managerial } \\
\text { perspective. }\end{array}$ & & 2016 & $\begin{array}{l}\text { Journal of Business } \\
\text { Research }\end{array}$ & $\begin{array}{l}\text { "Business ecosystems are characterized by an economic logic where each } \\
\text { actor contributes to the achievement of an overarching solution" (p4034) }\end{array}$ \\
\hline m73 & Hannah et al. & $\begin{array}{l}\text { Resource redeployment in } \\
\text { business ecosystems. In T. Folta, } \\
\text { C. Helfat, \& S. Karim (Eds.), } \\
\text { Resource redeployment and } \\
\text { corporate strategy (Vol. 35, pp. } \\
\text { 19-48). London, England: } \\
\text { Emerald Group Publishing } \\
\text { Limited. }\end{array}$ & & 2016 & $\begin{array}{l}\text { Advances in Strategic } \\
\text { Management }\end{array}$ & $\begin{array}{l}\text { "Ecosystems are characterized by high consumption-side } \\
\text { interdependence... Ecosystems are characterized by both cooperation and } \\
\text { competition." (p24) }\end{array}$ \\
\hline $\mathrm{m} 74$ & Ansari et al. & $\begin{array}{l}\text { The disruptor's dilemma: TiVo } \\
\text { and the US television ecosystem. }\end{array}$ & & 2016 & $\begin{array}{l}\text { Strategic Management } \\
\text { Journal }\end{array}$ & $\begin{array}{l}\text { "The task of managing such coopetitive relationships is all the more } \\
\text { challenging in systemic industries with multisided platforms and complex } \\
\text { ecosystems." (p1832) }\end{array}$ \\
\hline m79 & Pulkka et al. & $\begin{array}{l}\text { Applicability and benefits of the } \\
\text { ecosystem concept in the } \\
\text { construction industry. }\end{array}$ & & 2016 & $\begin{array}{l}\text { Construction } \\
\text { Management and } \\
\text { Economics }\end{array}$ & $\begin{array}{l}\text { "Thomas and Autio (2014) argue that all ecosystems share three } \\
\text { characteristics: (1) a network of participants, (2) governance system and } \\
\text { (3) shared logic. Each characteristic consists of three elements. The } \\
\text { network of participants consists of specialization, complementariness and } \\
\text { co-evolution; the governance system consists of authority structure, } \\
\text { membership control and task coordination; and the vision logic } \\
\text { characteristic consists of legitimacy, trust and mutual awareness." (p126) }\end{array}$ \\
\hline m81 & Adner & $\begin{array}{l}\text { Ecosystem as structure: An } \\
\text { actionable construct for strategy. }\end{array}$ & & 2017 & $\begin{array}{l}\text { Journal of } \\
\text { Management }\end{array}$ & $\begin{array}{l}\text { "An ecosystem is inherently multilateral. This means not only a multiplicity } \\
\text { of partners, but also a set of relationships that are not decomposable to an } \\
\text { aggregation of bilateral interactions...it means that the participating actors } \\
\text { in the system have a joint value creation effort as a general goal." (p42- } \\
43 \text { ) }\end{array}$ \\
\hline
\end{tabular}




\begin{tabular}{|c|c|c|c|c|c|c|}
\hline Code & Author & Title & Type & Year & Publisher & Quotes and Page (Emphasis Added) \\
\hline $\mathrm{m} 82$ & $\begin{array}{l}\text { Ritala and } \\
\text { Almpanopoul } \\
\text { ou }\end{array}$ & $\begin{array}{l}\text { In defense of 'eco' in innovation } \\
\text { ecosystem. }\end{array}$ & & 2017 & Technovation & $\begin{array}{l}\text { "the unique features of purposeful design and evolutionary nature may } \\
\text { make the innovation ecosystem concept viable for examining real-world } \\
\text { phenomena in both of these important respects. For that reason, it is } \\
\text { important for ecosystem scholars to understand which parts of the } \\
\text { ecosystem are (and can be) engineered, and which parts are self-organized } \\
\text { or co-evolved." (p41) }\end{array}$ \\
\hline n3 & $\begin{array}{l}\text { Aarikka- } \\
\text { Stenroos and } \\
\text { Ritala }\end{array}$ & $\begin{array}{l}\text { Network management in the era } \\
\text { of ecosystems: Systematic review } \\
\text { and management framework. }\end{array}$ & SLR & 2017 & $\begin{array}{l}\text { Industrial Marketing } \\
\text { Management }\end{array}$ & $\begin{array}{l}\text { "we outline two key theoretical constituents of the ecosystem } \\
\text { approach ...These include co-evolutionary logic, which defines the } \\
\text { interactions and processes between the actors, technologies, and } \\
\text { institutions of an ecosystem, and boundaries and composition, which } \\
\text { define the contextual breadth within which the relevant set of actors, } \\
\text { technologies, and institutions is situated." (p25) }\end{array}$ \\
\hline n4 & $\begin{array}{l}\text { Valkokari et } \\
\text { al. }\end{array}$ & $\begin{array}{l}\text { Orchestrating innovation } \\
\text { ecosystems: a qualitative analysis } \\
\text { of ecosystem positioning } \\
\text { strategies. }\end{array}$ & & 2017 & $\begin{array}{l}\text { Technology } \\
\text { Innovation } \\
\text { Management Review }\end{array}$ & $\begin{array}{l}\text { "the defining characteristic of innovation ecosystems is their ability to } \\
\text { adapt and evolve." (p13) }\end{array}$ \\
\hline n6 & $\begin{array}{l}\text { Russo-Spena } \\
\text { et al. }\end{array}$ & $\begin{array}{l}\text { Searching through the jungle of } \\
\text { innovation conceptualisations: } \\
\text { System, network and ecosystem } \\
\text { perspectives. }\end{array}$ & $\mathrm{SLR}^{\mathrm{a}}$ & 2017 & $\begin{array}{l}\text { Journal of Service } \\
\text { Theory and Practice }\end{array}$ & No \\
\hline n7 & $\begin{array}{l}\text { Kapoor and } \\
\text { Agarwal }\end{array}$ & $\begin{array}{l}\text { Sustaining superior performance } \\
\text { in business ecosystems: Evidence } \\
\text { from application software } \\
\text { developers in the iOS and } \\
\text { Android smartphone ecosystems. }\end{array}$ & & 2017 & Organization Science & $\begin{array}{l}\text { "Increasingly, business ecosystems are characterized by a firm that } \\
\text { orchestrates the functioning of the ecosystem by providing a platform and } \\
\text { setting the rules for other firms to leverage the platform and offer } \\
\text { complementary products to the users."(p531) "we offer a novel } \\
\text { characterization of complementors' ecosystem level interdependencies } \\
\text { that is rooted in the structural and evolutionary features of the ecosystem." } \\
\text { (p531) }\end{array}$ \\
\hline n8 & $\begin{array}{l}\text { Järvi and } \\
\text { Kortelainen }\end{array}$ & $\begin{array}{l}\text { Taking stock of empirical } \\
\text { research on business ecosystems: } \\
\text { a literature review. }\end{array}$ & SLR & 2017 & $\begin{array}{l}\text { International Journal } \\
\text { of Business and } \\
\text { Systems Research }\end{array}$ & $\begin{array}{l}\text { "Since its inception, the ecosystem construct has been defined by } \\
\text { characteristics such as interconnectedness, interdependencies, symbiosis } \\
\text { and co-evolution among actors." (p218) }\end{array}$ \\
\hline n10 & $\begin{array}{l}\text { Tsujimoto et } \\
\text { al. }\end{array}$ & $\begin{array}{l}\text { A review of the ecosystem } \\
\text { concept-Towards coherent } \\
\text { ecosystem design. }\end{array}$ & SLR & 2018 & $\begin{array}{l}\text { Technological } \\
\text { Forecasting and } \\
\text { Social Change }\end{array}$ & $\begin{array}{l}\text { "We follow these researchers and adopt the idea of self-organization for } \\
\text { the ecosystem definition... "multilayer" signifies that there are hierarchical } \\
\text { levels and/or separate layers in the ecosystem... relationships among the } \\
\text { actors are not confined to the business context...This last characteristic } \\
\text { will occasionally produce unintended results." (p55) }\end{array}$ \\
\hline $\mathrm{n} 12$ & Luo & $\begin{array}{l}\text { Architecture and evolvability of } \\
\text { innovation ecosystems. }\end{array}$ & & 2018 & $\begin{array}{l}\text { Technological } \\
\text { Forecasting and } \\
\text { Social Change }\end{array}$ & $\begin{array}{l}\text { "To characterize an ecosystem's evolution prospects, the lens of } \\
\text { analysis used in this paper is "evolvability." (p134) }\end{array}$ \\
\hline
\end{tabular}




\begin{tabular}{|c|c|c|c|c|c|c|}
\hline Code & Author & Title & Type & Year & Publisher & Quotes and Page (Emphasis Added) \\
\hline n21 & Kapoor & $\begin{array}{l}\text { Ecosystems: broadening the locus } \\
\text { of value creation. }\end{array}$ & & 2018 & $\begin{array}{l}\text { Journal of } \\
\text { Organization Design }\end{array}$ & $\begin{array}{l}\text { "the latter[ecosystem approach] is characterized by a demand-side pooled } \\
\text { interdependence with the downstream actor (or user) having the decision } \\
\text { rights with respect to the integration of the complements with the focal } \\
\text { offer" (p7) }\end{array}$ \\
\hline n22 & $\begin{array}{l}\text { Phillips and } \\
\text { Srai }\end{array}$ & $\begin{array}{l}\text { Exploring emerging ecosystem } \\
\text { boundaries: defining 'the game'. }\end{array}$ & & 2018 & $\begin{array}{l}\text { International Journal } \\
\text { of Innovation } \\
\text { Management }\end{array}$ & $\begin{array}{l}\text { "Research has highlighted the relevance of viewing organizations and their } \\
\text { environments as systems, characterised by interdependence, co-evolution, } \\
\text { non-linear behaviour and challenges." (p2) }\end{array}$ \\
\hline n23 & $\begin{array}{l}\text { Attour and } \\
\text { Lazaric }\end{array}$ & $\begin{array}{l}\text { From knowledge to business } \\
\text { ecosystems: emergence of an } \\
\text { entrepreneurial activity during } \\
\text { knowledge replication. }\end{array}$ & & 2018 & $\begin{array}{l}\text { Small Business } \\
\text { Economics }\end{array}$ & $\begin{array}{l}\text { "one of the pillars of business ecosystems is integration which gives rise to } \\
\text { tightly knit combinations of assets"(p1)"Business ecosystems are } \\
\text { characterized by a functional goal to enable technological development } \\
\text { and innovation." (p2) }\end{array}$ \\
\hline n25 & $\begin{array}{l}\text { Hannah and } \\
\text { Eisenhardt }\end{array}$ & $\begin{array}{l}\text { How firms navigate cooperation } \\
\text { and competition in nascent } \\
\text { ecosystems. }\end{array}$ & & 2018 & $\begin{array}{l}\text { Strategic Management } \\
\text { Journal }\end{array}$ & $\begin{array}{l}\text { "Ecosystems have unique features. First, ecosystems are organized around } \\
\text { a final product such that their components are complementary ... } \\
\text { Moreover, the interdependence among components can be complex ... } \\
\text { Cooperation and competition can also unfold simultaneously and } \\
\text { differently at multiple ecosystem levels: within components; across firms in } \\
\text { a focal ecosystem; and among rival ecosystems. These characteristics } \\
\text { increase the complexity of balancing cooperation and competition by firms } \\
\text { within ecosystems." (p3163) }\end{array}$ \\
\hline n26 & $\begin{array}{l}\text { Scaringella } \\
\text { and Radziwon }\end{array}$ & $\begin{array}{l}\text { Innovation, entrepreneurial, } \\
\text { knowledge, and business } \\
\text { ecosystems: Old wine in new } \\
\text { bottles?. }\end{array}$ & $\mathrm{SLR}^{\mathrm{a}}$ & 2018 & $\begin{array}{l}\text { Technological } \\
\text { Forecasting and } \\
\text { Social Change }\end{array}$ & No \\
\hline n28 & Walrave et al. & $\begin{array}{l}\text { Mapping, analyzing and } \\
\text { designing innovation ecosystems: } \\
\text { The Ecosystem Pie Model. }\end{array}$ & & 2018 & Long Range Planning & $\begin{array}{l}\text { "an ecosystem is characterized by a system-level goal in the form of a } \\
\text { coherent customer-oriented solution." ( } p 3)\end{array}$ \\
\hline n30 & $\begin{array}{l}\text { Bassis and } \\
\text { Armellini }\end{array}$ & $\begin{array}{l}\text { Systems of innovation and } \\
\text { innovation ecosystems: a } \\
\text { literature review in search of } \\
\text { complementarities. }\end{array}$ & SLR & 2018 & $\begin{array}{l}\text { Journal of } \\
\text { Evolutionary } \\
\text { Economics }\end{array}$ & $\begin{array}{l}\text { "the five key features of an innovation ecosystem (Complexity, Self- } \\
\text { organization, Emergence, Co-evolution and Adaptation) and a proposed } \\
\text { governance framework by adopting system complexity and evolutionary } \\
\text { theory." ( } 1063)\end{array}$ \\
\hline n32 & $\begin{array}{l}\text { Mars and } \\
\text { Bronstein }\end{array}$ & $\begin{array}{l}\text { The promise of the organizational } \\
\text { ecosystem metaphor: An } \\
\text { argument for biological rigor. }\end{array}$ & & 2018 & $\begin{array}{l}\text { Journal of } \\
\text { Management Inquiry }\end{array}$ & $\begin{array}{l}\text { "with regard to the five key ecosystem properties (Table 1),..Criterion } 1 \\
\text { They consist of a set of nodes, within which multiple players function and } \\
\text { interact Criterion } 2 \text { Nodes are linked to each other by flows of } \\
\text { information and resources Criterion } 3 \text { Not every node is linked, and those } \\
\text { that exist vary in strength and direction (positive, neutral, or negative) } \\
\text { Criterion } 4 \text { Nodes grow, shrink, are added, and are lost over time } \\
\text { Criterion } 5 \text { Nodes emerge from bottom-up processes, and persist or fail } \\
\text { based on how they are networked;" (p384) }\end{array}$ \\
\hline
\end{tabular}




\begin{tabular}{|c|c|c|c|c|c|c|}
\hline Code & Author & Title & Type & Year & Publisher & Quotes and Page (Emphasis Added) \\
\hline n33 & Lin & $\begin{array}{l}\text { The structural characteristics of } \\
\text { innovation ecosystem: a fashion } \\
\text { case. }\end{array}$ & & 2018 & $\begin{array}{l}\text { European Journal of } \\
\text { Innovation } \\
\text { Management }\end{array}$ & $\begin{array}{l}\text { "existing studies have investigated innovation ecosystems by first } \\
\text { characterising the external environment according to the structure of } \\
\text { interdependence and second examining the flow of inputs and outputs } \\
\text { connecting with the focal firm within the ecosystem." (p623) }\end{array}$ \\
\hline n34 & $\begin{array}{l}\text { Jacobides et } \\
\text { al. }\end{array}$ & Towards a theory of ecosystems. & & 2018 & $\begin{array}{l}\text { Strategic Management } \\
\text { Journal }\end{array}$ & $\begin{array}{l}\text { "An important but neglected characteristic of ecosystems is that they help } \\
\text { coordinate interrelated organizations that have significant } \\
\text { autonomy."(p2260)" This encapsulates three crucial attributes of an } \\
\text { ecosystem... First, "multilateral, nongeneric complementarities"... It is } \\
\text { precisely this attribute that underpins the particularities of ecosystems... } \\
\text { What makes ecosystems unique is that the interdependencies tend to be } \\
\text { standardized [modularity]within each role, which creates the need for a } \\
\text { new set of skills in terms of designing ecosystems...Finally, ecosystems are } \\
\text { not unilaterally hierarchically controlled." (p2264-2265) }\end{array}$ \\
\hline n35 & $\begin{array}{l}\text { Dedehayir et } \\
\text { al. }\end{array}$ & $\begin{array}{l}\text { Roles during innovation } \\
\text { ecosystem genesis: A literature } \\
\text { review. }\end{array}$ & $\mathrm{SLR}^{\mathrm{a}}$ & 2018 & $\begin{array}{l}\text { Technological } \\
\text { Forecasting and } \\
\text { Social Change }\end{array}$ & no \\
\hline n36 & $\begin{array}{l}\text { Shaw and } \\
\text { Allen }\end{array}$ & $\begin{array}{l}\text { Studying innovation ecosystems } \\
\text { using ecology theory. }\end{array}$ & & 2018 & $\begin{array}{l}\text { Technological } \\
\text { Forecasting and } \\
\text { Social Change }\end{array}$ & $\begin{array}{l}\text { "The significant characteristic of ecosystems is that they sustain } \\
\text { themselves in conditions of scarce resources by recycling." (p101) }\end{array}$ \\
\hline n37 & $\begin{array}{l}\text { de } \\
\text { Vasconcelos } \\
\text { Gomes et al. }\end{array}$ & $\begin{array}{l}\text { Unpacking the innovation } \\
\text { ecosystem construct: Evolution, } \\
\text { gaps and trends. }\end{array}$ & SLR & 2018 & $\begin{array}{l}\text { Technological } \\
\text { Forecasting and } \\
\text { Social Change }\end{array}$ & $\begin{array}{l}\text { "business ecosystem or innovation ecosystem are composed of } \\
\text { interconnected and interdependent network actors...may be led by a } \\
\text { keystone actor...are built on a platform...face cooperation and } \\
\text { competition...might have a lifecycle that follows a co-evolution process." } \\
\text { (p40) }\end{array}$ \\
\hline n38 & $\begin{array}{l}\text { Suominen et } \\
\text { al. }\end{array}$ & $\begin{array}{l}\text { A bibliometric review on } \\
\text { innovation systems and } \\
\text { ecosystems: a research agenda. }\end{array}$ & SLR & 2019 & $\begin{array}{l}\text { European Journal of } \\
\text { Innovation } \\
\text { Management }\end{array}$ & $\begin{array}{l}\text { "Hence, the essential characteristics of the business ecosystem } \\
\text { conceptualization of inter-organizational networks, and aiding its } \\
\text { differentiation from already existing frameworks, are its ecological science } \\
\text { origins." (p339) }\end{array}$ \\
\hline n39 & $\begin{array}{l}\text { Phillips and } \\
\text { Ritala }\end{array}$ & $\begin{array}{l}\text { A complex adaptive systems } \\
\text { agenda for ecosystem research } \\
\text { methodology. }\end{array}$ & & 2019 & $\begin{array}{l}\text { Technological } \\
\text { Forecasting and } \\
\text { Social Change }\end{array}$ & $\begin{array}{l}\text { "Ecosystem research has highlighted the managerial relevance of viewing } \\
\text { organizations and their environments as systems, characterized by } \\
\text { interdependence, co-evolution, non-linear behavior and scalable, system- } \\
\text { level opportunities and challenges"(p2) "co-evolution remains a widely } \\
\text { referred topic and is a central feature of ecosystems" (p10) }\end{array}$ \\
\hline n40 & Chae & $\begin{array}{l}\text { A General framework for } \\
\text { studying the evolution of the } \\
\text { digital innovation ecosystem: The } \\
\text { case of big data. }\end{array}$ & & 2019 & $\begin{array}{l}\text { International Journal } \\
\text { of Information } \\
\text { Management }\end{array}$ & $\begin{array}{l}\text { "the ecosystem are characterized as an evolutionary process involving } \\
\text { "variation and selective retention." (p84) }\end{array}$ \\
\hline
\end{tabular}




\begin{tabular}{|c|c|c|c|c|c|c|}
\hline Code & Author & Title & Type & Year & Publisher & Quotes and Page (Emphasis Added) \\
\hline $\mathrm{n} 41$ & Parente et al. & $\begin{array}{l}\text { Adapting and sustaining } \\
\text { operations in weak institutional } \\
\text { environments: A business } \\
\text { ecosystem assessment of a } \\
\text { Chinese MNE in Central Africa. }\end{array}$ & & 2019 & $\begin{array}{l}\text { Journal of } \\
\text { International Business } \\
\text { Studies }\end{array}$ & $\begin{array}{l}\text { "what differentiates the business ecosystem perspective from the networks } \\
\text { and value chain constructs is its nonlinear, multisided, coevolutionary } \\
\text { characteristic." (p277) }\end{array}$ \\
\hline n43 & Gupta et al. & $\begin{array}{l}\text { Business, innovation and digital } \\
\text { ecosystems landscape survey and } \\
\text { knowledge cross sharing. }\end{array}$ & $\mathrm{SLR}^{\mathrm{a}}$ & 2019 & $\begin{array}{l}\text { Technological } \\
\text { Forecasting and } \\
\text { Social Change }\end{array}$ & no \\
\hline n44 & Bacon et al. & $\begin{array}{l}\text { Coopetition in innovation } \\
\text { ecosystems: A comparative } \\
\text { analysis of knowledge transfer } \\
\text { configurations. }\end{array}$ & & 2019 & $\begin{array}{l}\text { Journal of Business } \\
\text { Research }\end{array}$ & $\begin{array}{l}\text { "Coopetition has been identified as an integral component of open } \\
\text { innovation ecosystems and is pursued in these contexts as a result of } \\
\text { various lines of inquiry." (p2) }\end{array}$ \\
\hline n45 & Planko et al. & $\begin{array}{l}\text { Coping with coopetition-Facing } \\
\text { dilemmas in cooperation for } \\
\text { sustainable development: The } \\
\text { case of the Dutch smart grid } \\
\text { industry. }\end{array}$ & & 2019 & $\begin{array}{l}\text { Business Strategy and } \\
\text { the Environment }\end{array}$ & $\begin{array}{l}\text { "build up a prosperous innovation ecosystem around their new } \\
\text { sustainability technology,...Coopetition is a good strategy when new } \\
\text { markets need to be created and consumers need to be educated." (p667) }\end{array}$ \\
\hline n46 & Senyo et al. & $\begin{array}{l}\text { Digital business ecosystem: } \\
\text { Literature review and a } \\
\text { framework for future research. }\end{array}$ & SLR & 2019 & $\begin{array}{l}\text { International Journal } \\
\text { of Information } \\
\text { Management }\end{array}$ & $\begin{array}{l}\text { "The main characteristics of DBEs are platform, symbiosis, co-evolution } \\
\text { and self-organisation." (p53) }\end{array}$ \\
\hline n48 & Mei et al. & $\begin{array}{l}\text { Exploring the effects of inter-firm } \\
\text { linkages on SMEs' open } \\
\text { innovation from an ecosystem } \\
\text { perspective: An empirical study } \\
\text { of Chinese manufacturing SMEs. }\end{array}$ & & 2019 & $\begin{array}{l}\text { Technological } \\
\text { Forecasting and } \\
\text { Social Change }\end{array}$ & $\begin{array}{l}\text { "An innovation ecosystem also represents the feature of structural } \\
\text { dynamics among heterogeneous stakeholders, including focal firms, } \\
\text { customers, suppliers, government agencies, and associations, among } \\
\text { others." (p119) }\end{array}$ \\
\hline n49 & Reeves et al. & $\begin{array}{l}\text { How Business Ecosystems Rise } \\
\text { (and Often Fall). }\end{array}$ & & 2019 & $\begin{array}{l}\text { MIT Sloan } \\
\text { Management Review }\end{array}$ & $\begin{array}{l}\text { "We focused on multicompany systems cited by at least one academic } \\
\text { paper as an ecosystem and then confirmed that they showed several } \\
\text { defining characteristics: (1) a large number of partners, (2) diversity } \\
\text { across industries, (3) relationships based on collaboration rather than } \\
\text { ownership, and (4) the ability for partners to join with limited friction." } \\
\text { (p1) }\end{array}$ \\
\hline n50 & $\begin{array}{l}\text { Yaghmaie and } \\
\text { Vanhaverbeke }\end{array}$ & $\begin{array}{l}\text { Identifying and describing } \\
\text { constituents of innovation } \\
\text { ecosystems. }\end{array}$ & SLR & 2019 & $\begin{array}{l}\text { EuroMed Journal of } \\
\text { Business }\end{array}$ & $\begin{array}{l}\text { "This complementarity is characteristic of the innovation ecosystem and it } \\
\text { indicates that the collaborating partners are all different from each } \\
\text { other."(p5)"Finally, innovation ecosystems are characterized by strong } \\
\text { dynamics over time." (p15) }\end{array}$ \\
\hline
\end{tabular}




\begin{tabular}{|c|c|c|c|c|c|c|}
\hline Code & Author & Title & Type & Year & Publisher & Quotes and Page (Emphasis Added) \\
\hline n51 & $\begin{array}{l}\text { Granstrand } \\
\text { and } \\
\text { Holgersson }\end{array}$ & $\begin{array}{l}\text { Innovation ecosystems: A } \\
\text { conceptual review and a new } \\
\text { definition. }\end{array}$ & SLR & 2019 & Technovation & $\begin{array}{l}\text { "These three cases... illustrate the presence of all the defining } \\
\text { characteristics of an innovation ecosystem as proposed in this article, } \\
\text { including the presence of complementary as well as substitute relations in } \\
\text { the sub-systems of actors, activities and artifacts, together with relations } \\
\text { between them involving rights allocation through market transactions... } \\
\text { Competitive relations existed on multiple levels both in the artifact and } \\
\text { actor systems, and mixed with cooperative relations into coopetition in all } \\
\text { cases." (p8) }\end{array}$ \\
\hline n52 & $\begin{array}{l}\text { Adner and } \\
\text { Feiler }\end{array}$ & $\begin{array}{l}\text { Interdependence, Perception, and } \\
\text { Investment Choices: An } \\
\text { Experimental Approach to } \\
\text { Decision Making in Innovation } \\
\text { Ecosystems. }\end{array}$ & & 2019 & Organization Science & $\begin{array}{l}\text { "Conjunctive interdependence is characteristic of ecosystem } \\
\text { settings." (p111) }\end{array}$ \\
\hline n54 & $\begin{array}{l}\text { Radziwon and } \\
\text { Bogers }\end{array}$ & $\begin{array}{l}\text { Open innovation in SMEs: } \\
\text { Exploring inter-organizational } \\
\text { relationships in an ecosystem. }\end{array}$ & & 2019 & $\begin{array}{l}\text { Technological } \\
\text { Forecasting and } \\
\text { Social Change }\end{array}$ & $\begin{array}{l}\text { "Business ecosystems can be characterized as consisting of a variety } \\
\text { of types of stakeholders, including suppliers, customers, competitors, } \\
\text { universities, and other complementors, all of whom play a different role } \\
\text { relative to the other actors in the value-creation process." (p576) }\end{array}$ \\
\hline n55 & Ding et al. & $\begin{array}{l}\text { Platform strategies for innovation } \\
\text { ecosystem: Double-case study of } \\
\text { Chinese automobile } \\
\text { manufactures. }\end{array}$ & & 2019 & $\begin{array}{l}\text { Journal of Cleaner } \\
\text { Production }\end{array}$ & $\begin{array}{l}\text { "The symbiosis of IE is thereby featured in the cooperation on innovations } \\
\text { among core enterprise, upstream suppliers, downstream customers, and/or } \\
\text { complementors." (p1566) }\end{array}$ \\
\hline n56 & $\begin{array}{l}\text { Pekkarinen et } \\
\text { al. }\end{array}$ & $\begin{array}{l}\text { Robotics in Finnish welfare } \\
\text { services: dynamics in an } \\
\text { emerging innovation ecosystem. }\end{array}$ & & 2019 & $\begin{array}{l}\text { European Planning } \\
\text { Studies }\end{array}$ & $\begin{array}{l}\text { "On the basis of the results, the ecosystem appears to be both 'a target for } \\
\text { managerial action' and 'self-evolving', in accordance with...The } \\
\text { ecosystem is self-evolving related to accelerating and hindering 'forces' as } \\
\text { well as mutual collaboration and adjustment between actors, but still it } \\
\text { seems that there is a need of purposeful action and management, for } \\
\text { instance in terms of having users participate." (p18) }\end{array}$ \\
\hline n57 & Fuller et al. & $\begin{array}{l}\text { The myths and realities of } \\
\text { business ecosystems. }\end{array}$ & & 2019 & $\begin{array}{l}\text { MIT Sloan } \\
\text { Management Review }\end{array}$ & $\begin{array}{l}\text { "The essential characteristics of business ecosystems are the following: } \\
\text { They are multi-entity, made up of groups of companies not belonging to a } \\
\text { single organization. They involve networks of shifting, semipermanent } \\
\text { relationships, linked by flows of data, services, and money. The } \\
\text { relationships combine aspects of competition and collaboration, often } \\
\text { involving complementarity between different products and capabilities (for } \\
\text { instance, smartphones and apps). Finally, in ecosystems, players coevolve } \\
\text { as they redefine their capabilities and relations to others over time." (p2) } \\
\text { "The danger of this myth is that it leads us to adopt static, deductive } \\
\text { approaches that are at odds with the dynamic, emergent character of } \\
\text { ecosystems." (p5) }\end{array}$ \\
\hline
\end{tabular}




\begin{tabular}{|c|c|c|c|c|c|c|}
\hline Code & Author & Title & Type & Year & Publisher & Quotes and Page (Emphasis Added) \\
\hline n59 & $\begin{array}{l}\text { Aksenova et } \\
\text { al. }\end{array}$ & $\begin{array}{l}\text { From Finnish AEC knowledge } \\
\text { ecosystem to business ecosystem: } \\
\text { lessons learned from the national } \\
\text { deployment of BIM. }\end{array}$ & & 2019 & $\begin{array}{l}\text { Construction } \\
\text { Management and } \\
\text { Economics }\end{array}$ & $\begin{array}{l}\text { "It is characterised by an interdependence of cooperating and competing } \\
\text { (but complementary) network of partners, a structured community, and it } \\
\text { plays a critical role in determining value co-creation and co-capture...The } \\
\text { network logic of the ecosystem is usually aligned with a keystone and is } \\
\text { characterised by a large number of loosely connected actors (niches) that } \\
\text { depend on each other for their mutual benefit and, through } \\
\text { interdependence, can co-create value that no single actor can." (p319) }\end{array}$ \\
\hline n61 & Beltagui et al. & $\begin{array}{l}\text { Exaptation in a digital innovation } \\
\text { ecosystem: The disruptive } \\
\text { impacts of 3D printing. }\end{array}$ & & 2020 & Research Policy & $\begin{array}{l}\text { "Ecosystems are complex adaptive systems (Choi et al., 2001) } \\
\text { characterized by the interplay among the behaviors of individual actors } \\
\text { and those of the whole system across indeterminate boundaries." (p3) }\end{array}$ \\
\hline n62 & Ganco et al. & $\begin{array}{l}\text { From Rugged Landscapes to } \\
\text { Rugged Ecosystems: Structure of } \\
\text { Interdependencies and Firms' } \\
\text { Innovative Search. }\end{array}$ & & 2020 & $\begin{array}{l}\text { Academy of } \\
\text { Management Review }\end{array}$ & $\begin{array}{l}\text { "Moreover, while the structure of interdependencies between the different } \\
\text { actors is touted as a key distinguishing feature of an ecosystem } \\
\text { perspective." (p2) }\end{array}$ \\
\hline n64 & $\begin{array}{l}\text { Thomas and } \\
\text { Autio }\end{array}$ & $\begin{array}{l}\text { Innovation ecosystems in } \\
\text { management: An organizing } \\
\text { typology. }\end{array}$ & & 2020 & $\begin{array}{l}\text { Oxford University } \\
\text { Press }\end{array}$ & $\begin{array}{l}\text { "we identify four distinguishing commonalities across different ecosystem } \\
\text { concepts in management. The first characteristic is that of participant het- } \\
\text { erogeneity...The second distinguishing characteristic is that ecosystems } \\
\text { facilitate an ecosystem output that is more encompassing than any single } \\
\text { participant could deliver alone...The third distinguishing characteristic is } \\
\text { the nature of interdependence among ecosystem participants...The fourth } \\
\text { distinguishing characteristic is the nature of ecosystem governance, which } \\
\text { relies primarily on non-contractual mechanisms." (p2) }\end{array}$ \\
\hline n65 & $\begin{array}{l}\text { Shipilov and } \\
\text { Gawer }\end{array}$ & $\begin{array}{l}\text { Integrating Research on } \\
\text { Interorganizational Networks and } \\
\text { Ecosystems. }\end{array}$ & & 2020 & $\begin{array}{l}\text { Academy of } \\
\text { Management Annals }\end{array}$ & $\begin{array}{l}\text { "The focus on value proposition as a defining feature of ecosystems } \\
\text { highlights that ecosystems cannot be reduced to a set of } \\
\text { interorganizational alliances or to a network of organizations." (p101) } \\
\text { "Ecosystems are characterized by the multilateral nature of dependencies } \\
\text { across their members...Another unique feature is that, within ecosystems, } \\
\text { groups of actors with similar types of interdependencies with other groups } \\
\text { of actors face similar governance rules[modularity]." (p102) }\end{array}$ \\
\hline n66 & $\begin{array}{l}\text { Harmaakorpi } \\
\text { and Rinkinen }\end{array}$ & $\begin{array}{l}\text { Regional development platforms } \\
\text { as incubators of business } \\
\text { ecosystems. Case study: The } \\
\text { Lahti urban region, Finland. }\end{array}$ & & 2020 & Growth and Change & $\begin{array}{l}\text { "all ecosystems have some common features. They are highly self- } \\
\text { sustaining systems that emerge, evolve and die in their own rhythm and } \\
\text { cannot be controlled from the outside easily." (p2) }\end{array}$ \\
\hline n69 & Hakala et al. & $\begin{array}{l}\text { Re-storying the Business, } \\
\text { Innovation and Entrepreneurial } \\
\text { Ecosystem Concepts: The Model- } \\
\text { Narrative Review Method. }\end{array}$ & SLR & 2020 & $\begin{array}{l}\text { International Journal } \\
\text { of Management } \\
\text { Reviews }\end{array}$ & $\begin{array}{l}\text { "key themes: Global competition, co-opetition; co-evolution, synergies, } \\
\text { market selection Collaboration, value co-creation, customer-facing } \\
\text { solutions, platforms, keystones, hubs..." (p7, table 1) }\end{array}$ \\
\hline
\end{tabular}




\begin{tabular}{|c|c|c|c|c|c|c|}
\hline Code & Author & Title & Type & Year & Publisher & Quotes and Page (Emphasis Added) \\
\hline n70 & Palmié et al. & $\begin{array}{l}\text { The evolution of the financial } \\
\text { technology ecosystem: An } \\
\text { introduction and agenda for future } \\
\text { research on disruptive innovations } \\
\text { in ecosystems. }\end{array}$ & & 2020 & $\begin{array}{l}\text { Technological } \\
\text { Forecasting and } \\
\text { Social Change }\end{array}$ & $\begin{array}{l}\text { "ecosystems are characterized by complementarities in production and/or } \\
\text { consumption and that the members of the ecosystem can coordinate these } \\
\text { complementarities without hierarchical governance..." (p3) }\end{array}$ \\
\hline n71 & Sant et al. & $\begin{array}{l}\text { The structure of an innovation } \\
\text { ecosystem: foundations for future } \\
\text { research. }\end{array}$ & $\operatorname{SLR}^{\mathrm{a}}$ & 2020 & Management Decision & no \\
\hline
\end{tabular}




\section{Appendix 2.2: Categories of key distinguishing features.}

\section{Various roles/actors}

\begin{tabular}{|c|}
\hline a large number of organizations $(\mathrm{m} 18)$ \\
\hline a set of nodes (n32) \\
\hline a large number of partners (n49) \\
\hline boundaries and composition ( $n 3)$ \\
\hline cocreation (m62) \\
\hline legitimacy, trust and mutual awareness (m79) \\
\hline not confined to the business context ( $n 10)$ \\
\hline not every node is linked (n32) \\
\hline $\begin{array}{l}\text { linked to each other by flows of information and } \\
\text { resources ( } 32 \text { ) }\end{array}$ \\
\hline ecological science origins ( $n 38)$ \\
\hline $\begin{array}{l}\text { structural dynamics among heterogeneous } \\
\text { stakeholder }(n 48)\end{array}$ \\
\hline diversity across industries ( $n 49)$ \\
\hline consisting of a variety of types of stakeholders (n54) \\
\hline shifting, semipermanent relationships ( $n 57)$ \\
\hline $\begin{array}{l}\text { the behaviors of individual actors and those of the } \\
\text { whole system across indeterminate boundaries (n61) }\end{array}$ \\
\hline participant heterogeneity (n64) \\
\hline platform (m14) \\
\hline platform (n46) \\
\hline platform (m58) \\
\hline the presence of crucial hubs $(\mathrm{m} 4)$ \\
\hline innovation platforms ( $\mathrm{m} 20)$ \\
\hline $\begin{array}{l}\text { a firm that orchestrates the functioning of the } \\
\text { ecosystem }(n 7)\end{array}$ \\
\hline focal firm (n33) \\
\hline a keystone actor (n37) \\
\hline platforms, keystones, hubs (n69) \\
\hline
\end{tabular}

\section{Self-organization}

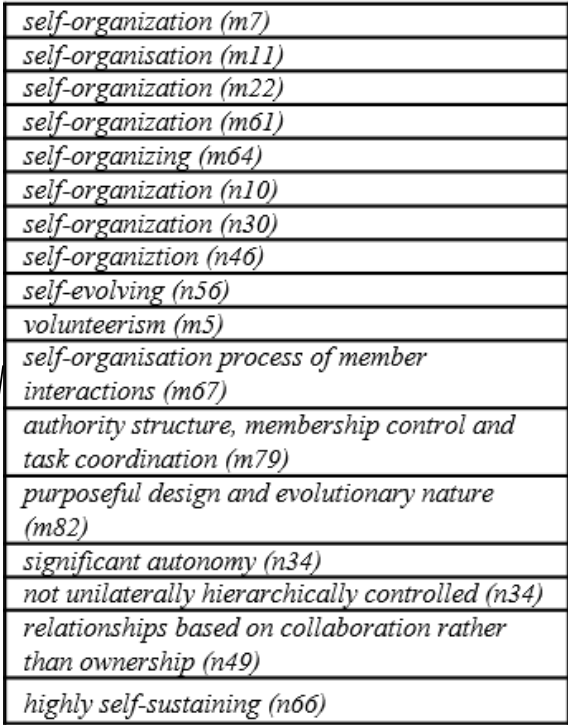

\section{Nonlinearity}

non-linear value creation process $(m 43)$

non-linear aspect (m44)

non-linear behaviour and challenges (n22)

non-linear behavior and scalable (n39)

nonlinear (n41)

continuous forming, re-forming, and dissolving ( $m 71)$

unintended results ( $\mathrm{n} 10$ )

nodes emerge from bottom-up processes ( $n 32)$

nodes grow, shrink, are added, and are lost

over time (n32)

strong dynamics over time (n50)

not a trivial machine, with a defined input-

output ratio (n52)

non-contractual mechanisms (n64)

\section{Shared Vision}

share a common goal $(\mathrm{m} 22)$

a common set of goals and objectives ( 1 32)

a shared set of knowledge and skills (m32)

value creation and value appropriation and use

(m44)

a joint value creation effort as a general goal

(m81)

a functional goal (n23)

a system-level goal (n28)

system-level opportunities and challenges

(n39)

a target for managerial action ( $n 56)$

an ecosystem output ( 164 )

value proposition ( $\mathrm{n} 65$ )

value co-creation and customer-facing

solutions (n69) 


\section{Complementarity}

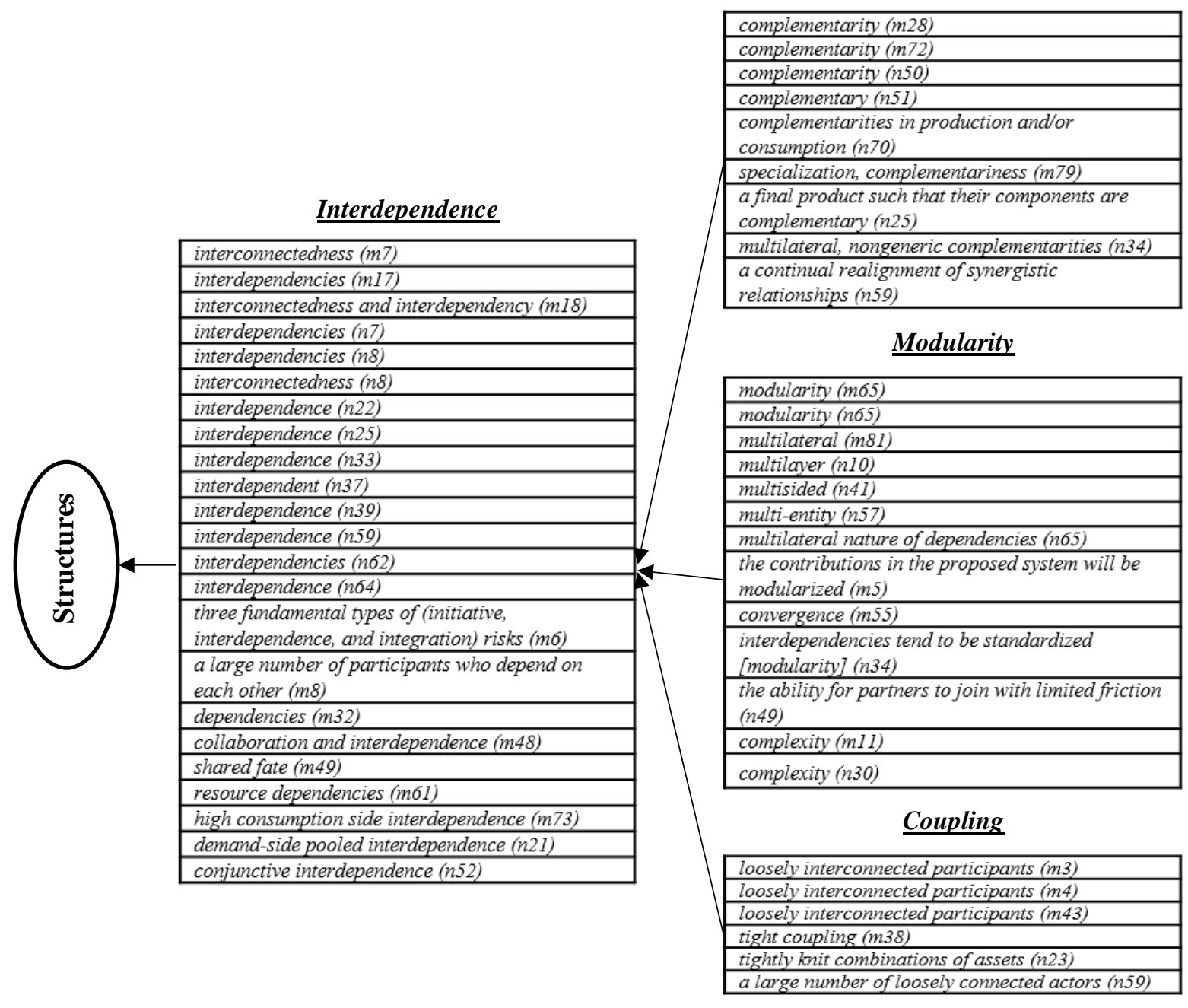


Chapter 2

Emergence

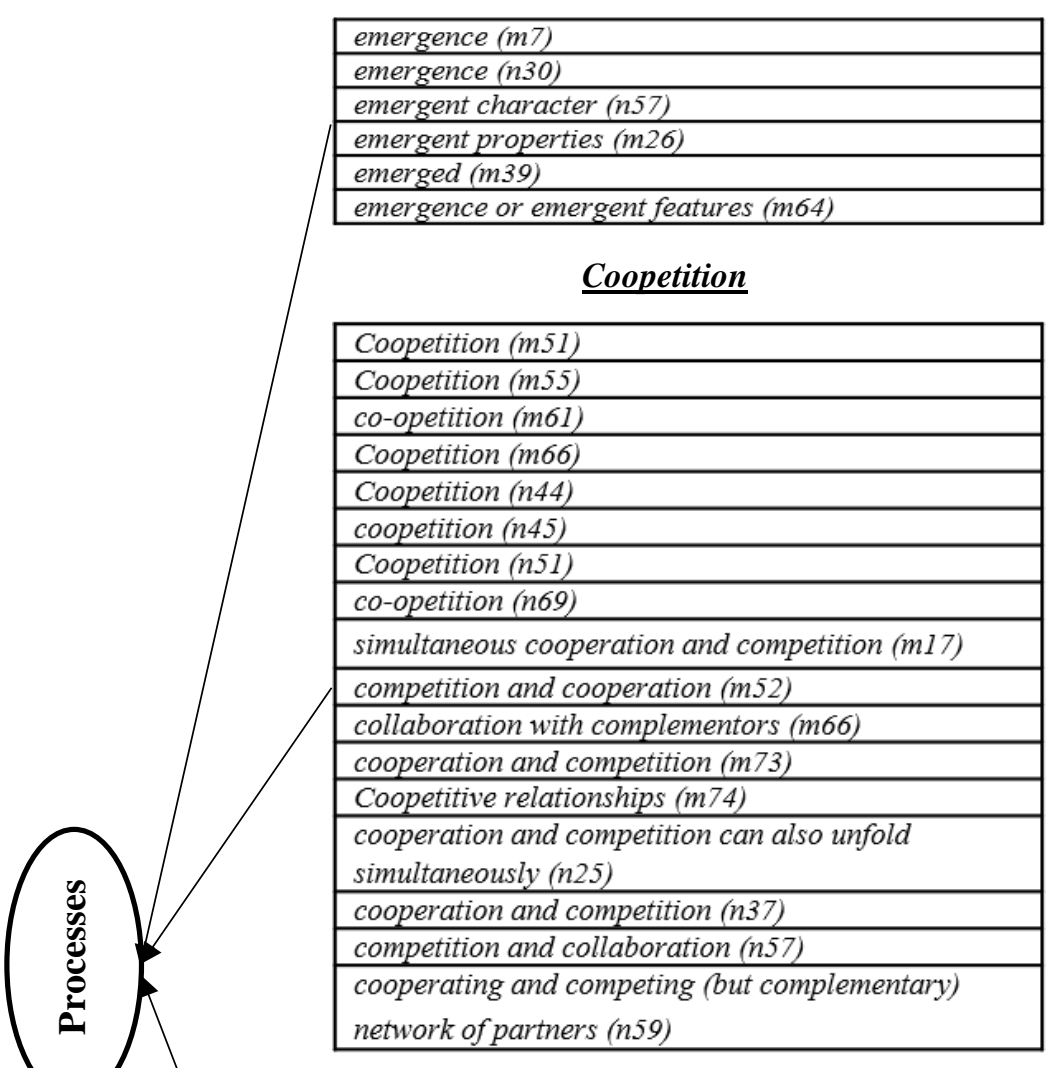

\section{Co-evolution}

\begin{tabular}{|c|c|}
\hline co-evolution (m7) & symbiosis (m14) \\
\hline co-evolution (m14) & symbiosis (m58) \\
\hline co-evolution (m15) & symbiosis (n8) \\
\hline co-evolution $(\mathrm{m} 30)$ & symbiosis $(n 46)$ \\
\hline co-evolution (m58) & symbiosis (n55) \\
\hline co-evolution (m63) & adaptation (mIl) \\
\hline co-evolution (n8) & dynamic co-evolution ( $\mathrm{m} 18$ ) \\
\hline co-evolution (n22) & symbiotic relationship ( $m 29)$ \\
\hline co-evolution (n30) & $\begin{array}{l}\text { evolution of networks of } \\
\text { interconnected actors towards new } \\
\text { states }(m 44)\end{array}$ \\
\hline co-evolution (n36) & co-evolutionary logic (n3) \\
\hline co-evolution (n37) & ability to adapt and evolve (n4) \\
\hline co-evolution (n39) & evolvability (n12) \\
\hline $\begin{array}{l}\text { coevolutionary } \\
(n 41)\end{array}$ & adaptation (n30) \\
\hline co-evolution (n46) & evolutionary process $(n 40)$ \\
\hline co-evolution (n69) & players coevolve (n57) \\
\hline
\end{tabular}




\section{CHAPTER 3}

\section{Building and Sustaining Emerging Ecosystems through New Focal Ventures: Evidence from China's Bike-sharing Industry}

\section{Based on:}

1. Han, J., Zhou, H., Lowik, S., \& De Weerd-Nederhof, P. C. (2018). Building emerging ecosystems by focal new ventures: Evidence from the bike-sharing industry in China. Paper presented at the $6^{\text {th }}$ Asian SME Conference, Tokyo, Japan.

2. Han, J., Zhou, H., Lowik, S., \& De Weerd-Nederhof, P. C. (2018). Building emerging ecosystems by focal new ventures: Evidence from the bike-sharing industry in China. Paper presented at the $2^{\text {th }}$ Annual High Technology Small Firms Conference, Groningen, Netherlands.

3. Han, J., Zhou, H., Lowik, S., \& De Weerd-Nederhof, P. C. (2019). Building emerging ecosystems by focal new ventures: Evidence from the bike-sharing industry in China. Paper presented at the $79^{\text {th }}$ Annual Meeting of the Academy of Management, Boston, USA.

4. Han, J., Zhou, H., Lowik, S., \& De Weerd-Nederhof, P. C. (2019). Building emerging ecosystems by focal new ventures: Evidence from the bike-sharing industry in China. Paper presented at the $26^{\text {th }}$ Innovation and Product Development Management Conference, Leicester, United Kingdom.

5. This manuscript of this chapter is currently under review ( $2^{\text {nd }}$ round of revision \& resubmission) at Technological Forecasting and Social Change. 
Abstract: Building and sustaining an emerging ecosystem is a necessary yet tedious task for ambitious new ventures. While ecosystems research has theorized that overcoming economic and coopetitive challenges is crucial for ecosystem emergence and viability, they largely overlook the effects of sociopolitical challenges as well as the interplay between multiple (i.e., economic, coopetitive, and sociopolitical) challenges to the emergence and viability of ecosystems. By repositioning the sociopolitical challenges in the ecosystem development model, this study answers the research question on how new focal ventures can develop ecosystemspecific strategies to recognize and overcome a combination of economic, coopetitive, and socio-political co-evolution challenges so as to ensure a viable ecosystem. Qualitative results from a multiple-case study of two surviving and two failed emerging bike-sharing ecosystems in China reveal that new focal ventures develop ecosystem-specific strategies in three strategizing forms: (1) niche experimentation, which enables new focal ventures to obtain a more holistic understanding of the co-evolution challenges residing in economic and sociopolitical ecosystem environments; (2) strategic versatility, whereby ecosystem-specific strategies positively and simultaneously reinforce each other and collectively overcome the multiple co-evolution challenges in two ecosystem environments; and (3) strategic suboptimality, whereby new focal ventures sacrifice the short-term efficacy of specific strategies to reinforce the long-term effectiveness of related strategies so as to maintain ecosystem-level competitiveness. These key findings indicate the nonlinear structural and intertemporal ecosystem dynamics that need to be considered in ecosystem development literature as well as by ecosystem practitioners. 


\subsection{INTRODUCTION}

New ventures are increasingly taking focal roles ("new focal ventures" hereafter) in new ecosystems in order to offer complex innovations (Dougherty and Dunne, 2011; Hannah and Eisenhardt, 2018). An ecosystem is defined as a symbiotic community of interdependent organizations (e.g., suppliers, lead producers, competitors, other sociopolitical stakeholders) and individuals (e.g., end-users) who combine their individual offerings into a coherent innovation (Adner, 2006; Moore, 1996). A viable ecosystem, building on all ecosystem actors co-evolving toward shared visions (Liu and Rong, 2015), gives new focal ventures sustainable competitive advantages, such as accessible complementary resources (Williamson and De Meyer, 2012), more entrepreneurial opportunities (Overholm, 2015), and resilience during major technology transitions (Adner and Kapoor, 2016).

While the benefits are clear, achieving a viable ecosystem is problematic for new focal ventures, especially during the ecosystem's nascent development stages, when co-evolution challenges often hamper the process of aligning key ecosystem actors. Here, we define coevolution challenges as all possible obstacles related to collaborating and aligning with other ecosystem actors and inhibiting the success of complex innovations proposed by new focal ventures (Adner, 2006). Co-evolution challenges differ from industry-specific entry challenges in mature markets in the level of uncertainty they cause. The industry-specific entry challenges confronted by new ventures, such as complex production processes (structural challenges) and competitive reactions from incumbents (strategic challenges), are relatively predictable (Lofstrom et al., 2014) and appear to negatively impact new venture growth (Robinson and McDougall, 2001). However, co-evolution challenges in the ecosystem setting are unpredictable and can have high impact on the performance of the co-produced innovation, and consequently on the viability of the entire ecosystem.

Researchers have been increasingly considering the ecosystems’ emergence and viability, especially when steered by ambitious new ventures (Dattée et al., 2018; Fuller et al., 2019; Hannah and Eisenhardt, 2018; Overholm, 2015; Pekkarinen et al., 2019; Walrave et al., 2018). The literature has shown that focal actors (i.e., new focal ventures) must align with and motivate various non-focal actors (i.e., key ecosystem actors) to make unique contributions to the proposed innovations (Jacobides et al., 2018); this could initiate the emergence of an ecosystem (Autio and Thomas, 2014; Gupta et al., 2020). To further ensure the ecosystems’ viability, the non-focal actors' unique contributions should be continuously aligned to materialize their 
shared visions, that is, successful delivery of complex innovations to the marketplace. However, focal actors often encounter co-evolution challenges during the aforementioned processes.

To illustrate, consider Better Place, a new focal venture launched in 2007 to promote the revolutionary full electric vehicles (FEVs). Better Place initiated a FEV ecosystem by integrating various actors and tested their prototype FEVs using Denmark and Israel as pilot markets. However, the company had to declare bankruptcy in 2013 because it did not align with the key ecosystem actors. Specifically, it misinterpreted Denmark's green attitude toward FEVs, leading to inactive consumer buying behaviors; second, it did not foresee the Israeli government's change in energy policy focus from promoting to reducing electricity consumption, resulting in inconsistent political support; third, it took an antagonistic approach to automobile incumbents and FEV competitors (cf. Noel and Sovacool, 2016; Sovacool et al., 2017). Thus, Better Place failed to recognize and struggled to manage multiple co-evolution challenges involving ecosystem actors. This raises the question as to how young ecosystem leaders such as Better Place can develop strategies to deal with such co-evolution challenges.

In response to these co-evolution challenges, ecosystem development research suggests that focal actors should effectively execute ecosystem-specific strategies, that is, strategic actions taken by focal actors to align non-focal ecosystem actors into ecosystems, secure their leadership role in the ecosystems, and thus ensure the ecosystems' emergence and viability (Adner, 2017; Parente et al., 2019; Rong et al., 2015; Williamson and De Meyer, 2012).

Despite the progress made by this stream of the literature, we argue that the relationship between co-evolution challenges, ecosystem-specific strategies, and ecosystem-level outcomes might require further theoretical development for three reasons. First, most studies emphasize the economic and coopetitive co-evolution challenges to new focal ventures (Adner and Kapoor, 2010; Kwak et al., 2018; Liu and Rong, 2015; Planko et al., 2019), overlooking the role of sociopolitical challenges. The premise is that "peripheral" sociopolitical actors are mostly insignificant (e.g., Ansari et al., 2016; Pierce, 2009) or serve as enabling factors only in the ecosystems’ early growth stages (e.g., Li and Garnsey, 2014; Overholm, 2015; Snihur et al., 2018). However, as the Better Place vignette suggests, peripheral sociopolitical actors may not directly contribute value, but can exert significant restrictions on ecosystem development (e.g., Ma et al., 2018; Nakamura and Kajikawa, 2018; Peltola et al., 2016; Rong et al., 2017). Downplaying these actors in the current ecosystem development model might limit current understandings on how new focal ventures effectively address multiple co-evolution challenges using ecosystem-specific strategies. 
Second, extant research reveals that focal actors could achieve a viable ecosystem by executing effective strategies to overcome the corresponding co-evolution challenges, that is, by coping with economic challenges via effective economic strategies or political challenges via effective political strategies. The interplay between different ecosystem-specific strategies, which is vital for early-stage ecosystems development, is often overlooked in these studies. However, ecosystem actors are multilaterally intertangled (de Vasconcelos Gomes et al., 2018; Randhawa et al., 2021; Zhang and Wang, 2018). Different co-evolution challenges arise simultaneously and sometimes become intricately intertwined (Adner, 2017; Jacobides et al., 2018). For instance, in some emerging or underdeveloped economies, the co-evolution challenges from regulators might easily ignite and intertwine with the economic co-evolution challenges and thereby limit the ecosystem's building speed (Meyer and Peng, 2016; Parente et al., 2019). It thus becomes relevant to examine how new focal ventures combine different types of ecosystem-specific strategies, that is, the specific strategies used to simultaneously cope with multiple co-evolution challenges and better promote the ecosystem's viability. Under these circumstances, the current one-sided view of the challenge-strategy mechanism touted by a majority of scholars cannot fully explain the emerging ecosystem's development.

Third, ecosystem scholars emphasize their static view on the effectiveness of ecosystemspecific strategies in their research, assuming that once focal actors have executed these strategies effectively, they can align with non-focal actors firmly for all time and create a viable ecosystem (e.g., Iansiti and Levien, 2004; Li, 2009; Walrave et al., 2018). However, the overall process of ecosystem emergence and viability is iterative and time-consuming (Dedehayir et al., 2018). Thus, the intertemporal perspective of the effectiveness of ecosystem-specific strategies is worth investigating; that is, an ecosystem-specific strategy corresponding to one actor at one point of time affecting the effectiveness of the corresponding strategy of another actor at another point of time (Kaplan and Orlikowski, 2013), with long-term influence on ecosystem-level outcomes (see Holgersson et al., 2018). To the best of our knowledge, little insights are found in extant ecosystems literature on how new focal ventures can lever or avoid intertemporal interplay between ecosystem-specific strategies, that is, the strategizing forms used to cope with multiple co-evolution challenges and reap long-term ecosystem-level results.

From these research gaps, we formulate our research question as follows: "How can new focal ventures develop ecosystem-specific strategies to recognize and overcome a combination of economic, coopetitive, and socio-political co-evolution challenges so as to ensure a viable ecosystem?” To answer this research question, we conducted a multiple-case study (Eisenhardt 
and Graebner, 2007) on China’s emerging and fast-growing bike-sharing ecosystems from 2015 to 2018. Using rich qualitative process data (cf. Langley, 1999) and the critical incident technique (CIT; Flanagan, 1954), we examined how new focal ventures strategically recognized and overcame multiple co-evolution challenges from birth to expansion in two surviving and two failed bike-sharing ecosystems. These four young ecosystems, operating in a transitional institutional context, fit our research purpose because they underwent rapid growth for 18 months (2015 to early 2018) and encountered multiple developmental obstacles (Van Waes et al., 2018).

This study contributes to the ecosystem development literature by examining the strategizing forms that new focal ventures use to develop ecosystem-specific strategies and manage the ecosystem-level co-evolution challenges. More specifically, we identify and conceptualize three firm-level strategizing forms new focal ventures develop to achieve ecosystem-level competitiveness. First, via an effective niche experimentation (i.e., innovation experimentation with key ecosystem actors in small spatial locations), we show that new focal ventures can extend the ecosystem boundaries with economic and coopetitive as well as sociopolitical ecosystem environments and thereby create a more complete vision on emerging ecosystems. This allows for new focal ventures to better recognize the multiplicity of coevolution challenges, that is, economic and coopetitive as well as social and political challenges. This insight further suggests that the spatial context plays a key role in early-stage ecosystem development. Second, this study extends the current theorization on focal venture's ecosystemspecific strategies by considering the dynamic interactions between different ecosystemspecific strategies both in the same and across two different ecosystem environments as well as over time. We reveal that new focal ventures can overcome multiple co-evolution challenges by combining their different strategies in the form of strategic versatility and thus enable multiple and complex ecosystem actor interactions, to promote ecosystem development. This finding goes beyond the dominant view that ecosystem dynamics exist in a hub-and-spoke structure among focal and nonfocal actors. Third, we show that new focal ventures sacrifice instant individual benefits for long-term ecosystem-level competitiveness in the form of strategic suboptimality. This finding provides new insights into the negative and positive externalities in emerging ecosystem development and extends the burgeoning literature emphasizing the disadvantages of negative externalities for focal actors. Our finding offers a temporal dimension that can turn the disadvantages of negative externalities into ecosystemlevel competitive advantages and ensure the viability of emerging ecosystems. 


\subsection{THEORETICAL BACKGROUND}

\subsubsection{Repositioning the sociopolitical environment in emerging ecosystems}

To fully understand the development and viability of an emerging ecosystem (one lying between birth and expansion; Moore, 1996; Mahmoud-Jouini and Charue-Duboc, 2017), we need to take a holistic view of the key functional groups of actors (Dedehayir et al., 2018) and the dynamic interactions between them (Ma et al., 2018). Therefore, we use an institutional lens to conceptualize the emerging ecosystems and build on the work of ecosystem theorists who have recently introduced this lens to gain insights into ecosystem governance principles as well as actor coordination dynamics (Almpanopoulou et al., 2019; Autio and Thomas, 2014, 2018; Zhang and Wang, 2018).

We visualize the institutional lens of emerging ecosystems by positioning the sociopolitical environment as a separate yet explicitly connected layer to the economic and coopetitive environment (see Figure 3.1), inspired by Geels’s (2014) work on the innovation industry, which comprises two environments, and apply the rationale to the setting of emerging ecosystems. We thus reposition and integrate the sociopolitical environment in relation to what the ecosystem development literature considers the dominant economic and coopetitive environment, and examine the sociopolitical challenges and investigate how new focal ventures implement ecosystem-specific strategies collectively to address multiple co-evolution challenges. We conceptualize the latter as specific strategizing forms.

As depicted in Figure 3.1, we argue that an ecosystem's core includes new focal ventures and their competitors (e.g., rivals with competitive ecosystem solutions). On the one hand, these categorized actors compete in the same markets because they share innovation attributes, business processes, preliminary industrial identities and mindsets, and organizational arrangements (Moore, 1996). On the other hand, emerging ecosystems in their infancy must stay close to one another in order to collaborate and protect their new businesses (de Vasconcelos Gomes et al., 2018; Planko et al., 2019; Reeves et al., 2019; Rong and Shi, 2014). Furthermore, we embed the ecosystem's core into two ecosystem environments (Oliver, 1997; Scott, 2008). The economic ecosystem environment comprises direct value-creation and valuesupport actors as well as other extended material resource providers (Moore, 1996). The sociopolitical ecosystem environment encompasses sociopolitical actors such as (non)governmental agencies, social media, public discourses, and the broader public (cf. Dedehayir et al., 2018). 


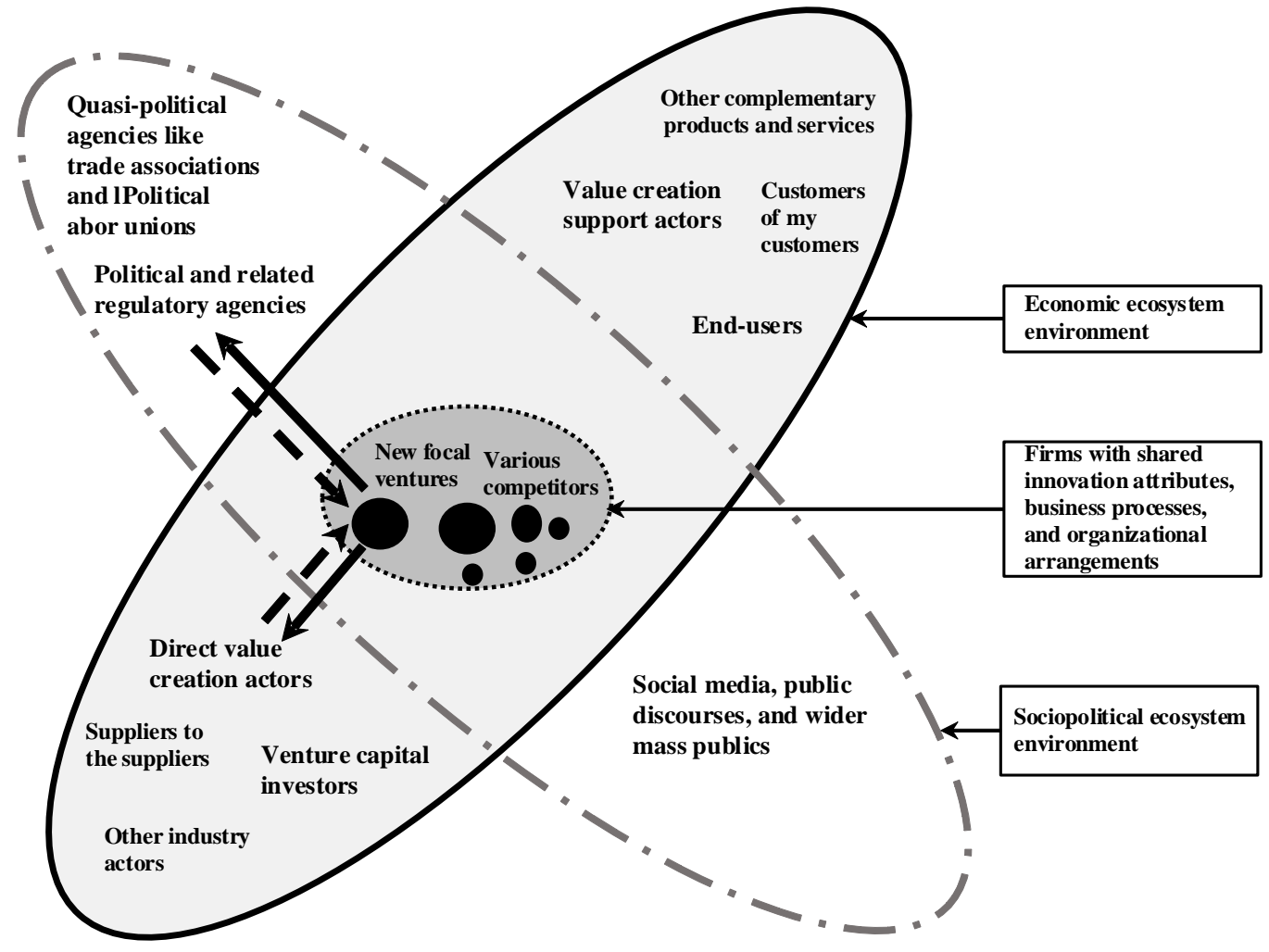

Note: First, this model follows the "core-peripheral" configuration developed by Moore (1996: 27). All non-focal actors co-evolving around proposed innovations (proposed by focal actors) are equally important for ecosystem development. It contrasts with Moore's original model, where non-focal actors are positioned based on value contributions to the innovations. Non-focal actors get closer to the ecosystem's core if their contributions are more direct. Second, this model integrates the institutional rationale from Geels (2014). Non-focal actors are positioned in two ecosystem environments in which co-evolution challenges prevail. Focal actors need to strategize to shape these actors and environments to their advantages.

Figure 3.1: Extended model on emerging ecosystem (from Moore [1996: 27], Geels [2014]).

Considering the ecosystem dynamics, Figure 3.1 shows that new focal ventures face multiple co-evolution challenges from various actors in the core and two environments (depicted as dashed arrows). Thus, for an ecosystem's emergence and viability, the main task of new focal ventures is to take strategic actions and shape the economic and coopetitive as well as, importantly, socio-political ecosystem actors (depicted as solid arrows) in their favor in order to maintain a leadership position (Autio and Thomas, 2018; Parente et al., 2019; Santos and Eisenhardt, 2009) and persuade the ecosystem participants to recognize a shared vision(s) and achieve ecosystem-level competitiveness (Liu and Rong, 2015; Snihur et al., 2018; Wareham et al., 2014). Thus, managing two ecosystem environments simultaneously is key to developing emerging ecosystems (Aarikka-Stenroos and Ritala, 2017; Oliver, 1997; Walrave et al., 2018). 


\subsubsection{Co-evolution challenges and ecosystem-specific strategies}

For new focal ventures, co-evolution challenges generally go "beyond the firm's usual internal boundaries to encompass external factors” (Adner, 2006, p. 9), representing firm-external obstacles related to collaboration with other actors, and inhibit the success of complex innovations (Adner and Kapoor, 2010; Liu and Rong, 2015). Scholars refer to co-evolution challenges more specifically as technological bottlenecks (Hannah and Eisenhardt, 2018) and interdependence risks (Adner, 2006, 2012) in the economic environment, competitive tensions in the ecosystem's core (Ansari et al., 2016), and institutional barriers in the sociopolitical environment (Almpanopoulou et al., 2019). We comprehensively combine these definitions by considering all the possible challenges related to collaborating and aligning with actors from the ecosystem's core and two environments, and inhibit the success of complex innovation under the common heading-co-evolution challenges (Adner, 2006).

Given the different definitions, the literature has identified four key co-evolution challenge types: economic, coopetitive, political, and social. Economic and coopetitive co-evolution challenges flow from the economic ecosystem environment and ecosystems' core (see Figure 3.1). These challenges relate to complementary resource reliance/shortages (Hellström et al., 2015; Joo and Shin, 2018; Kwak et al., 2018; Sandström, 2016) and competitive threats (Hedman and Henningsson, 2015; Planko et al., 2019), which are key to ecosystem development (Adner, 2006, 2012; Oliver, 1997). For instance, 3-D printing startups have struggled to connect to crowdfunding networks (Kwak et al., 2018) and pivotal technological partners (Sandström, 2016), and established traditional banks are exerting pressure on new mobile payment ecosystems (Hedman and Henningsson, 2015).

Social and political co-evolution challenges are arguably as critical as economic and coopetitive challenges for understanding ecosystem development. They arise from the sociopolitical ecosystem environment and refer to the obstacles (i.e., regulatory expectations, social fitness) that block the realization of co-created complex innovations (Walrave et al., 2018). Scholars have, for instance, noted that China's FEV ventures find it difficult to expand ecosystems owing to conflicting local and central government regulations (Rong et al., 2017), while Japan's mass media campaigns undermine the organic development of new energy ecosystems (Hara et al., 2015).

Along with co-evolution challenges, scholars have shown that new focal ventures should develop ecosystem-specific strategies to address these challenges (Autio and Thomas, 2014, 
2018). According to Adner (2017) and Ma and Hou (2020), the design and execution of ecosystem-specific strategies have the dual goal of creating ecosystem-wide competitiveness and keeping the focal actors' leadership role. In light of this rationale, economic strategies are designed to address economic co-evolution challenges by inviting the economic actors' contributions to complex innovations and commitment to emerging ecosystems. For instance, studies have shown that focal actors can strategically open their innovation platforms (Gawer and Cusumano, 2014; Liu and Rong, 2015; Zhang and Liang, 2011), share proprietary assets (Holgersson et al., 2018; Leten et al., 2013; Williamson and De Meyer, 2012), orchestrate synergetic knowledge and capabilities (Dhanaraj and Parkhe, 2006; Dougherty and Dunne, 2011; Hienerth et al., 2014; Ritala et al., 2013), and diffuse plausible ecosystem visions (Prince et al., 2014; Rong et al., 2017). Focal actors can thus co-create the ecosystems' complex innovations with non-focal complementors.

Furthermore, the literature theorizes on how focal actors manage their symbiotic relationships with competitors via coopetitive strategies (Planko et al., 2019) and thus address their coopetitive co-evolution challenges. On the one hand, focal ventures apply defensive strategies to collaborate with existing competitors and create mutual market areas, especially when their complex innovations are new to the market (Jones et al., 2020). They can also use offensive strategies to protect their market share and position by deliberately igniting price wars or setting higher market entry barriers (Hedman and Henningsson, 2015). On the other hand, they have to fend off the external disruptors whose identical competitive business models (Snihur et al., 2018) or more innovative customer solutions (Ansari et al., 2015) pose coopetitive tensions to focal ventures as well as the entire ecosystem.

Recent studies have also offered insights into how to solve sociopolitical co-evolution challenges (Autio and Thomas, 2014). For instance, focal ventures can use alternative corporate political strategies such as lobbying, strategic dialogue, and constituency building, which have different levels of effectiveness in influencing regulators in various contexts (see Dougherty and Dunne, 2011; Hara et al., 2015; Zhang and Wang, 2018). Moreover, new complex innovations have to satisfy socio-cultural expectations such as social fitness and lifestyle choices (Rong et al., 2017). Useful social strategies such as social framing (Randhawa et al., 2021; Russo-Spena et al., 2020; Snihur et al., 2018) and persuasion strategies (Hara et al., 2015) can help create a favorable social environment for the early ecosystems. 
Table 3.1: An overview of the ecosystem literature on co-evolution challenges and ecosystem-specific strategy ${ }^{\text {a }}$

\begin{tabular}{|c|c|c|c|c|c|}
\hline Authors & Research Question/Purpose & $\begin{array}{l}\text { Ecosystem } \\
\text { Environment } \\
\text { Focus }\end{array}$ & $\begin{array}{l}\text { Specific Co- } \\
\text { Evolution Challenge }\end{array}$ & $\begin{array}{l}\text { Proposed Ecosystem- } \\
\text { Specific Strategy }\end{array}$ & Ecosystem-Level Outcome \\
\hline $\begin{array}{l}\text { Zhang and } \\
\text { Liang (2011) }\end{array}$ & $\begin{array}{l}\text { To assess the keystone strategy of China } \\
\text { Mobile and to explore the success factors and } \\
\text { problems of China Mobile's strategy. }\end{array}$ & $\begin{array}{l}\text { Economic } \\
\text { environment }\end{array}$ & $\begin{array}{l}\text { Economic } \\
\text { challenges }\end{array}$ & $\begin{array}{l}\text { Economic (keystone) } \\
\text { strategies }\end{array}$ & $\begin{array}{l}\text { Ecosystem emergence and } \\
\text { viability }\end{array}$ \\
\hline $\begin{array}{l}\text { Rong et al. } \\
\text { (2015) }\end{array}$ & $\begin{array}{l}\text { How firms follow the business ecosystem } \\
\text { approach to enter a foreign market and deal } \\
\text { with complex, untraditional challenges. }\end{array}$ & $\begin{array}{l}\text { Economic } \\
\text { environment }\end{array}$ & $\begin{array}{l}\text { Economic } \\
\text { challenges }\end{array}$ & $\begin{array}{l}\text { Economic (orchestration) } \\
\text { strategies }\end{array}$ & Ecosystem emergence \\
\hline $\begin{array}{l}\text { Hedman and } \\
\text { Henningsson } \\
(2015)\end{array}$ & $\begin{array}{l}\text { To explain how the digitization of payments } \\
\text { affects competition and collaboration among } \\
\text { traditional and new stakeholders of the } \\
\text { payments ecosystem. }\end{array}$ & $\begin{array}{l}\text { Coopetitive } \\
\text { environment }\end{array}$ & $\begin{array}{l}\text { Coopetitive } \\
\text { challenges }\end{array}$ & Coopetitive strategies & $\begin{array}{l}\text { Individual leadership roles } \\
\text { in ecosystems and } \\
\text { ecosystem stability }\end{array}$ \\
\hline $\begin{array}{l}\text { Ansari et al. } \\
(2016)\end{array}$ & $\begin{array}{l}\text { What are the challenges that an entrant, } \\
\text { especially a start-up firm, confronts in } \\
\text { introducing a disruptive innovation into an } \\
\text { ecosystem, and how does it address them. }\end{array}$ & $\begin{array}{l}\text { Coopetitive } \\
\text { environment }\end{array}$ & $\begin{array}{l}\text { Coopetitive } \\
\text { challenges }\end{array}$ & $\begin{array}{l}\text { (Temporal) Coopetitive } \\
\text { strategies }\end{array}$ & $\begin{array}{l}\text { No ecosystem-level outcome } \\
\text { Inter-organizational levels: } \\
\text { less coopetitive tensions } \\
\text { with competitive incumbents }\end{array}$ \\
\hline $\begin{array}{l}\text { Hara et al. } \\
(2015)\end{array}$ & $\begin{array}{l}\text { To examine mechanisms of how orchestrators } \\
\text { align peripheral ecosystem actors. }\end{array}$ & $\begin{array}{l}\text { Socio-political } \\
\text { environment }\end{array}$ & Societal challenges & $\begin{array}{l}\text { Social (persuasion) } \\
\text { strategies }\end{array}$ & Ecosystem adaptability \\
\hline $\begin{array}{l}\text { Joo and Shin } \\
\text { (2018) }\end{array}$ & $\begin{array}{l}\text { To examine effects of customer participation } \\
\text { on creating economic value and social value } \\
\text { within the business ecosystem. }\end{array}$ & $\begin{array}{l}\text { Economic } \\
\text { environment }\end{array}$ & $\begin{array}{l}\text { Economic } \\
\text { challenges }\end{array}$ & $\begin{array}{l}\text { Economic (orchestration) } \\
\text { strategies }\end{array}$ & $\begin{array}{l}\text { Ecosystem-level } \\
\text { sustainability }\end{array}$ \\
\hline $\begin{array}{l}\text { Dattée et al. } \\
\text { (2018) }\end{array}$ & $\begin{array}{l}\text { How does an ecosystem champion compel } \\
\text { others to commit to a de novo ecosystem } \\
\text { creation effort. }\end{array}$ & $\begin{array}{l}\text { Economic } \\
\text { environment }\end{array}$ & $\begin{array}{l}\text { Economic } \\
\text { challenges }\end{array}$ & $\begin{array}{l}\text { Economic (visioning and } \\
\text { orchestration) strategies }\end{array}$ & $\begin{array}{l}\text { Emergence and viability of } \\
\text { early-stage ecosystems }\end{array}$ \\
\hline $\begin{array}{l}\text { Planko et al. } \\
\text { (2019) }\end{array}$ & $\begin{array}{l}\text { How focal actors building an innovation } \\
\text { ecosystem minimize the inherent risks of } \\
\text { collaborating with competitors. }\end{array}$ & $\begin{array}{l}\text { Coopetitive } \\
\text { environment }\end{array}$ & $\begin{array}{l}\text { Coopetitive } \\
\text { challenges }\end{array}$ & $\begin{array}{l}\text { Economic (orchestration) } \\
\text { strategies }\end{array}$ & $\begin{array}{l}\text { No ecosystem-level outcome } \\
\text { less coopetitive tensions } \\
\text { with key complementors }\end{array}$ \\
\hline $\begin{array}{l}\text { Gupta et al. } \\
\text { (2020) }\end{array}$ & $\begin{array}{l}\text { To analyze early firm strategy for the } \\
\text { emerging global EV industry that resulted in } \\
\text { higher growth pockets. }\end{array}$ & $\begin{array}{l}\text { Economic } \\
\text { environment }\end{array}$ & $\begin{array}{l}\text { Economic } \\
\text { challenges }\end{array}$ & $\begin{array}{l}\text { Economic (positioning) } \\
\text { strategies }\end{array}$ & Ecosystem emergence \\
\hline $\begin{array}{l}\text { Masucci et } \\
\text { al. (2020) }\end{array}$ & $\begin{array}{l}\text { How can the hub firm remove technological } \\
\text { bottlenecks in the business ecosystem. }\end{array}$ & $\begin{array}{l}\text { Economic } \\
\text { environment }\end{array}$ & $\begin{array}{l}\text { Economic } \\
\text { challenges }\end{array}$ & $\begin{array}{l}\text { Economic (outbound } \\
\text { open innovation) } \\
\text { strategies }\end{array}$ & Ecosystem viability \\
\hline $\begin{array}{l}\text { Russo-Spena } \\
\text { et al. (2020) }\end{array}$ & $\begin{array}{l}\text { How innovation ecosystems emerge and } \\
\text { become established. }\end{array}$ & $\begin{array}{l}\text { Economic } \\
\text { environment }\end{array}$ & $\begin{array}{l}\text { Economic } \\
\text { challenges }\end{array}$ & $\begin{array}{l}\text { Economic (orchestration) } \\
\text { and social (framing) } \\
\text { strategies }\end{array}$ & $\begin{array}{l}\text { Ecosystem emergence and } \\
\text { viability }\end{array}$ \\
\hline
\end{tabular}




\begin{tabular}{|c|c|c|c|c|c|}
\hline Authors & Research Question/Purpose & $\begin{array}{l}\text { Ecosystem } \\
\text { Environment } \\
\text { Focus } \\
\end{array}$ & $\begin{array}{l}\text { Specific Co- } \\
\text { Evolution Challenge }\end{array}$ & $\begin{array}{l}\text { Proposed Ecosystem- } \\
\text { Specific Strategy }\end{array}$ & Ecosystem-Level Outcome \\
\hline $\begin{array}{l}\text { Ritala et al. } \\
\text { (2013) }\end{array}$ & $\begin{array}{l}\text { To explore mechanisms related to how leading } \\
\text { firms may facilitate value creation and capture } \\
\text { in ecosystem context. }\end{array}$ & $\begin{array}{l}\text { Economic and } \\
\text { socio-political } \\
\text { environment }\end{array}$ & Economic challenges & $\begin{array}{l}\text { Economic (keystone and } \\
\text { orchestration) strategies }\end{array}$ & $\begin{array}{l}\text { No ecosystem-level outcome } \\
\text { Individual value capture } \\
\text { within ecosystems }\end{array}$ \\
\hline $\begin{array}{l}\text { Rong et al. } \\
\text { (2017) }\end{array}$ & $\begin{array}{l}\text { In a comparison of Chinese and European EV } \\
\text { industries, how do the focal companies } \\
\text { manage their business ecosystems. }\end{array}$ & $\begin{array}{l}\text { Economic and } \\
\text { socio-political } \\
\text { environment }\end{array}$ & $\begin{array}{l}\text { Economic and socio- } \\
\text { political challenges }\end{array}$ & $\begin{array}{l}\text { Economic (visioning, } \\
\text { platform management) } \\
\text { and political (institution } \\
\text { reconfiguring) strategies }\end{array}$ & $\begin{array}{l}\text { Ecosystem emergence and } \\
\text { viability }\end{array}$ \\
\hline $\begin{array}{l}\text { Hannah and } \\
\text { Eisenhardt } \\
\text { (2018) }\end{array}$ & $\begin{array}{l}\text { How do firms successfully balance } \\
\text { competition and cooperation over time in } \\
\text { ecosystems. }\end{array}$ & $\begin{array}{l}\text { Economic and } \\
\text { coopetitive } \\
\text { environment }\end{array}$ & $\begin{array}{l}\text { Economic and } \\
\text { coopetitive } \\
\text { challenges }\end{array}$ & $\begin{array}{l}\text { Coopetitive (bottleneck, } \\
\text { system, component) } \\
\text { strategies }\end{array}$ & $\begin{array}{l}\text { New ecosystem survival and } \\
\text { growth }\end{array}$ \\
\hline $\begin{array}{l}\text { Snihur et al. } \\
\text { (2018) }\end{array}$ & $\begin{array}{l}\text { How does a disruptive BM innovator align } \\
\text { framing and adaptation of its business model } \\
\text { over the disruption process. }\end{array}$ & $\begin{array}{l}\text { Economic and } \\
\text { coopetitive } \\
\text { environment }\end{array}$ & $\begin{array}{l}\text { Economic and } \\
\text { coopetitive } \\
\text { challenges }\end{array}$ & $\begin{array}{l}\text { Social (framing) } \\
\text { strategies }\end{array}$ & $\begin{array}{l}\text { New ecosystem emergence } \\
\text { and rapid growth }\end{array}$ \\
\hline $\begin{array}{l}\text { Holgersson } \\
\text { et al. (2018) }\end{array}$ & $\begin{array}{l}\text { To analyze the co-evolution of strategic IP } \\
\text { management and innovation ecosystems. }\end{array}$ & $\begin{array}{l}\text { Economic and } \\
\text { coopetitive } \\
\text { environment }\end{array}$ & $\begin{array}{l}\text { Economic and } \\
\text { coopetitive } \\
\text { challenges }\end{array}$ & $\begin{array}{l}\text { Economic (intellectual } \\
\text { property) strategies }\end{array}$ & $\begin{array}{l}\text { Individual leadership roles } \\
\text { and ecosystem long-term } \\
\text { competitiveness }\end{array}$ \\
\hline $\begin{array}{l}\text { Jones et al. } \\
(2020)\end{array}$ & $\begin{array}{l}\text { How does interfirm cooperation in innovation } \\
\text { ecosystems evolve in the face of conflict. }\end{array}$ & $\begin{array}{l}\text { Economic and } \\
\text { coopetitive } \\
\text { environment }\end{array}$ & $\begin{array}{l}\text { Coopetitive } \\
\text { challenges }\end{array}$ & $\begin{array}{l}\text { (Dual) cooperative } \\
\text { strategies }\end{array}$ & $\begin{array}{l}\text { Balanced coopetitive } \\
\text { tensions within ecosystems }\end{array}$ \\
\hline $\begin{array}{l}\text { de } \\
\text { Vasconcelos } \\
\text { Gomes et al. } \\
\text { (2018) }\end{array}$ & $\begin{array}{l}\text { How do entrepreneurs manage collective } \\
\text { uncertainties in the innovation ecosystem. }\end{array}$ & $\begin{array}{l}\text { Economic, } \\
\text { coopetitive, socio- } \\
\text { political } \\
\text { environment }\end{array}$ & $\begin{array}{l}\text { Economic and } \\
\text { Coopetitive and } \\
\text { socio-political } \\
\text { challenges }\end{array}$ & $\begin{array}{l}\text { Economic } \\
\text { (experimentation and } \\
\text { platform-based) } \\
\text { strategies }\end{array}$ & $\begin{array}{l}\text { No ecosystem-level outcome } \\
\text { Firm-level survival }\end{array}$ \\
\hline $\begin{array}{l}\text { Zhang and } \\
\text { Wang } \\
\text { (2018) }\end{array}$ & $\begin{array}{l}\text { How Alibaba managed the formalization of } \\
\text { dominant business ecosystem logics at and } \\
\text { across the macro (national), industry, and } \\
\text { business ecosystem levels. }\end{array}$ & $\begin{array}{l}\text { Economic, } \\
\text { coopetitive, socio- } \\
\text { political } \\
\text { environment }\end{array}$ & $\begin{array}{l}\text { Economic and } \\
\text { Coopetitive and } \\
\text { socio-political } \\
\text { challenges }\end{array}$ & $\begin{array}{l}\text { Economic (keystone) and } \\
\text { political } \\
\text { (institutionalization- } \\
\text { influencing) strategies }\end{array}$ & $\begin{array}{l}\text { Ecosystem emergence and } \\
\text { viability }\end{array}$ \\
\hline $\begin{array}{l}\text { Randhawa et } \\
\text { al. (2021) }\end{array}$ & $\begin{array}{l}\text { How an incumbent firm approached the } \\
\text { constraints, and used cognitive artifacts to } \\
\text { transform its value chain into a collaborative } \\
\text { ecosystem. }\end{array}$ & $\begin{array}{l}\text { Economic, } \\
\text { coopetitive, socio- } \\
\text { political } \\
\text { environment }\end{array}$ & $\begin{array}{l}\text { Economic and } \\
\text { Coopetitive and } \\
\text { socio-political } \\
\text { challenges }\end{array}$ & $\begin{array}{l}\text { Economic } \\
\text { (experimentation and } \\
\text { open innovation) and } \\
\text { social (cognitive } \\
\text { framing) strategies }\end{array}$ & Ecosystem emergence \\
\hline
\end{tabular}


Table 3.1 summarizes the extant empirical studies on the four-dimensional co-evolution challenges flowing from the ecosystem's core and two environments, as well as the suggested ecosystem-specific strategies available to new focal ventures and the resulting ecosystem-level outcomes.

\subsubsection{Our proposed conceptual framework}

An examination of the literature in Table 3.1 on ecosystem development and the co-evolution challenges, ecosystem-specific strategies, and ecosystem-level outcomes has revealed two gaps.

First, of the twenty reviewed papers, only six have considered the sociopolitical environment. However, as the Better Place case has illustrated in the Introduction, besides their enabling or insignificant role played in the early growth stages of ecosystems, peripheral sociopolitical actors exert significant restrictions on e ecosystems' development, particularly the emerging public good-related ecosystems (Ansari et al., 2016; Li and Garnsey, 2014; Overholm, 2015; Pierce, 2009; Snihur et al., 2018). Their inability to recognize and overcome the effects of sociopolitical actors might hamper new focal ventures from effectively designing and executing ecosystem-specific strategies addressing multiple co-evolution challenges.

Second, a few studies (reviewed in Table 3.1) have considered the criticality of the economic, coopetitive, and/or socio-political co-evolution challenges to ecosystem outcomes (e.g., emergence and viability). The empirical results of these studies show that the focal actors should execute effective ecosystem-specific strategies to address the corresponding coevolution challenges, that is, by addressing economic challenges via economic strategies and political challenges via political strategies (de Vasconcelos Gomes et al., 2018; Randhawa et al., 2021; Zhang and Wang, 2018). The one-sided view of designing and implementing focal ventures' ecosystem-specific strategies might limit our understanding of the interactive effects of different ecosystem-specific strategies on ecosystem development. However, this is relevant because ecosystem actors in emerging ecosystems are interdepended multilaterally (Adner, 2017; Jacobides et al., 2018) and the different co-evolution challenges from heterogeneous non-focal actors are not set beforehand but usually happen simultaneously, and are sometimes intricately intertwined (Hannah and Eisenhardt, 2018; Suarez and Oliva, 2005).

Moreover, the empirical studies in Table 3.1 suggest that focal actors should consider only the maximized short-term effectiveness of each ecosystem-specific strategy to tie up with nonfocal actors firmly (Iansiti and Levien, 2004; Li, 2009; Walrave et al., 2018). This static view of designing and implementing ecosystem-specific strategies mismatches with ecosystem 
reality. The process of building viable ecosystems is not linear or short-term oriented, but highly iterative and time-consuming (Dedehayir et al., 2018). An ecosystem-specific strategy corresponding to one actor at one point of time might affect the effectiveness of the corresponding strategy of another actor at another point of time (Kaplan and Orlikowski, 2013) and thereby have a long-term influence on ecosystem-level outcomes (see Holgersson et al., 2018). The intertemporal interplay between ecosystem-specific strategies has not been examined in the literature, thus limiting our understanding of how new focal ventures manage their intertemporal interplay between ecosystem-specific strategies to their advantage and achieve long-term ecosystem-level competitiveness, especially considering the high uncertainties in early-stage ecosystems (Dattée et al., 2018).

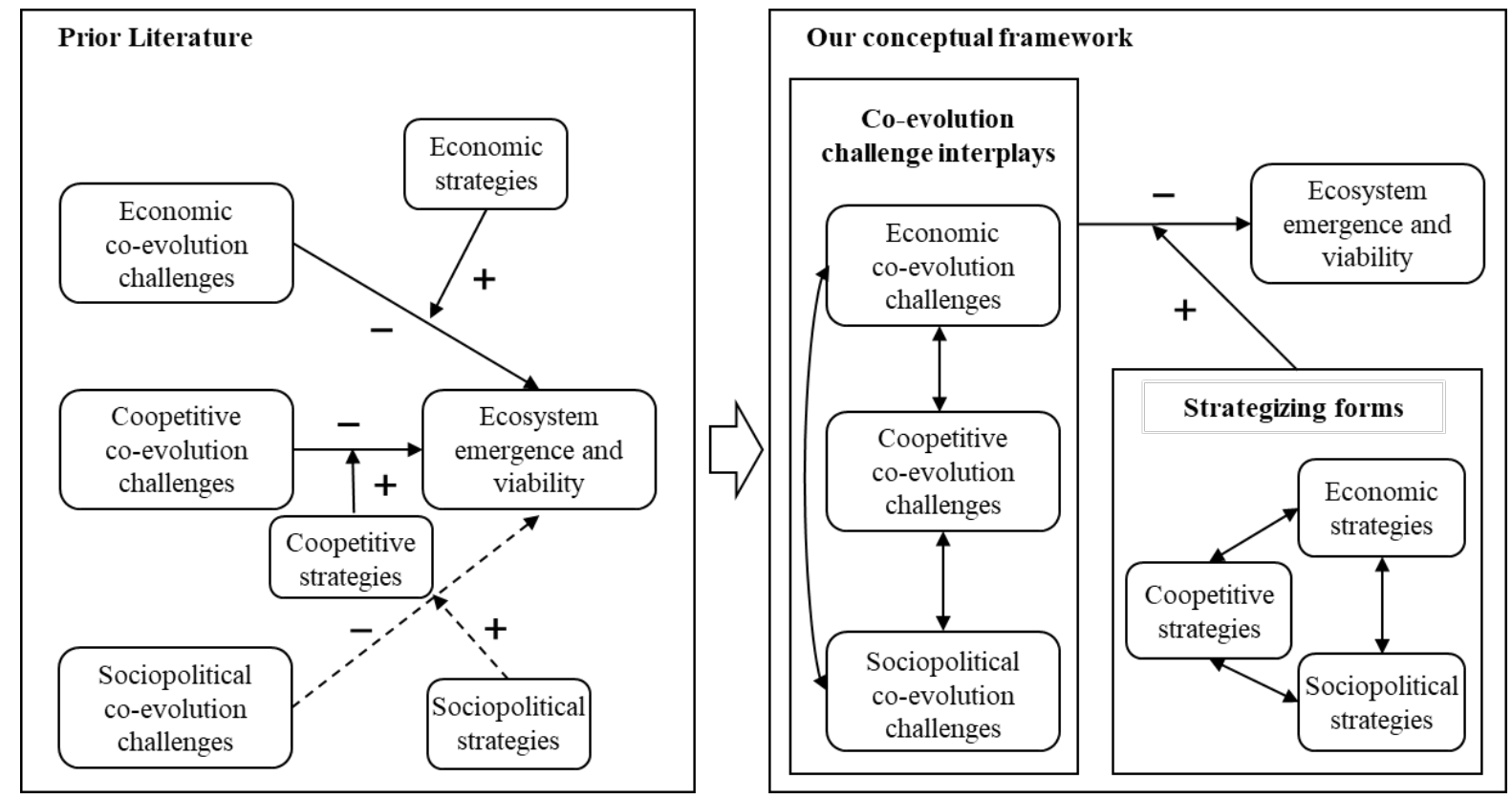

Note: “-” indicates that co-evolution challenges hamper ecosystem's emergence and viability; "+ ” indicates that ecosystem-specific strategies help overcome co-evolution challenges, thereby driving ecosystem's emergence and viability. Two-sided arrows represent the cross-sectional or intertemporal dynamic interactions.

Figure 3.2: Conceptual framework of this study.

To sum up, the extant ecosystem literature (1) explores four major co-evolution challenges that new focal ventures may encounter and (2) suggests ecosystem-specific strategies for focal ventures. However, it does not clarify how new focal ventures can recognize the four coevolution challenges holistically as the occurrence of different co-evolution challenges is unforeseeable and very often complexly intertangled in early-stage ecosystems. Besides, the current one-sided and static views on the focal actors' design and implementation of ecosystem-specific strategies fail to explain the ecosystem-level (long-term) outcomes (see the 
left-hand side box in Figure 3.2). To address these gaps, we propose our conceptual framework in the right-hand side box in Figure 3.2. We consider the multiplicity of co-evolution challenges by equalizing the sociopolitical actors, assuming that these challenges occur simultaneously and affect one another. Moreover, we specifically name the strategic activities and actions that enable the holistic recognition and integrative resolution of multiple co-evolution challenges in strategizing forms. We investigate specifically the strategizing forms exceeding the current one-sided and static effects of ecosystem-specific strategies. Considering the right-hand side box in Figure 3.2, we ask as to how new focal ventures can develop ecosystem-specific strategies, that is, what specific strategizing forms can be used to recognize and overcome multiple (economic, coopetitive, and socio-political) co-evolution challenges and ensure a viable ecosystem.

\subsection{METHODOLOGY}

\subsubsection{Research setting}

We deepen our understanding of emerging ecosystem development by adopting a more holistic view of the underexplored ecosystem dynamics of the co-evolution challenges and ecosystemspecific strategies, thus conceptualizing the specific strategizing forms new focal ventures implement to address the multiplicity of co-evolution challenges. For this, we employ a qualitative approach using the inductive case study method. We use a multiple-case study research design, which has the advantage of increasing the external validity of our theorization, facilitating theory replication and leading to a more generalizable theory (Eisenhardt, 1989; Eisenhardt and Graebner, 2007; Yin, 2013). Figure 3.3 presents our methodological strategies.

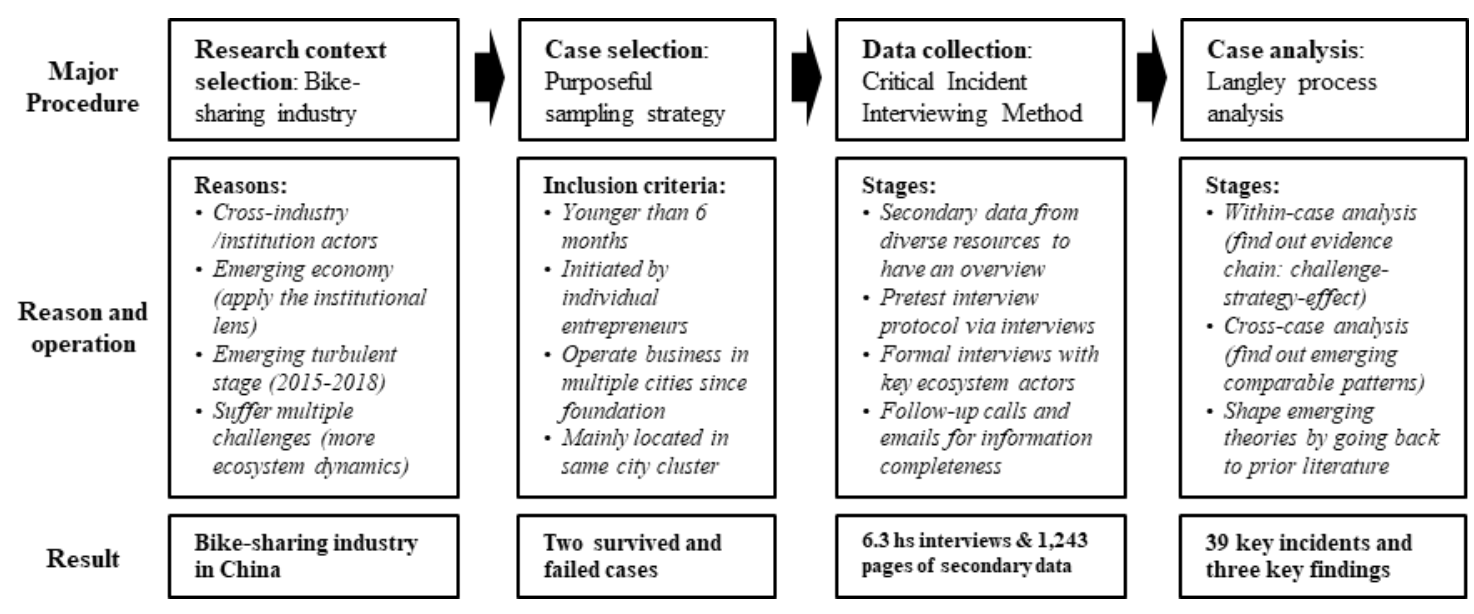

Figure 3.3: Overview of methodological strategies. 
We chose China's bike-sharing industry as the ecosystem research context for three major reasons. First, focusing on an emerging rather than mature economy (e.g., Western Europe, North America) is rewarding because institutional voids (especially legal systems) in the former cause ambitious entrepreneurs to face the market uncertainties and opportunities (Meyer and Peng, 2016; Parente et al., 2019). Second, dockless bike sharing managed by commercial ventures rather than local governments is an emerging (public transportation) industry that has attracted various cross-industry/geography/institution participants in China and grown rapidly since 2015 (Ma et al., 2018). The rapid rise in China’s bike-sharing industry can be attributed to the country's technology and market readiness. The large number of smartphone users as well as high mobile payment penetration rates in China (L'Huillier, 2017) makes it easy for fintech startups to reach a vast market cheaply. The relevant technologies, such as GPS tracking, solar energy, and narrow-band Internet of Things (NB-IoT), have matured and become widely applicable. They make dockless bikes traceable, reducing the losses due to theft and travel to less undesirable destinations. The ongoing urbanization of several Chinese cities has created severe first- and last-kilometer connectivity challenges for city dwellers. Dockless bike sharing offers a good value proposition to this challenge by providing wider coverage and multiple application scenarios; it also helps ease the weekday commuting, traffic congestion, and air pollution problems (Zhang et al., 2015). After 18 months of rapid growth, the industry hit a plateau in the first quarter of 2018. This turbulent (i.e., ambiguous, unpredictable, fast-paced) period is suitable for research focus because it presents various ecosystem dynamics. Third, new bike-sharing services had to initially face reactions from the public and government agencies, fierce competition, and threats from China's Internet giants all at once (Ma et al., 2018; Van Waes et al., 2018); this allowed us to observe the focal actors' strategic actions.

\subsubsection{Case selection}

We selected two survival and two failed cases from a population of 77 candidates with similar bike-sharing service business models in China (see Figure 3.3). For this, we first identified four focal ventures. All of them were (1) younger than six months (founded before the spring of 2017, that is, prior to the industry's strong development), (2) independently initiated by entrepreneurs, (3) not single-city operators, and (4) located in the Jing-Jin-Ji metropolitan cluster (known as "Beijing-Tianjin-Hebei” [BJ-TJ-HB] or the "National Capital Region of China”). For each new focal venture, we identified the economic actors, close competitors, and sociopolitical actors, to determine the actor boundaries for the four bike-sharing ecosystems. 
We considered these four carefully selected and extreme cases as representative and capable of providing interesting comparable insights (Eisenhardt, 1989).

The two survival cases, which we labelled Redbike and Yellowbike, pioneered the novel bike-sharing business model and the industry's development with a combined market share of over $90 \%$ following the industry boom. Redbike started in 2015 with support from an angel investor. It developed smart lock technologies and tested its business model in Shanghai until November 2016. It then decided to expand massively into China. Yellowbike was founded by student entrepreneurs in Beijing in 2014. They tried several business models and finally decided on a bike-sharing service as their business focus. They began to operate bikes outside their campus in October 2016 when, as several respondents noted, "the scuffles began.”

In contrast, the two failed cases, Bluebike and Greenbike, which were strong market competitors, ceased business after one year of operation. Bluebike shifted its focus from racing bike manufacturing to bike-sharing services in mid-November 2016. It attracted huge investment and a large customer base with its extremely comfortable bikes. From spring to summer 2017, it was rated among the top three bike-sharing services. However, owing to its strategic failure in marketing and fundraising, Bluebike had to cease operation in November 2017. Greenbike started at the same time as Bluebike. Its chief executive officer (CEO) was the only investor. From spring 2017, the firm's customer based increased 40-fold, from 100,000 to 4 million, in just four months. However, it had to file for bankruptcy in November 2017 owing to its failure to raise funds and from salient social criticisms of its operations.

\subsubsection{Data collection}

We drew our data primarily from 22 semi-structured interviews and 11 publicly available online interviews. Besides these interviews with selected ventures, we complemented our data with interviews of various ecosystem actors, including senior managers from related strategic suppliers, business partners, bike-sharing experts, social reporters, and political and quasipolitical agencies. We applied the snowball strategy to obtain additional interviewees. All respondents were anonymized for confidentiality reasons. Moreover, we triangulated our data using six secondary resource types, such as quarterly industrial reports, regulatory documents, and open company documents (see Appendix 3.1). In total, we obtained 26.3 hours of recorded interviews and 1,243 double-spaced pages of secondary data resources.

Face-to-face interviews were conducted based on an interview protocol, the key concepts of which are summarized in Table 3.1. In the protocol, the co-evolution challenges related to 
the potential and practical problems (or synonymous concepts such as obstacles, risks, and threats) faced by new focal ventures while collaborating and aligning with other ecosystem actors during ecosystem development. The ecosystem-specific strategies related to the focal ventures' emergent or deliberate action to address external problems (Mintzberg and Waters, 1985). We operationalized the ecosystem-specific strategies into economic, coopetitive, political, and social types. We tested and then adjusted the interview protocol during two pilot interviews with Redbike's international business partners and one informal communication with a Redbike insider (see Appendix 3.2).

We applied CIT (Flanagan, 1954; see Maguire et al. [2004] for an example in institutional research) to collect the required information. This approach allowed us to consider a clear temporal order and sequence with a discrete set of events based on a story or historical narrative (Pentland, 1999; Van de Ven and Huber, 1990). We started with questions providing the respondents with a holistic understanding of the bike-sharing ecosystem. We then followed up with the main interview questions asking the informants to chronologically describe at least one recent incident they regarded as (1) an example of struggling to develop and commercialize bike-sharing services and (2) critical for explaining how focal ventures respond to co-evolution challenges. For relevance, the events or incidents had to be fairly successful (positive) or unsuccessful (negative).

To ensure accurate and completely process-based information, the interviewer (the first author) sometimes asked the respondents to provide additional factual details through questions such as How do you know? What happened next? What did this lead to? or Who was affected? To avoid disrupting the respondents' thought process, these explanatory questions were raised after describing an entire event or incident. For the interviewees unable to recall any (especially negative) event or incident, we prepared a list of categorized incidents (143, 102, 33, and 16 incidents about Redbike, Yellowbike, Bluebike, and Greenbike, respectively) from two Chinese entrepreneurship service dot-coms (huxiu.com and 36kr.com). The interviewees were asked to complement, correct, or delete these incidents from our list and to add something in addition about the unsuccessful or negative ones on the list. To ensure that the accounts were complete and accurate, we also used follow-up calls and e-mails asking for additional information when necessary. All interviews were transcribed, coded, and analyzed using NVivo 11 software.

\subsubsection{Data analysis}


Our data analysis involved two steps: within-case analysis and cross-case analysis (Eisenhardt, 1989). For within-case analysis, we used process-analyzing strategies (Langley, 1999; Pentland, 1999; Van de Ven, 1992). We first assessed and identified the co-evolution challenges. Thus, we found and chronologically constructed 39 key incidents (see Figure 3.4), each of which included elements such as time, place, events, and actors. We also found the co-evolution challenges and critical incidents in our setting highly correlated (e.g., the incident Central government released industry guidelines is both a key event and co-evolution challenge). Specifically, we identified the major co-evolution challenges building on interview transcripts wherein respondents expressed serious problems, troubles, risks, or obstacles challenging their ability to offer bike-sharing services with other ecosystem actors. We enhanced the completeness of information from the incident lists captured online, which also described the challenges (and synonymous concepts) that new focal ventures faced. We then juxtaposed the detailed information of secondary narratives from direct interviews, confirming seven to eleven major co-evolution challenges for each case. Each co-evolution challenge was supported and thus triangulated by at least two evidentiary quotations.

We then confirmed the new focal ventures' ecosystem-specific strategies and their correlations to co-evolution challenges. We again relied on the critical incidents arising from their close relationship with strategic actions and activities (e.g., releasing a new bike-sharing version is both a key event and economically strategic action). Any strategic action by a focal bike-sharing venture could be considered as long as it was executed to address a co-evolution challenge we had confirmed. For this analysis, we used various strategy definitions and relevant indicators to help find the temporal challenge-strategy links in the data.

Finally, we considered the interactive effects of ecosystem-specific strategies; this was a step forward in conceptualizing specific strategizing forms the new focal ventures implemented. We repeated the previous analysis to identify the ecosystem-specific strategies, but this time we identified the relationship between the implemented strategies. We could identify the ecosystem-specific strategies' “extra” (in)effectiveness from the informants' statements such as "this activity has further roles in," "it can immediately help to solve another issue," or "it causes an extra problem such as ....” We designated the positive/negative strategizing effects as symbols + or - after confirming such links with relevant quotations in the data.

From the above, we could integrate all the identified challenge-strategy-effect patterns (as illustrated in Appendix 3.3) on the basis of their causal progressions of explanation and understanding. When we arrived at a defensible interpretation, we could inductively formulate 
storylines for individual ecosystem co-evolution processes, to serve as the basis of within-case analysis. The first author completed the case drafts, while the second and third co-authors reviewed them independently. When conflicts arose, we reviewed our dataset for corroborative evidence and used data from secondary sources (Eisenhardt, 1989; Miles et al., 2014). To ensure the validity of our findings, we compared them with the information in industrial reports, company white papers, news media, and other documents. Furthermore, we checked some key information with industry insiders and experts. When we identified information gaps, we iteratively searched various data resources for clarification or complementary information. As the write-up evolved, all the narratives were read and commented on by authors and key informants, and adjusted as needed.

Following the within-case analysis, our cross-case analysis confirmed the similarities and differences between the four cases concerning emerging patterns (Miles et al., 2014). Following the same approach as in Overholm (2015) and Santos and Eisenhardt (2009), we initially compared the surviving cases. From the tentative constructs, we added another two cases to develop more robust ones. Thus, the authors could note and carefully discuss all the plausible theoretical constructs that were essentially similar. We sharpened the conceptual meanings of these newly emerged constructs by frequently linking back to the literature (Eisenhardt, 1989). Once we reached a close and satisfactory match between the data and theory, and were confident to build logical arguments and clarify our contributions, we ended the comparison process. This iterative analysis resulted in the data structure presented in Figure 3.5. 
2017

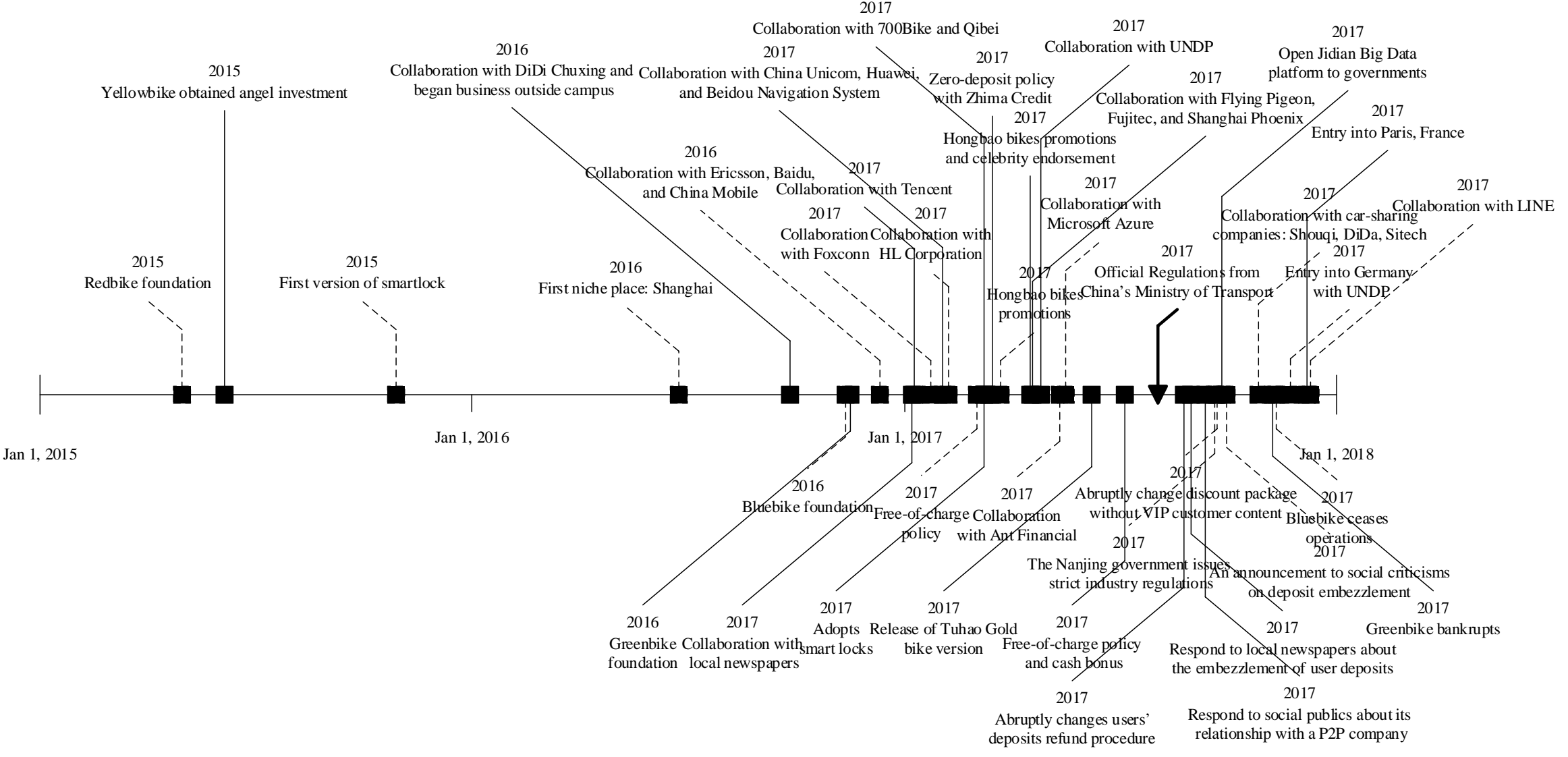

Note: The square and triangle arrows serve the purpose of chronological visualization of critical events. The 11 dotted and 11 solid square arrows upper upon the timeline respectively represent Redbike's and Yellowbike's critical events; 7 dotted and 9 solid square arrows under the timeline respectively show critical events of Bluebike and Greenbike. The thick solid triangle arrow denotes the industrial turning point. It is based on qualitative integration derived from interviewee's statements, industrial documents, and newspapers.

Figure 3.4: Chronology of key events. 


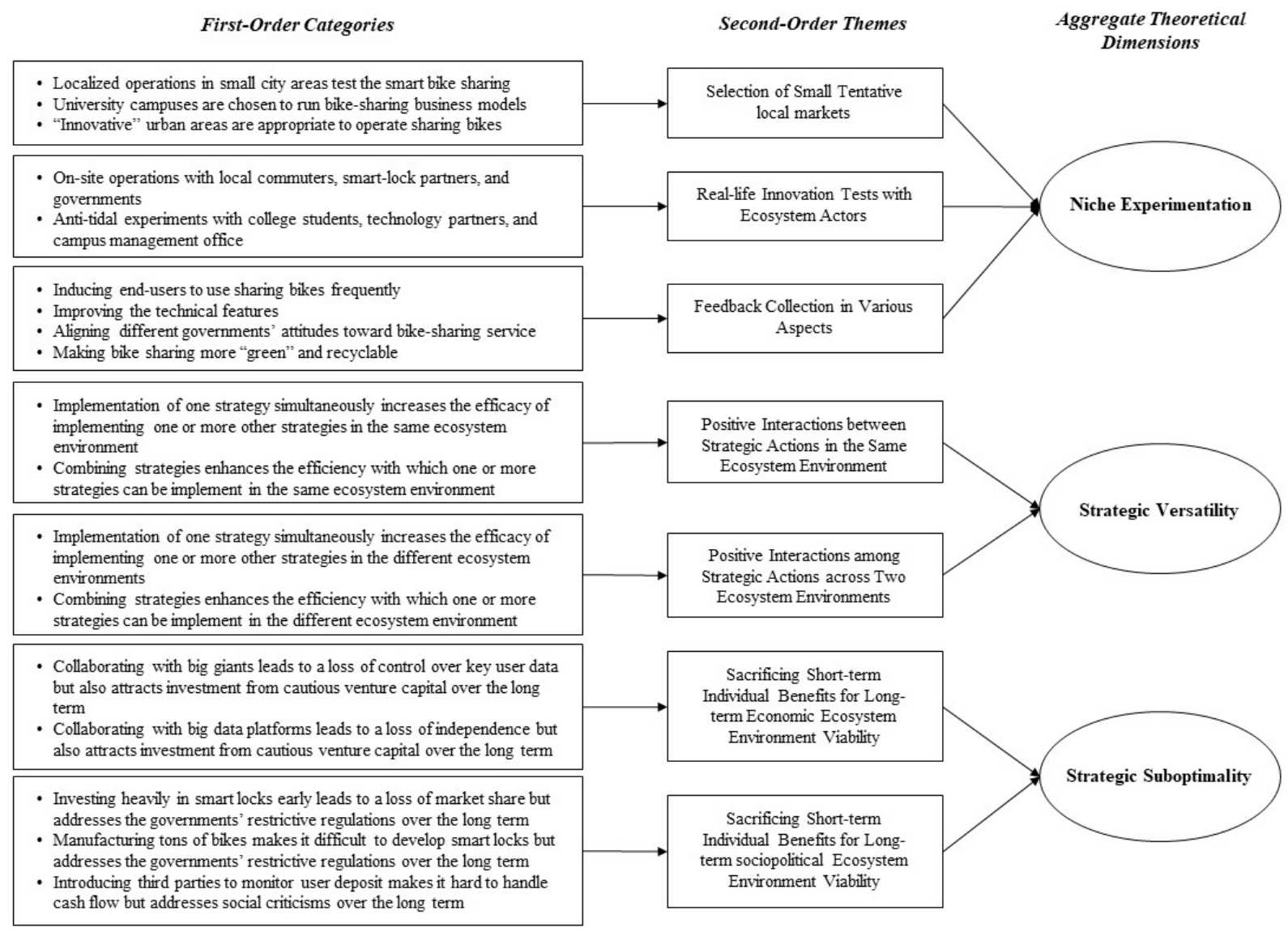

Figure 3.5: Data structure.

\subsection{FINDINGS}

Three key findings on specific strategizing forms emerged from our within- and cross-case analyses (see Appendix 3.3). First, we identified one strategizing form by which new focal ventures make sense of their emerging ecosystems by recognizing the multiplicity of coevolution challenges. We then discussed the other two strategizing forms by which new focal ventures can simultaneously and effectively deal with multiple co-evolution challenges and lead to emerging ecosystem development.

\subsubsection{Recognizing co-evolution challenges from two ecosystem environments: niche experimentation}

The results of the following case analysis indicate that new focal ventures must first determine who might pose challenges to their bike-sharing services and then build a new ecosystem around them. We start with the two survival ecosystems steered by Redbike and Yellowbike, and illustrate how they recognized the co-evolution challenges in their emerging ecosystem. 
Redbike localized their operations in small city areas such as Shanghai Yangpu as a pilot niche location and then used three places in Beijing, Guangzhou, and Shenzhen to test their smart digital lock bikes. Thus, it recognized the possible challenges from economic actors, and gradually understood the user behaviors of customers and obtained sufficient experience in bike distribution. In their words, "During our early local tests, we observed that people want fashionable-looking bikes. We then found that riding bikes may not be in fashion for most users... how to educate them to use bike-sharing services requires more time” (RB1). Redbike also recognized that affecting users' behaviors and collecting real-time user data were challenging without a smart lock on bikes: "No one before has succeeded in applying smart locks in massive application scenarios like us. We need to enhance this and must not stop” (RB6). Moreover, Redbike noticed that no transitional bike manufacturers were sufficiently qualified to become suppliers because their smart bikes had special components and designs. In the words of an early operation partner, "Who wants to offer a separate new line for a new company? It's risky” (RB3). This concern increased as Redbike saw the need for a large order volume if it wanted to expand into more cities. Thus, Redbike recognized the economic coevolution challenges as critical factors in the ecosystem development.

Furthermore, Redbike confirmed the indispensable yet unambiguous role of local governments. While local governments provided bikeways and public parking areas, depending on Redbike to solve the last-mile problem, the conflicting requirements of local bureaus troubled Redbike. For instance, the transport and environment bureaus welcomed them, but the urban management bureau and subdistrict offices considered them troublesome because they had to put in extra supervisory efforts as "central governments took an acquiescent attitude toward this new industry, and they want to let it move first and see what will happen” (PA3). The absence of official regulations raised primary jurisdiction questions among local bureaus and Redbike had to find ways to align these conflicting regulatory motives: "We sought to satisfy both the local and central government simultaneously....Since we started, we suggested to governments that the bike-sharing industry, which provides public goods for society, should have market entry systems” (RB1). It also balanced fashionable-looking bikes for its customers and durable bikes for the broader public. A Redbike co-founder stated, "We made bikes sustainably very early on. They have a lifespan of at least four years. We want to avoid people's criticisms about metal waste” (RB6). As shown, Redbike developed a deep understanding of sociopolitical actors' roles in constructing a viable bike-sharing ecosystem. Through an experiment conducted locally on a small scale, Redbike gained a complete view of the 
economic and sociopolitical environments of its ecosystem and was able to proactively defend itself against multiple co-evolution challenges by collecting feedback from various actors.

Similarly, Yellowbike, in the startup stage, probed the bike-sharing mode on walledgarden (Beijing) university campuses. Staying on niche campuses, Yellowbike recognized the critical influence of young customers, bike suppliers, and governments on ecosystem development early on: "We turned to campuses, where students were picky and hard to satisfy" (YB6). By doing so, Yellowbike spotted the challenge of getting customers to use dockless bike-sharing services and found many ways to attract students. Picky school-based users represent the price-sensitive customers who switch to bikes of other colors without switching costs. Young university users preferred bikes that were not shabby and had easy bike accessibility on streets, necessitating a set of solid bike suppliers and a powerful "brain” to monitor the bikes. According to the Yellowbike co-founders, "Scale advantage takes precedence over technological advantage in such a business" (YB2). Offering more bikes made a big difference in building the economy-of-scale advantages. However, too many bikes would be bothersome to governments, and this came to Yellowbike's attention early on: "Both ventures had frequent contacts with different governments from the outset. They [the governments] often asked us what else they could do and how they could help. At the time, our attitude was: don't make trouble” (PA3). “The GR [Government Relationship] department was there when I joined the company. We emphasize corporate-political relationships, because we sincerely want to help solve a 'social pain spot'” (YB4). As evidence shows, Yellowbike's simultaneous awareness of the importance of both economic and sociopolitical actors helped it to cognitively form a fairly complete ecosystem boundary with which to proactively defend itself against multiple co-evolution challenges.

Our data show that the two survival cases used a typical cognitive strategizing form, which we conceptualize as niche experimentation, to make sense of their co-evolution challenges in the economic, coopetitive, and sociopolitical ecosystem environments. In this niche experimentation, new focal ventures tested their imperfect products or services as well as immature business models in small markets or closed geographic areas before entering the mass market. Through real-world operations, new focal ventures can display the performance of technical features and obtain responses, opinions, and assessments from local actors who are not accessible in in-house labs.

We validate (or contrast) the emerging pattern in the two survival cases by considering the two failed cases Bluebike and Greenbike. With years of technology accumulation, an 
established customer base, and eight partnering bike plants, Bluebike rushed into no less than eight local markets. Unlike Redbike and Yellowbike, Bluebike did not feel that governments or social actors posed potential challenges because it found that local governments "welcomed" it. Rather, it sought investments to manufacture more high-quality bikes. As a reporter recalled, “[Bluebike], as a latecomer, had to sacrifice more resources to capture a large market share. This is indisputable and was a priority at the time” (BR3). An exclusive focus on economic coevolution challenges brought Bluebike short-term market benefits. No proactive preparation for enduring sociopolitical blocking effects eroded its long-term economic viability: "It was so arrogant when it was at its most successful stage. It should have got as much money as possible from the foundation. But, after August, many investors were spectacularly crowded into the top two. It was too late. Who wants to invest in an uncompetitive follower?” (BS2).

Unlike Bluebike, Greenbike conducted innovation experiments in three local cities (in Shangdong province), to obtain an incomplete view of the challenges posed by governments. The Yantai government occasionally interfered in its trial operations; the Jinan government first had a positive attitude toward bike-sharing services but soon established strict market entry systems. Such policy inconsistency puzzled Greenbike, who considered such "elusive” governments as "not innovative enough.” Greenbike finally exited these early markets, moving to open-minded and innovative ones. They stated as follows: “Governments' elusive attitudes impacted on our market decisions. This is also true for many others who had to have good relationships with them... we have no extra energy to meet their diverse needs” (GB1). This shows that inadequate interactions with governments rendered its growth myopic. As late entrants in these innovative cities, Greenbike operated smoothly because the actors involved had been "educated" by pioneers. As Greenbike’s CEO recalled, “During our early development, our operation hit the best very soon. We easily got 10,000 to 200,000 registered users every day...Y You didn't need to worry about anything except putting your bikes on streets. My God! There should exist such an easy business in the world” (GB3). However, they also recognized the challenge of rapidly expanding with more bikes: "We initially outsourced the operations jobs to experienced ones, but they refused to continue working because of the huge numbers of bikes being distributed" (GB1). "We have to race against time to distribute bikes as much as possible” (GB2).

Data from the two failed cases show that Greenbike did not implement niche experimentation effectively, and Bluebike did not implement it at all. In particular, they both underestimated the sociopolitical challenges, which prevented them from overcoming the social 
criticism and political condemnation that arose after the central Transport Ministry's official regulations were issued in August 2017; this is considered the industry's turning point. Consequently, these sociopolitical co-evolution challenges eroded the viable economic ecosystem environments, resulting in the bankruptcy of these two ventures and failed ecosystems.

In sum, our cross-case analysis shows the advantages of niche experimentation in initiating and sustaining emerging ecosystems. Our finding supports Adner (2012), who noted that, before ecosystems become full-fledged, ecosystem builders must set an ecosystem boundary via the so-called "minimum viable ecosystem"-referring to the actors on whom they must rely on to build their ecosystems. Dattée et al. (2018) recently argued that bootstrapping technological visions with various potential actors can facilitate early-stage ecosystem development. Our finding adds to this stream of the literature by showing that successful new focal ventures construct ecosystem boundaries via high-level performance of niche experimentations through small-scale geographic trials, by which they can analyze the on-site responses of various contextualized actors and identify with whom they should co-evolve in the future (Autio et al., 2014). Spatial context plays an important role in strategizing niche experimentation because small-scale geographic trials allow new focal ventures enough time and attention to monitor the real conditions of innovation development with limited cost, meanwhile helping new focal ventures make sense of ecosystem-scale boundary including actor structures (e.g., social mediums are indirect ecosystem actors), actor dynamics (e.g., regulators might change their attitudes toward new bike-sharing mode), and ecosystem-specific interaction relationships (e.g., social critics affect customers' acts). In this respect, niche experimentation is a relatively safe innovation strategizing form for small firms leading ecosystem development (Mahmoud-Jouini and Charue-Duboc, 2017). By this, new focal ventures can gain a holistic view of their ecosystem and address their multiple co-evolution challenges more proactively and holistically. We therefore propose the following proposition:

Proposition 1: New focal ventures that implement niche experimentation effectively are more likely to form a complete ecosystem boundary consisting of a holistic understanding of their co-evolution challenges in both their ecosystem economic and sociopolitical environments than those that do not pursue niche experimentation or implement it ineffectively.

\subsubsection{Overcoming co-evolution challenges: strategic versatility and strategic suboptimality}


While niche experimentation helps focal ventures proactively recognize the co-evolution challenges' multiplicity in two ecosystem environments, knowing how to simultaneously and strategically overcome these challenges provides practical solutions to the ecosystem coevolution and development processes. By building upon the existing ecosystem-specific strategies and examining how some of these collectively address one or more co-evolution challenges, our within- and cross-case analyses identify two specific strategizing forms that survival focal ventures adopt to drive and sustain their emerging ecosystems: strategic versatility and strategic suboptimality. In strategic versatility, focal ventures employ strategies to tackle certain co-evolution challenges while enhancing the efficacy of their other implemented ecosystem-specific strategies. In strategic suboptimality, focal ventures intentionally sacrifice their ecosystem-specific strategies' short-term efficacy to enhance the effectiveness of future implemented ecosystem-specific strategies. Through either of the strategizing forms, new focal ventures aim to maintain ecosystem-level competitiveness.

\subsubsection{New focal ventures' strategizing form: strategic versatility}

Redbike and Yellowbike, the two survival cases, show how certain ecosystem-specific strategies effectively interact with each other and work collectively to address multiple coevolution challenges.

To solve the challenge of finding stable bike suppliers to manufacture specialized bikes for their sharing service, Redbike signed exclusive contracts with a bike component provider and a bike assembler. This economic (supply chain management) strategy not only scaled up with a stable supply but also eased market competition (competitive offensive strategy): "Monopolize the upstream suppliers, leaving small ones to rivals” (RB1). "It's no problem when you have ten thousand customers. But when it comes to one or ten million, you have to find a proper way out” (RB4). The second incident concerned Redbike’s Hongbao marketing promotion. This economic (marketing) strategy was intended to induce customers to use illegally parked bikes, which in turn reduced offline operation costs and complaints from local community offices (anticipatory political strategy): "Users are encouraged to ride misplaced bikes with discount or cash bonus. We help to reduce management trouble for local community offices who always require us to distribute and manage bikes well” (RB6). These results demonstrate that Redbike implemented one ecosystem-specific strategy to address a particular co-evolution challenge. However, such action simultaneously and positively affected the 
implementation of another such strategy corresponding to a different challenge. Consequently, these strategies interactively and collectively overcame multiple co-evolution challenges.

A similar pattern emerges in the Yellowbike case. Yellowbike's early success on campuses made it popular among college students, attracting several angel investors (economic vision diffusion strategy). These investors also helped Yellowbike obtain access to end-users, bike deployment, and bridging fundraising (economic marketing strategy): “They [DiDi] help to do many things. Especially, I remember it directing car-sharing users to us. So the urban commuters could use complementary mobility services. This is a win-win situation” (YB2). Yellowbike also conducted a Hongbao marketing promotion and obtained celebrity endorsements (economic marketing strategy), which had two effects: customers recognized its distinct brand identity, and it received fewer complaints from local governments (anticipatory political strategy). Online reports claimed as follows: “This strategy is brilliant. They [Redbike and Yellowbike] have fewer complaints from urban management bureaus.” Moreover, to deal with social criticisms about its low-quality bikes and improve their rigid social strategies (e.g., a PR denouncement), Yellowbike first cooperated with two bike design ventures to improve its bikes' body structure, and it also strategically collaborated with three established Chinese telecom giants to replace mechanical locks with smart locks. This close cooperation with quasipolitical agencies lent Yellowbike an air of trustworthiness and the combination of economic (innovation orchestration) and social (corporate responsibility) strategies countered public perceptions.

Our findings from the two survival cases reveal the dynamic interplay between the different ecosystem-specific strategies implemented by new focal ventures. When implementing one or a combination of ecosystem-specific strategies to address certain coevolution challenges, such strategic action will likely bring new challenges or affect other strategies addressing a different challenge. The positive interplay between them will increase the efficacy of these strategies and create a "killing two birds with one stone" effect, helping new focal ventures address multiple co-evolution challenges effectively. We conceptualize this set of positively enforced and collectively executed ecosystem-specific strategies as the strategizing form of strategic versatility.

We next turn to the two failed cases, Bluebike and Greenbike. Although we also find dynamic interplay between the ecosystem-specific strategies implemented by these two focal ventures, instead of positive enforcement, we find negative interaction between these strategies, 
making the other ecosystem-specific strategy implementation difficult; thus, they carried out strategic versatility ineffectively.

Bluebike initially received financial support from two venture capitalists, motivating it to "play a protracted game to establish dominance” (BR4). To this end, it combined economic and coopetitive (offensive) strategies. To swiftly capture a market share, Bluebike aggressively announced a free-of-charge policy in March 2017, shocking all the players: "This policy [an aggressive price war] has temporary benefits. In the long range, it does not seem good” (BR3). Moreover, although Bluebike started well by collaborating with incumbent mobile payment providers, helping it to attract dramatic numbers of customers and making it one of the top three bike-sharing ventures within two months, its subsequent economic (marketing) strategies for retaining users had negative effects on its corporate political and economic (vision diffusion) strategies. Specifically, Bluebike first released Bluegogo-Pro, the best smart bike on the streets. It then offered users a 180-day discount package and collaborated widely with commercial partners to offer complementary services. Unfortunately, the inappropriate political elements involved in its marketing activities triggered an investigation by China’s public security office. An informant confirmed that "stupid activities thoroughly de-legitimated its business" (BR1), and the resulting negative media attention caused several potential investors to withdraw. Its CEO stated in an open letter as follows: "We have been cursed since June 2017, first with an advertising accident that affected a large investment and possible acquisition” (BB3). These negative incidents as well as Bluebike’s inability to address multiple co-evolution challenges eventually led to its bankruptcy in November 2017. Thus, its ecosystem failed.

Similarly, Greenbike was initially forced to capture its market share quickly. For this, they effectively combined a set of economic strategies with coopetitive strategy to obtain end-users. Greenbike decided to abandon Bluetooth-based locks and began developing smart locks with traditional lock producers. Simultaneously, they released Tuhao Gold bike-sharing, which had a fashionable design and useful functions. This economic (innovation orchestration) strategy helped them attract millions of customers at low cost. An informant clearly recalled that "We can approach users more precisely with their help” (GB1). Moreover, with the free-of-charge policy and bonus cash (coopetitive offensive strategy), the number of registered users rose sharply, and "Greenbike even surpassed Bluebike in July” (quarterly industrial report). Although Greenbike had "beautiful operation data on some major cities," a subsequent economic (marketing) strategy caused difficulties in implementing both the economic and sociopolitical strategies. Greenbike intended to improve the end-users’ payment experience by 
adjusting the deposit refunding procedure. This action swiftly led to widespread public concern about Greenbike's misuse of customer deposits, and the relationships with a financial P2P company led to further doubts. The company responded to these concerns ineffectively through social strategies (issue management and diagnostic framing), but this caused the major partners to cease their collaboration (economic supply chain management strategy), and a "possible merger also failed” (BR2; economic vision diffusion strategy). To make it worse, China's Consumer Association sued Greenbike (reactive political strategy). Overwhelmed by these events, Greenbike ceased operation in December 2017; thus, its ecosystem also failed.

Overall, our data point to a dynamic perspective on strategy formulation and implementation (Farjoun, 2002), as opposed to the linear, deterministic perspective densely promoted in the literature (e.g., Guo and Bouwman, 2016; Zhang and Liang, 2011). Our findings reveal interactive effects between economic and coopetitive strategy implementation (see Hannah and Eisenhardt, 2018), and, more broadly, economic, coopetitive, political, and social strategies. The effectiveness of new focal ventures' business strategies is traditionally considered separately (e.g., McGee et al., 1995; Porter, 1980). In ecosystems where the actors are technologically and socially interdependent (Moore, 1996), strategy formulation and implementation need to be considered systematically (Farjoun, 2002). Therefore, formulating and implementing ecosystem-specific strategies that breed positive interactive effects holistically (i.e., strategic versatility) can help new focal ventures overcome multiple coevolution challenges simultaneously and increase the effectiveness of their efforts toward ecosystem development. Hence, we propose the following proposition:

Proposition 2: New focal ventures that can formulate and implement strategic versatility are more likely to overcome multiple co-evolution challenges and foster their ecosystem development than those that perform strategic versatility ineffectively (i.e., with negative interactions between their ecosystem-specific strategies).

\subsubsection{New focal ventures' strategizing form: strategic suboptimality}

In addition to strategic versatility, we also observe that new focal ventures (survival cases) compromised their short-term competitive advantages to gain long-term developmental momentum. We conceptualize such strategizing form as strategic suboptimality.

Redbike invested more than half of its financial resources in developing smart locks (economic innovation orchestration strategy). It retained this philosophy even when market competition increased in the spring of 2017, when it collaborated with Ericsson and China 
Mobile to enhance NB-IoT technologies, Baidu Cloud to develop electric fence technologies, and Qualcomm to develop mobile SIM card technologies. This was both costly and technologically uncertain, but Redbike considered it worthwhile. However, considering Redbike's best practices, government regulations absorbed the technical features of its smart locks, with political advantages for Redbike (anticipatory political strategy). A bike-sharing scholar said that "if you look at current patent litigations [on bike-sharing] and then governments' technical requirements, they are much more forward-looking than others” (BS2). Redbike saw governments as a key piece in its ecosystem blueprint puzzle. Redbike sacrificed short-term economic benefits for the return of long-term legitimacy from the government. Moreover, Redbike strategically collaborated with Tencent-Wechat in an economic (supply chain management) strategy to gain access to more end-users in the long term. The price paid was a temporary loss of those who used Redbike's own app, making it difficult for Redbike to acquire user data: "Tencent, who wanted to popularize its mobile payment instrument, strategically invested in it afterwards” (BR2). Similarly, by connecting to the Microsoft Azure data service platform (economic supply chain management strategy), Redbike was forced to share user data with the platform, but it gained the long-term advantage of accuracy in monitoring its fleet-floating bikes. These collaborations brought further long-term benefits. Tencent's investment in Redbike (economic vision diffusion strategy) resulted in fewer complaints from local governments (defensive political strategy). As a Redbike manager confirmed, "We helped many governments to manage the messy streets with shared abundant and accurate user data” (RB6). All these findings show that Redbike sacrificed the short-term (temporary) benefits of certain ecosystem-specific strategies for the long-term benefits of other strategies.

Yellowbike used a similar approach. It collaborated only with high-profile bike manufacturers. This economic (supply chain management) strategy was so costly that Yellowbike's CEO had to focus on rollover fundraising to support it. However, on the upside, the suppliers could be satisfied with continuous large orders, and Yellowbike gained monopolistic power by controlling more than half of the total bike supply. This monopolistic power further gave Yellowbike long-term benefits by enhancing a (defensive) political strategy to deal with government regulations that were considered potential problems. For example, the Environmental Protection Ministry inspected upstream bike factories and allowed only highprofile factories to continue operation. Furthermore, the large-scale production of Yellowbike flooded every city corner, making "local governments take it seriously during regulation- 
making” (BS1). A Yellowbike city manager noted that Yellowbike "is [when you become] too big to fail. As a new industry, governments don't anticipate quick failure when you have a fifty percent market share. They want to take advantage of you, because you can provide jobs and you can reduce the pressure on public finances” (YB2). Moreover, collaborating with Zhima Credit in March 2017 (economic marketing strategy), Yellowbike announced a zero-deposit policy, temporarily restricting itself from fully utilizing the substantial customer deposits. In the long term, such strong action defended them from broad social criticism for embezzling users' deposits (social prognostic framing strategy). An industry reporter noted that "customer deposit misuse is an open secret. Many bankrupted bike-sharing ventures embezzled the money to buy new bikes or even to invest in the stock market...the most practical way to let social publics and customers trust you is to charge no deposits” (BR4). Moreover, collaborating with DiDi, the biggest car-sharing platform in the market (economic supply chain management strategy), might help Didi extend the niche markets of their car-sharing platform and create a potential competitor by sharing user data. The CEO emphasized that "as a data-driven hightech, user data is our unique assets...the user data are valuable when you open your ecosystems to others who can help you use them correctly...we have no choice but to share with them.” In the long run, such strategizing forms induced DiDi to invest money and human resources (economic vision diffusion strategy) in Yellowbike, leading to its fast growth.

We did not observe similar strategizing forms implemented by Bluebike and Greenbike in our data analyses. The lack of niche experimentation caused both firms to overlook the longterm restrictive influences of sociopolitical actors. They believed that it was enough to follow the government directions. Their short-term focus was to solve economic problems. Specifically, Bluebike believed it “move[d] much too far ahead of customers' needs” (online news report), with a narrow focus on the best bike-sharing bikes. This economic strategy brought them the short-term benefit of a large number of users. However, in the long term, they failed to address certain regulatory requirements (e.g., on smart locks, digital fencing, and user data platforms), attracting criticism from regulators and social media. A bike-sharing scholar noted that "Bluebike should have prepared far earlier for the rules of the game set by regulators, as they've had enough money and resources to do so since their foundation” (BS2). The early effortless success of Greenbike led them into a trap: it believed that bikes represented customers (unsupervised customer deposits), and that it had to produce more bikes (economic marketing strategy). This approach led Greenbike to underestimate certain key challenges such as regulatory pressures and strong public doubts in its next developmental stages. As Greenbike’s 
CEO recalled, "We made just a small mistake but we did not expect the power of the social media. Somehow, they 'killed' us” (GB3).

In sum, our data illustrate the rewards deferred with the use of strategic suboptimality, offering new insight into the strategies' temporality; strategy scholars argue that this needs to be considered (Kaplan and Orlikowski, 2013; Ott et al., 2017). Our findings demonstrate intertemporal strategic effects between ecosystem-specific strategies, some of which may look suboptimal from the perspective of a focal venture but create positive effects at the ecosystem level in the long(er) term. This key insight confirms what Fuller et al. (2019, p. 6) meant when they speculated that "[e]nacting such a strategy can feel counterintuitive” in an ecosystem setting. The strategy management literature emphasizes individual maximum competitive advantages when firms formulate and implement business strategies (Porter, 1980; Santos and Eisenhardt, 2009; Williamson and De Meyer, 2012). In contrast, some recent ecosystem studies have shown that focal actors execute ecosystem-specific strategies to achieve ecosystem-level competitive advantages (Holgersson et al., 2018; Joo and Shin, 2018; Ma and Hou, 2020). We extend this emerging body of the literature by identifying the important strategizing form of strategic suboptimality, the sacrifice of short-term individual benefits to bring long-term ecosystem-level competitiveness. From the above insights, we propose the following proposition:

Proposition 3: New focal ventures that implement strategic suboptimality are more likely to overcome multiple co-evolution challenges over time and sustain their ecosystem development than those that do not implement strategic suboptimality.

\subsection{DISCUSSION}

To complement the ecosystem development and management literature (e.g., Autio and Thomas, 2014; Overholm, 2015; Hannah and Eisenhardt, 2018), this study tries to answer the question of how new focal ventures develop ecosystem-specific strategies to recognize and overcome a combination of economic, coopetitive, and socio-political co-evolution challenges and ensure the viability of their emerging ecosystem. Using the inductive multiple-case study approach, we show that the new focal ventures of two survival ecosystems holistically recognize multiple co-evolution challenges from economic and sociopolitical ecosystem environments through niche experimentation, a cognitive strategizing form. This enables them to proactively defend multiple co-evolution challenges by collecting feedback from various ecosystem actors. This may lay a solid foundation for crafting two strategizing forms to manage 
ecosystem challenges, strategic versatility and suboptimality. New focal ventures can implement these strategizing forms to overcome multiple co-evolution challenges simultaneously and over time, so as to drive and sustain their ecosystem development.

\subsubsection{Theoretical contribution}

Our findings make several important theoretical contributions to the ecosystem development literature. First, we reintegrate and examine the overlooked sociopolitical challenges in the framework of emerging ecosystems development. Our key insight is that the multiple coevolution challenges to new ecosystem development are contingent on the nature of the proposed core innovations. Ecosystem studies focus on the economic co-evolution challenges that new focal ventures may encounter, as the ecosystem value propositions they focus on relate more to technological and customer value than social value (e.g., see Adner and Kapoor, 2010, 2016; Hannah and Eisenhardt, 2018). We have extended this body of the literature by examining the emerging ecosystems offering public good-related innovations, where the technological, customer, and social values (associated economic, coopetitive, and sociopolitical co-evolution challenges) are found equally critical for ecosystem development (Ma et al., 2018).

Our research on niche experimentation shows that spatial context is essential to the earlystage innovation ecosystems (Autio et al., 2014). Most ecosystem studies argue that ecosystems are created around core value propositions (Adner, 2017) and digital platforms (e.g., Gawer and Cusumano, 2014; Li, 2009), and that the ecosystem actors therefore align independently of geographic locations (Zahra and Nambisan, 2011). Thus, scholars often take the view that there is little need to consider the spatial context in which ecosystems emerge. However, a competing argument that our findings support posits that an "innovation ecosystem...involve[s] the logic of actor interdependence within a particular context (spatial dimension)" (Ritala and Almpanopoulou, 2017, p. 41), and a "spatial context may have an influence on entrepreneurial and innovation ecosystem” (Clarysse et al., 2014, p. 1175). Put simply, the initial conditions in a geographic context, including the key ecosystem actors (e.g., local governments, pilot endusers), are critical for the genesis of complex innovations (Autio et al., 2014). As our study shows, new focal ventures acquire onsite feedback (though small-scale and incomplete) from local contexts such as on technical functions, customer demand, and political/social stakeholder attitudes. Such effective experimentation has enabled new focal ventures to obtain a holistic view of the emerging ecosystems, thereby helping them to deal with complexities and uncertainties more effectively as the ecosystems evolve. Future studies on public good-related 
ecosystems should consider spatial contexts as a critical factor in empirical analyses to understand the emerging ecosystem's emergence and viability.

Second, we offer a nonlinear structural view of within-ecosystem dynamics, triggered intentionally by focal actors with less power, resources, and ecosystem management experience, to the current ecosystem development literature. In general, ecosystem dynamics refer to the interaction between actors and how such interactions impact ecosystem-level outcomes (Davis, 2016). Although some scholars have argued that focal actors must strategically manage (Snihur et al., 2018) or even control (Dattée et al., 2018) various ecosystem dynamic types to drive ecosystem development, their arguments are based on the assumption that focal actors' strategic actions have only direct linear effect on dyadic nonfocal actors (e.g., Gómez-Uranga et al., 2014; Guo and Bouwman, 2016; Kolloch and Dellermann, 2018; Leten et al., 2013; Liu and Rong, 2015). By adding to such hub-and-spoke structural ecosystem dynamics, our findings reveal the ecosystem dynamics among nonfocal actors resulting from new focal ventures’ purposeful strategizing. From primarily the constraints of strategic resources and power, new focal ventures would find it difficult to control the dyadic ecosystem dynamics while ensuring the viability of their ecosystems, making the strategic efficiency in strategy decision making inevitable (Ott et al., 2017; Santos and Eisenhardt, 2009). Using strategic versatility, an organic combination of positively reinforced ecosystem-specific strategies would to some extent make up for the resource, knowledge, and experience deficiency, with which new focal ventures build the individual- and, more importantly, ecosystem-level advantages. Moreover, from the nonlinear structural ecosystem dynamics, more strategic focus is required on coordinating the actor dynamics crossing ecosystem environments than in a single ecosystem environment. This new insight answers the recent calls of Jacobides et al. (2018) and Walrave et al. (2018) for a more nuanced understanding of the ecosystem dynamics going beyond the actor level popular in the literature. Taken together, future studies should consider a more dynamic and holistic view on actor-ecosystem strategic interactions as well as their effects to explain the ecosystem development process.

Third, we have advanced the intertemporal understanding of ecosystem externalities in the entrepreneurial setting where young focal ventures compete in nascent markets by building emerging viable ecosystems. Extending Overholm (2015) and Hannah and Eisenhardt (2018), we show that negative and positive ecosystem-level externalities occur during the ecosystemcreation process. Negative externalities rooted in suboptimal strategic action prevent new focal ventures from protecting their markets, allowing for a more competitive ecosystem in the short 
term (Overholm, 2015). However, from an intertemporal perspective, such negative externalities gradually turn positive for them. This transition is closely related to their proactiveness in sacrificing temporary developmental advantages. This allows them to defend the intertwined, overwhelming co-evolution challenges from two ecosystem environments, which is important in the long term. Thus, future studies should specially consider intertemporal factors (longer time horizon in particular) in analyzing ecosystem-specific strategies to explicate ecosystem development.

\subsubsection{Managerial implications}

This study has implications for managers of new focal ventures who seek better public goodrelated ecosystems. First, for ambitious entrepreneurs, the inward-to-outward entrepreneurial mindset is fundamental to innovative product or service experimentation. This includes the traditional in-house lab experiments to test an innovation's technical feasibility as well as sociospatial experimentation with key local ecosystem actors to grasp the social fitness and political acceptability of an overall offering. To acquire high-quality feedback from local actors, location strategies need to be well tailored to position the innovation activities in places likely to promote the development and commercialization of innovations (Ferreira et al., 2017). Besides, it also requires entrepreneurs to be alert to any signal from local contextualized actors, even though some might not contribute value directly. For more meaning to these signals, entrepreneurs can consult or have frequent dialogue with different contextualized actors to comprehend the ecosystem structures. This systemic process can help them pinpoint all the uncertainties inherent in the proposed innovations and thus formulate a compelling ecosystem scenario that managers can rely on to realize public-good innovations successfully.

Next, managers in early-stage ecosystem contexts should shift their managerial attention away from sole focus on separate effectiveness to a dynamic, complex interplay between strategic actions. New focal ventures usually face scarce resources and experience limitations, but they can leverage the interactive functions of strategic actions via organic and temporal strategizing (Farjoun, 2002). For instance, they may benefit from collaborating with multifunctional partners who can provide various key resources and help to solve other coevolution problems. However, besides such deliberately planned actions, new focal ventures should also closely monitor their emerging responsive strategic actions, which could lead to unforeseeable consequences for interdependent ecosystem actors. These remarks resonate with Mintzberg and Waters' (1985) advice that, because emerging strategies are always 
dysfunctional when the environment (e.g., an emerging ecosystem) is too unstable or complex to understand, strategic managers should be meticulous in the strategizing process. To some extent, pure deliberate strategies may restrict strategic flexibility.

Ultimately, managers should balance the negative and positive externalities of early-stage ecosystem creation. They should realize that they can mitigate such negative externalities in the short term by increasing the market entry costs, such as strong IP protection and proprietary asset control (Holgersson et al., 2018; Leten et al., 2013). However, to enable such a counterintuitive (i.e., suboptimal) strategizing form to produce the expected effects (positive externalities on ecosystems), managers should have a clear-cut view of the emerging ecosystems' boundary. For this, entrepreneurs should have ecosystem awareness (Nambisan and Baron, 2013; Overholm, 2015) and ecological thinking capability (Ritala and Almpanopoulou, 2017; Zahra and Nambisan, 2012) to ground the new focal ventures'strategic actions (e.g., the distribution of resources and attention; Ott et al. [2017]). This also requires considerable resource commitment, the management teams' full understanding of the coevolution challenges, strategic adherence across a long period of time, and consistent directions at different managerial levels.

\subsection{LIMITATIONS}

Our study has several limitations. Although the focus of our research—ecosystem emergence (from birth to expansion) —allows for observing the focal actors' active and frequent strategic action (Dedehayir et al., 2018; Rong and Shi, 2014), we could not capture the phenomenon that occurs in the ecosystem renewal stage, when focal actors must reshape the ecosystem actors so as to offer new innovations (Autio and Thomas, 2018). Unlike during the early development stages, the co-evolution challenges from sociopolitical actors during the renewal stage are not easy to address. This makes it difficult for focal actors to influence the ecosystem actors and gain ecosystem competitiveness (Zhang and Wang, 2018). Thus, future longitudinal studies considering this transformative period could offer insights into how new focal ventures implement successful strategic actions and thereby reveal other key properties of strategizing forms.

Our special research setting (emerging economies) may limit theoretical generalizability (Yin, 2013). As Van Waes et al. (2018) noted, regulatory agencies in Amsterdam (also Paris, Melbourne, and San Francisco) are keeping an eye on new bike-sharing ventures from their genesis, rather than being bystanders like most Chinese local governments. We infer that the 
contextual difference may affect the research results because new focal ventures in these developed economies would consider solving sociopolitical obstacles as their strategic priority with a strong sense of sociopolitical ecosystem environment from the outset. The innovations offered by emerging drone ecosystems relate more to public benefits, with new focal ventures trying to overcome both the economic and sociopolitical co-evolution challenges to develop novel ecosystems (see Nakamura and Kajikawa, 2018). From these observations, we consider it necessary to conduct more comparative studies across institutional and industrial boundaries and derive more robust conclusions.

Further, we need to mention one theoretical assumption of our study. The study has referred to focal actors (those responsible for managing ecosystems) and nonfocal actors (those passively playing the ecosystem game). We did not consider the nonfocal actors' ecosystemspecific strategies as possible influential factors. This may be an oversimplification, particularly in case of high dynamism. Although the literature has explored the nonfocal roles' ecosystemspecific strategies (Ansari et al., 2016; Nambisan and Baron, 2013; Snihur et al., 2018), no study has examined both the focal and nonfocal actors' ecosystem-specific strategies; this presents a great research opportunity. Thus, future studies should examine how and when the interactive (tradeoff, reinforcing, or dampening) effects between them will occur and, importantly, determine the effects on ecosystem development.

Finally, this is a qualitative study. One limitation relates to the CIT method we relied on. A degree of zoom-in effect always exists, whereby a limited selection of key events allows one to focus on specific actor interactions while ignoring others. Our limitation of accessing the different ecosystem actors amplified such effects. However, we believe that our multiple data types and constant triangulations during data analysis mitigate this limitation to a large extent.

\subsection{CONCLUSION}

While the ecosystems literature has argued that new ecosystem creation focuses exclusively on economic and coopetitive co-evolution challenges, this study adopts a much more holistic lens, to add a puzzle piece by also considering the sociopolitical challenges in an analysis of building and sustaining a public good-related ecosystem. Our robust comparative and qualitative results reveal several complex and dynamic interplay between multiple co-evolution challenges that require new focal ventures to (1) holistically recognize them via effective socio-spatial niche experimentations and (2) address them via specific strategizing forms with the ecosystemspecific strategies positively reinforced and intertemporally combined. Managers and 
entrepreneurs trying to offer public good-related products or services should manage their within-ecosystem and inter-ecosystem dynamics seriously and consider the spatial context as a key factor in the success of ecosystem genesis.

\subsection{REFERENCES}

Aarikka-Stenroos, L., \& Ritala, P. (2017). Network management in the era of ecosystems: Systematic review and management framework. Industrial Marketing Management, 67, 2336.

Adner, R. (2006). Match your innovation strategy to your innovation ecosystem. Harvard Business Review, 84(4), 98-108.

Adner, R. (2012). The wide lens: A new strategy for innovation. London: Penguin.

Adner, R. (2017). Ecosystem as structure: An actionable construct for strategy. Journal of Management, 43(1), 39-58.

Adner, R., \& Kapoor, R. (2010). Value creation in innovation ecosystems: How the structure of technological interdependence affects firm performance in new technology generations. Strategic Management Journal, 31(3), 306-333.

Adner, R., \& Kapoor, R. (2016). Innovation ecosystems and the pace of substitution: Re-examining technology S-curves. Strategic Management Journal, 37(4), 625-648.

Almpanopoulou, A., Ritala, P., \& Blomqvist, K. (2019, January). Innovation Ecosystem Emergence Barriers: Institutional Perspective. In Proceedings of the 52nd Hawaii International Conference on System Sciences. https://hdl.handle.net/10125/60070.

Ansari, S. S., Garud, R., \& Kumaraswamy, A. (2016). The disruptor's dilemma: TiVo and the US television ecosystem. Strategic Management Journal, 37, 1829-1853.

Autio, E., Kenney, M., Mustar, P., Siegel, D., \& Wright, M. (2014). Entrepreneurial innovation: The importance of context. Research Policy, 43(7), 1097-1108.

Autio, E., \& Thomas, L. (2014). Innovation ecosystems: Implication for innovation management. In M. Dodgson, D. M. Gann, N. Phillips (Eds.), The Oxford handbook of innovation management (pp. 204-288). Oxford, U.K.: Oxford University Press.

Autio, E., \& Thomas, L. (2018). Tilting the Playing Field: Towards an Endogenous Strategic Action Theory of Ecosystem Creation. In World Scientific Reference on Innovation Volume 3: Open Innovation, Ecosystems and Entrepreneurship: Issues and Perspectives (pp. 111-140). New Jersey: World Scientific Publishing.

Clarysse, B., Wright, M., Bruneel, J., \& Mahajan, A. (2014). Creating value in ecosystems: Crossing the chasm between knowledge and business ecosystems. Research Policy, 43(7), 1164-1176.

Dattée, B., Alexy, O., \& Autio, E. (2018). Maneuvering in poor visibility: How firms play the ecosystem game when uncertainty is high. Academy of Management Journal, 61(2), 466498.

Davis, J. P. (2016). The group dynamics of interorganizational relationships collaborating with multiple partners in innovation ecosystems. Administrative Science Quarterly, 64, 621-661.

de Vasconcelos Gomes, L. A., Salerno, M. S., Phaal, R., \& Probert, D. R., 2018. How entrepreneurs manage collective uncertainties in innovation ecosystems. Technological Forecasting and Social Change, 128, 164-185. 
Dedehayir, O., Mäkinen, S. J., \& Ortt, J. R. (2018). Roles during innovation ecosystem genesis: A literature review. Technological Forecasting and Social Change, 136, 18-29.

Dhanaraj, C., \& Parkhe, A. (2006). Orchestrating innovation networks. Academy of Management Review, 31(3), 659-669.

Dougherty, D., \& Dunne, D. D. (2011). Organizing ecologies of complex innovation. Organization Science, 22(5), 1214-1223.

Eisenhardt K. M. (1989). Building theories from case study research. Academy of Management Review, 14(4), 532-550.

Eisenhardt, K. M., \& Graebner, M. E. (2007). Theory building from cases: Opportunities and challenges. Academy of Management Journal, 50(1), 25-32.

Farjoun, M. (2002). Towards an organic perspective on strategy. Strategic Management Journal, 23(7), 561-594.

Ferreira, J. J., Fernandes, C. I., \& Raposo, M. L. (2017). The effects of location on firm innovation capacity. Journal of the Knowledge Economy, 8(1), 77-96.

Flanagan, J. C. (1954). The critical incident technique. Psychological Bulletin, 51(4), 327-358.

Fuller, J., Jacobides, M. G., \& Reeves, M. (2019). The myths and realities of business ecosystems. MIT Sloan Management Review, 60(3), 1-9.

Gawer, A., \& Cusumano, M. A. (2014). Industry platforms and ecosystem innovation. Journal of Product Innovation Management, 31(3), 417-433.

Geels, F. W. (2014). Reconceptualising the co-evolution of firms-in-industries and their environments: Developing an inter-disciplinary Triple Embeddedness Framework. Research Policy, 43(2), 261-277.

Gómez-Uranga, M., Miguel, J. C., \& Zabala-Iturriagagoitia, J. M. (2014). Epigenetic economic dynamics: The evolution of big internet business ecosystems, evidence for patents. Technovation, 34(3), 177-189.

Guo, J., \& Bouwman, H. (2016). An analytical framework for an m-payment ecosystem: A merchants' perspective. Telecommunications Policy, 40(2), 147-167.

Gupta, R., Mejia, C., Gianchandani, Y., \& Kajikawa, Y. (2020). Analysis on formation of emerging business ecosystems from deals activities of global electric vehicles hub firms. Energy Policy, 145, 111532. https://doi.org/10.1016/j.enpol.2020.111532.

Hannah, D. P., \& Eisenhardt, K. M. (2018). How firms navigate cooperation and competition in nascent ecosystems. Strategic Management Journal, 39(12), 3163-3192.

Hara, Y., Endo, T., \& Kobayashi, H. (2015). The hidden abode of network orchestration: The case of de-legitimated diesel cars in Japan. Industrial Marketing Management, 49, 15-21.

Hedman, J., \& Henningsson, S. (2015). The new normal: Market cooperation in the mobile payments ecosystem. Electronic Commerce Research and Applications, 14(5), 305-318.

Hellström, M., Tsvetkova, A., Gustafsson, \& M., Wikström, K. (2015). Collaboration mechanisms for business models in distributed energy ecosystems. Journal of Cleaner Production, 102, 226-236.

Hienerth, C., Lettl, C., \& Keinz, P. (2014). Synergies among producer firms, lead users, and user communities: The case of the LEGO producer-user ecosystem. Journal of Product Innovation Management, 31(4), 848-866. 
Holgersson, M., Granstrand, O., \& Bogers, M. (2018). The evolution of intellectual property strategy in innovation ecosystems: uncovering complementary and substitute appropriability regimes. Long Range Planning, 51(2), 303-319.

Iansiti, M., \& Levien, R. (2004). Strategy as ecology. Harvard Business Review, 82(3), 68-81.

Jacobides, M. G., Cennamo, C., \& Gawer, A. (2018). Towards a theory of ecosystems. Strategic Management Journal, 39(18), 2255-2276.

Joo, J., \& Shin, M. M. (2018). Building sustainable business ecosystems through customer participation: A lesson from South Korean cases. Asia Pacific Management Review, 23(1), $1-11$.

Jones, S. L., Leiponen, A., \& Vasudeva, G. (2020). The evolution of cooperation in the face of conflict: Evidence from the innovation ecosystem for mobile telecom standards development. Strategic Management Journal, 42, 710-740.

Kaplan, S., \& Orlikowski, W. J. (2013). Temporal work in strategy making. Organization Science, 24(4), 965-995.

Kolloch, M., \& Dellermann, D. (2018). Digital innovation in the energy industry: The impact of controversies on the evolution of innovation ecosystems. Technological Forecasting and Social Change, 136, 254-264.

Kwak, K., Kim, W., \& Park, K. (2018). Complementary multiplatforms in the growing innovation ecosystem: Evidence from 3D printing technology. Technological Forecasting and Social Change, 136, 192-207.

L'Huillier, R. (2017). China's audacious and inventive new generation of entrepreneurs. The Economist. Retrieved from https:/www.economist.com/briefing/2017/09/23/chinasaudacious-and-inventive-new-generation-of-entrepreneurs. Accessed 10 April 2018

Langley, A. (1999). Strategies for theorizing from process data. Academy of Management Review, 24(4), 691-710.

Leten, B., Vanhaverbeke, W., Roijakkers, N., Clerix, A., \& Van Helleputte, J. (2013). IP Models to Orchestrate Innovation Ecosystems. California Management Review, 55(4), 51-64.

Li, J. F., \& Garnsey, E. (2014). Policy-driven ecosystems for new vaccine development. Technovation, 34(12), 762-772.

Li, Y.-R. (2009). The technological roadmap of Cisco's business ecosystem. Technovation, 29(5), 379-386.

Liu, G., \& Rong, K. (2015). The nature of the co-evolutionary process: Complex product development in the mobile computing industry's business ecosystem. Group \& Organization Management, 40(6), 809-842.

Lofstrom, M., Bates, T., \& Parker, S. C. (2014). Why are some people more likely to become smallbusinesses owners than others: Entrepreneurship entry and industry-specific barriers. Journal of Business Venturing, 29(2), 232-251.

Ma, H., \& Hou, H. (2020). Ecosystem strategy: Who should adopt it and how? Organizational Dynamics, 100805. https://doi.org/10.1016/j.orgdyn.2020.100805.

Ma, Y., Rong, K., Mangalagiu, D., Thornton, T. F., \& Zhu, D. (2018). Co-evolution between urban sustainability and business ecosystem innovation: Evidence from the sharing mobility sector in Shanghai. Journal of Cleaner Production, 188, 942-953. 
Maguire, S., Hardy, C., \& Lawrence, T. B. (2004). Institutional entrepreneurship in emerging fields: HIV/AIDS treatment advocacy in Canada. Academy of Management Journal, 47(5), 657679.

Mahmoud-Jouini, S. B., \& Charue-Duboc, F. (2017). Experimentations in emerging innovation ecosystems: specificities and roles. The case of the hydrogen energy fuel cell. International Journal of Technology Management, 75(1-4), 28-54.

Masucci, M., Brusoni, S., \& Cennamo, C. (2020). Removing bottlenecks in business ecosystems: The strategic role of outbound open innovation. Research Policy, 49(1), 103823. https://doi.org/10.1016/j.respol.2019.103823.

McGee, J. E., Dowling, M. J., \& Megginson, W. L. (1995). Cooperative strategy and new venture performance: The role of business strategy and management experience. Strategic Management Journal, 16(7), 565-580.

Meyer, K. E., \& Peng, M. W. (2016). Theoretical foundations of emerging economy business research. Journal of International Business Studies, 47(1), 3-22.

Miles, M. B., Huberman, A. M., \& Saldana, J. (2014). Qualitative data analysis: A method sourcebook. CA, US: Sage Publications.

Mintzberg, H., \& Waters, J. A. (1985). Of strategies, deliberate and emergent. Strategic Management Journal, 6(3), 257-272.

Moore, J. F. (1996). The death of competition: Leadership and strategy in the age of business ecosystems. New York: HarperBusiness.

Nakamura, H., \& Kajikawa, Y. (2018). Regulation and innovation: How should small unmanned aerial vehicles be regulated? Technological Forecasting and Social Change, 128, 262-274.

Nambisan, S., \& Baron, R. A. (2013). Entrepreneurship in innovation ecosystems: Entrepreneurs' self-regulatory processes and their implications for new venture success. Entrepreneurship Theory and Practice, 37(5), 1071-1097.

Noel, L., \& Sovacool, B. K. (2016). Why Did Better Place Fail? Range anxiety, interpretive flexibility, and electric vehicle promotion in Denmark and Israel. Energy Policy, 94, 377386.

Oliver C. (1997). The Influence of Institutional and Task Environment Relationships on Organizational Performance: The Canadian Construction Industry. Journal of Management Studies, 34(1), 99-124.

Ott, T. E., Eisenhardt, \& K. M., Bingham, C. B. (2017). Strategy formation in entrepreneurial settings: Past insights and future directions. Strategic Entrepreneurship Journal, 11(3), 306325.

Overholm, H. (2015). Collectively created opportunities in emerging ecosystems: The case of solar service ventures. Technovation, 39, 14-25.

Parente, R., Rong, K., Geleilate, J. M. G., \& Misati, E. (2019). Adapting and sustaining operations in weak institutional environments: A business ecosystem assessment of a Chinese MNE in Central Africa. Journal of International Business Studies, 50(2), 275-291.

Pekkarinen, S., Tuisku, O., Hennala, L., \& Melkas, H. (2019). Robotics in Finnish welfare services: dynamics in an emerging innovation ecosystem. European Planning Studies, 1-21.

Peltola, T., Aarikka-Stenroos, L., Viana, E., \& Mäkinen, S. (2016). Value capture in business ecosystems for municipal solid waste management: Comparison between two local environments. Journal of Cleaner Production, 137, 1270-1279. 
Pentland B. T. (1999). Building process theory with narrative: From description to explanation. Academy of Management Review, 24(4), 711-724.

Pierce, L. (2009). Big losses in ecosystem niches: How core firm decisions drive complementary product shakeouts. Strategic Management Journal, 30(3), 323-347.

Planko, J., Chappin, M. M., Cramer, J., \& Hekkert, M. P. (2019). Coping with coopetition—Facing dilemmas in cooperation for sustainable development: The case of the Dutch smart grid industry. Business Strategy and the Environment, 28(5), 665-674.

Porter, M. E. (1980). Competitive strategy: Techniques for analyzing industries and competition. New York: Free Press.

Prince, K., Barrett, M., \& Oborn, E. (2014). Dialogical strategies for orchestrating strategic innovation networks: The case of the Internet of Things. Information and Organization, 24(2), 106-127.

Randhawa, K., West, J., Skellern, K., \& Josserand, E. (2021). Evolving a Value Chain to an Open Innovation Ecosystem: Cognitive Engagement of Stakeholders in Customizing Medical Implants. California Management Review, 63(2), 101-134.

Reeves, M., Lotan, H., Legrand, J., \& Jacobides, M. G. (2019). How Business Ecosystems Rise (and Often Fall). MIT Sloan Management Review, 60(4), 1-6.

Ritala, P., Agouridas, V., Assimakopoulos, D., \& Gies, O. (2013). Value creation and capture mechanisms in innovation ecosystems: a comparative case study. International Journal of Technology Management, 63(3-4), 244-267.

Ritala, P., \& Almpanopoulou, A. (2017). In defense of 'eco' in innovation ecosystem. Technovation, 60, 39-42.

Robinson, K. C., \& McDougall, P. P. (2001). Entry barriers and new venture performance: a comparison of universal and contingency approaches. Strategic Management Journal, 22(67), 659-685.

Rong, K., \& Shi, Y. (2014). Business ecosystems: Constructs, configurations, and the nurturing process. London: Palgrave Macmillan.

Rong, K., Shi, Y., Shang, T., Chen, Y., \& Hao, H. (2017). Organizing business ecosystems in emerging electric vehicle industry: Structure, mechanism, and integrated configuration. Energy Policy, 107, 234-247.

Rong, K., Wu, J., Shi, Y., \& Guo, L. (2015). Nurturing business ecosystems for growth in a foreign market: Incubating, identifying and integrating stakeholders. Journal of International Management, 21(4), 293-308.

Russo-Spena, T., Tregua, M., Amitrano, C. C., \& Bifulco, F. (2020). Addressing Socio-Material Issues for an Emerging Innovation Ecosystem: Insights From Cultural Heritage. IEEE Transactions on Engineering Management, 1-13. doi: 10.1109/TEM.2020.3040746.

Sandström, C. G. (2016). The non-disruptive emergence of an ecosystem for 3D Printing-Insights from the hearing aid industry's transition 1989-2008. Technological Forecasting and Social Change, 102, 160-168.

Santos, F. M., \& Eisenhardt, K. M. (2009). Constructing markets and shaping boundaries: Entrepreneurial power in nascent fields. Academy of Management Journal, 52(4), 643-671.

Scott, W. R., 2008. Institutions and organizations: Ideas and interests (3rd ed.). Los Angeles: Sage Publications. 
Snihur, Y., Thomas, L. D., \& Burgelman, R. A. (2018). An ecosystem-level process model of business model disruption: The disruptor's gambit. Journal of Management Studies, 55(7), 1278-1316.

Sovacool, B. K., Noel, L., \& Orsato, R. J. (2017). Stretching, embeddedness, and scripts in a sociotechnical transition: explaining the failure of electric mobility at Better Place (20072013). Technological Forecasting and Social Change, 123, 24-34.

Suarez, F. F., \& Oliva, R. (2005). Environmental change and organizational transformation. Industrial and Corporate Change, 14(6), 1017-1041.

Van de Ven, A. H. (1992). Suggestions for studying strategy process: A research note. Strategic Management Journal, 13(S1), 169-188.

Van de Ven, A. H., \& Huber, G. P. (1990). Longitudinal field research methods for studying processes of organizational change. Organization Science, 1(3), 213-219.

Van Waes, A., Farla, J., Frenken, K., de Jong, J. P., \& Raven, R. (2018). Business model innovation and socio-technical transitions. A new prospective framework with an application to bike sharing. Journal of Cleaner Production, 195, 1300-1312.

Walrave, B., Talmar, M., Podoynitsyna, K. S., Romme, A. G. L., \& Verbong, G. P. (2018). A multilevel perspective on innovation ecosystems for path-breaking innovation. Technological Forecasting and Social Change, 136, 103-113.

Wareham, J., Fox, P. B., \& Cano Giner, J. L. (2014). Technology ecosystem governance. Organization Science, 25(4), 1195-1215.

Williamson, P. J., \& De Meyer, A. (2012). Ecosystem advantage: How to successfully harness the power of partners. California Management Review, 55(1), 24-46.

Yin, R. K. (2013). Case study research: Design and methods (4th ed.). Thousand Oaks, CA: Sage Publications.

Zahra, S. A., \& Nambisan, S. (2011). Entrepreneurship in global innovation ecosystems. AMS Review, 1(1), 4-17.

Zahra, S. A., \& Nambisan, S. (2012). Entrepreneurship and strategic thinking in business ecosystems. Business Horizons, 55(3), 219-229.

Zhang, J., \& Liang, X.-J. (2011). Business ecosystem strategies of mobile network operators in the 3G era: The case of China Mobile. Telecommunications Policy, 35(2), 156-171.

Zhang, Q., \& Wang, Y. (2018). Struggling towards virtuous coevolution: institutional and strategic works of Alibaba in building the Taobao e-commerce ecosystem. Asian Business \& Management, 17(3), 208-242.

Zhang, L., Zhang, J., Duan, Z. Y., \& Bryde, D. (2015). Sustainable bike-sharing systems: characteristics and commonalities across cases in urban China. Journal of Cleaner Production, 97, 124-133. 
Appendix 3.1: An overview of the interviews and other resources.

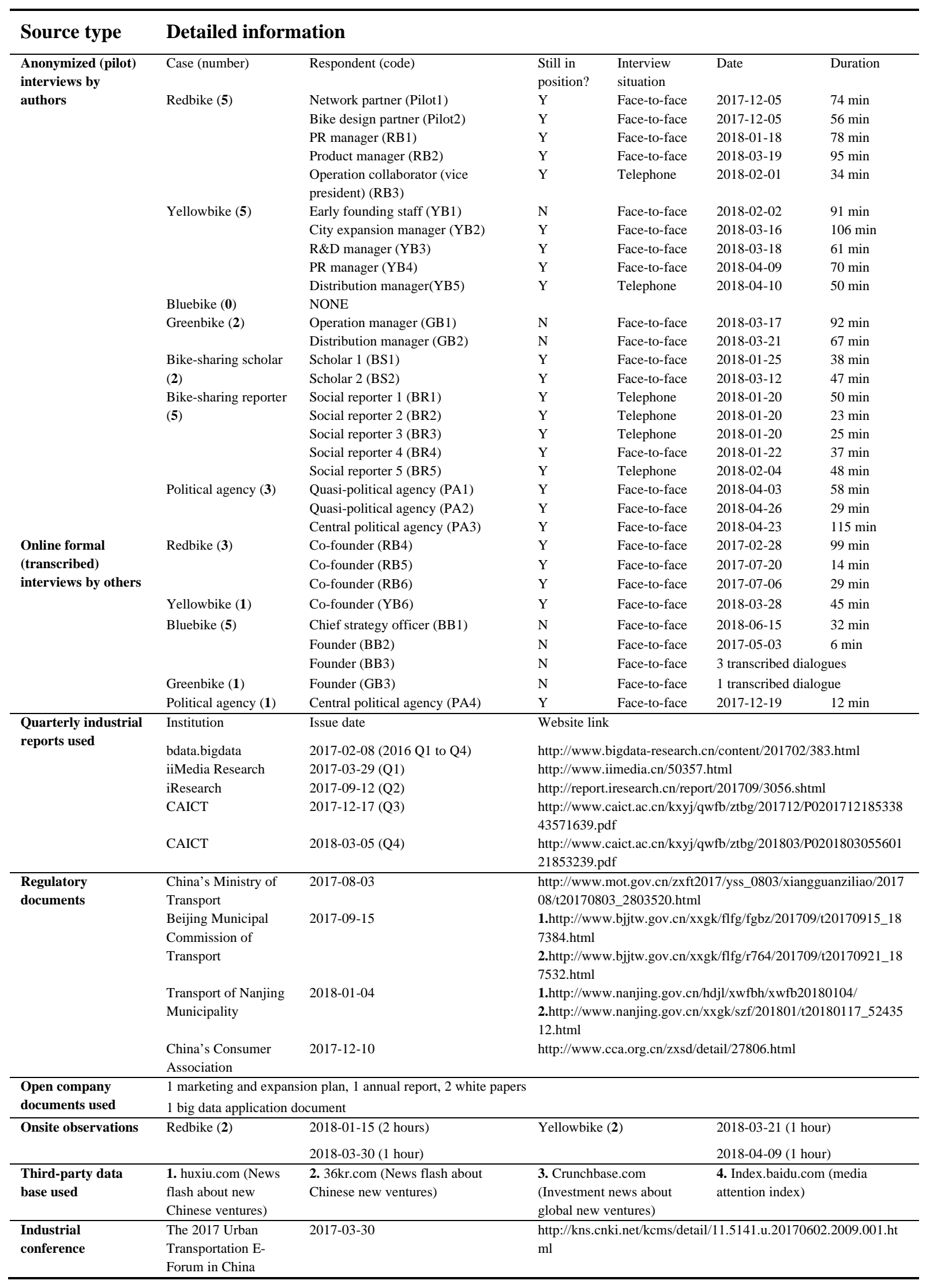




\section{Appendix 3.2: Interview protocol.}

\section{Section 1}

1. Please tell me about your personal background—your education, industrial experience, current job, and so on.

2. Please give a brief history of the bike-sharing industry.

3. What is your opinion of business ecosystems around the bike-sharing industry? Who are the key actors and what are key environments? Which bike-sharing ecosystems do you know?

4. How do these bike-sharing ecosystems differ? What are the main characteristics in which they differ?

5. Are there generic stages of development that all ecosystems undergo? What are these stages' main characteristics and processes?

6. How would you characterize the ecosystems (from Q4) according to the stages of development?

7. To your knowledge, what should a focal actor's roles and activities be in these stages?

\section{Section 2}

8. According to your experience and observations, what are the typical challenges or problems for bikesharing companies to build up and develop their ecosystems in each of the stages? Can you give some specific examples about when, where, and with whom such typical challenges or problems are likely to occur?

9. According to your observations and knowledge, how do bike-sharing companies overcome these typical challenges you referred to? Who succeeds in making them and how? Who failed and why? (follow-up questions in certain environments)

10. Now, I want to discuss the specific case of the ${ }^{* * *}$ ecosystem. How would you describe this ecosystem?

a. Who are the actors?

b. What are the main activities and developments in this ecosystem?

c. What do you consider to be the most critical events in this ecosystem so far?

c1. I have summarized a list of key events relating to the challenges of ***. Could you tell me, according to your observations and knowledge, how *** (which actions did *** take) to overcome these challenges? Do you consider these actions to be successful or unsuccessful? Why?

c2. Did you observe the similar actions taken by other bike-sharing companies such as \#\#\#, the biggest competitor of ***, to overcome the same challenges? If yes, do you consider these actions by these companies to be successful or unsuccessful? If not, to your knowledge, which actions have they taken, how, and why? Do you consider these actions by these companies to be successful or unsuccessful?

11. What are the effects of above actions and activities on other actors, for instance, customers, partners, suppliers, competitors, policy-makers, the media, etc.?

(follow-up questions in certain ecosystem environments)

12. According to your observations, what are the specific criticisms, doubts, and debates from social publics (including you) relating to bike-sharing companies and the industry (especially to a certain company)? When did you have such specific criticisms and why?

13. Can you tell us more about some competition and collaboration activities between bike-sharing companies (especially *** vs. \#\#\#)? Have you observed possible positive or negative impacts on other actors, for instance, customers, partners, suppliers, policy-makers, the media, etc.? If yes, what are they?

14. Do you have anything else to share, besides our discussions about the bike-sharing industry and bike-sharing companies?

\section{The end. Thank you very much for your cooperation!}


Appendix 3.3: Within-case analyses process ${ }^{\mathrm{a}}$.

\begin{tabular}{|c|c|c|c|c|}
\hline Case & $\begin{array}{l}\text { Co-evolution } \\
\text { Challenge }\end{array}$ & $\begin{array}{l}\text { Economic or Coopetitive } \\
\text { or Political or Social } \\
\text { Strategy: Critical Event }\end{array}$ & $\begin{array}{l}\text { Ecosystem-Specific Strategy (Effect) } \\
\text { (Representative Quotes) }^{\mathrm{b}}\end{array}$ & $\begin{array}{l}\text { New focal venture's } \\
\text { strategizing forms } \\
\text { (Proposed Constructs) }\end{array}$ \\
\hline \multirow[t]{4}{*}{ Redbike } & $\begin{array}{l}\text { How to successfully } \\
\text { operate bike-sharing at } \\
\text { initial urban areas. }\end{array}$ & - & $\begin{array}{l}\text { Partner with socio-political actors and technology partners } \\
\text { - "We sought to satisfy both the local and central government } \\
\text { simultaneously...Doing such business well undoubtedly could not } \\
\text { ignore them. Since we started, we suggested to governments that the } \\
\text { bike-sharing industry, which provides public goods for society, } \\
\text { should have market entry systems." (RB1); "I've worked in } \\
\text { automotive industry for many years. I definitely know how hard it is } \\
\text { to create such an intelligent product from the scratch. I realized we } \\
\text { should rely on talents from others, such as from high-techs } \\
\text { developing smartlocks." (RB4); } \\
\text { Technical functions, customers' demands, and political/social } \\
\text { stakeholders' attitudes } \\
\text { - "During our early local tests, we observed that people want } \\
\text { fashionable-looking bikes. We then found that riding bikes may not } \\
\text { be in fashion for most users... how to educate them to use bike- } \\
\text { sharing services requires more time." (RB1); "We know that } \\
\text { unlocking is slow in the early stage. People have a bad experience in } \\
\text { riding. People will say it is our problem or will blame NB-IoT } \\
\text { technology.... it's just a start. No one before has succeeded in } \\
\text { applying smartlocks in massive application scenarios like us. We } \\
\text { need to enhance this and must not stop.” (RB6); "We made bikes } \\
\text { sustainably very early on. They have a lifespan of at least four years. } \\
\text { We did not anticipate criticism about metal waste.” (RB6) }\end{array}$ & Niche experimentation \\
\hline & $\begin{array}{l}\text { How to find stable } \\
\text { bike-suppliers to } \\
\text { manufacture } \\
\text { specialized shared } \\
\text { bikes. }\end{array}$ & $\begin{array}{l}\text { Economic (supply chain } \\
\text { management) strategy: } \\
\text { Collaboration with HL } \\
\text { Corporation and Foxconn }\end{array}$ & $\begin{array}{l}\text { Coopetitive (offensive) strategy (+) } \\
\text { - "Monopolize the upstream suppliers, leaving small ones to rivals." } \\
\text { (RB1); "It's no problem when you have ten thousand customers. But } \\
\text { when it comes to one or ten million, you have to find a proper way } \\
\text { out." (RB4) }\end{array}$ & Strategic versatility \\
\hline & $\begin{array}{l}\text { How to educate and } \\
\text { attract customers to use } \\
\text { bike-sharing service. }\end{array}$ & $\begin{array}{l}\text { Economic (marketing) } \\
\text { strategy: Hongbao bikes } \\
\text { promotions }\end{array}$ & $\begin{array}{l}\text { (Anticipatory) political strategy (+) } \\
\text { "Users are encouraged to ride misplaced bikes with discount or cash } \\
\text { bonus. We help to reduce management trouble for local community } \\
\text { offices who always require us to distribute and manage bikes } \\
\text { well..." (RB6) }\end{array}$ & Strategic versatility \\
\hline & $\begin{array}{l}\text { How to expand into } \\
\text { new markets quickly. }\end{array}$ & $\begin{array}{l}\text { Economic (supply chain } \\
\text { management) strategy: } \\
\text { Collaboration with Tencent }\end{array}$ & $\begin{array}{l}\text { Economic (vision diffusion) strategy }(+) \\
\text { - “Tencent, who wanted to popularize its mobile payment instrument, } \\
\text { strategically invested in it [Redbike] afterwards.” (BR2) }\end{array}$ & Strategic suboptimality \\
\hline
\end{tabular}




\begin{tabular}{|c|c|c|c|c|}
\hline Case & $\begin{array}{l}\text { Co-evolution } \\
\text { Challenge }\end{array}$ & $\begin{array}{l}\text { Economic or Coopetitive } \\
\text { or Political or Social } \\
\text { Strategy: Critical Event }\end{array}$ & $\begin{array}{l}\text { Ecosystem-Specific Strategy (Effect) } \\
\text { (Representative Quotes) }^{\mathrm{b}}\end{array}$ & $\begin{array}{l}\text { New focal venture's } \\
\text { strategizing forms } \\
\text { (Proposed Constructs) }\end{array}$ \\
\hline \multirow{4}{*}{ Yellowbike } & $\begin{array}{l}\text { How to manage } \\
\text { hundreds of thousands } \\
\text { of dockless shared } \\
\text { bikes on streets. }\end{array}$ & $\begin{array}{l}\text { Economic (innovation } \\
\text { orchestration) strategy: } \\
\text { Collaboration with Ericsson, } \\
\text { Baidu, and China Mobile; } \\
\text { Collaboration with the } \\
\text { Microsoft Azure data service } \\
\text { platform }\end{array}$ & $\begin{array}{l}\text { (Anticipatory) political strategy (+) } \\
\text { - "Governments initially had no regulations on GPS-enabled } \\
\text { smartlocks. We were the first company to do this. This helped us a lot } \\
\text { to enter major cities with strict rules.” (RB1); "They had foresight. It } \\
\text { makes sense that your products are designed to solve social } \\
\text { problems, that government will certainly accept you. You are the } \\
\text { example that newcomers should follow." (PA4) } \\
\text { (Proactive) political strategy }(+) \\
\text { - "We have to do that... We helped many governments to manage the } \\
\text { messy streets with shared abundant and accurate user data." (RB6) }\end{array}$ & Strategic suboptimality \\
\hline & $\begin{array}{l}\text { How to tentatively } \\
\text { operate dockless shared } \\
\text { bikes on campus. }\end{array}$ & - & $\begin{array}{l}\text { Partner with local socio-political actors, investors, and end-users } \\
\text { - "After several failures, we gradually know we should be more } \\
\text { meticulous and start to find the reliable angel findings by making use } \\
\text { of my social networks..." (CEO, Online interview); “we finally } \\
\text { chose the dockless bike-sharing models... whether normal cyclists } \\
\text { would like to accept this new way of riding? Actually, we do not } \\
\text { know at the beginning...” (YB5); "I feel worried about the operation } \\
\text { on the streets...probably the campus was a good place which we } \\
\text { know everything... campus management office has the final } \\
\text { decision.” (Co-founder, Public speech). } \\
\text { Technical functions, customers' demands, and political/social } \\
\text { stakeholders' attitudes } \\
\text { - "We turned to campuses, where students were picky and hard to } \\
\text { satisfy." (YB6); "Specifically, we carried out a set of anti-tidal tests } \\
\text { to improve the efficiency of bikes use by tons of students, and update } \\
\text { our operation strategies with the data captured from campus } \\
\text { users"(YB4). “...think about these tests, we collected many } \\
\text { interesting information from them, which convinced us that we get } \\
\text { the right way." (YB2). }\end{array}$ & Niche experimentation \\
\hline & $\begin{array}{l}\text { How to align with } \\
\text { strong investors to } \\
\text { manufacture new } \\
\text { shared bikes. }\end{array}$ & $\begin{array}{l}\text { Economic (vision diffusion) } \\
\text { strategy: Obtain investment } \\
\text { from DiDi Chuxing }\end{array}$ & $\begin{array}{l}\text { Economic (marketing) strategy (+) } \\
\text { - "They [DiDi] help to do many things. Especially, I remember it } \\
\text { directing car-sharing users to us. So the urban commuters could use } \\
\text { complementary mobility services. This is a win-win situation.” (YB2) }\end{array}$ & Strategic versatility \\
\hline & $\begin{array}{l}\text { How to attract urban } \\
\text { customers to use } \\
\text { dockless shared bikes. }\end{array}$ & $\begin{array}{l}\text { Economic (marketing) } \\
\text { strategy: Hongbao bikes } \\
\text { promotions and celebrity } \\
\text { endorsement }\end{array}$ & $\begin{array}{l}\text { (Anticipatory) political strategy }(+) \\
\text { - "This strategy is brilliant. They [Redbike and Yellowbike] have } \\
\text { fewer complaints from urban management bureaus." (online } \\
\text { reports) }\end{array}$ & Strategic versatility \\
\hline
\end{tabular}




\begin{tabular}{|c|c|c|c|c|}
\hline Case & $\begin{array}{l}\text { Co-evolution } \\
\text { Challenge }\end{array}$ & $\begin{array}{l}\text { Economic or Coopetitive } \\
\text { or Political or Social } \\
\text { Strategy: Critical Event }\end{array}$ & $\begin{array}{l}\text { Ecosystem-Specific Strategy (Effect) } \\
\text { (Representative Quotes) }^{\mathrm{b}}\end{array}$ & $\begin{array}{l}\text { New focal venture's } \\
\text { strategizing forms } \\
\text { (Proposed Constructs) }\end{array}$ \\
\hline & $\begin{array}{l}\text { How to manage } \\
\text { hundreds and } \\
\text { thousands shared bikes } \\
\text { in different cities. }\end{array}$ & $\begin{array}{l}\text { Economic (innovation } \\
\text { orchestration) strategy: } \\
\text { Collaboration with 700Bike } \\
\text { and Qibei; Collaboration } \\
\text { with China Unicom, Huawei, } \\
\text { and Beidou Navigation } \\
\text { system } \\
\text { Social (corporate } \\
\text { responsibility) strategy: } \\
\text { Collaboration with the } \\
\text { UNDP }\end{array}$ & $\begin{array}{l}\text { Social (prognostic framing) strategy (+) } \\
\text { - "You see the new version of our bikes. It is strong enough, more than } \\
\text { the initial versions." (YB6); "I remember that CCTV took us as a } \\
\text { good example and advertises for us... Also, Apple’s Tim Cook visited } \\
\text { our company." (YB1); "Of course, we acquired a lot of experience } \\
\text { and resources from them during our ongoing collaboration." (YB2) }\end{array}$ & Strategic versatility \\
\hline & $\begin{array}{l}\text { How to build scale } \\
\text { advantages to dominate } \\
\text { the market. }\end{array}$ & $\begin{array}{l}\text { Economic (supply chain } \\
\text { management) strategy: } \\
\text { Exclusively collaboration } \\
\text { with Flying Pigeon, Fujitec, } \\
\text { and Shanghai Phoenix }\end{array}$ & $\begin{array}{l}\text { (Defensive) political strategy (+) } \\
\text { - "Because it collaborated with several high-profile companies. Small } \\
\text { bike manufacturers were ordered to suspend business for } \\
\text { rectification.” (GB1); “...that is [when you become too big to fail]. } \\
\text { As a new industry, governments don't anticipate quick failure when } \\
\text { you have a fifty percent market share. Instead, they will ask how } \\
\text { governments can help you by making beneficial regulations. They } \\
\text { want to take advantage of you because you can provide jobs and you } \\
\text { can reduce the pressure on public finances.” (YB2) }\end{array}$ & Strategic suboptimality \\
\hline & $\begin{array}{l}\text { How to reduce social } \\
\text { complaints of } \\
\text { embezzling users' } \\
\text { deposits. }\end{array}$ & $\begin{array}{l}\text { Economic (marketing) } \\
\text { strategy: Announced the } \\
\text { zero-deposit policy with } \\
\text { Zhima Credit }\end{array}$ & $\begin{array}{l}\text { Social (prognostic framing) strategy }(+) \\
\text { - "A zero-deposit policy in many cities is practical and more concrete. } \\
\text { I personally feel they should have adopted it earlier." (BS1); } \\
\text { "Customer deposit misuse is an open secret. Many bankrupted bike- } \\
\text { sharing ventures embezzled the money to buy new bikes or even } \\
\text { invested in the stock market... The criticisms on websites were not } \\
\text { unfounded... In my opinion, the most practical way to let social } \\
\text { publics and customers trust you is by charging no deposits." (BR4) }\end{array}$ & Strategic suboptimality \\
\hline Bluebike & $\begin{array}{l}\text { How to acquire } \\
\text { investment as quickly } \\
\text { as possible to offer } \\
\text { best-quality bikes for } \\
\text { customers. }\end{array}$ & - & $\begin{array}{l}\text { Rush into several markets directly } \\
\text { - "It was so arrogant when it was at its most successful. It should have } \\
\text { got as much money as possible from the foundation. But, after } \\
\text { August, many investors were spectacularly crowded into the top two. } \\
\text { It was too late. Who wants to invest in an uncompetitive follower?" } \\
\text { (BS2); "[Bluebike] as a latecomer had to sacrifice more resources to } \\
\text { capture a large market share. This was indisputable and a priority at } \\
\text { that moment." (BR3). }\end{array}$ & $\begin{array}{l}\text { Niche experimentation } \\
\text { (No implementation) }\end{array}$ \\
\hline
\end{tabular}




\begin{tabular}{|c|c|c|c|c|}
\hline Case & $\begin{array}{l}\text { Co-evolution } \\
\text { Challenge }\end{array}$ & $\begin{array}{l}\text { Economic or Coopetitive } \\
\text { or Political or Social } \\
\text { Strategy: Critical Event }\end{array}$ & $\begin{array}{l}\text { Ecosystem-Specific Strategy (Effect) } \\
\text { (Representative Quotes) }^{\mathrm{b}}\end{array}$ & $\begin{array}{l}\text { New focal venture's } \\
\text { strategizing forms } \\
\text { (Proposed Constructs) }\end{array}$ \\
\hline & $\begin{array}{l}\text { How to compete for } \\
\text { dominating the bike- } \\
\text { sharing service market } \\
\text { efficiently and } \\
\text { effectively. }\end{array}$ & $\begin{array}{l}\text { Economic (supply chain } \\
\text { management) strategy: } \\
\text { Collaboration with Ant } \\
\text { Financial; } \\
\text { Coopetitive (offensive) } \\
\text { strategy: Free-of-charge } \\
\text { policy }\end{array}$ & $\begin{array}{l}\text { Economic (marketing) strategy (+) } \\
\text { - “[An aggressive price war] has temporary benefits. In the long } \\
\text { range, it does not seems good.” (BR3); "This is about survival or } \\
\text { distinction. We use this strategy to wash away competitors with bad } \\
\text { bikes..." (COO, Online interview); "The customer increase was } \\
\text { immediate and striking. Bluebike has established its status in the } \\
\text { bike-sharing industry.” (online report). }\end{array}$ & Strategic versatility \\
\hline & $\begin{array}{l}\text { How to keep loyal end- } \\
\text { users to use the new } \\
\text { version of shared bikes. }\end{array}$ & $\begin{array}{l}\text { Economic (marketing) } \\
\text { strategy: Collaboration with } \\
\text { ZPLAY Games to do } \\
\text { marketing activities }\end{array}$ & $\begin{array}{l}\text { (Anticipatory) political strategy (-) } \\
\text { - "These stupid [marketing] activities thoroughly de-legitimated its } \\
\text { business." (BR1) } \\
\text { Economic (vision diffusion) strategy (-) } \\
\text { - "We have been cursed since June, first with an advertising accident } \\
\text { that affected a large investment and with possible acquisition." } \\
\text { (BB1); "Our quick growth stopped because of this unforeseeable } \\
\text { accident. I just do not know what happened and nobody can tell” } \\
\text { (BB2). }\end{array}$ & $\begin{array}{l}\text { Strategic versatility } \\
\text { (Ineffective implementation) }\end{array}$ \\
\hline & $\begin{array}{l}\text { How to address central } \\
\text { and local governments' } \\
\text { strict regulations. }\end{array}$ & $\begin{array}{l}\text { (Reactive) corporate political } \\
\text { strategy: The official } \\
\text { announcement for end-users }\end{array}$ & $\begin{array}{l}\text { Economic (supply chain management) strategy (-) } \\
\text { - We feel so sorry for all the customers. We have to stop the payment } \\
\text { system so as to protect the remaining deposits." (Alipay online } \\
\text { announcement) }\end{array}$ & $\begin{array}{l}\text { Strategic versatility } \\
\text { (Ineffective implementation) }\end{array}$ \\
\hline & $\begin{array}{l}\text { How to sustain the } \\
\text { bike-sharing service in } \\
\text { major home cities. }\end{array}$ & $\begin{array}{l}\text { Economic (marketing) } \\
\text { strategy: Abruptly changed } \\
\text { its discount package without } \\
\text { VIP customers' consent }\end{array}$ & $\begin{array}{l}\text { Social (diagnostic framing) strategy (-) } \\
\text { - "Local newspapers [Shengyang and Chengdu] publicly challenged } \\
\text { Bluebike and demanded that it respond. Since then, many social } \\
\text { media and We-media joined the propaganda" (Online report). }\end{array}$ & $\begin{array}{l}\text { Strategic versatility } \\
\text { (Ineffective implementation) }\end{array}$ \\
\hline & $\begin{array}{l}\text { How to deal with social } \\
\text { criticisms about } \\
\text { embezzling users' } \\
\text { deposits. }\end{array}$ & $\begin{array}{l}\text { Social (diagnostic framing) } \\
\text { strategy: Avoid to respond to } \\
\text { the social criticisms }\end{array}$ & $\begin{array}{l}\text { (Reactive) political strategy (-) } \\
\text { - "[Greenbike and Bluebike] should meet our appeals. Otherwise, on } \\
\text { behalf of users, they will be prosecuted." (PA4); "Slanders are out } \\
\text { of their control...they should not have cheated the publics" (BS1). }\end{array}$ & $\begin{array}{l}\text { Strategic versatility } \\
\text { (Ineffective implementation) }\end{array}$ \\
\hline Greenbike & $\begin{array}{l}\text { How to test bike- } \\
\text { sharing service in } \\
\text { urban areas. }\end{array}$ & - & $\begin{array}{l}\text { Political/social stakeholders' attitudes } \\
\text { - "Governments' elusive attitudes impacted on our market decisions. } \\
\text { This is also true for many others who had to have good relationships } \\
\text { with them... we have no extra energy to meet their diverse needs." } \\
\text { (GB1); "We initially outsourced the operations jobs to experienced } \\
\text { ones, but they refused to continue working because of the huge } \\
\text { numbers of bikes being distributed.” (GB1) }\end{array}$ & $\begin{array}{l}\text { Niche experimentation } \\
\text { (Ineffective implementation) }\end{array}$ \\
\hline
\end{tabular}




\begin{tabular}{|c|c|c|c|c|}
\hline Case & $\begin{array}{l}\text { Co-evolution } \\
\text { Challenge }\end{array}$ & $\begin{array}{l}\text { Economic or Coopetitive } \\
\text { or Political or Social } \\
\text { Strategy: Critical Event }\end{array}$ & $\begin{array}{l}\text { Ecosystem-Specific Strategy (Effect) } \\
\text { (Representative Quotes) }^{\mathrm{b}}\end{array}$ & $\begin{array}{l}\text { New focal venture's } \\
\text { strategizing forms } \\
\text { (Proposed Constructs) }\end{array}$ \\
\hline & $\begin{array}{l}\text { How to operate shared } \\
\text { bikes more effectively } \\
\text { and efficiently. }\end{array}$ & $\begin{array}{l}\text { Economic (innovation } \\
\text { orchestration) strategy: } \\
\text { Adopted smartlocks and } \\
\text { gave up Bluetooth-related } \\
\text { technologies }\end{array}$ & $\begin{array}{l}\text { Economic (marketing) strategy (+) } \\
\text { - "We can approach users more precisely with their help." (GB1) }\end{array}$ & Strategic versatility \\
\hline & $\begin{array}{l}\text { How to outperform the } \\
\text { competitors effectively. }\end{array}$ & $\begin{array}{l}\text { Economic (innovation } \\
\text { orchestration) strategy: } \\
\text { Release the Tuhao Gold } \\
\text { bike-sharing version }\end{array}$ & $\begin{array}{l}\text { Economic (marketing) strategy }(+) \\
\text { - "When they released this } 3.0 \text { version, It became an overnight hit on } \\
\text { social media platforms. Many customers want to use these new } \\
\text { bikes." (GB2); "I think they take it as a kind of marketing actions to } \\
\text { catch end-users' attention and it works very well actually" } \\
\text { (Industrial analyst, Online report) }\end{array}$ & Strategic versatility \\
\hline & $\begin{array}{l}\text { How to attract end- } \\
\text { users quickly. }\end{array}$ & $\begin{array}{l}\text { Coopetitive (offensive) } \\
\text { strategy: Free-of-charge } \\
\text { policy and cash bonus }\end{array}$ & $\begin{array}{l}\text { Economic (marketing) strategy (+) } \\
\text { - "Greenbike even surpassed Bluebike in July." (quarterly industrial } \\
\text { report); "We have beautiful operation data on some major cities, } \\
\text { such as Shenyang and Beijing." (GB3) }\end{array}$ & Strategic versatility \\
\hline & $\begin{array}{l}\text { How to sustain bike- } \\
\text { sharing service in } \\
\text { cities. }\end{array}$ & $\begin{array}{l}\text { Economic (marketing) } \\
\text { strategy: Abruptly changed } \\
\text { users' deposit refund } \\
\text { procedure }\end{array}$ & $\begin{array}{l}\text { Social (diagnostic framing) strategy (-) } \\
\text { - "It just becomes a vicious circle [customers' runs on reclaims and } \\
\text { negative reports]." (GB2) }\end{array}$ & $\begin{array}{l}\text { Strategic versatility } \\
\text { (Ineffective implementation) }\end{array}$ \\
\hline & $\begin{array}{l}\text { How to address salient } \\
\text { social doubts about } \\
\text { illegally embezzling } \\
\text { customers' deposits. }\end{array}$ & $\begin{array}{l}\text { Social (issue management) } \\
\text { strategy: A short public } \\
\text { announcement }\end{array}$ & $\begin{array}{l}\text { Economic (marketing) strategy (-) } \\
\text { - “This is absolutely fruitless. People think it’s just a fiction.” (GB1) } \\
\text { Economic (supply chain management) strategy (-) } \\
\text { - "Until it returns all the money, we will stop our collaboration." } \\
\quad \text { (Partner's public announcement) }\end{array}$ & $\begin{array}{l}\text { Strategic versatility } \\
\text { (Ineffective implementation) }\end{array}$ \\
\hline & $\begin{array}{l}\text { How to address salient } \\
\text { social criticisms about } \\
\text { its relationship with a } \\
\text { financial P2P company. }\end{array}$ & $\begin{array}{l}\text { Social (diagnostic framing) } \\
\text { strategy: The CEO was } \\
\text { deposed by the board } \\
\text { committee }\end{array}$ & $\begin{array}{l}\text { Economic (vision diffusion) strategy (-) } \\
\text { - "The possible merger also failed." (BR2) } \\
\text { (Reactive) political strategy (-) } \\
\text { - "[Greenbike and Bluebike] should meet our demands. Otherwise, on } \\
\text { behalf of users, they will be prosecuted." (PA4) }\end{array}$ & $\begin{array}{l}\text { Strategic versatility } \\
\text { (Ineffective implementation) }\end{array}$ \\
\hline
\end{tabular}

Note: a: This is only a subset of our analysis, included here for illustration purposes. The complete set is available from the authors on request; $b:$ : + and "-"indicate positive and negative interactive effects of the two types of ecosystem-specific strategies, respectively. 



\section{CHAPTER 4}

\section{Learning to Swim in the Pool Before Surfing in the Sea: A Study of Local Innovation Experimentation}

\section{Based on:}

1. Han, J., Löwik, S., Zhou, H., de Weerd-Nederhof, P. \& Wang, Y. (2021). Learning to swim in the pool before surfing in the sea: a study of local innovation experimentation. Paper presented at the $81^{\text {st }}$ Annual Meeting of Academy of Management, Virtual.

2. Han, J., Löwik, S., Zhou, H., de Weerd-Nederhof, P. \& Wang, Y. (2021). Learning to swim in the pool before surfing in the sea: a study of local innovation experimentation. Paper presented at the XXXII ISPIM Innovation Conference (Virtual), Berlin, Germany. 
ABSTRACT: Successful delivery of complex innovations to mass societies requires innovative firms and key partners to firstly perform a series of experimentation activities at the small-scale local society level. In this study, we define such localized experimentation processes as Local Innovation Experimentation (LIE). LIE helps managers form a complete innovation-ecosystem boundary around the proposed complex innovations. To better understand what determines success of LIE, we adopt the managerial dynamic capabilities framework, assuming that top management team-based capabilities have a positive impact on the performance of LIE and that such relationships are further contingent on the level of local innovation support. Using a sample of 111 innovative Chinese firms, we examine our hypotheses by applying PLS-SEM models. Our empirical findings support the assertion that managers with higher metacognitive capability, networking capability, or learning agility perform better in the LIE. Moreover, the positive relationship between network capability and the performance of LIE, and between learning agility and the performance of LIE become stronger if managers use strong local networking support and local innovation facilities support respectively. By introducing the dynamic capabilities perspective into the examination of LIE, our most important contribution is a more detailed understanding of cross firm-system level mechanisms that underlie the very early stage of an innovation ecosystem. 


\subsection{INTRODUCTION}

Designing and performing local innovation experimentation is fundamental for helping firms to develop complex innovations. Local Innovation Experimentation (hereafter, we use LIE) refers to a strategic innovation process that a focal firm and its key partners test the feasibility of innovative products (services/processes) in local small-scale societies to make them sufficiently mature to enter mass societies. Compared to regular market testing (Dolan and Matthews, 1993; Klompmaker, 1976; Piller and Susumu, 2006) and business-driven experimentations (Aminoff and Pihlajamaa, 2020; Murray and Tripsas, 2004), the LIE targets a broader range of ecosystem-related actors, such as governments and citizen groups, next to the usual economic actors such as customers, retailers, and suppliers.

Considering a typical example in the bike-sharing industry, Han et al. (2018) found that two Chinese bike-sharing ventures (Redbike and Yellowbike) experimented with smart dockless sharing bikes in local, small-scale societies (i.e., Yangpu District of Shanghai and Beijing college campus). Through a set of experiments with key partners, they explored multifaceted dimensions of the feasibility for sharing bikes, such as technical features, real-world riders' feedback, competitors’ reactions, and both social and regulatory attitudes. As a result, two ventures were able to develop innovation ecosystems around smart sharing bikes. In contrast, their two strong competitors did things differently. Bluebike skipped the localized experimentation process and rushed into mass societies directly; Greenbike operated the experimentation process ineffectively because it misinterpreted the local regulators' feedback. Two competitors with ineffective LIEs led them to bankruptcy and failure's in developing viable bike-sharing ecosystems.

Despite the strategic importance for firms' survival and developments of innovation ecosystems, the high-level performance of LIE is not easily achievable. First, the management of key partners is problematic. The LIE is time-consuming, requiring key partners' considerable resources to be invested into the proposed complex innovations (Chesbrough and Teece, 1996). Whether the proposed innovations could be turned into commercially successful ones is unknown at the outset to all actors engaged in the innovation co-creation process (Pekkarinen et al., 2020). Due to varying perceptions of uncertainties toward whether investment will pay off, focal firms' collaboration capabilities become indispensable to stabilize key partners' commitment. 
Second, specific capabilities must interpret diverse feedback from local ecosystem actors whose dynamic interactions would otherwise hamper the LIE results. Prior literature has articulated that market testing and business-driven experimentations aim to cope with new products' technical uncertainties and competitors' reactions, with a focus on innovations' economic environment (Aminoff and Pihlajamaa, 2020; Di Benedetto, 1999; Klompmaker, 1976; Piller and Susumu, 2006). Beyond the economic environment, the LIE requires focal firms to also work around non-technical uncertainties (regulatory compliance and societal fitness) in the particular socio-political environment. It is plausible that during new products' ongoing exposure to the public, on-site feedback from both ecosystem environments is not as straightforward as in regular marketing tests, but often interacting, surprising, and seemingly random (Gillier and Lenfle, 2019). Such feedback ambiguity causes problems for focal firms in making precise interpretations about the proposed innovations.

Third, the feedback ambiguity adds a high level of complexity such that new technical and non-technical problems during the LIE arise unpredictably. This makes it imperative that managers should be problem-solving competent to make trade-offs between innovations' various dimensions in a timely manner. Market tests and business experiments pursue innovation-market fit by pinpointing the best answers to innovations' technical dimensions (Hampel et al., 2020). Managers also seek, via LIE, for non-technical dimensions of innovations (e.g., governmental restriction and social refusal). They often have to sacrifice technical dimensions to meet changing demands from local regulatory agencies (Oskam et al., 2020). To what extent managers could balance the technical and non-technical dimensions, therefore, determines whether or not the proposed innovations would be successful in mass societies (see Pekkarinen et al., 2020).

As a result of these challenges, namely, partner instability, feedback ambiguity, and problem complexity inherent in LIE, it becomes crucial to understand how managers can deliver a high-level LIE performance. To date, in the limited number of case studies, scholars have merely showed the main principles of LIE and its connections to the innovation ecosystem emergence (e.g., Mahmoud-Jouini and Charue-Duboc, 2017). When looking into the mechanisms behind the successful emergence of an innovation ecosystem, the existing literature has indicated the importance of focal firms' dynamic capabilities (e.g., Cao et al., 2020; Feng et al., 2019; Kashan and Mohannak, 2017; Lütjen et al., 2019; Velu, 2015; Walrave et al., 2018). Thus, it is reasonable to anticipate that focal firms' dynamic capabilities as important antecedents would also determine the LIE's performance due to its relation to an 
innovation ecosystem during its very early stage. Hence, we ask: what organizational dynamic capabilities can lead focal firms to deliver the high LIE performance?

To address the research question, we adopted the dynamic managerial capability framework promoted by Adner and Helfat (2003). We hypothesize that focal firms' three key capabilities, that is, metacognitive capability (top managers' cognition), networking capability (top managers' social capital), and learning agility (top managers' human capital), are associated with a high LIE performance. Moreover, LIE is a socio-spatially embedded strategic innovation process (Ansell and Bartenberger, 2016). The spatial context might explain the variation in LIE implementation by focal ventures having similar capabilities. We hence consider that the localized innovation supports (i.e., consultancy services, networking opportunities, and innovation facilities), which represent available resources offered by geographically nearby third-parties (Autio et al., 2018; Morretta et al., 2020; Spigel, 2017), might exert contingent effects on the relationships between capabilities and LIE performance.

We run PLS-SEM models to attempt to corroborate our hypotheses using a sample of 111 innovative firms that operate in Chinese high-tech industries. The path models support our hypotheses that managers' metacognition capability measured as the effectiveness of feedback processing, networking capability (as proxied by the effectiveness of partner management), and learning agility (measured as the effectiveness of problem addressing), are positively associated with the performance of LIE carried out by focal firms. Except for the metacognition capabilityLIE relationship, positive effects of networking capability and learning agility on LIE are strengthened when the local environment provides more networking opportunities and various innovation facilities.

Our study makes three primary contributions. First, using the operationalized measurement, we broaden the applicability of LIE as a research construct in innovation studies. Second, we integrate the managerial dynamic capabilities perspective into the examination of the LIE's performance variability. Our empirical results suggest that dynamic capabilities reflecting the TMTs' cognition, human capital, and social capital correlate positively to the LIE. It is suggested that to understand what leads to the high performance of innovation-centric experimentations similar to the LIE, scholarly attention should be paid to the multiple, higherorder dynamic capabilities, as opposed to the single, generic ones. Third, we add theoretical insights into the cross-level mechanisms that underlie the emergence of an innovation ecosystem. While most scholars only highlight the LIE's importance to the successful emergence of an innovation ecosystem, our study takes a further step to investigate key 
antecedents of focal firm capabilities and their interaction with ecosystem-level contingency factors. This makes our study depart from the current literature, which usually theorizes the direct link between focal firms' dynamic capabilities and the emergence and growth of an innovation ecosystem. Hence, we answer recent calls for theoretical nuances regarding how an innovation ecosystem emerges at all. Furthermore, a theoretical implication is that future research should consider multiple levels to examine how an innovation ecosystem emerges.

\subsection{THEORY AND HYPOTHESIS DEVELOPMENT}

In this section, we first develop a model of the LIE from an innovation ecosystem perspective. Then, based on the capability literature, three TMT-based capabilities are posited to influence LIE's performance. Considering the regional innovation context, we further hypothesize how the relationships between three capabilities and LIE are contingent on three local innovation supports.

\subsubsection{A model of the LIE: from an innovation ecosystem perspective}

The LIE may be viewed as a strategic innovation process that involves design, implementation, execution, and refinement of experimentation actions, decisions, and activities for complex innovation development. For instance, a big company and ten partners work to experiment with new hydrogen-electric solutions in interested local communities (Mahmoud-Jouini and CharueDuboc, 2017). Brazilian ventures conducted collective experiments to test biotech products' feasibility before they were successfully diffused into mass societies (de Vasconcelos Gomes et al., 2018). As such, the LIE is purposely undertaken by firms to more closely link the proposed innovations to the fast-changing demands of mass societies (Hampel et al., 2020; Murray and Tripsas, 2004).

Based on some peculiarities of the LIE, conceptualizing it from an innovation ecosystem perspective is sensible, for three significant reasons. First, the innovations proposed by focal firms tend to be systemic, suggesting that such innovations "can be realized only in conjunction with related, complementary innovations” (Chesbrough and Teece, 1996, p. 128). Besides, such proposed novelties are complex, in which they "comprise many parts with unknown and unpredictable interactions” (Dougherty and Dunne, 2011, p. 1214). Such unknown uncertainties prompt all experimenters - that is, focal firms and key partners - to search generatively for its optimal performance landscape (Dattée et al., 2018). Thus, it is expected that all experimenters might struggle into liabilities of an innovation ecosystem's nascence, where the overall 
perimeters of novel innovations are not yet stabilized, additional contributors to innovations are not all identified, and interdependency rules between contributors are still not entirely defined. Such innovation ecosystem nascence conforms to what Adner (2012) justified that all experimenters formed as the ecosystem's core create a "minimum viable ecosystem” (see "the core” in Figure 4.1).

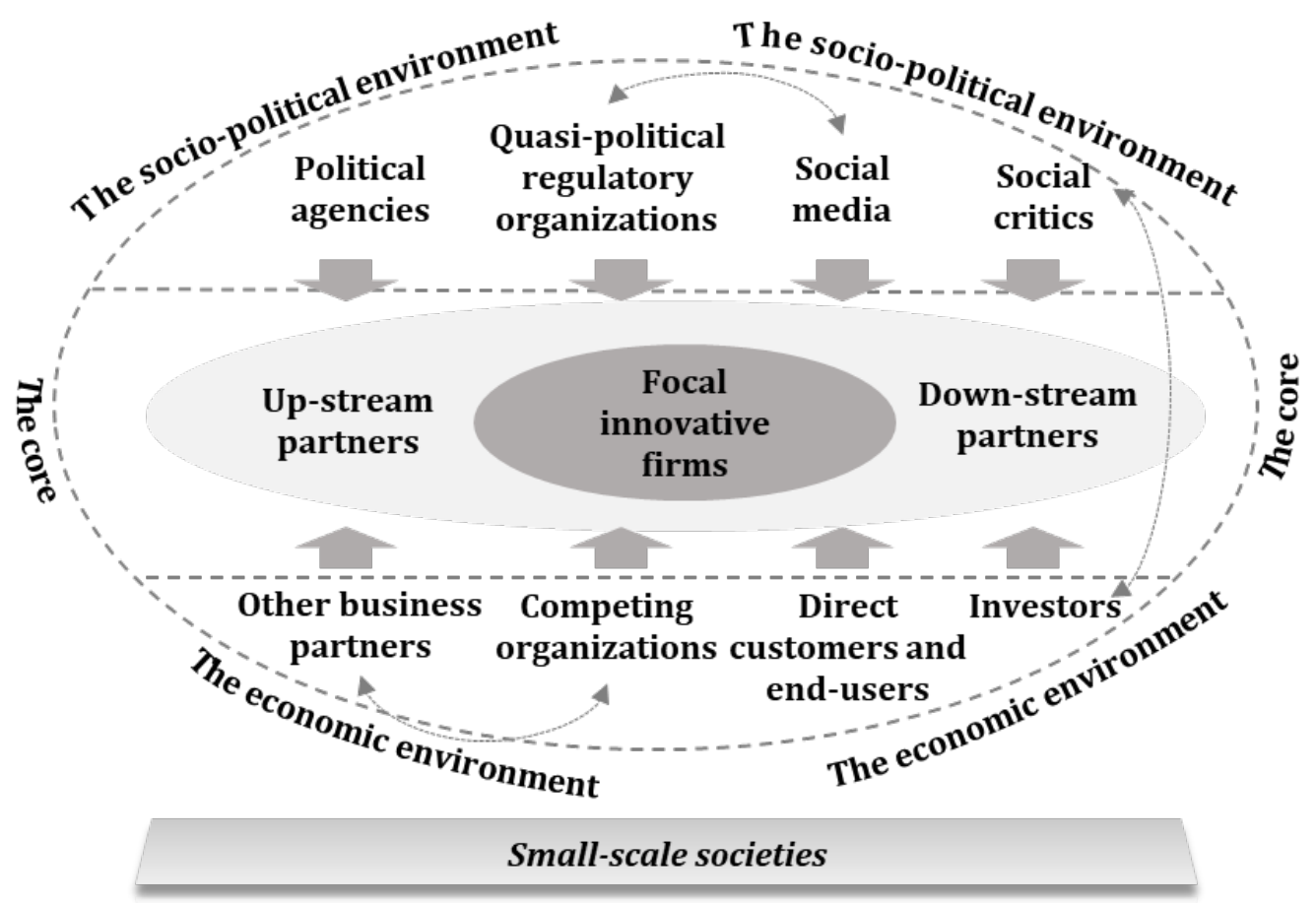

Figure 4.1: A model of the LIE (Adapted from Adner, 2012).

Second, due to the proposed innovations' systemic and complex nature, experimenters should collectively design and perform experimentation activities at an innovation ecosystem scale to reduce uncertainties. As depicted in Figure 4.1, through the LIE, experimenters aim to probe uncertainties in the economic (i.e., technical functions, customers' demands, and competitors' reactions) and socio-political environments (regulators' attitudes and societal feedback) (Oskam et al., 2020; Pekkarinen et al., 2020; von Pechmann et al., 2015). This differs from regular marketing Beta tests and business experiments that target uncertainties in the economic environment (e.g., Aminoff and Pihlajamaa, 2020; Klompmaker, 1976). Consequently, effective LIE assists experimenters in outlining the innovation ecosystem boundary around the proposed innovations, thereby paving the way for innovations future development based on a viable innovation ecosystem. Specifically, as the dotted circle and lines in Figure 4.1 showed, such ecosystem-specific boundary includes, for example, actor structures (e.g., social medium are indirect ecosystem contributors), actor dynamics (e.g., central 
regulators will impose restrictions on innovation development), and ecosystem-specific interaction relationships (e.g., social critics affect investors’ acts).

Third, the uncertainties distributed in an ecosystem-scale require LIE to be executed in local small-scale societies. According to scholars, local small-scale societies refer to, for example, college campuses (Han et al., 2018), hospitals (Hyysalo and Hakkarainen, 2014), or specific urban districts (Noel and Sovacool, 2016). The underlining principle is that unlike inhouse experimentations restricted to controlled conditions (Ansell and Bartenberger, 2016; Thomke, 2003), experimenters could collect economic and socio-political uncertainties in realworld local societies (Mahmoud-Jouini and Charue-Duboc, 2017; Pekkarinen et al., 2020). Besides, the logic of close-to-real-life is in line with the contextualization literature that emphasizes the affordance of spatial context in developing entrepreneurial innovations (Autio et al., 2014; Ferreira et al., 2017; Zahra et al., 2014). In the case of the LIE, local knowledge providers - such as universities - empower complex innovation development with nonredundant knowledge and cutting-edge technologies (Clarysse et al., 2014; Morretta et al., 2020). Through the on-site feedback from local agencies, they can foresee how local agencies in other similar regions might treat the proposed innovations, thereby helping formulate futureoriented strategic plans and actions (Zahra and Nambisan, 2012). Moreover, the spatial regions are on a small scale so that managers have enough time and attention to monitoring the innovation development's real conditions. More importantly, it incurs limited costs for experimenters when they failed specific innovation purposes. In this respect, positioning LIE in small-scale societies is a safer innovation strategy for small firms that lead the LIE (Han et al., 2018). In all, taking such small-scale local societies as the springboards, focal firms become more confident in progressing towards mass societies with well-aligned economic and sociopolitical environments in which their proposed innovations operated (Walrave et al., 2018).

Despite the literature that has revealed main the principles related to the LIE and its connection to the emergence of the full-fledged innovation ecosystem, the knowledge about what leads to the high performance of LIE remains under-investigated. Current researchers have pointed out that the emergence and growth of innovation ecosystems depend primarily on focal firms’ dynamic capabilities. It is arguable that focal firms’ dynamic capabilities also play a vital role in the LIE. However, it was found that most studies focus on a single generic type of capability. For instance, scholars either related senior management team's cognitive capabilities (Cao et al., 2020; Nambisan and Baron, 2013), knowledge management capabilities (Kashan and Mohannak, 2017; Velu, 2015), innovation orchestration capabilities (Dougherty and Dunne, 
2011), or platform management capabilities (Liu and Rong, 2015) to the emergence of an innovation ecosystem. Yet particular agents of focal firms' interpretation of and response to uncertainties in two ecosystem environments requires broader thinking about the dynamic capabilities. In other words, understanding the LIE from the dynamic capabilities portfolio point of view seems to be valid (Feng et al., 2019; Lütjen et al., 2019). Following this line of thought, we rely on the dynamic managerial capabilities framework promoted by Adner and Helfat (2003). They claim that "dynamic managerial capabilities reflect three underlying factors: managerial human capital, managerial social capital, and managerial cognition” (Adner and Helfat, 2003, p. 1020). We then resort to theorizing how focal firms' metacognitive capability, networking capability, and learning agility influence the LIE performance.

Besides, existing innovation management research has widely revealed that the results of most strategic innovation projects are rooted in the specific innovation contexts that they are attached to (Autio et al., 2014; Ferreira et al., 2017; Zahra et al., 2014). The LIE is a sort of socio-spatially embedded innovation process (Ansell and Bartenberger, 2016). A holistic study of the LIE also requires the inclusion of salient effects that result from the regional innovation context the proposed innovations are embedded into. Hence, our model incorporates three key local innovation supports (i.e., consultancy services, networking opportunities, and innovation facilities) as moderating factors.

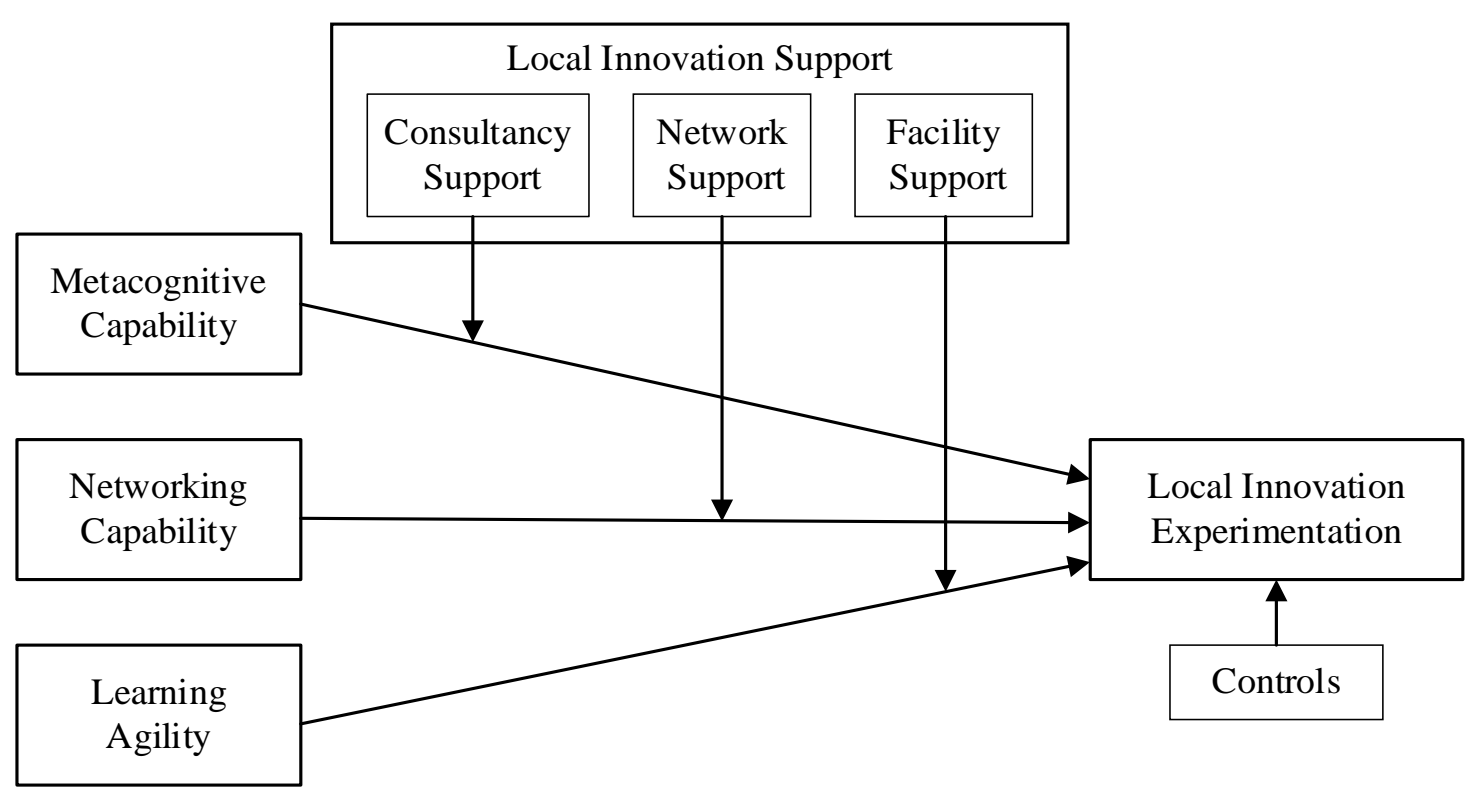

Figure 4.2: Conceptual model. 
The overall conceptual model integrating LIE, capabilities, and regional innovation supports is depicted in Figure 4.2. In what follows, we will demonstrate proposed relationships in the model in greater detail.

\subsubsection{Hypotheses development}

Before our six hypotheses development, it is important to note that we see focal firms' three capabilities at the top management team (TMT) level. This is because an organization's behaviors and overall performance reflect, and are determined by, its TMT's behaviors and performance (Hambrick and Mason, 1984). This link is much apparent when organizations respond strategically to change, adapt, and renew themselves for growth and survival in complex, turbulent environments (Carpenter et al., 2004; Teece, 2007), which fits precisely to the LIE. Grounded into the managerial capability literature, we will explicate how TMTs' metacognitive capability, networking capability, learning agility, which reflects focal firms' capabilities in cognition (Helfat and Peteraf, 2015), social capital (Acquaah, 2007), and human capital (Colombo and Grilli, 2005) respectively, relate to the LIE.

\subsubsection{Relating metacognitive capability to LIE}

To understand how focal firms conduct LIE effectively, we first focus on the role of metacognitive capability. Following Haynien and Shepherd (2009), we define metacognitive capability as a TMT's ability to reflect upon, understand, and consciously control their cognitive thinking related to a complex task. The metacognition literature has long demonstrated that under environments featured by high uncertainties, individuals with metacognitive competence would not rely cognitively on single thinking modes, habits, and strategies, and thus could better reduce the normal cognitive biases (e.g., overconfidence, selfjustification) (Haynie et al., 2012; Zahra and Nambisan, 2012). Specifically, through high-order “thinking about thinking” (Schraw and Dennison, 1994), metacognitively aware managers can think beyond existing knowledge structures and domain-specific experiences, resulting in multiple decision frameworks that maximize the likelihood of achieving tricky innovation goals (Haynie et al., 2010).

The idea of metacognitive capability is useful in our investigation of the LIE for three major reasons. First, metacognitively skilled TMTs could better harness various feedback that emerges from the LIE (Mitchell et al., 2011). As demonstrated previously, managers decide to implement the LIE to recognize technical and non-technical feedback as completely as possible. 
However, the ambiguity of multiple feedback streams requires availability to process information systematically. Based on these, studies revealed that metacognitively-skilled individuals would like to treat complex tasks in a self-regulated process (Cho and Linderman, 2019). In this sense, they first analyze their cognitive strengths and weaknesses when feedback floods in. These self-mindful practices help avoid falling into cognitive biases by detaching themselves from the previous self-centered to a system-level perspective of feedback (Kudesia, 2019). Besides, instead of processing feedback separately to allow one-on-one interpretations, managers separate useful information from the noise by combining different cognitive ways of hypothesizing, thereby providing more decision alternatives (Haynie et al., 2010). Last, temporally monitoring implemented strategies endows their metacognitions with the ability to iteratively adapt to the fast-changing environments (Haynie et al., 2012).

Second, metacognitively competent managers can tackle value tensions in the LIE. Key partners as value complementors are essential for the LIE, during which focal firms have to emphasize value creation rather than just value co-capture activities (Pekkarinen et al., 2020). Accordingly, tensions in the form of an imbalance between value co-creation and co-capture in this process. The co-created value at the ecosystem (not individual) level indicates that early key partners have a high probability of losing benefits from proposed innovations if the LIE fails (Oskam et al., 2020). To mitigate these drawbacks, managers of focal firms with high metacognitive skills are reported to manage discrepant goals better than other firms (Nambisan and Baron, 2013). They are more capable of employing non-conventional cognitive mechanisms such as abductive reasoning or counterfactuals to align the present with the future and balance the individual and whole (Haynie et al., 2010). In the analysis by Pidun et al. (2020), Airbnb's early quick success in the U.S. local community was attributed to the metacognitive choices that managers took to balance the value co-capture and co-creation tension with key partners in both the present and future.

Third, metacognitively self-aware managers are said to show high contextual adaptability. Generally, managers select local small-scale societies in which to perform LIE. However, very often, deliberately selected local societies are unrepresentative in aspects such as end-users, regulation requirements, and cultural preferences, requiring strengthened mental abilities to ensure contextual adaptability (Haynie et al., 2012). Cognitive psychologists have argued that managers' high metacognition associates positively with cross-cultural performance, such as creativity, reasoned decision-making, and strong adaptability (Mor et al., 2013). This suggests that culturally intelligent managers rely less on established cultural assumptions; instead, they 
are more capable of integrating inter-cultural communications, observations, reflections into novel cognitive understanding not accessible to individuals with less metacognition (Lorenz et al., 2018). For example, Better Place operated novel full electric vehicles (FEV) in two city regions: Copenhagen and Tel Aviv. They failed due to the failure to interpret Danish end-users' green attitudes toward FEV and Israel governments' regulatory focus (Noel and Sovacool, 2016). Based on the preceding arguments, we hypothesize that:

Hypothesis 1: TMTs with high metacognitive capabilities are more likely to show high LIE performance.

\subsubsection{Relating networking capability to LIE}

The LIE requires various key partners that are "minimum but viable”. "Minimum but viable" partners suggest that the unique value could still be created with the smallest, indispensable configuration of key partners (cf. Adner, 2012). To ally with key participants in the LIE, the literature has suggested the role of networking capability, referring to a firm's ability to initiate, develop, and even terminate diverse collaborative relationships (Mitrega et al., 2012, 2017). Such a definition extends the previous ones, which view networking capability as efforts made to form and maintain new collaborations to obtain unique resources held by potential partners (Walter et al., 2006). In LIE, direct key partners are viable because their close engagement makes an innovation's primary functions realized, improved, or revolutionized under dynamic demands, thus guaranteeing its core value. By tapping into portfolios of social ties, focal firms can first approach and persuade interested partners by presenting profitable business models (Bojovic et al., 2018; Feng et al., 2019), quality intellectual property (Pidun et al., 2020), substantial economic and social value (Doblinger et al., 2019), measurable results from early lead adopters (Dolan and Matthews, 1993). Using persuasion efforts, managers could involve key partners effectively into the shared visions.

After initiating partnerships successfully, managers with higher networking capabilities can orchestrate key partners to perform sets of future-oriented experiments. Note that key partners usually come from distant industrial domains, geographically distant areas, and institutional sections (Furr and Shipilov, 2018). These are sometimes referred to as "uncommon partners”, such as the well-known vehicle incumbents, presented in Better Place's experimentation activities (Noel and Sovacool, 2016). Note also that all experimenters developing a new-to-market complex innovation jointly for the first time, will face a heightened 
fear of opportunism and the sense of distrust might prosper. The orchestration mechanism, such as building common communication platforms, could enhance mutual trust and cause a sense of membership (Dougherty and Dunne, 2011; Liu and Rong, 2015); besides, focal firms as the relationship broker purposefully exploit synergies among partners, which in turn favor the LIE (Dougherty and Dunne, 2011). Last, through orchestrating key partners, focal firms hold partners in a shared fate so that some big incumbents if involved, cannot play the dominance (Gassmann et al., 2010). This is often the case for cross-border collaborations where asymmetric power between focal firms and big incumbents might otherwise erode LIE performance.

As a series of experiments needs attention, time, and resources, a superior networking capability suggests that focal firms could sever undesirable partnerships to enhance the LIE's efficiency. A plethora of innovation literature showed that too many collaborators and too few collaborators lead to less optimal collaboration performance (Hottenrott et al., 2016). Expanding on this line of reasoning, we hypothesize that focal firms would proactively sustain a minimum portfolio of key partners. To do so, they claim explicit assumptions on the proposed innovations. Partners do not perceive acceptable might quit ongoing LIE (Randhawa et al., 2020). Such strategic partner termination decisions lowers opportunism and the appropriation of risks (Mitrega et al., 2017). We hence suggest the following:

Hypothesis 2: TMTs with high networking capability are more likely to deliver high LIE performance.

\subsubsection{Relating learning agility to LIE}

The key purpose of the LIE is to reduce uncertainties around complex innovations (MahmoudJouini and Charue-Duboc, 2017). It is expected that managers of focal firms might encounter various emergent problems. As such, just as managers who are expert at problem-solving will be rewarded with satisfying innovation results (Atuahene-Gima and Wei, 2011), so too they will see decent LIE performance (von Pechmann et al., 2015). In our study, learning agility refers to managers' higher-order learning ability to detect problems and improvements, assemble needed resources to launch effective responses, judge the benefits and risks of initiating action, and execute actions with speed and flexibility (DeRue et al., 2012; Sambamurthy et al., 2003). Emphasizing the swiftness and flexibility of problems addressing in the LIE is advantageous, for two reasons. 
First, a high level of learning agility confers focal firms' first-mover advantages since they balance the cost, quality, and profitability of proposed innovations. Agile managers keep abreast of small improvements, mismatches, and abnormalities related to the innovation's realtime performance during experiments. For improvements, they leverage rapid learning circles to iterate quickly new knowledge into the next rounds of experiments, thereby reducing innovation exposure risks by applying the most up-to-date components of innovation (Aminoff and Pihlajamaa, 2020; Murray and Tripsas, 2004). When subtle mismatches and abnormalities are detected, agile learners can propose quality solutions creatively by exchanging new information, knowledge, and resources with key partners frequently (Overby et al., 2006). Therefore, such collective efforts sparked by active learners make them free from cost and time pressures.

Second, managers with learning agility defend their leadership during the LIE. As described in the preceding paragraph, problem detecting and solving require key partners' efforts, allowing parties to co-develop a nuanced understanding of what goes on in each other's operations and thus respond quickly and adapt to emerging demands or sudden changes encountered (Seidl and Werle, 2018). From this perspective, learning agility is a shared capability and the asymmetric capability distribution exists among focal firms and key partners (Carmeli et al., 2017). However, the higher the learning agility that focal firms possess compared to the partners, the more likely they can safeguard leadership during the LIE. This is rewarding when big established firms, which feature with high learning abilities, stay in the network of experimentation activities (Diestre and Rajagopalan, 2012). The outperformed skills in pinpointing changes, and further, proposing high-quality alternative solutions ensure that focal firms lead the navigation of LIE, rather than being bypassed or replaced by strong learners. We hence have the following:

Hypothesis 3: TMTs with high learning agility are more likely to deliver high LIE.

\subsubsection{The moderating role of local innovation support as a spatial context}

Given that the LIE is a socio-spatially embedded innovation process (Autio et al., 2014; Grashof et al., 2019; Zahra et al., 2014), we then seek to understand the effects of local innovation supports on the relationship between three capabilities and the LIE. Our theorizing builds significantly on the recent entrepreneurship ecosystem research that emphasizes the critical role of the systemic innovation agencies in a region supporting firms' innovation opportunity pursuit, 
experimentations, scale-up (Autio et al., 2018). By local innovation support, we mean the local supporters' acts of providing focal firms with access to valued resources to fulfill innovation goals (Kaufmann and Tödtling, 2002; Patton and Kenney, 2005). Supports are "materialrelevant” (Spigel, 2017), being either convenience-based in which supporters expect economic compensations, or value-based in which there is no expectation of reciprocity (Hanlon and Saunders, 2007). In all, we expect that focal firms obtain more remarkable LIE results if they approach various innovation supports (e.g., consultancy services, networking opportunities, and innovation facilities).

The first expectation is that approaching consultancy services will help focal firms perform LIE better. First, domain-specific insights into acquired feedbacks enable the sharpness of the metacognitive analyzing process. On the one hand, though managers are metacognitively aware, they are often susceptible to the shortage of domain-specific knowledge and experience. They therefore are new to experimenting with new products in an uncertain environment. On the other hand, local agencies' in-depth insights as "raw materials” of cognitive values are accessible to managers, resulting in richer and well-founded strategic decisions. Second, consultants from credible sources, like investment agencies, venture capitalists, experts, help managers cross-check profoundly whether metacognitive interpretations of feedbacks are tenable or not, thereby assisting in forming consistent experimentation strategies (Mitchell et al., 2011). Such benefits are more evident when focal firms decide to experiment with proposed innovations in foreign, unfamiliar regions (Noel and Sovacool, 2016). In this scenario, managers who are more inclined to use local consultancy services, such as marketing entry advice, investment suggestions, and regulative comments, might have better LIE results than others who do so less or not at all. Hence,

Hypothesis 4a: More frequent use of professional (e.g., marketing, financial, and regulatory) consultancy services offered by local agencies strengthens the positive effect of focal firms' metacognitive capability on LIE performance.

Our second expectation boils down to the findings that local third-parties' various networking activities promote a higher LIE performance. First, managers can win the interest partners that are industrially or geographically remote by fully capitalizing on networking opportunities, such as business and technology conferences. Consider an ambitious manager's desire to experiment with proposed innovations in foreign regions. They acquire legitimacy effectively from attending networking activities organized by local agencies (e.g., chamber of 
commerce or international consortia) whose endorsements pave the way for first-time collaborations (Parente et al., 2019). Second, through networking events, such as academic conferences, technology transfers, trade exhibitions, focal firms have opportunities to perfect innovations by applying advanced technologies. As a result, key partners' extended stay in LIE could be confirmed along with the proposed innovations' enhanced success rate. Third, activities like industrial standard-making meetings contribute to the stability of key partners in the LIE. According to Giudici et al. (2018), neutral third-parties independent of economic interests are in the best position to ease collaborative conflicts. Therefore, mutual trust between focal firms and key partners will be improved by such local arbitrators' networking events. Thus,

Hypothesis 4b: More frequently using networking activities arranged by local innovation agencies strengthens the positive effect of focal firms' networking capability on the LIE performance.

Our third expectation is that managers making the most use of enabling facilities have better LIE results. A fundamental assumption is that managers would be beset with a flood of feedback that is messy and emergent, when their experimentation activities (1) are in early periods, or (2) expand into regions simultaneously. As such, localized innovation-related infrastructures, such as test centers, IT digital equipment, and specialized manufacturing facilities, offer an excellent vehicle to augment the effects of managers' feedback processing capacity (Autio et al., 2018). To this purpose, first, various innovation facilities, such as realtime data monitoring systems/platforms, not only help data collection but to translate, combine, filter, and align data so that reliable problem-solving heuristics can be much reinforced (Overby et al., 2006; Sambamurthy et al., 2003). Second, well-architected innovation facilities catalyze the effects of managers' response capability on LIE results. For example, some emergent technical needs could be only met by sophisticated devices owned by local universities or national labs (Spigel, 2017). Moreover, integrated facilities, such as public living labs, offer managers opportunities to fulfil complex technical requirements altogether (Hyysalo and Hakkarainen, 2014). In sum, we conclude:

Hypothesis 4c: More frequent use of innovation facilities provided by local innovation agencies strengthens the positive effect of focal firms' learning agility on LIE performance. 


\subsection{DATA AND METHODOLOGY}

\subsubsection{Research setting and data collection}

Since no public dataset offers all of the information needed to test our hypothesized relationships, we use the questionnaire survey method to collect our data. Before conducting the survey, a questionnaire (in English) was designed and the scales were checked iteratively to enhance the content validity. Indicators for LIE (dependent variable), three capabilities (independent variable), and local innovation support (moderator) were adapted from (or inspired by) the existing literature.

Our data collection process involved two main steps. First, we conducted interviews with six science park managers in the Netherlands (four) and China (two) and our trial surveyed 16 respondents from these science parks. Feedback from them has three benefits. We were able to pilot-test our moderating effects. For example, we put questions to managers, such as "In terms of the above examples you give, did any companies seek help from your science park management team to carry out local innovation experimentation? If yes, what are the specific supports/services you provided to them?”. Second, we were better able to pinpoint into groups which our potential respondents fell. As one respondent suggested, "possibly, SME collaboration platforms might have enough examples. According to my experience, there are some doing innovation experiments...”. Third, we can better deal with potential issues such as wording, grammar, readability, or structure/layout of the survey.

Second, we selected two Chinese innovation-oriented platforms, namely, Newba and Koochang, to obtain access to a representative population consisted of 111 valid respondents. These two platforms are suitable because they consisting of enough samples that tend to develop new products or services by allying cross-industry partners. As the Newba CEO said, "our platform is the one that promotes 'cross-border' innovation”. Therefore, it is argued that firms might need the LIE to increase the success rate because of the newness of products or services to the market. To provide greater clarity about items, we translated the survey into Chinese. The first author and a hired translator used the back-translation method to ensure that the identical or an acceptably similar meaning remained across the two language versions (Brislin, 1970). Next, (1) to ensure that respondents completed surveys, we used Wenjuanxin (a webbased survey instrument similar to Qualtrics) to collect the data between 19 March and 19 June 2020. (2) We initially received 124 responses from top managers. They were allowed to fill in the survey after being informed of one of the latest innovation projects that resemble the LIE 
as we defined it. To ensure respondent competency, managers were only those who were part of the decision-makers concerning the referred innovation project(s). (3) Six responses out of 124 with more than 90\% repeated values (e.g., answering strongly (dis)agree with almost all items) were removed from the data set, to mitigate the negative impact of data skewing on parameter estimation and confidence intervals. (4) Further, the other seven responses of the remaining 118 spending less than 300 seconds were deleted after checking each response's timestamps - this ensured that only informants who treated surveys seriously.

Table 4.1: Descriptive statistics $(\mathrm{N}=111)$.

\begin{tabular}{llll}
\hline Item & Scale & $\mathbf{n}$ & \% \\
\hline Innovation Hub & Four Innovation Hubs & 60 & $54.1 \%$ \\
& Others & 51 & $45.9 \%$ \\
Company Age & $\leqslant 2000$ & 30 & $27.0 \%$ \\
& $2001-2005$ & 9 & $8.1 \%$ \\
& $2006-2010$ & 15 & $13.5 \%$ \\
Size & $2011-2015$ & 29 & $26.1 \%$ \\
& $2015-C u r r e n t$ & 28 & $25.2 \%$ \\
& $\leqslant 10$ & 6 & $5.4 \%$ \\
& $11-50$ & 22 & $19.8 \%$ \\
& $51-100$ & 14 & $12.6 \%$ \\
& $101-500$ & 20 & $18.0 \%$ \\
& $\geqslant 501$ & 49 & $44.1 \%$ \\
& Renewable energy and new material & 32 & $28.8 \%$ \\
& Electric vehicle and mobile Internet & 27 & $24.3 \%$ \\
& Next-generation mobile communication technology & 17 & $15.3 \%$ \\
& Manufacturing and artificial intelligence (AI) & 16 & $14.4 \%$ \\
& Biomedicine and devices & 7 & $6.3 \%$ \\
& Others & 12 & $10.9 \%$ \\
\hline
\end{tabular}

Table 4.1 provides descriptive statistics about the final sample $(\mathrm{N}=111)$. As shown, 60 respondents (54.1\%) are from four innovation hubs in China (i.e., Beijing, Shanghai, Guangzhou, and Shenzhen), where in contrasting to others, well-architected innovation resources are accessible for firms (see the recent report by CBRE, 2019). Over half of the sample were younger than ten years (51.3\%). The simultaneous examination of both new and established firms provide many reliable results. Besides, our $44.1 \%$ of the sample are firms with over 500 full-time employee indicating a balanced distribution of both SMEs and big firms. Finally, a typical feature of our sample is that most of them belong to emerging high-tech industries (for example, next-generation mobile communication technology, 15.3\%) or crossborder industrial domains (renewable energy and new material, 28.8\%; electric vehicle and mobile Internet, 24.3\%; manufacturing and AI, 14.4\%; biomedicine and devices, 6.3\%).

\subsubsection{Measurement}


Measurement specification requires operationalizing measurement models as either reflective or formative (Bollen and Lennox 1991). This choice in turn guides the selection of suitable methods for subsequent data reliability and validity assessments (Diamantopoulos and Winklhofer 2001). Specifically, for three capabilities and three types of local innovation supports, we adopted previously validated measures for the survey; inspired by previous experimentation literature, we created a three-item instrument to measure the LIE (see Appendix 4.1).

Dependent variable. LIE was measured as a first-order formative construct comprising three items. Given that the LIE scale is unavailable in previous literature, we developed relevant scales by following theoretical guidelines (Diamantopoulos and Winklhofer 2001). First, we proposed initial dimensions and indicators by referring particularly to Thomke (2003), whose characterizations of experimentation in developing new products have seven key aspects: fidelity, refinement, cost, duration, timing in progress, knowledge target, and participants involved. Relevant items were initially co-developed by the authors according to these seven aspects. We then circulated the LIE definition, seven dimensions, and the initially proposed indicators among three innovation professors and three industry experts. Two rounds of reviewing processes ensured that three of seven key aspects - involved participants (actor variety), fidelity (close to real-life), knowledge target (feedback) - are fundamental to LIE. Second, we operationalized the three aspects into relevant indicators reviewed by two academic entrepreneurs, four experts, and ten doctoral researchers.

To measure LIE performance, respondents needed to report their recent innovation project(s) during which they executed LIE by (1) collaborating with key partners ("the same industry”, "totally different industry”, “university/research institutes”, "governmental partners” to "societal partners"), (2) experimenting with novel products involving real-life actors in different developmental stages (“innovation ideas”, “mock-ups”, “initial prototypes”, “improved versions” to "ready-for-mass-market”), and (3) receiving on-site feedback on proposed products (“technical functions”, “real-life end-users' demands”, “competitors’ reactions”, “political agencies’ attitudes” to “societal stakeholders’ attitudes”). Each indicator (Experiment_1 to Experiment_3) was converted as the sum of the selected items. Scores ranged from 0 to 5; higher scores meaning the higher level of each indicator. For instance, concerning the actor variety, the " 0 " = no partners were engaged in LIE, indicating the lowest level of actor variety; the " 5 " = all five types of partners participated in LIE, indicating the highest level of actor variety. 
Independent variable. Three capabilities were reflective variables and used seven-point Likert scales ( $1=$ strongly disagree; $7=$ strongly agree). Specifically, the metacognitive capability was measured using 19 items adopted from Haynie and Shepherd (2009). This variable comprised two subdimensions: metacognitive knowledge (items Metacog_11 to Metacog_111) and metacognitive experience (items Metacog_21 to Metacog_28). These items captured TMT members' treatments of important management and operational activities/decisions in turbulent environments. We asked for example, "Our TMT members can think of several solutions to solve a problem and choose the best one.”. The measurement of networking capability followed Mitrega et al. (2012). These items measured managerial practices regarding how CEOs manage strategic collaborations (items Network_1 to Network_7). Likewise, a representative question was: "We try many ways to persuade and "lock in” our partners in cooperation with us.”. Learning agility was used to assess problemsensing speed (items Learn_11 to Learn_14) and solution quality (items Learn_21 to Learn_23) when top managers solve problems during the innovation development process. Seven items from Atuahene-Gima and Wei (2011) were adopted. A typical question was "our company was always able to quickly recognize small mismatches/abnormalities during our product development process".

Moderators. We measured local innovation support using three first-order reflective constructs ( 1 = very rarely used; 5 = very often used). We followed Spigel (2017) who suggested that three "material-relevant" types of supports (i.e., consultancy services [Support_11 to Support_14], networking activities [Support_21 to Support_24], innovation facilities [Support_31 to Support_34]) offered by local institutions are vital for firms' innovation activities. For example, we asked respondents: how often do you use the following local consultancy services to facilitate new product development activities: (a) market consultancy services; (b) regulatory consultancy services; (c) financial consultancy services; (d) other related consultancy services, such as (...).

Control variable. We included ten controls in our analysis, as these variables have been found to directly or indirectly influence the LIE performance. First, we controlled for “innovation hub” as the closer the innovative firms get to four innovation hubs (Yes = Beijing, Shanghai, Guangzhou, and Shenzhen; No = others), the more likely they will notice and leverage innovation supports from local institutions (Spigel, 2017), thereby possibly increasing the LIE performance. Second, we considered "firm age" (year), "firm size” (the number of fulltime employees), and "firm structure” (number of management layers and departments). Our 
choice of these is grounded on their acknowledged influence on learning agility (AtuaheneGima and Wei, 2011) and our dependent variable LIE (Thomke, 2003). Third, “TMT number”, “TMT industry diversity”, “TMT education diversity” needed to be controlled as the capability literature suggests that they correlate positively with the level of managers' metacognitive capability (see Mitchell et al., 2011) networking capability (see Mitręga et al., 2017), and learning agility (Sambamurthy et al., 2003), which in turn might influence LIE performance. Finally, “TMT risk propensity” and “innovativeness of products” are associated closely with CEOs' decisions to carry out LIE (Thomke, 2003). Four items in Kraiczy et al. (2015) were employed to assess TMT's overall propensity to risk, either being risk preference or risk aversion. Six items from Talke et al. (2015) were averaged to assess whether innovative products adopt new technologies and are new to markets or not.

Common Method Bias (CMB). We took several steps to alleviate concerns about CMB in our collected data. When designing the survey, the study used different response formats and scale endpoints for variables. When surveying, we assured respondents of confidentiality and encouraged honest responses by reminding them that there were no right or wrong answers. We also applied Harman's single-factor test by entering all variables into one-factor analysis. The results indicated that no serious single method factor existed (Kock 2015). The first factor accounted for only $17.22 \%$ of the variance, whereas the remaining factors accounted for $63.97 \%$. Furthermore, we used a latent common method factor to estimate the loadings on every item in the PLS path model, in addition to each item's loading on its theoretical construct (Kock 2015). Comparing the estimated path model relationships with and without each additional marker variable, we found no noticeable differences; all conceptualized paths maintained their statistical significance.

\subsection{ANALYSIS AND RESULTS}

Prior to our analysis, an assessment of whether our collected data show desirable statistical power was made. To estimate the minimum sample size, the ten-times rule, which considers the variable that has the highest number of predictors, was used (Goodhue et al., 2012). In our case, six was the maximum number of links pointing at the LIE construct, which means that 60 is the minimum sample size $(6 \times 10=60)$. Further, a G Power Analysis (GPower 3.1.9.4 software) was performed (Cunningham and McCrum-Gardner, 2007). Results showed that while for a medium effect size $\left(\mathrm{f}^{2}=0.30\right)$ at the alpha level of 0.05 , we needed a minimum sample size of 82 to achieve the acceptable power of 0.800 . Therefore, our sample $\mathrm{N}=111$ 
exceeded the required minimums and ensured the statistical analysis's reliability. Also, we conducted a post hoc statistical power analysis. The average effect size for the relationships included in the proposed model was 0.248 which, with an alpha level of 0.05 and four predictors, provided a statistical power of 0.762 , was close to the accepted threshold of 0.800 . The results of the two statistical power analyses above confirm that the empirical analysis's nonsignificant effects are not the result of the sample size.

We tested our hypotheses using the Partial Least Squares SEM (PLS-SEM) through ADANCO 2.2.0. PLS-SEM has advantages in processing simultaneously latent reflective and formative variables, samples in small size, relying less on distributional assumptions and, importantly, “identifying key 'driver' constructs” via a complex research model such as ours (Hair et al., 2011; Henseler and Dijkstra, 2015). Following PLS-SEM guidelines (Fassott et al., 2016; Henseler et al., 2016; van Riel et al., 2017), we performed a three-stage approach to evaluate our model: (1) assessment of global model fit, (2) assessment of the measurement model, and (3) assessment of the structural model. To find the significance of indices, we used the bootstrap procedure, with non-parametric resampling 5000 replications to achieve the estimates’ standard error.

\subsubsection{Assessment of overall goodness of model}

We evaluated the overall goodness of model fit of our saturated model by examining the standardized root mean squared residual (SRMR), unweighted least squares (ULS) discrepancy ( $\mathrm{d}_{\mathrm{ULS}}$ ), and geodesic discrepancy $\left(\mathrm{d}_{\mathrm{G}}\right)$ (Henseler et al., 2016). The lower values suggest a good fit of the proposed model. Table 4.2 shows that the results for confirmatory composite analysis provide empirical support for the structure of our composite constructs at first- and secondorder levels: the SRMR value was 0.047 (HI95 $=0.051)$ and 0.043 (HI95 $=0.053)$, well below the common cut-off threshold of 0.08 ; the values of duls was 1.454 (HI95 = 1.724) and 1.113 $(\mathrm{HI95}=1.126)$, and the $\mathrm{d}_{\mathrm{G}}$ was $1.745(\mathrm{HI95}=2.055)$ and $1.353(\mathrm{HI95}=1.662)$.

Table 4.2: Results for the confirmatory composite analysis.

\begin{tabular}{lllllll}
\hline \multirow{2}{*}{ Discrepancy } & \multicolumn{2}{l}{ First-order level } & & \multicolumn{2}{l}{ Second-order level } \\
\cline { 2 - 7 } & Value & HI95 & Conclusion & Value & HI95 & Conclusion \\
\hline SRMR & 0.047 & 0.051 & Supported & 0.043 & 0.053 & Supported \\
$\mathrm{d}_{\mathrm{ULS}}$ & 1.454 & 1.724 & Supported & 1.113 & 1.126 & Supported \\
$\mathrm{d}_{\mathrm{G}}$ & 1.745 & 2.055 & Supported & 1.353 & 1.662 & Supported \\
\hline
\end{tabular}




\subsubsection{Assessment of the measurement model}

Once the proposed model's overall quality had been established, we continued to assess the internal consistency reliability, and the convergent and discriminant validity of key constructs.

Indicator reliability. Table 4.3 shows that three capability constructs have individual indicator reliability values (i.e., loading ${ }^{2}$ ) that are greater than the minimum acceptable level of 0.4 and close to the preferred level of 0.7, except for Metacog_26 and Metacog_27 for metacognitive capability (0.478 and 0.541 , respectively) which had adverse effects on convergent validity and internal consistency reliability and so were deleted. Weights for dependent variables (minimum value 0.206 of Experiment_3) are above 0.2 and bootstrapping results show inter-item significance (Chin, 1998).

Internal consistency reliability. We use three measures to measure the reliability: Cronbach’s alpha, Dijkstra-Henseler's rhoA $\left(\rho_{\mathrm{A}}\right)$, and Jöreskog's rho $(\rho c)$. From Table 4.4, the inter-item consistency reliability values of Cronbach's alpha range from 0.806 to 0.866, which above the threshold of 0.7 as suggested by Nunnally (1978). The most consistent reliability Dijkstra- Henseler's rho $\left(\rho_{\mathrm{A}}\right)$ - that measure for PLS construct scores, also achieved satisfactory reliability value, ranging from 0.799 to 0.869 (Dijkstra and Henseler, 2015). Also, the Jöreskog's rho $(\rho \mathrm{c})$ (known as composite reliability) values range from 0.829 to 0.870 , which exceeded the recommended value of 0.7 (Nunnally, 1978). Hence, the overall reliability has achieved satisfactorily in terms of high internal consistency reliability.

Convergent validity. Based on data results, the constructs’ Average Variance Extracted (AVE) was in the range of 0.653 and 0.833 , which exceeded the recommended value of 0.5 (Fornell and Larcker, 1981). Therefore, our measurement model shows adequate convergent validity. 
Table 4.3: Factor Loadings and weights for measured constructs.

\begin{tabular}{|c|c|c|c|c|c|c|}
\hline Item Abbreviation & Metacog & Network & Learn & Support1 & Support2 & Support3 \\
\hline Metacog_11 & 0.822 & 0.724 & 0.660 & 0.635 & 0.614 & 0.458 \\
\hline Metacog_12 & 0.797 & 0.712 & 0.624 & 0.632 & 0.598 & 0.480 \\
\hline Metacog_13 & 0.835 & 0.722 & 0.648 & 0.650 & 0.573 & 0.422 \\
\hline Metacog_14 & 0.842 & 0.715 & 0.685 & 0.666 & 0.625 & 0.548 \\
\hline Metacog_15 & 0.858 & 0.750 & 0.686 & 0.622 & 0.626 & 0.560 \\
\hline Metacog_16 & 0.811 & 0.607 & 0.552 & 0.629 & 0.464 & 0.454 \\
\hline Metacog_17 & 0.793 & 0.654 & 0.564 & 0.600 & 0.476 & 0.479 \\
\hline Metacog_18 & 0.788 & 0.637 & 0.629 & 0.585 & 0.571 & 0.514 \\
\hline Metacog_19 & 0.803 & 0.659 & 0.640 & 0.632 & 0.577 & 0.512 \\
\hline Metacog_110 & 0.787 & 0.589 & 0.553 & 0.581 & 0.495 & 0.458 \\
\hline Metacog_111 & 0.845 & 0.653 & 0.595 & 0.616 & 0.544 & 0.503 \\
\hline Metacog_21 & 0.835 & 0.690 & 0.631 & 0.590 & 0.548 & 0.383 \\
\hline Metacog_22 & 0.848 & 0.686 & 0.617 & 0.604 & 0.572 & 0.402 \\
\hline Metacog_23 & 0.849 & 0.724 & 0.647 & 0.616 & 0.612 & 0.440 \\
\hline Metacog_24 & 0.828 & 0.711 & 0.662 & 0.562 & 0.514 & 0.506 \\
\hline Metacog_25 & 0.795 & 0.651 & 0.601 & 0.529 & 0.502 & 0.468 \\
\hline Metacog_28 & 0.806 & 0.438 & 0.351 & 0.496 & 0.374 & 0.346 \\
\hline Network_1 & 0.728 & 0.911 & 0.766 & 0.621 & 0.771 & 0.623 \\
\hline Network_2 & 0.713 & 0.907 & 0.741 & 0.562 & 0.719 & 0.593 \\
\hline Network_3 & 0.721 & 0.904 & 0.748 & 0.609 & 0.736 & 0.543 \\
\hline Network_4 & 0.721 & 0.875 & 0.685 & 0.586 & 0.712 & 0.583 \\
\hline Network_5 & 0.717 & 0.903 & 0.742 & 0.582 & 0.754 & 0.579 \\
\hline Network_6 & 0.736 & 0.910 & 0.777 & 0.585 & 0.753 & 0.585 \\
\hline Network_7 & 0.747 & 0.868 & 0.735 & 0.669 & 0.698 & 0.563 \\
\hline Learn_11 & 0.655 & 0.760 & 0.808 & 0.493 & 0.672 & 0.674 \\
\hline Learn_12 & 0.683 & 0.733 & 0.810 & 0.486 & 0.628 & 0.649 \\
\hline Learn_13 & 0.667 & 0.744 & 0.915 & 0.496 & 0.644 & 0.705 \\
\hline Learn_14 & 0.676 & 0.737 & 0.897 & 0.563 & 0.637 & 0.707 \\
\hline Learn_21 & 0.652 & 0.732 & 0.890 & 0.533 & 0.635 & 0.683 \\
\hline Learn_22 & 0.717 & 0.732 & 0.895 & 0.532 & 0.624 & 0.662 \\
\hline Learn_23 & 0.717 & 0.751 & 0.855 & 0.481 & 0.673 & 0.642 \\
\hline Support_11 & 0.714 & 0.612 & 0.543 & 0.880 & 0.578 & 0.553 \\
\hline Support_12 & 0.648 & 0.572 & 0.502 & 0.892 & 0.499 & 0.444 \\
\hline Support_13 & 0.609 & 0.583 & 0.482 & 0.875 & 0.481 & 0.387 \\
\hline Support_14 & 0.633 & 0.576 & 0.468 & 0.851 & 0.488 & 0.503 \\
\hline Support_21 & 0.602 & 0.801 & 0.681 & 0.538 & 0.813 & 0.525 \\
\hline Support_22 & 0.618 & 0.755 & 0.644 & 0.539 & 0.826 & 0.494 \\
\hline Support_23 & 0.670 & 0.768 & 0.686 & 0.557 & 0.813 & 0.524 \\
\hline Support_24 & 0.589 & 0.727 & 0.611 & 0.507 & 0.799 & 0.468 \\
\hline Support_31 & 0.472 & 0.534 & 0.599 & 0.471 & 0.494 & 0.844 \\
\hline Support_32 & 0.515 & 0.581 & 0.690 & 0.478 & 0.470 & 0.825 \\
\hline Support_33 & 0.545 & 0.584 & 0.694 & 0.478 & 0.512 & 0.817 \\
\hline Support_34 & 0.508 & 0.587 & 0.670 & 0.487 & 0.477 & 0.846 \\
\hline Experiment_1 & \multicolumn{6}{|c|}{0.610 (weight, VIF = 2.289) } \\
\hline Experiment_2 & \multicolumn{6}{|c|}{0.305 (weight, VIF = 2.389) } \\
\hline Experiment_3 & \multicolumn{6}{|c|}{0.206 (weight, VIF = 2.762) } \\
\hline Metacog_26 & \multicolumn{6}{|c|}{0.478} \\
\hline Metacog_27 & \multicolumn{6}{|l|}{0.541} \\
\hline
\end{tabular}

Note: Metacognitive capability = Metacog, Networking capability $=$ Network, Learning agility $=$ Learn, Consultancy support $=$ Support1, Network support $=$ Support2, Facility support $=$ Support3, LIE = Experiment; Variance inflation factor = VIF; Metacog_26 and Metacog_27 are two deleted items since their $t$-values are below the expected significance level ( $\left.p_{\text {two-tailed }}>0.05\right)$. 
Internal consistency and convergent validity are not applied to formative variables (Bollen and Lennox 1991). Instead, to demonstrate construct validity, we tested for multicollinearity using the variance inflation factor (VIF) (Diamantopoulos and Winklhofer 2001). The results did not indicate any problems in our only formative construct; the VIF values were well below the cut-off value of 5 (Table 4.3). We also checked the condition indices to identify multicollinearity, and all values were less than 30 (Hair et al. 2011). By applying a bootstrapping procedure, we established the significance of the index weights. We tested for nomological validity by linking each index to the constructs it was expected to link with; the direction of the relationships was reasonable in the context of our proposed model (Diamantopoulos and Winklhofer 2001). Finally, the correlations between constructs did not raise any concern (see Table 4.5 in the next section).

Discriminant validity. To assess discriminant validity, we used both the Fornell-Larcker criterion (FL) and the Heterotrait-Monotrait ratio of correlations (HTMT). The FL criterion compares AVE's square root in each latent (reflective) variable with latent variable correlations. Our data suggest that each construct's AVE's square root was greater than its highest correlation with any other constructs. The correlation matrix in Table 4.4 shows that discriminant validity was thus established for all constructs. Next, to assess if the construct is truly distinct from other constructs (Henseler et al., 2015), we proceeded to test HTMT values. Our study-wide maximum HTMT is 0.764 , below the strictest threshold of 0.85 , and confirms the discriminant validity of measurement.

Table 4.4: Reliability and validity of construct measurement.

\begin{tabular}{lllllll}
\hline Constructs & $(\boldsymbol{\rho A})$ & $\mathbf{( \rho c )}$ & $\mathbf{C A}$ & $\mathbf{A V E}$ & FL & HTMT \\
\hline Metacognitive capability & 0.869 & 0.870 & 0.866 & 0.653 & 0.589 & 0.758 \\
Networking capability & 0.860 & 0.866 & 0.859 & 0.804 & 0.699 & 0.764 \\
Learning agility & 0.859 & 0.866 & 0.859 & 0.803 & 0.684 & 0.700 \\
Consultancy support & 0.799 & 0.829 & 0.798 & 0.765 & 0.557 & 0.660 \\
Network support & 0.834 & 0.852 & 0.833 & 0.833 & 0.699 & 0.623 \\
Facility support & 0.811 & 0.834 & 0.806 & 0.781 & 0.567 & 0.694 \\
\hline
\end{tabular}

Note: Dijkstra-Henseler's rho $=(\rho A) ;$ Jöreskog's rho $=(p c) ; C A=$ Cronbach's Alpha; Average Variance Extracted $=(A V E) ;$ Maximum Fornell-Larcker criterion $=F L ;$ Maximum Heterotrait-Monotrait ratio of correlations $=$ HTMT . 
Table 4.5: Correlations matrix of the constructs at the second- and first-order levels.

\begin{tabular}{|c|c|c|c|c|c|c|c|c|c|c|c|c|c|c|c|c|c|c|c|c|c|c|c|}
\hline Item & 1 & 2 & 3 & 4 & 5 & 6 & 7 & 8 & 9 & 10 & 11.1 & 11.2 & 11.3 & 12.1 & 12.2 & 12.3 & 13 & 13.1 & 13.2 & 14 & 15 & 15.1 & 15.2 \\
\hline 1 Hub & & & & & & & & & & & & & & & & & & & & & & & \\
\hline 2 Age & .190 & & & & & & & & & & & & & & & & & & & & & & \\
\hline 3 Size & .377 & -.536 & & & & & & & & & & & & & & & & & & & & & \\
\hline 4 Layer & .286 & -.508 & .778 & & & & & & & & & & & & & & & & & & & & \\
\hline 5 Department & .160 & -.387 & .617 & .597 & & & & & & & & & & & & & & & & & & & \\
\hline 6 TMT_Number & .188 & -.451 & .744 & .677 & .595 & & & & & & & & & & & & & & & & & & \\
\hline 7 TMT_Industry & .163 & .237 & -.121 & -.148 & -.121 & -.173 & & & & & & & & & & & & & & & & & \\
\hline 8 TMT_Education & -.015 & .046 & .240 & .240 & .311 & .261 & .248 & & & & & & & & & & & & & & & & \\
\hline 9 TMT_Risk & -.038 & -.006 & -.069 & -.109 & .093 & .003 & -.005 & .073 & & & & & & & & & & & & & & & \\
\hline 10 Innovativeness & -.033 & -.034 & -.064 & -.037 & -.037 & -.071 & .070 & -.022 & .105 & & & & & & & & & & & & & & \\
\hline 11.1 Experiment1 & .192 & -.020 & .078 & .045 & .111 & .115 & .021 & .200 & .101 & .066 & & & & & & & & & & & & & \\
\hline 11.2 Experiment2 & .167 & .029 & .058 & .053 & .091 & .035 & .073 & .065 & .094 & .073 & .626 & & & & & & & & & & & & \\
\hline 11.3 Experiment 3 & .136 & .075 & .091 & -.027 & .100 & .068 & .095 & .115 & .167 & .157 & .677 & .675 & & & & & & & & & & & \\
\hline 12.1 Consultancy & .560 & -.036 & .137 & .012 & .174 & .081 & .003 & .110 & .187 & .225 & .498 & .483 & .503 & & & & & & & & & & \\
\hline 12.2 Network & .511 & -.104 & .040 & .020 & .128 & .083 & .093 & .215 & .146 & .170 & .591 & 618 & .531 & .483 & & & & & & & & & \\
\hline 12.3 Facility & .586 & -.054 & .148 & .133 & .279 & .215 & -.006 & .285 & .147 & .100 & .568 & .532 & .500 & .482 & .619 & & & & & & & & \\
\hline 13 Metacog & .113 & -.008 & .047 & .035 & .196 & .083 & -.180 & .101 & .249 & .189 & .554 & .457 & .533 & .600 & .572 & .510 & & & & & & & \\
\hline 13.1 Knowledge & .158 & -.129 & .164 & .089 & .237 & .112 & -.217 & .050 & .259 & .180 & .580 & .497 & .536 & .587 & .577 & .503 & .853 & & & & & & \\
\hline 13.2 Experience & .209 & .037 & -.006 & -.024 & .120 & .077 & -.081 & .146 & .240 & .145 & .561 & .475 & .475 & .559 & .565 & .480 & .854 & .788 & & & & & \\
\hline 14 Networking & .058 & -.184 & .123 & .135 & .238 & .187 & -.052 & .270 & .188 & .197 & .665 & .601 & .555 & .555 & .665 & .699 & .609 & .630 & .604 & & & & \\
\hline 15 Learn & .024 & -.119 & .119 & .105 & .219 & .150 & -.070 & .230 & .172 & .070 & .660 & .594 & .552 & .411 & .649 & .514 & .522 & .543 & .503 & .506 & & & \\
\hline 15.1 Sense & .043 & -.088 & .114 & .054 & .175 & .107 & -.069 & .184 & .153 & .086 & .641 & .605 & .576 & .462 & .591 & .660 & .517 & .532 & .480 & .659 & .891 & & \\
\hline 15.2 Response & .097 & -.097 & .123 & .115 & .239 & .157 & -.036 & .235 & .185 & .054 & .683 & .569 & .581 & .453 & .658 & .458 & .515 & .532 & .501 & .514 & .918 & .795 & \\
\hline
\end{tabular}

to "10" are controls; Item "11.1" to "11.3" refer to three indicators of LIE; "12.1" = Consultancy support; "12.2" = Network support; "12.3" = Facility support. 
Collinearity. We first computed VIF values to examine the collinearity. The result showed that VIF values for all exogenous constructs (e.g., three capabilities and three supports) ranged between 2.817 (consultancy support) and 4.984 (networking capability), indicating that the results were not negatively affected by collinearity since all were less than 5 (Hair et al., 2011). Besides, Table 4.5 reports the correlations among all hypothesized and control variables in this study. Except for within-construct correlations, inter-construct correlations are well below 0.65 thresholds, suggesting that our estimations are not biased by the multicollinearity problem (Tabachnick and Fidell, 1996).

Coefficient of determination $\left(R^{2}\right)$. The $\mathrm{R}^{2}$ value of the endogenous construct is a measure of the variance explained in the model's predictive accuracy. According to Hair et al. (2011), $\mathrm{R}^{2}$ values of $0.75,0.50$, and 0.25 may be considered substantial, moderate, and weak, respectively. Results for our dependent variable - LIE - had a high $\mathrm{R}^{2}$ value of 0.754 (see Model 7 in Table 4.6). Considering the possibility of extrinsic factors and alternatives, we think our $\mathrm{R}^{2}$ values are fairly good.

\subsubsection{Estimation of the structural model}

After establishing reliability and validity, we assessed the structural model by re-sampling about 200 times to reach the number of 5000 samples for bootstrapping (Hair et al., 2011). Path coefficients. Model 7 in Table 4.6 presents the direct effects of the three capabilities on the LIE. The $\mathrm{R}^{2}$ indicated that the three capabilities explained $25.2 \%, 33.67 \%, 33.6 \%$ of the variance in the dependent variable of LIE, respectively. Bootstrapping results revealed positive and significant effects of three capabilities on the LIE. Networking capability had the strongest and positive effect on LIE $(\beta=0.336, p<0.01)$, followed by learning agility $(\beta=0.331, p<0.01)$, and metacognitive capability $(\beta=0.252, p<0.01)$. Therefore, H1, H2, and H3 were supported. Besides, the $f^{2}$ values in our hypothesized significant relationships ranged from 0.238 to 0.260 (see Table 4.6) (values below 0.020, above 0.150, and above 0.350 represent weak, medium, and strong effect sizes). The results indicate that our structural model shows good explanatory power. 
Table 4.6: Results for the structural model analysis.

\begin{tabular}{|c|c|c|c|c|c|c|c|c|}
\hline Item & Model 0 & Model 1 & Model 2 & Model 3 & Model 4 & Model 5 & Model 6 & Model 7 \\
\hline Metacog $\rightarrow$ LIE (H1) & $\begin{array}{l}0.259 * * \\
(2.932) \\
{[0.012 .0 .328]}\end{array}$ & $\begin{array}{l}0.258^{* *} \\
(2.930) \\
{[0.012 .0 .338]}\end{array}$ & $\begin{array}{l}0.256^{* *} \\
(2.832) \\
0.017 .0 .3471\end{array}$ & $\begin{array}{l}0.258^{* *} \\
(2.930) \\
{[0.037 .0 .385]}\end{array}$ & $\begin{array}{l}0.255^{* *} \\
(2.790) \\
0.019 .0 .428]\end{array}$ & $\begin{array}{l}0.254^{* *} \\
(2.770) \\
0.020 .0 .5487\end{array}$ & $\begin{array}{l}0.255^{* *} \\
(2.790) \\
{[0.019 .0 .568]}\end{array}$ & $\begin{array}{l}0.252^{* *} \\
(2.732) \\
{[0.011 .0 .628]}\end{array}$ \\
\hline Network $\rightarrow$ LIE (H2) & $\begin{array}{l}0.418^{* * *} \\
(4.969) \\
{[0.126 .0 .599]}\end{array}$ & $\begin{array}{l}0.416 * * * \\
(4.930) \\
{[0.159 .0 .651]}\end{array}$ & $\begin{array}{l}0.408^{* * *} \\
(4.786) \\
{[0.203 .0 .618]}\end{array}$ & $\begin{array}{l}0.417 * * * \\
(4.944) \\
{[0.126 .0 .599]}\end{array}$ & $\begin{array}{l}0.399 * * * \\
(4.581) \\
{[0.144 .0 .516]}\end{array}$ & $\begin{array}{l}0.389 * * * \\
(3.569) \\
{[0.116 .0 .589]}\end{array}$ & $\begin{array}{l}0.346 * * \\
(3.426) \\
{[0.126 .0 .599]}\end{array}$ & $\begin{array}{l}0.336 * * \\
(3.069) \\
{[0.120 .0 .566]}\end{array}$ \\
\hline Learn $\rightarrow$ LIE (H3) & $\begin{array}{l}0.361^{* * *}(3.558) \\
{[0.076 .0 .561]}\end{array}$ & $\begin{array}{l}0.350 * * *(3.537) \\
{[0.103 .0 .557]}\end{array}$ & $\begin{array}{l}0.343^{* * *}(3.539) \\
{[0.145 .0533]}\end{array}$ & $\begin{array}{l}0.353 * * *(3.548) \\
{[0.105 .0 .566]}\end{array}$ & $\begin{array}{l}0.340 * * *(3.540) \\
{[0.075 .0 .561]}\end{array}$ & $\begin{array}{l}0.351^{* * *}(3.538) \\
{[0105.0 .567]}\end{array}$ & $\begin{array}{l}0.333 * *(3.388) \\
{[0.066 .0 .560]}\end{array}$ & $\begin{array}{l}0.331^{* *}(3.380) \\
{[0.060 .0 .559]}\end{array}$ \\
\hline Support1 $\rightarrow$ LIE & & $0.078(0.957)$ & $0.073(0.858)$ & & & & & $\begin{array}{l}0.060(2.588) \\
{[-0.077 .0 .321]}\end{array}$ \\
\hline Support1 x Metacog $\rightarrow$ LIE (H3a) & & & $\begin{array}{l}0.049(-0.495) \\
{[-0.154 .0 .049]}\end{array}$ & & & & & $\begin{array}{l}0.044(-0.488) \\
{[-0.137 .0 .149]}\end{array}$ \\
\hline Support2 $\rightarrow$ LIE & & & & $\begin{array}{l}0.189 *(1.989) \\
{[0.026 .0 .570]}\end{array}$ & $\begin{array}{l}0.187 *(1.988) \\
{[0.025 .0550]}\end{array}$ & & & $\begin{array}{l}0.188 *(1.987) \\
{[0.036 .0 .561]}\end{array}$ \\
\hline Support2 x Network $\rightarrow$ LIE (H3b) & & & & & $\begin{array}{l}0.289 * *(2.610) \\
{[0.070 .0560]}\end{array}$ & & & $\begin{array}{l}0.283^{* *}(2.588) \\
{[0.076 .0 .561]}\end{array}$ \\
\hline Support3 $\rightarrow$ LIE & & & & & & $\begin{array}{l}0.168 *(3.118) \\
{[0.016 .0 .461]}\end{array}$ & $\begin{array}{l}0.167 *(3.018) \\
{[0.017 .0 .561]}\end{array}$ & $\begin{array}{l}0.163^{*}(2.988) \\
{[0.014 \cdot 0.778]}\end{array}$ \\
\hline Support3 $\times$ Learn $\rightarrow$ LIE (H3c) & & & & & & & $\begin{array}{l}0.228 *(2.600) \\
{[0.176 .0 .664]}\end{array}$ & $\begin{array}{l}0.225 *(2.588) \\
{[0.170 .0 .756]}\end{array}$ \\
\hline Hub $\rightarrow$ LIE (CV) & $-0.157(-2.560)$ & $-0.156(-2.574)$ & $-0.145(-2.760)$ & $-0.152(-2.584)$ & $-0.146(-2.574)$ & $-0.147(-2.560)$ & $-0.147(-2.560)$ & $-0.159(-2.612)$ \\
\hline Age $\rightarrow$ LIE (CV) & $0.129 *(2.999)$ & $0.133 *(3.678)$ & $0.132 *(3.670)$ & $0.130 *(3.098)$ & $0.125 *(2.789)$ & $0.129 *(2.999)$ & $0.129 *(2.999)$ & $0.121 *(2.110)$ \\
\hline Size $\rightarrow$ LIE (CV) & $-0.016(-0.250)$ & $-0.025(-0.299)$ & $-0.022(-0.239)$ & $-0.025(-0.299)$ & $-0.016(-0.250)$ & $-0.016(-0.250)$ & $-0.015(-0.244)$ & $-0.011(-0.181)$ \\
\hline Layer $\rightarrow$ LIE (CV) & $-0.003(-0.034)$ & $-0.009(-0.094)$ & $-0.008(-0.088)$ & $-0.008(-0.088)$ & $-0.007(-0.693)$ & $-0.008(-0.084)$ & $-0.005(-0.034)$ & $-0.003(-0.034)$ \\
\hline Department $\rightarrow$ LIE (CV) & $0.005(0.075)$ & $-0.004(0.068)$ & $0.005(0.075)$ & $0.006(0.078)$ & $0.005(0.075)$ & $0.004(0.068)$ & $0.004(0.068)$ & $0.005(0.075)$ \\
\hline TMT Number $\rightarrow$ LIE (CV) & $0.063(0.077)$ & $0.060(0.066)$ & $0.057(0.056)$ & $0.061(0.067)$ & $0.060(0.066)$ & $0.061(0.067)$ & $0.057(0.056)$ & $0.053(0.047)$ \\
\hline TMT Industry $\rightarrow$ LIE (CV) & $0.088 *(1.992)$ & $0.084 \dagger(1.920)$ & $0.084 \dagger(1.920)$ & $0.088 \dagger(1.949)$ & $0.073+(1.822)$ & $0.088 \dagger(1.949)$ & $0.088 *(1.992)$ & $0.076+(1.769)$ \\
\hline TMT Education $\rightarrow$ LIE (CV) & $-0.080 \dagger(-1.535)$ & $-0.080 \dagger(-1.535)$ & $-0.088 *(-1.992)$ & $-0.085 \dagger(-1.386)$ & $-0.080 \dagger(-1.535)$ & $-0.088 *(-1.992)$ & $-0.080 \dagger(-1.535)$ & $-0.073(-1.236)$ \\
\hline TMT Risk $\rightarrow$ LIE (CV) & $-0.047(-0.801)$ & $-0.049(-0.819)$ & $-0.049(-0.867)$ & $-0.040(-0.664)$ & $-0.041(-0.654)$ & $-0.049(-0.819)$ & $-0.047(-0.801)$ & $-0.038(-0.574)$ \\
\hline Innovativeness $\rightarrow$ LIE (CV) & $-0.015(-0.265)$ & $-0.020(-0.354)$ & $-0.023(-0.425)$ & $-0.024(-0.517)$ & $-0.012(-0.222)$ & $-0.020(-0.354)$ & $-0.015(-0.265)$ & $-0.022(-0.426)$ \\
\hline Endogenous variable & & & & & & & & \\
\hline LIE $\left[\mathrm{R}^{2}\right.$. Adjusted $\left.\mathrm{R}^{2}\right]$ & {$[0.792 .0 .764]$} & [0.794. 0.764] & {$[0.795 .0 .763]$} & [0.792. 0.764] & {$[0.803 .0 .772]$} & {$[0.795 .0 .764]$} & {$[0.805 .0 .764]$} & {$[0.812 .0 .772]$} \\
\hline Cohen's $f^{2}$ & & & & & & & & \\
\hline Metacog $\rightarrow$ LIE (H1) & 0.246 & 0.245 & 0.238 & 0.247 & 0.245 & 0.248 & 0.246 & 0.243 \\
\hline Network $\rightarrow$ LIE (H2) & 0.260 & 0.259 & 0.256 & 0.259 & 0.257 & 0.258 & 0.257 & 0.255 \\
\hline Learn $\rightarrow$ LIE (H3) & 0.251 & 0.244 & 0.252 & 0.247 & 0.246 & 0.251 & 0.249 & 0.248 \\
\hline Support1 x Metacog $\rightarrow$ LIE (H3a) & & & 0.010 & & & & & 0.009 \\
\hline Support2 x Network $\rightarrow$ LIE (H3b) & & & & & 0.233 & & & 0.232 \\
\hline Support3 x Learn $\rightarrow$ LIE (H3c) & & & & & & & 0.228 & 0.226 \\
\hline
\end{tabular}

${ }^{* * *} p<0.001$ [based on $n=5000$, two-tailed test]; $C V=$ control variable. 
Moderating effects. Given that our dependent variable was modeled as a composite factor, and to avoid multicollinearity issues, we adopted the two-stage approach suggested by Fassott and Henseler (2016) to estimate moderating effects for each of our three moderators. In the first stage, path models comprising direct effects were run to calculate the independent and moderating variables' construct scores. In the second stage, the interaction terms were built as the product term of the extracted construct scores from the first step of each moderator with the independent variable. Table 4.6 presents the results of our analysis. Models 1, 3, 5 introduced the additional direct effect of three supports on LIE, while Model 2 includes the interaction term to measure the moderating effect of consultancy support on the relationship between metacognitive capability and LIE to test H4a. The results reveal that consultancy support does not moderate the metacognitive capability-LIE relationship $(\beta=0.044, p>0.05)$, thus rejecting H4a. At this, high metacognitively aware individuals tend to be more confident in their judgments, inferences, and strategic decisions. One could also speculate that metacognitive skills developed through mainly systemic training (Mor et al., 2013; Kudesia, 2019) are deeply engrained so are not easily affected by concrete consultancy offered by local agencies. Similarly, Model 4 tests H4b by introducing the moderation effects of networking support on the networking capability-LIE relationship. Our findings lead us to confirm H4b by indicating the positive moderating effect of networking support $(\beta=0.283$, $p<0.01)$. Finally, Model 5 tests the effects of facility support on the learning agility-LIE relationship ( $\beta=0.225, p<0.05$ ), also confirming our expectation of H4c.

\subsection{DISCUSSION}

What drivers innovative firms' LIE effectively? We addressed this question by conceptualizing the LIE as a strategic innovation process in which focal firms and key partners experiment with complex innovations in local small-scale societies. Research results suggest that three TMTbased capabilities at a high level contribute to the high performance of LIE. Further, the use of specific local innovation supports are accountable for the LIE performance differences. Based on these results, we contribute to the existing literature in three major ways.

\subsubsection{Theoretical contributions}

First of all, this study contributes to the existing innovation literature by providing an operationalized measurement of the LIE. Although increasingly, the literature has argued that the LIE is strategically important to the final success of complex innovative products or services 
(e.g., Han et al., 2018; Mahmoud-Jouini and Charue-Duboc, 2017; Pekkarinen et al., 2020; von Pechmann et al., 2015), they do not shed light on the key features of this noticeable phenomenon in industries. Based on the experimentation literature (Gillier and Lenfle, 2019; Thomke, 2003) and employing a rigorous scale development approach (Diamantopoulos and Winklhofer 2001), this study makes an extension by developing three dimensions (i.e., actor variety, close to reallife, and feedback) that are essential to the LIE. Moreover, quantitative results verify the overall quality of such three dimensions. In this way, our study broadens the applicability of LIE as a operationalized research construct into the innovation studies, and allows scholars to further empirically study antecedents and outcomes of LIEs.

Our second major contribution lies in the integration of the dynamic capabilities perspective into LIE, which answers recent calls to explore antecedents and contextual factors related to the experimentation process (see Hampel et al., 2020). Earlier innovation literature has long suggested that market tests and business-driven experimentations' effectiveness determines innovations' market performance (Aminoff and Pihlajamaa, 2020; Piller and Susumu, 2006). Such individual firm-centric experimentation processes tend to interact exclusively with the economic environment (economic and competitive actors). Through the capability lens, scholars found the criticality of organizational learning capability to effective market tests and business-driven experimentations (e.g., Aminoff and Pihlajamaa, 2020; Bojovic et al., 2018; Gillier and Lenfle, 2019; Murray and Tripsas, 2004). The learning capabilities are based on managers' human capital, which helps individual firms absorb new knowledge or technologies and apply them to innovations.

In contrast, in the LIE setting in which more partners are involved, experimentation activities are much more iterative, multidimensional feedback related to innovations are complex (economic, coopetitive, and socio-political actors), the effectiveness and final performance of LIE depend on a set of dynamics capabilities. Echoing the capability literature, our research points out that the LIE-centric dynamic capabilities should reflect exactly how TMTs deploy the accumulated cognition, human capital, and social capital (Acquaah, 2007; Adner and Helfat, 2003; Colombo and Grilli, 2005; Teece, 2007). Besides, the required dynamic capabilities should be higher-order or strategic (Haynie et al., 2010; Mitrega et al., 2012; Sambamurthy et al., 2003). Overall, our research lends empirical support to the notion that the managerial dynamic capabilities framework provides an appropriate lens through which to examine the LIE. Therefore, future studies are recommended to pay more attention to 
the multiple, higher-order dynamic capabilities (as opposed to single, generic capabilities) to unveil the antecedents of innovation experimentation phenomena similar to LIE we studied.

Our third major contribution comes down to the theoretical addition of the cross-level mechanisms that underlie the very early stage of an innovation ecosystem. Most studies focus on the system level to explain the emergence and growth of an innovation ecosystem. Typically, it was unearthed that geography-based knowledge ecosystems (Attour and Lazaric, 2020; Clarysse et al., 2014) or supply chains (Letaifa, 2014; Randhawa et al., 2020) could be transformed into innovation ecosystems. Besides, another salient body of literature takes a cross-level perspective to examine how focal firms' dynamic capabilities (Feng et al., 2019; Lütjen et al., 2019) or strategies (Hannah and Eisenhardt, 2018) (at the firm level) act on the emergence and growth of an innovation ecosystem (at the system level). Expanding on the cross-level perspective, empirical results from our research highlight that focal firms' dynamic capabilities impact the LIE in the first place. These results make our research depart from the current theorization, directly linking dynamic capabilities and the emergence of an innovation ecosystem. In this way, we answer recent calls for more nuanced insights into understanding how an innovation ecosystem emerges at all (Thomas and Autio, 2020). Also, our study examined another dimension of the cross-level mechanisms. Systemic innovation supports in innovation regions (system level) significantly impact the capabilities-LIE relationships (firmlevel). Hence, it seems that to understand the system phenomenon of innovation ecosystem emergence fully, future work should take a multi-level view to examine simultaneously the ecosystem-related factors at the system (even higher) as well as the firm (or lower) levels.

\subsubsection{Managerial implications}

Our study provides two major guidelines for managers to achieve the high-level performance of the LIE. First, top managers of focal firms should continuously improve the TMT portfolio to ensure its optimal structure and diversity. More specifically, when enrolling new top executives, they should emphasize new members' cross-industry working experiences, the rich track records in strategic departments or organizations, diverse educational backgrounds, diverse life experiences, and so on (Talke et al., 2011). Such special enrolment criteria bring focal firms - especially small firms and new ventures - into possession of sufficient cognition, social capital, and human capital, which are further converted into three LIE-related capabilities. Furthermore, considering the trained nature of managers' metacognition (Kudesia, 2019), focal firms must invest in specially-designed training courses, executive-centered management 
programs, and on-site communications. Based on these strategic human resource practices, managers' cognitive habits, preferences, and deficits could be shaped to avoid major strategic errors in decision-making.

Second, superior absorptive capacity (skills or routines) transforms regional innovation resources into organization-level and even ecosystem-level advantages. Our research results highlight that LIE's performance is a contingent on the combination of organizational capabilities and the regional innovation supports/resources. Yet the complementary effects between capabilities and regional resources do not take place autonomously. Instead, it is expected that managers should take the initiative to recognize, acquire, and transform diverse innovation resources around their local environments (Morretta et al., 2020). To promote such resource acquisition and transformation process more effectively, managers must make effective location strategies. The location strategy as a type of innovation strategy is developed to position the innovation activities in places that are likely to promote the development and commercialization of the innovations (Ferreira et al., 2017). In this way, managers should locate LIE in suitable small-scale societies to better pinpoint all the uncertainties inherent in each proposed innovation. More importantly, effective location strategies also suggest that managers will save time and money if the selected small-scale societies are situated in or in close to innovative resource-rich regions.

\subsubsection{Limitations}

Two limitations in this research warrant more scholarly care. First, our research samples are from two innovation-oriented platforms in an emerging economy (China), and this choice probably restricts the generalizability of the key findings to other institutional settings. According to the extant literature, an important reason that innovative firms chose to carry out LIE is to discover the economic and, importantly, socio-political uncertainties about the proposed innovations (Mahmoud-Jouini and Charue-Duboc, 2017; Pekkarinen et al., 2020). Furthermore, based on the LIE results, they can better develop innovation diffusion plans and strategies, and consequently capture value successfully from such innovations. Clearly, the Chinese setting is a special one in which to examine LIE. More specifically, the legal and social systems remain underdeveloped so that managers just do not know how regulatory agencies and the publics with treat new products or services. The most effective way is to first put them into regions at small-scale and monitor the on-site socio-political reactions. This operation might be different in other economics. For managers in an under-developed economy, they 
might suffer more serious problems from socio-political agencies. While managers in a mature economy might know upfront pretty well how socio-political stakeholders would treat the innovations in the well-established legal and social systems. Considering such disparity, scholars have opportunities to check the LIE model's applicability in other institutional settings.

The second limitation relates to the data collection method. Our study employed a key informant approach and relied on single-source retrospective data (Avolio et al., 1991). In our theory, we view firm-level dynamic capabilities at the TMT-level. So credible information about the theorized organizational capabilities would be acquired through an aggregation of all TMT members' self-reported information, instead of the one key informant we used in the data collection procedure. To minimize this bias, future research is recommended to combine selfreported data from multiple informants. Moreover, more robust research results would perhaps be obtained if both the independent (TMT-based capabilities) and dependent (LIE) variables were measured independently at different points in time. In other words, instead of the crosssectional design adopted for this study, future work should consider the inter-temporal data collection method in the hope of arriving at casual inferences about the observed relationships.

\subsubsection{Future directions}

Two future avenues are worth exploring to understand the LIE antecedents and contingent factors, in consideration of LIE's critical function in the emergence of an innovation ecosystem. First, the antecedents of capabilities need to be better understood. By being not limited to the three TMT-based capabilities we focus on in the study, it would be interesting to explore whether some other managerial dynamic capabilities correlate positively with the high-level performance of LIE. Besides, a more interesting question is whether there are some complex interactions between different capabilities. Based on the extant capability literature, the TMTs' cognitions, human capital, and social capital, which act as the foundations for organizational capabilities, reinforce each other during the organization's growth (Adner and Helfat, 2003). For instance, the case study by Feng et al. (2019) showed that the social capital in managers of start-ups helps improve the low pre-existing levels of managerial cognitions, which further benefits to developing an innovation ecosystem. Hence, it is expected that during the LIE from the early to later stages, different types of capabilities might reinforce each other, thereby possibly promoting a higher level LIE performance. Future studies could combine longitudinal case studies and fuzzy-set qualitative comparative analysis (fs/QCA) methods in the hope of yielding further interesting results. Using comparable cases, researchers could not only know a 
comprehensive portfolio of capabilities that play a positive role in the LIE but also better understand how capabilities interact over time with rich process data. Through the fs/QCA method (Fiss, 2011), researchers can gain more in-depth insights into which bundles of capabilities have the most/least positive effects on the LIE's performance.

Second, a comprehensive examination is needed to understand the role of the regional innovation context in LIE. In this article, we have focused on the material-related innovation supports as the moderation effects. Our PLS-SEM results verified the complementary effects of two key supports on the capabilities. Yet in the innovation regions, there are also "nonmaterial” innovation resources (Morretta et al., 2020). As opposed to the material-related resources, "non-material” innovation resources are intangible resources, including mainly the social (e.g., the vitality of social networks) and cultural (e.g., cultural orientation) innovation supports. The inclusion of these two intangible resources in the LIE model would further enrich our understanding of how the regional innovation context matters. Despite its importance in theory, such inclusion poses methodological challenges because possible influences from these two types of innovation resources on innovative firms and their innovation activities are said to be both slow and indirect (Spigel, 2017). For this reason, we thus suggest that scholars should adopt a hybrid methodology by integrating qualitative and quantitative data to draw clearer connections between capabilities, regional innovation resources, and LIE.

\subsection{CONCLUSION}

By what means can innovative firms best benefit from the high performance offered by LIE, which is essential for the successful emergence of an innovation ecosystem around proposed complex innovations? Previous research has already illustrated the main principles regarding LIE. Going one step further, this study explains what kinds of antecedents and contingency can predict the high-level performance of the LIE. PLS-SEM results suggest that three TMT-based capabilities (metacognition, networking capability, and learning agility) and two types of material-relevant local innovation supports (network activities and facility) matter significantly. This study has highlighted the benefits of taking the managerial dynamic capabilities perspective to better understand the cross-level mechanisms underlying a systemic phenomenon: the emergence of an innovation ecosystem.

\subsection{REFERENCES}


Acquaah, M. (2007). Managerial social capital, strategic orientation, and organizational performance in an emerging economy. Strategic Management Journal, 28(12), 1235-1255.

Adner, R. (2012). The wide lens: A new strategy for innovation. London: Penguin.

Adner, R., \& Helfat, C. E. (2003). Corporate effects and dynamic managerial capabilities. Strategic Management Journal, 24(10), 1011-1025.

Aminoff, A., \& Pihlajamaa, M. (2020). Business experimentation for a circular economy-Learning in the front end of innovation. Journal of Cleaner Production, 275, 124051. https://doi.org/10.1016/j.jclepro.2020.124051

Ansell, C. K., \& Bartenberger, M. (2016). Varieties of experimentalism. Ecological Economics, 130, 64-73.

Attour, A., \& Lazaric, N. (2020). From knowledge to business ecosystems: emergence of an entrepreneurial activity during knowledge replication. Small Business Economics, 54(2), 575-587

Atuahene-Gima, K., \& Wei, Y. (2011). The vital role of problem-solving competence in new product success. Journal of Product Innovation Management, 28(1), 81-98.

Autio, E., Kenney, M., Mustar, P., Siegel, D., \& Wright, M. (2014). Entrepreneurial innovation: The importance of context. Research Policy, 43(7), 1097-1108.

Autio, E., Nambisan, S., Thomas, L. D., \& Wright, M. (2018). Digital affordances, spatial affordances, and the genesis of entrepreneurial ecosystems. Strategic Entrepreneurship Journal, 12(1), 72-95.

Avolio, B. J., Yammarino, F. J., \& Bass, B. M. (1991). Identifying common methods variance with data collected from a single source: An unresolved sticky issue. Journal of Management, 17(3), 571-587.

Brislin, R. W. (1970). Back-translation for cross-cultural research. Journal of Cross-cultural Psychology, 1(3), 185-216.

Bojovic, N., Genet, C., \& Sabatier, V. (2018). Learning, signaling, and convincing: The role of experimentation in the business modeling process. Long Range Planning, 51(1), 141-157.

Bollen, K., \& Lennox, R. (1991). Conventional wisdom on measurement: A structural equation perspective. Psychological Bulletin, 110(2), 305-314.

Cao, X., Ouyang, T., Balozian, P., \& Zhang, S. (2020). The Role of Managerial Cognitive Capability in Developing a Sustainable Innovation Ecosystem: A Case Study of Xiaomi. Sustainability, 12(17), 71-76.

Carmeli, A., Zivan, I., Gomes, E., \& Markman, G. D. (2017). Underlining micro sociopsychological mechanisms of buyer-supplier relationships: Implications for interorganizational learning agility. Human Resource Management Review, 100577. https://doi.org/10.1016/j.hrmr.2016.12.002

Carpenter, M. A., Geletkanycz, M. A., \& Sanders, W. G. (2004). Upper echelons research revisited: Antecedents, elements, and consequences of top management team composition. Journal of Management, 30(6), 749-778.

CBRE (2019). Retrieved from https://www.cbre.com/research-and-reports/Asia-Pacific-MajorReport---Programming-Asia-Pacific-Tech-Cities-as-Global-Tech-Hubs-April-2019.

Accessed 10 October 2020

Chesbrough, H.W., \& D. J. Teece (1996). When is virtual virtuous?: Organizing for innovation. Harvard Business Review, 74, 65-73. 
Chin, W. W. (1998). The partial least squares approach to structural equation modeling. Modern Methods for Business Research, 295(2), 295-336.

Cho, Y. S., \& Linderman, K. (2019). Metacognition-based process improvement practices. International Journal of Production Economics, 211, 132-144.

Clarysse, B., Wright, M., Bruneel, J., \& Mahajan, A. (2014). Creating value in ecosystems: crossing the chasm between knowledge and business ecosystems. Research Policy, 43, 1164-1176.

Colombo, M. G., \& Grilli, L. (2005). Founders' human capital and the growth of new technologybased firms: A competence-based view. Research Policy, 34(6), 795-816.

Cunningham, J. B., \& McCrum-Gardner, E. (2007). Power, effect and sample size using GPower: Practical issues for researchers and members of research ethics committees. Evidence Based Midwifery, 5(4), 132-136.

Dattée, B., Alexy, O., \& Autio, E. (2018). Maneuvering in poor visibility: How firms play the ecosystem game when uncertainty is high. Academy of Management Journal, 61(2), 466498.

de Vasconcelos Gomes, L. A., Salerno, M. S., Phaal, R., \& Probert, D. R. (2018). How entrepreneurs manage collective uncertainties in innovation ecosystems. Technological Forecasting and Social Change, 128, 164-185.

DeRue, D. S., Ashford, S. J., \& Myers, C. G. (2012). Learning agility: In search of conceptual clarity and theoretical grounding. Industrial and Organizational Psychology, 5(3), 258-279.

Di Benedetto, C. A. (1999). Identifying the key success factors in new product launch. Journal of Product Innovation Management, 16(6), 530-544.

Diamantopoulos, A., \& Winklhofer, H. M. (2001). Index construction with formative indicators: an alternative to scale development. Journal of Marketing Research, 38, 269-277.

Diestre, L., \& Rajagopalan, N. (2012). Are all 'sharks' dangerous? new biotechnology ventures and partner selection in R\&D alliances. Strategic Management Journal, 33(10), 1115-1134.

Dijkstra, T. K., \& Henseler, J. (2015). Consistent partial least squares path modeling. MIS Quarterly, 39(2), 297-316.

Doblinger, C., Surana, K., \& Anadon, L. D. (2019). Governments as partners: The role of alliances in US cleantech startup innovation. Research Policy, 48(6), 1458-1475.

Dolan, R. J., \& Matthews, J. M. (1993). Maximizing the utility of customer product testing: beta test design and management. Journal of Product Innovation Management, 10(4), 318-330.

Dougherty, D., \& Dunne, D. D. (2011). Organizing ecologies of complex innovation. Organization Science, 22(5), 1214-1223.

Fassott, G., Henseler, J., \& Coelho, P. (2016). Testing moderating effects in PLS path models with composite variables. Industrial Management \& Data Systems, 116, 1887-1900.

Feng, N., Fu, C., Wei, F., Peng, Z., Zhang, Q., \& Zhang, K. H. (2019). The key role of dynamic capabilities in the evolutionary process for a startup to develop into an innovation ecosystem leader: An indepth case study. Journal of Engineering and Technology Management, 54, 81-96.

Ferreira, J. J., Fernandes, C. I., \& Raposo, M. L. (2017). The effects of location on firm innovation capacity. Journal of the Knowledge Economy, 8(1), 77-96.

Fiss, P. C. (2011). Building better causal theories: A fuzzy set approach to typologies in organization research. Academy of Management Journal, 54(2), 393-420. 
Fornell, C., \& Larcker, D. F. (1981). Evaluating structural equation models with unobservable variables and measurement error. Journal of Marketing Research, 18(1), 39-50.

Furr, N., \& Shipilov, A. (2018). Building the right ecosystem for innovation. MIT Sloan Management Review, 59(4), 59-64.

Gassmann, O., Zeschky, M., Wolff, T., \& Stahl, M. (2010). Crossing the industry-line: breakthrough innovation through cross-industry alliances with 'non-suppliers'. Long Range Planning, 43(5-6), 639-654.

Gillier, T., \& Lenfle, S. (2019). Experimenting in the unknown: lessons from the Manhattan project. European Management Review, 16(2), 449-469.

Giudici, A., Reinmoeller, P., \& Ravasi, D. (2018). Open-system orchestration as a relational source of sensing capabilities: Evidence from a venture association. Academy of Management Journal, 61(4), 1369-1402.

Goodhue, D. L., Lewis, W., \& Thompson, R. (2012). Does PLS have advantages for small sample size or non-normal data?. MIS Quarterly, 36(3), 981-1001.

Grashof, N., Hesse, K., \& Fornahl, D. (2019). Radical or not? The role of clusters in the emergence of radical innovations. European Planning Studies, 27(10), 1904-1923.

Hair, J. F., Ringle, C. M., \& Sarstedt, M. (2011). PLS-SEM: Indeed a silver bullet. Journal of Marketing Theory and Practice, 19(2), 139-152.

Hambrick, D. C., \& Mason, P. A. (1984). Upper echelons: The organization as a reflection of its top managers. Academy of Management Review, 9(2), 193-206.

Hampel, C., Perkmann, M., \& Phillips, N. (2020). Beyond the lean start-up: experimentation in corporate entrepreneurship and innovation. Innovation, 22, 1-11.

Hanlon, D., \& Saunders, C. (2007). Marshaling resources to form small new ventures: Toward a more holistic understanding of entrepreneurial support. Entrepreneurship Theory and Practice, 31(4), 619-641.

Han, J., Shah-Zhou, H., Lowik, S. J. A., \& de Weerd, P. (2018). Building and sustaining the emerging ecosystems by focal new ventures: evidence from the bike-sharing industry in China. Working Paper.

Hannah, D. P., \& Eisenhardt, K. M. (2018). How firms navigate cooperation and competition in nascent ecosystems. Strategic Management Journal, 39(12), 3163-3192.

Haynie, J. M., \& Shepherd, D. A. (2009). A measure of adaptive cognition for entrepreneurship research. Entrepreneurship Theory and Practice, 33(3), 695-714.

Haynie, J. M., Shepherd, D. A., Mosakowski, E., \& Earley, P. C. (2010). A situated metacognitive model of the entrepreneurial mindset. Journal of Business Venturing, 25(2), 217-229.

Haynie, J. M., Shepherd, D. A., \& Patzelt, H. (2012). Cognitive adaptability and an entrepreneurial task: The role of metacognitive ability and feedback. Entrepreneurship Theory and Practice, 36(2), 237-265.

Helfat, C. E., \& Peteraf, M. A. (2015). Managerial cognitive capabilities and the microfoundations of dynamic capabilities. Strategic Management Journal, 36(6), 831-850.

Henseler, J. and Dijkstra, T.K. (2015), “ADANCO 2.0.1”, Composite Modeling, Kleve, available at: www.compositemodeling.com.

Henseler, J., Hubona, G., \& Ray, P. A. (2016). Using PLS path modeling in new technology research: updated guidelines. Industrial Management \& Data Systems, 116, 2-20. 
Hottenrott, H., \& Lopes-Bento, C. (2016). R\&D partnerships and innovation performance: Can there be too much of a good thing?. Journal of Product Innovation Management, 33(6), 773-794.

Hyysalo, S., \& Hakkarainen, L. (2014). What difference does a living lab make? Comparing two health technology innovation projects. CoDesign, 10(3-4), 191-208.

Kashan, A. J., \& Mohannak, K. (2017). The Role of Knowledge Integration in Capability Development and Emergence of Innovation Ecosystem. International Journal of Innovation and Technology Management, 14(5), 1-18.

Klompmaker, J. E. (1976). Test Marketing in New Product Development. Harvard Business Review, 54(3), 128-138.

Kock, N. (2015). Common method bias in PLS-SEM: A full collinearity assessment approach. International Journal of e-Collaboration, 11(4), 1-10.

Kaufmann, A., \& Tödtling, F. (2002). How effective is innovation support for SMEs? An analysis of the region of Upper Austria. Technovation, 22(3), 147-159.

Kraiczy, N. D., Hack, A., \& Kellermanns, F. W. (2015). What makes a family firm innovative? CEO risk-taking propensity and the organizational context of family firms. Journal of Product Innovation Management, 32(3), 334-348.

Kudesia, R. S. (2019). Mindfulness as metacognitive practice. Academy of Management Review, 44(2), 405-423.

Letaifa, S.B. (2014). The uneasy transition from supply chains to ecosystems: The valuecreation/value-capture dilemma. Management Decision, 52, 278-295.

Liu, G., \& Rong, K. (2015). The nature of the co-evolutionary process: Complex product development in the mobile computing industry's business ecosystem. Group \& Organization Management, 40(6), 809-842.

Lorenz, M. P., Ramsey, J. R., \& Richey Jr, R. G. (2018). Expatriates’ international opportunity recognition and innovativeness: The role of metacognitive and cognitive cultural intelligence. Journal of World Business, 53(2), 222-236.

Lütjen, H., Schultz, C., Tietze, F., \& Urmetzer, F. (2019). Managing ecosystems for service innovation: A dynamic capability view. Journal of Business Research, 104, 506-519.

Mahmoud-Jouini, S. B., \& Charue-Duboc, F. (2017). Experimentations in emerging innovation ecosystems: specificities and roles. The case of the hydrogen energy fuel cell. International Journal of Technology Management, 75(1-4), 28-54.

Mitchell, J., Shepherd, D., \& Sharfman, M.P. (2011). Erratic strategic decisions: when and why managers are inconsistent in strategic decision making. Strategic Management Journal, 32, 683-704.

Mitrega, M., Forkmann, S., Ramos, C., \& Henneberg, S. C. (2012). Networking capability in business relationships-Concept and scale development. Industrial Marketing Management, 41(5), 739-751.

Mitrega, M., Forkmann, S., Zaefarian, G., \& Henneberg, S. (2017). Networking capability in supplier relationships and its impact on product innovation and firm performance. International Journal of Operations \& Production Management, 37, 577-606.

Mor, S., Morris, M. W., \& Joh, J. (2013). Identifying and training adaptive cross-cultural management skills: The crucial role of cultural metacognition. Academy of Management Learning \& Education, 12(3), 453-475. 
Morretta, V., Syrett, S., \& Ramirez, L. S. (2020). Territorial capital as a source of firm competitive advantage: evidence from the North and South of Italy. European Planning Studies, 28(12), 2390-2408.

Murray, F. and Tripsas, M. (2004). The Exploratory Processes of Entrepreneurial Firms: The Role of Purposeful Experimentation. Advances in Strategic Management, 21, 45-75.

Nambisan, S., \& Baron, R. A. (2013). Entrepreneurship in innovation ecosystems: Entrepreneurs' self-regulatory processes and their implications for new venture success. Entrepreneurship Theory and Practice, 37(5), 1071-1097.

Noel, L., \& Sovacool, B. K. (2016). Why did better place fail?: range anxiety, interpretive flexibility, and electric vehicle promotion in Denmark and Israel. Energy Policy, 94, 377-386.

Nunnally, J. (1978). Psychometric Theory (2nd ed), New York: McGraw-Hill.

Oskam, I., Bossink, B., \& de Man, A. P. (2020). Valuing value in innovation ecosystems: How cross-sector actors overcome tensions in collaborative sustainable business model development. Business \& Society. https://doi.org/10.1177/0007650320907145.

Overby, E., Bharadwaj, A., \& Sambamurthy, V. (2006). Enterprise agility and the enabling role of information technology. European Journal of Information Systems, 15(2), 120-131.

Parente, R., Rong, K., Geleilate, J. M. G., \& Misati, E. (2019). Adapting and sustaining operations in weak institutional environments: A business ecosystem assessment of a Chinese MNE in Central Africa. Journal of International Business Studies, 50(2), 275-291.

Patton, D., \& Kenney, M. (2005). The spatial configuration of the entrepreneurial support network for the semiconductor industry. $R \& D$ Management, 35(1), 1-16.

Pekkarinen, S., Tuisku, O., Hennala, L., \& Melkas, H. (2020). Robotics in Finnish welfare services: dynamics in an emerging innovation ecosystem. European Planning Studies, 28(8), 15131533.

Pidun, U., Reeves, M., \& Schüssler, M. (2020). How Do You “Design” a Business Ecosystem? Retrieved from https://www.bcg.com/publications/2020/how-do-you-designa-businessecosystem.aspx. Assessed 2 March 2020

Piller, F. T., \& Susumu, O. (2006). Reducing the risks of new product development. MIT Sloan Management Review, 47(2), 65-71.

Randhawa, K., West, J., Skellern, K., \& Josserand, E. (2021). Evolving a Value Chain to an Open Innovation Ecosystem: Cognitive Engagement of Stakeholders in Customizing Medical Implants. California Management Review, 63(2), 101-134.

Sambamurthy, V., Bharadwaj, A., \& Grover, V. (2003). Shaping agility through digital options: Reconceptualizing the role of information technology in contemporary firms. MIS Quarterly, 237-263.

Seidl, D., \& Werle, F. (2018). Inter-organizational sensemaking in the face of strategic metaproblems: Requisite variety and dynamics of participation. Strategic Management Journal, 39(3), 830-858.

Schraw, G., \& Dennison, R. S. (1994). Assessing metacognitive awareness. Contemporary Educational Psychology, 19(4), 460-475.

Spigel, B. (2017). The Relational Organization of Entrepreneurial Ecosystems. Entrepreneurship Theory and Practice, 41(1), 49-72.

Tabachnick, B. G., \& Fidell, L. S. (1996). Using multivariate statistics, New York: Harper Collins. 
Talke, K., Salomo, S., \& Kock, A. (2011). Top management team diversity and strategic innovation orientation: The relationship and consequences for innovativeness and performance. Journal of Product Innovation Management, 28(6), 819-832.

Teece, D. J. (2007). Explicating dynamic capabilities: the nature and microfoundations of (sustainable) enterprise performance. Strategic Management Journal, 28(13), 1319-1350.

Thomke, S. (2003). Experimentation Matters: Unlocking the Potential of New Technologies for Innovation, Cambridge: Harvard Business School Press.

Thomas, L. D. W., \& Autio, E. (2020). Innovation ecosystems in management: An organizing typology. In Oxford Encyclopedia of business and management, Oxford: Oxford University Press.

Velu, C. (2015). Knowledge management capabilities of lead firms in innovation ecosystems. AMS review, 5(3-4), 123-141.

von Pechmann, F., Midler, C., Maniak, R., \& Charue-Duboc, F. (2015). Managing systemic and disruptive innovation: lessons from the Renault Zero Emission Initiative. Industrial and Corporate Change, 24(3), 677-695.

van Riel, A. C., Henseler, J., Kemény, I., \& Sasovova, Z. (2017). Estimating hierarchical constructs using consistent partial least squares. Industrial Management \& Data Systems, 177, 459477.

Walrave, B., Talmar, M., Podoynitsyna, K. S., Romme, A. G. L., \& Verbong, G. P. (2018). A multilevel perspective on innovation ecosystems for path-breaking innovation. Technological Forecasting and Social Change, 136, 103-113.

Walter, A., Auer, M., \& Ritter, T. (2006). The impact of network capabilities and entrepreneurial orientation on university spin-off performance. Journal of Business Venturing, 21(4), 541567.

Zahra, S. A., \& Nambisan, S. (2012). Entrepreneurship and strategic thinking in business ecosystems. Business Horizons, 55(3), 219-229.

Zahra, S. A., Wright, M., \& Abdelgawad, S. G. (2014). Contextualization and the advancement of entrepreneurship research. International Small Business Journal, 32(5), 479-500. 


\section{Appendix 4.1: Questionnaire.}

\section{English Version}

\section{Part 1 General Information}

1 Which year did your company establish?

2 How many full-time employees approximately do your company have?

3 How many management layers approximately do your company have?

4 How many functional departments approximately do your company have?

5 How many executives in your top management team?

6 Industry experience diversity in your top management team Indicate the simple percentage of people in your top managers who has before worked outside of the industry domain that your company currently operates:

$$
0 \% \quad 1 \%-25 \% \quad 26 \%-50 \% \quad 51 \%-75 \% \quad 76 \%-100 \%
$$

7 Education about your top management team

Indicate the simple percentage of people in your top managers who has master or higher education degrees:

$$
0 \% \quad 1 \%-25 \% \quad 26 \%-50 \% \quad 51 \%-75 \% \quad 76 \%-100 \%
$$

\begin{tabular}{|c|c|c|c|c|c|c|}
\hline \multicolumn{2}{|c|}{$\begin{array}{l}\text { strongly } \\
\text { disagree }\end{array}$} & & & & \multicolumn{2}{|c|}{$\begin{array}{r}\text { Strongly } \\
\text { agree }\end{array}$} \\
\hline $\mathrm{O}$ & $\mathrm{O}$ & $\mathrm{O}$ & $\mathrm{O}$ & $\mathrm{O}$ & $\mathrm{O}$ & $\mathrm{O}$ \\
\hline $\mathrm{O}$ & $\mathrm{O}$ & $\mathrm{O}$ & $\mathrm{O}$ & $\mathrm{O}$ & $\mathrm{O}$ & $\mathrm{O}$ \\
\hline
\end{tabular}

8 General risk-taking propensity of your top management team

In general, our top managers believe that owing to the nature of the environment, bold, widely ranging acts are necessary to achieve the company's objectives

When confronted with decision-making situations involving uncertainty, our top managers typically adopt a bold, aggressive posture in order to maximize the probability of exploiting potential opportunities

\section{Part 2 Innovation Activity with Your Partners}

\section{Did (or does) your company carry out the Local Innovation Experimentation?}

$\checkmark$ Local innovation experimentations occur when a company as well as their innovation partners want to test the feasibility of new innovative products (services/processes) in local small-scale market before they become mature to go to mass market.

$\checkmark$ Doing local innovation experimentation is to know technical function, customers' demands, and political/social stakeholders' attitudes about the new innovative products (services). 
Examples are (1) a new healthcare device for elderly people is tentatively used by local elderly citizens; (2) a new solar energy solution for eco-consumers is tentatively used by local customers.

Think of one of your latest innovation projects which resembles a Local Innovation

\section{Experimentation as described above, and provide information:}

What is the innovative product (service) about?

Market newness of the innovative product (service)?

1 It serves new customer needs - customer needs we had not served before

2 It requires changes in established attitude and behavioral patterns from customers

3 It requires major learning efforts by customers

$$
\text { strongly }
$$

disagree

$\mathrm{O}$

$$
\mathrm{O}
$$

$\mathrm{O} \quad \mathrm{O}$

$\mathrm{O} \quad \mathrm{O}$

$\mathrm{O} \quad \mathrm{O}$

$\mathrm{O} \quad \mathrm{O}$

$\mathrm{O} \quad \mathrm{O}$

O O

4 It takes us up against new competitors - competitors we have never faced before

What partners did your company collaborate with to do the Local Innovation

\section{Experimentation?}

1 Partners from the same industry domain as ours

2 Partners from totally different industry domain(s). The industry domain(s) different from ours is (are)

3 Non-industry technology partners like universities and public research institutes

4 Political partners like governmental agencies

5 Societal partners like social media, activists, and non-governmental organizations (NGOs)

What kinds of tools did your company and partners use to do the Local Innovation Experimentation?

1 Innovation ideas of products (services)

2 Mock-ups of products (services)

3 Initial prototyping products (services) of intended use

4 Improved versions of products (services)

5 Ready-for-mass-market products (services)

What were the feedbacks that your company and partners received during the Local Innovation Experimentation?

1 Technical function related to our innovative products (services)

2 Real-life end-users/customers' demands related to our innovative products (services)

3 Competitors' reactions related to our innovative products (services)

$\mathrm{O}$

$\mathrm{O}$

$\begin{array}{ll}\mathrm{O} & \mathrm{O} \\ \mathrm{O} & \mathrm{O} \\ \mathrm{O} & \mathrm{O} \\ \mathrm{O} & \mathrm{O} \\ \mathrm{O} & \mathrm{O}\end{array}$

\section{Part 3 Your Company’s Key Capability}

Cognitive Capability

Indicate the information about yourself and your top management team (TMT) members when to treat important management and operation activities/decisions. 


\begin{tabular}{|c|c|c|c|c|c|c|c|c|}
\hline \multirow[b]{2}{*}{1} & \multirow[b]{2}{*}{$\begin{array}{l}\text { Our top management team (TMT) members can think of } \\
\text { several solutions to solve a problem and choose the best } \\
\text { one }\end{array}$} & \multicolumn{2}{|c|}{$\begin{array}{l}\text { strongly } \\
\text { disagree }\end{array}$} & \multirow[b]{2}{*}{$\mathrm{O}$} & \multirow[b]{2}{*}{$\mathrm{O}$} & \multirow[b]{2}{*}{$\mathrm{O}$} & \multicolumn{2}{|c|}{$\begin{array}{r}\text { Strongly } \\
\text { agree }\end{array}$} \\
\hline & & $\mathrm{O}$ & $\mathrm{O}$ & & & & $\mathrm{O}$ & $\mathrm{O}$ \\
\hline 2 & $\begin{array}{l}\text { Our TMT members always challenge our own } \\
\text { assumptions about a task before we begin to solve it }\end{array}$ & $\mathrm{O}$ & $\mathrm{O}$ & $\mathrm{O}$ & $\mathrm{O}$ & $\mathrm{O}$ & $\mathrm{O}$ & $\mathrm{O}$ \\
\hline 3 & $\begin{array}{l}\text { Our TMT members always think about how others may } \\
\text { react to our actions }\end{array}$ & $\mathrm{O}$ & $\mathrm{O}$ & $\mathrm{O}$ & $\mathrm{O}$ & $\mathrm{O}$ & $\mathrm{O}$ & $\mathrm{O}$ \\
\hline 4 & $\begin{array}{l}\text { We find ourselves automatically employing strategies } \\
\text { that have worked successfully in the past }\end{array}$ & $\mathrm{O}$ & $\mathrm{O}$ & $\mathrm{O}$ & $\mathrm{O}$ & $\mathrm{O}$ & $\mathrm{O}$ & $\mathrm{O}$ \\
\hline 5 & $\begin{array}{l}\text { Our TMT members can perform the best when we } \\
\text { already have knowledge of the task }\end{array}$ & $\mathrm{O}$ & $\mathrm{O}$ & $\mathrm{O}$ & $\mathrm{O}$ & $\mathrm{O}$ & $\mathrm{O}$ & $\mathrm{O}$ \\
\hline 6 & $\begin{array}{l}\text { Our TMT members can create our own examples to } \\
\text { make acquired information more meaningful }\end{array}$ & $\mathrm{O}$ & $\mathrm{O}$ & $\mathrm{O}$ & $\mathrm{O}$ & $\mathrm{O}$ & $\mathrm{O}$ & $\mathrm{O}$ \\
\hline 7 & $\begin{array}{l}\text { Our TMT members try to use strategies that have } \\
\text { worked successfully in the past }\end{array}$ & $\mathrm{O}$ & $\mathrm{O}$ & $\mathrm{O}$ & $\mathrm{O}$ & $\mathrm{O}$ & $\mathrm{O}$ & $\mathrm{O}$ \\
\hline 8 & $\begin{array}{l}\text { Our TMT members ask ourselves questions about the } \\
\text { task before we begin to finish it }\end{array}$ & $\mathrm{O}$ & $\mathrm{O}$ & $\mathrm{O}$ & $\mathrm{O}$ & $\mathrm{O}$ & $\mathrm{O}$ & $\mathrm{O}$ \\
\hline 9 & $\begin{array}{l}\text { Our TMT members try to translate new information } \\
\text { from outside into our own words }\end{array}$ & $\mathrm{O}$ & $\mathrm{O}$ & $\mathrm{O}$ & $\mathrm{O}$ & $\mathrm{O}$ & $\mathrm{O}$ & $\mathrm{O}$ \\
\hline 10 & $\begin{array}{l}\text { Our TMT members try to break problems down into } \\
\text { smaller components }\end{array}$ & $\mathrm{O}$ & $\mathrm{O}$ & $\mathrm{O}$ & $\mathrm{O}$ & $\mathrm{O}$ & $\mathrm{O}$ & $\mathrm{O}$ \\
\hline 11 & $\begin{array}{l}\text { Our TMT members focus on the meaning and } \\
\text { significance of new information from outside }\end{array}$ & $\mathrm{O}$ & $\mathrm{O}$ & $\mathrm{O}$ & $\mathrm{O}$ & $\mathrm{O}$ & $\mathrm{O}$ & $\mathrm{O}$ \\
\hline 1 & $\begin{array}{l}\text { Our TMT members can think about what we really need } \\
\text { to accomplish before we begin a task }\end{array}$ & $\mathrm{O}$ & $\mathrm{O}$ & $\mathrm{O}$ & $\mathrm{O}$ & $\mathrm{O}$ & $\mathrm{O}$ & $\mathrm{O}$ \\
\hline 2 & $\begin{array}{l}\text { Our TMT members can use different strategies } \\
\text { depending on different task situations }\end{array}$ & $\mathrm{O}$ & $\mathrm{O}$ & $\mathrm{O}$ & $\mathrm{O}$ & $\mathrm{O}$ & $\mathrm{O}$ & $\mathrm{O}$ \\
\hline 3 & $\begin{array}{l}\text { Our TMT members can best organize time to } \\
\text { accomplish our company goals }\end{array}$ & $\mathrm{O}$ & $\mathrm{O}$ & $\mathrm{O}$ & $\mathrm{O}$ & $\mathrm{O}$ & $\mathrm{O}$ & $\mathrm{O}$ \\
\hline 4 & $\begin{array}{l}\text { Our TMT members are good at organizing different } \\
\text { information from outside }\end{array}$ & $\mathrm{O}$ & $\mathrm{O}$ & $\mathrm{O}$ & $\mathrm{O}$ & $\mathrm{O}$ & $\mathrm{O}$ & $\mathrm{O}$ \\
\hline 5 & $\begin{array}{l}\text { Our TMT members know what kind of information is } \\
\text { most important to consider when faced with a problem }\end{array}$ & $\mathrm{O}$ & $\mathrm{O}$ & $\mathrm{O}$ & $\mathrm{O}$ & $\mathrm{O}$ & $\mathrm{O}$ & $\mathrm{O}$ \\
\hline 6 & $\begin{array}{l}\text { Our TMT members consciously focus our attention on } \\
\text { important information }\end{array}$ & $\mathrm{O}$ & $\mathrm{O}$ & $\mathrm{O}$ & $\mathrm{O}$ & $\mathrm{O}$ & $\mathrm{O}$ & $\mathrm{O}$ \\
\hline 7 & $\begin{array}{l}\text { Our TMT members sometimes depend on our intuitions } \\
\text { to formulate strategies }\end{array}$ & $\mathrm{O}$ & $\mathrm{O}$ & $\mathrm{O}$ & $\mathrm{O}$ & $\mathrm{O}$ & $\mathrm{O}$ & $\mathrm{O}$ \\
\hline 8 & $\begin{array}{l}\text { Sometimes our "gut" tells us when a given strategy we } \\
\text { use will be the most effective }\end{array}$ & $\mathrm{O}$ & $\mathrm{O}$ & $\mathrm{O}$ & $\mathrm{O}$ & $\mathrm{O}$ & $\mathrm{O}$ & $\mathrm{O}$ \\
\hline
\end{tabular}

Networking Capability

Indicate the information of your company regarding the form, care of, and use of, diverse partner relationships (e.g., suppliers, technology partners, investors, governments, NGOs etc.). 
We try to customize collaboration forms with our partners

strongly

disagree

strongly

2 We try many ways to persuade and "lock in” our partners in cooperation with us

3 We work closely with our partners when developing our innovative products/services

4 We provide our partners with valuable resources that can help them better develop innovative products/services

5 We often communicate with our partners regarding mutual expectations on innovative products/services

6 We use our influences to solve problems of our partners

7 We try to develop an understanding of the reasons why the relationship with our partners is negatively affected

Learning Capability

Indicate how your company and partners collectively recognize, and respond to, diverse problems during new innovation development process.

$\begin{array}{lllllll}\mathrm{O} & \mathrm{O} & \mathrm{O} & \mathrm{O} & \mathrm{O} & \mathrm{O} & \mathrm{O} \\ \mathrm{O} & \mathrm{O} & \mathrm{O} & \mathrm{O} & \mathrm{O} & \mathrm{O} & \mathrm{O}\end{array}$

$\begin{array}{lllllll}\mathrm{O} & \mathrm{O} & \mathrm{O} & \mathrm{O} & \mathrm{O} & \mathrm{O} & \mathrm{O}\end{array}$

$\begin{array}{lllllll}\mathrm{O} & \mathrm{O} & \mathrm{O} & \mathrm{O} & \mathrm{O} & \mathrm{O} & \mathrm{O}\end{array}$

$\begin{array}{lllllll}\mathrm{O} & \mathrm{O} & \mathrm{O} & \mathrm{O} & \mathrm{O} & \mathrm{O} & \mathrm{O}\end{array}$

$\begin{array}{lllllll}\mathrm{O} & \mathrm{O} & \mathrm{O} & \mathrm{O} & \mathrm{O} & \mathrm{O} & \mathrm{O}\end{array}$

$\begin{array}{lllllll}\mathrm{O} & \mathrm{O} & \mathrm{O} & \mathrm{O} & \mathrm{O} & \mathrm{O} & \mathrm{O}\end{array}$

strongly

disagree

1 Our company and partners react adequately fast to problems emerged from product development activities

2 Our company and partners are timely to find out any nuanced changes relating to our product development process

3 Our company and partners are able to quickly recognize small mismatches/abnormalities during our product development process

4 Our company and partners are able to quickly recognize small improvements during our product development process

1 Our company and partners are always able to identify several alternative solutions for each problem encountered in product development activities

2 Our company and partners seemed to always come up with high-quality ideas or creative solutions to product development problems encountered

3 It is always easy for our company and partners to collectively identify new ways, tools, or solutions to the product development problems encountered

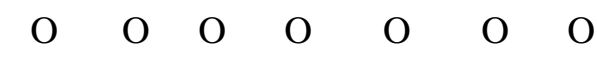
trongly agree

$\begin{array}{ccccccc}\mathrm{O} & \mathrm{O} & \mathrm{O} & \mathrm{O} & \mathrm{O} & \mathrm{O} & \mathrm{O} \\ \mathrm{O} & \mathrm{O} & \mathrm{O} & \mathrm{O} & \mathrm{O} & \mathrm{O} & \mathrm{O} \\ \mathrm{O} & \mathrm{O} & \mathrm{O} & \mathrm{O} & \mathrm{O} & \mathrm{O} & \mathrm{O}\end{array}$

$\begin{array}{lllllll}\mathrm{O} & \mathrm{O} & \mathrm{O} & \mathrm{O} & \mathrm{O} & \mathrm{O} & \mathrm{O}\end{array}$

$\begin{array}{ccccccc}\mathrm{O} & \mathrm{O} & \mathrm{O} & \mathrm{O} & \mathrm{O} & \mathrm{O} & \mathrm{O} \\ \mathrm{O} & \mathrm{O} & \mathrm{O} & \mathrm{O} & \mathrm{O} & \mathrm{O} & \mathrm{O} \\ \mathrm{O} & \mathrm{O} & \mathrm{O} & \mathrm{O} & \mathrm{O} & \mathrm{O} & \mathrm{O}\end{array}$

\section{Part 4 Local Innovation Supports Your Company Used}

Indicate what kinds of local Innovation supports or services you used to facilitate your innovation development activities. 


\begin{tabular}{|c|c|c|c|c|c|c|c|c|}
\hline & & $\begin{array}{l}\text { rarely } \\
\text { use }\end{array}$ & & & & & & $\begin{array}{r}\text { often } \\
\text { use }\end{array}$ \\
\hline 1 & Market consultancy services & $\mathrm{O}$ & $\mathrm{O}$ & $\mathrm{O}$ & $\mathrm{O}$ & $\mathrm{O}$ & $\mathrm{O}$ & $\mathrm{O}$ \\
\hline 2 & Regulation consultancy services & $\mathrm{O}$ & $\mathrm{O}$ & $\mathrm{O}$ & $\mathrm{O}$ & $\mathrm{O}$ & $\mathrm{O}$ & $\mathrm{O}$ \\
\hline 3 & Financial consultancy services & $\mathrm{O}$ & $\mathrm{O}$ & $\mathrm{O}$ & $\mathrm{O}$ & $\mathrm{O}$ & $\mathrm{O}$ & $\mathrm{O}$ \\
\hline 4 & $\begin{array}{l}\text { Others related consultancy } \\
\text { services: }\end{array}$ & $\mathrm{O}$ & $\mathrm{O}$ & $\mathrm{O}$ & $\mathrm{O}$ & $\mathrm{O}$ & $\mathrm{O}$ & $\mathrm{O}$ \\
\hline 1 & Business communication events & $\mathrm{O}$ & $\mathrm{O}$ & $\mathrm{O}$ & $\mathrm{O}$ & $\mathrm{O}$ & $\mathrm{O}$ & $\mathrm{O}$ \\
\hline 2 & Technology transfer exchanges & $\mathrm{O}$ & $\mathrm{O}$ & $\mathrm{O}$ & $\mathrm{O}$ & $\mathrm{O}$ & $\mathrm{O}$ & $\mathrm{O}$ \\
\hline 3 & Trade exchange activities & $\mathrm{O}$ & $\mathrm{O}$ & $\mathrm{O}$ & $\mathrm{O}$ & $\mathrm{O}$ & $\mathrm{O}$ & $\mathrm{O}$ \\
\hline 4 & $\begin{array}{l}\text { Others related networking } \\
\text { activities: }\end{array}$ & $\mathrm{O}$ & $\mathrm{O}$ & $\mathrm{O}$ & $\mathrm{O}$ & $\mathrm{O}$ & $\mathrm{O}$ & $\mathrm{O}$ \\
\hline 1 & Innovation test facilities and centers & $\mathrm{O}$ & $\mathrm{O}$ & $\mathrm{O}$ & $\mathrm{O}$ & $\mathrm{O}$ & $\mathrm{O}$ & $\mathrm{O}$ \\
\hline 2 & IT digital facilities and equipment & $\mathrm{O}$ & $\mathrm{O}$ & $\mathrm{O}$ & $\mathrm{O}$ & $\mathrm{O}$ & $\mathrm{O}$ & $\mathrm{O}$ \\
\hline 3 & Specialized manufacturing facilities & $\mathrm{O}$ & $\mathrm{O}$ & $\mathrm{O}$ & $\mathrm{O}$ & $\mathrm{O}$ & $\mathrm{O}$ & $\mathrm{O}$ \\
\hline 4 & $\begin{array}{l}\text { Other related innovation } \\
\text { facilities: }\end{array}$ & $\mathrm{O}$ & $\mathrm{O}$ & $\mathrm{O}$ & $\mathrm{O}$ & $\mathrm{O}$ & $\mathrm{O}$ & $\mathrm{O}$ \\
\hline
\end{tabular}




\section{Chinese Version}

\section{《本地化创新实验影响因素问卷调查》}

尊敬的女士/先生:

十分感谢您能拨几接受本问卷调查! 除基本信息外，本问卷内容主要涉及三个方面：一是 您所在公司和合作伙伴所经历的一项创新活动 - “本地化创新实验” ; 二是与实施该创新活动 相关的 3 个组织核心能力; 三是与实施该项创新活动相关的 3 种本地创业服务。

如需了解更多与本研究相关的信息，请点击网页：

https://www.utwente.nl/en/bms/nikos/research/projects-and-partners/ecosystem-as-advantage/

\section{本研究作者郑重承诺：您所报告的所有信息不会对任何第三方泄露，仅用于学术研究！}

再次感谢您对本研究的大力支持!

\section{第一部分 基本信息}

\section{a 公司基本情况}

1、您所在公司已经成立了多少年
1 年以下
$1-5$ 年
$5-10$ 年
$10-15$ 年
15 年以上

2、公司所属的行业是

移动/新一代互联网新能源/材料及应用生物医药及医疗设备 智能交通及设备制造其他

3、您所在公司目前的全职员工数量大致有：
$1-10$ 人
11-50人
51-100人
$101-500$ 人
501 人及以上

4、您所在公司目前的管理层级（即下级向上级汇报工作的层级数）大致有：
无管理层级
1 级
2 级
3 级
4 级及以上

5、公司目前的职能部门（如财务部、人力部、运营部）大致有：
暂无职能细分
$2-3$ 个
$4-5$ 个
6-7 个
8 个及以上

\section{b 高管团队基本情况}

1、近几年公司高管团队成员数量维持在：
1 人
2-3人
4-5人
6-7人
8 人及以上

2、高管团队成员中有其他 (多个) 行业工作背景的大致占比为:
$0 \%$
$1 \%-25 \%$
$26 \%-50 \%$
$51 \%-75 \%$
$76 \%-100 \%$

3、高管团队成员中硕、博士研究生学历的大致占比为:
$0 \%$
$1 \%-25 \%$
$26 \%-50 \%$
$51 \%-75 \%$
$76 \%-100 \%$

c 总的来说, 我们高管团队,

1、强调新产品研发投入、技术领先和突破式创新

2、偏好于选择具备高风险、高回报的创新产品项目

3、强调在面对复杂竞争环境时，通过高投入实现组织绩效目标

4、面对高决策不确定风险时，依然采取乐观进取的姿态来开拓市场 


\section{第二部分 本地化创新实验}

定义：“本地化创新实验” 被定义一种创新活动：企业及其合作伙伴经常先在小范围区域市场 内对创新产品/服务进行可行性实验，然后使创新产品/服务更成熟地走向更大范围的消费市场。 例子：Ofo 小黄车在走向全国前首先在北京市高校内进行一系列创新实验, 以检验共享单车的 技术功能、消费者的骑行反馈、及其他社会（社区）对该新生事物的态度。

\section{请您回顾公司最近几年众多创新产品项目中，与本地化创新实验所定义类似的一个项目：}

a 该新产品/服务的新颖性表现在：

1、会改变消费者固有的消费行为和习惯

2、需要主流消费者具备一定的学习能力

3、使用了本行业内从来没使用过的新技术

4、该产品中所包含的新技术会使快速迭代旧技术

5、该产品使用了可以极大提高其功能的新技术

6、生产该产品所使用的技术极大推动了行业发展

\section{b 参与或帮助该新产品实验测试的成员有:}

1、本行业中的合作伙伴

2、与本行业完全不同的跨界合作伙伴

3、科研院校机构

4、相关政府机构

5、相关媒体及非盈利机构

c 在本地化创新实验过程中, 新产品当时所处的形态是:

1、概念化阶段

2、实体模型阶段

3、初始可使用阶段

4、已多次改进（优化）版本阶段

5、可大规模投向市场阶段

\section{d 在本地化创新实验过程中, 我们和合作伙伴知道了:}

1、新产品所需要改进 (完善) 的其他技术功能

2、消费者对新产品的真实反馈（实际需求）

3、竞争对手对新产品的反应

4、政府管理部门对新产品的态度

5、社会媒体 (行业专家学者) 对新产品的反响 


\section{第三部分 认知能力、合作能力及学习能力}

\section{a 在公司管理决策过程中，我们公司高管团队，}

1、总能针对某个管理问题, 找出多种 (并选出最佳) 解决方案

2、总能在解决某个管理问题前, 跳出对该问题的既定设想

3、总是会考虑对于我们的企业行动，外部第三方会做出如何反应

4、总能马上找到在过去就得以成功实施的相关战略措施

5、总能在对某个管理问题有足够了解后，制定好相关战略措施

6、总能从自身经历出发，赋予已知信息更多内涵

7、总能想到在过去就已成功实施过的各种战略措施

8、总是在解决某个问题前，先仔细勘酌

9、总能将外部获得的各种信息，转换为自己能懂的语言

10、总能将某个大问题，肢解成许多小问题来解决

11、总能敏锐地抓到外部信息的重点和内涵

\section{b 在公司管理决策过程中，我们公司高管团队，}

1、总能在解决某个管理问题前，就想好了要达成的既定目标

2、总能根据不同的任务情境，采取不同的应对策略

3、总能规划好时间来达成组织目标

4、总是很擅长综合分析不同的外部信息

5、总能在碰到某个问题时，知道哪种外部信息需要优先考虑

6、总能十分清晰地对关键外部信息给予高度关注

7、总能依赖直觉制定相关战略措施

8、有时凭借直觉，就知道最有效的战略措施是哪个

c 我们公司，

1、总能根据不同的合作伙伴，采取不同的合作形式

2、总能采用多种途径，来说服合作伙伴与我们长期合作

3、总在合作研发新产品过程中，与合作伙伴密切配合

4、总为合作伙伴提供各种资源，来帮助他们研发新产品

5、总是与合作伙伴就彼此对新产品的期望，保持持续沟通

6、总能靠自身的影响力, 为合作伙伴解决一些复杂问题

7、总是能弄清楚，为何与合作伙伴的合作关系会出现裂痕 


\section{d 我们公司和合作伙伴,}

1、总能快速响应新产品研发过程中出现的各种问题

2、总能及时发现有关新产品研发过程中的出现的细节变化

3、总能快速发现新产品研发过程中的出现的一些异常情况

4、总能快速发现新产品研发过程中的出现的一些细微起色

5、总能制定出好几种方案, 来解决新产品研发过程中碰到的某个困难

6、总能制定出一些高质量方案, 来解决新产品研发过程中碰到的困难

7、总能制作一些新的/实用的工具, 来解决新产品研发过程中碰到的困难

\section{第四部分 本地化创业支持}

\section{a 针对第三方提供的咨询服务, 我们在新产品研发过程中,}

1、使用过相关的创新过程和市场分析咨询服务

2、使用过相关的政策咨询服务

3、使用过相关的财务/会计咨询服务

4、使用过其他与产品研发相关的咨询服务

\section{b 针对第三方中介组织的活动（服务），我们在新产品研发过程中，}

1、参加过各种和商务交流 (洽谈) 相关的活动

2、参加过各种和技术交流 (转换) 相关的活动

3、参加过各种和商品展销会 (贸易会) 相关的活动

4、参加过其他和新产品研发相关的中介活动

c 针对第三方提供的创新设备（服务）, 我们在新产品研发过程中,

1、使用过相关的产品测试设备（测试中心）

2、使用过相关的 IT 数字化设备 (数据库)

3、使用过相关的特种生产设备(机器)

4、使用过其他和新产品研发相关的创新设备（服务） 



\section{CHAPTER 5}

\section{Toward a Complex Adaptive System: The Case of the Zhongguancun Entrepreneurship Ecosystem}

Based on:

1. Han, J., Ruan, Y., Wang, Y., \& Zhou, H. (2018). Toward a complex adaptive system: The case of the Zhongguancun entrepreneurship ecosystem. Paper presented at the $32^{\text {nd }}$ RENT conference, Toledo, Spain.

2. Han, J., Ruan, Y., Wang, Y., \& Zhou, H. (2019). Toward a complex adaptive system: The case of the Zhongguancun entrepreneurship ecosystem. Paper presented at the $27^{\text {th }}$ Annual High Technology Small Firms Conference, Enschede, Netherlands.

3. Han, J., Ruan, Y., Wang, Y., \& Zhou, H. (2021). Toward a complex adaptive system: The case of the Zhongguancun entrepreneurship ecosystem. Journal of Business Research, 128, 537-550. 
ABSTRACT: Viable entrepreneurship ecosystems (EEs), which provide sustainable competitive advantages to innovative regions, have become increasingly important for producing high-impact entrepreneurial firms. However, little is known about the complexity nature that viable EEs uncover under specific regional entrepreneurial contexts. By integrating the EE literature and complex adaptive system (CAS) theory, we conducted a case study on the Zhongguancun EE in China. We demonstrate six interrelated complexity properties of a viable EE: a large number of self-organized agents, nonlinear interactions, (in)sensitivity to initial conditions, adaptation to the environment, emergence of successful entrepreneurial firms, and coevolution. Moreover, the integration of these six complexity properties offers an overarching understanding of how the Zhongguancun EE maintained its viability over time. We contribute to the EE literature by developing a more nuanced complexity-based understanding of a viable EE and extend CAS theory at the ecosystem level by highlighting an EE's adaptive process to maintain its viability. 


\subsection{INTRODUCTION}

In recent years, regional entrepreneurship and innovation policies have changed their focus from stressing entrepreneurship quantity (i.e., the number of new firms and self-employment rate) to entrepreneurship quality (i.e., entrepreneurial firms with high growth potential) (Acs et al., 2017; Brown and Mason, 2017; O'Connor et al., 2017). Following such policy transitions, Entrepreneurship Ecosystem (EE), which is defined as "a set of interdependent actors and factors coordinated in such a way that they enable productive entrepreneurship within a particular territory” (Stam, 2015, p. 1765), shifted its focus to individual entrepreneurs and the entrepreneurial contexts in which they are embedded (Acs et al., 2014; Autio et al., 2014). Given the strategic role of EEs in promoting sustainable economic competitiveness, there is a consensus among various governmental agencies to create and sustain well-functioning EEs in the innovative regions (Mason and Brown, 2014).

Although the concept of EE has attracted increasing research attention, the complexity of its nature is not well understood by the extant research (Brown and Mason, 2017). First, little is known about nonlinear synergies among EE components. Previous studies have documented the necessary entrepreneurial components for a viable EE ${ }^{(3)}$ (Autio and Levie, 2017; Feld, 2012; Isenberg, 2014; Mason and Brown, 2014) and examined how synergetic interactions among these EE components lead to performance variance (Colombelli et al., 2017; Spigel, 2015). However, it has been observed that EEs with the same components may demonstrate different performances in terms of producing successful entrepreneurial firms (Spigel, 2015) because EE outcomes (i.e., high impact entrepreneurship) depend on the components' diversity and coherence (Roundy et al., 2017), and they often should be explained by nonlinear multicausalities (Alvedalen and Boschma, 2016; Stam, 2015).

Second, scholars have applied the process perspective to EE development (Goswami et al., 2018; Letaifa and Rabeau, 2013; Mack and Mayer, 2016; Spigel and Harrison, 2018). However, the theorization from the process perspective needs further understanding. Although life cycle theory dominates the current discussion, some viable EEs have been found to take a discontinuous path to becoming resilient to their environments (Auerswald and Dani, 2017; Roundy et al., 2017) rather than following a predesigned evolutionary route from birth to decline (Malecki, 2018).

\footnotetext{
${ }^{3}$ In this paper, a viable EE refers to an EE that has the system-level ability to give rise to successful entrepreneurial firms (Acs et al., 2017; Brown and Mason, 2017; Mason and Brown, 2014; Stam, 2015).
} 
Third, EE is partially a location-bounded phenomenon. Most of the literature argues that territory specificity is a defining feature of $\mathrm{EE}$ and sets the research boundaries of EEs to either certain nations, subnational regions, or city areas (e.g., Goswami et al., 2018; Mack and Mayer, 2016; Spigel, 2015). However, emerging research suggests that digital infrastructure and technologies reduce entrepreneurship spatial dependence (e.g., Autio et al., 2018; Sussan and Acs, 2017). EEs should therefore be considered using multidimensional geographic scales.

Taken together, the complexity nature of EEs in terms of multicausality, discontinuity, and multidimensionality remains largely underexplored in the existing literature. Some scholars have separately discussed EE complexity properties, leading to a fragmented view (see discussion in Isenberg, 2016; O'Connor et al., 2017). Recent works building on Complex Adaptive System (CAS) theory have offered a more complete view of the complexity properties shared by EEs and discussed how these properties relate to the birth of EEs (Aeeni and Saeedikiya, 2019; Roundy et al., 2018). However, these conceptual endeavors failed to provide any empirical evidence of complexity-based EEs and were constrained to the EE birth stage.

To address these research gaps, in the present paper, we aim to offer empirical insights into complexity-based EEs by answering the following research question: how can an EE uncover its complexity properties across different developmental stages to maintain its viability? We conduct a qualitative case study of the Zhongguancun Science Park (hereinafter referred to as the Zhongguancun EE), a viable EE located in Beijing, China (cf. Du et al., 2018; Li et al., 2017). The Zhongguancun EE is considered a viable EE because over 70 unicorns were born there from 2012 to 2018. ${ }^{(4)}$ This EE has become viable through four distinct developmental stages since its genesis in the 1980s; simultaneously, its increasing level of complexity - that is, the multiplicity, diversity, and multilateral interactions of EE agentssupports to our intention to apply CAS theory. Following the recommended procedures for qualitative data analysis (Gioia et al., 2013; Strauss and Corbin, 1990), we identify six interrelated complexity properties that the Zhongguancun EE exhibits: a large number of selforganized agents, nonlinear interactions, (in)sensitivity to initial conditions, adaptation to the environment, emergence of successful entrepreneurial firms, and coevolution. In addition, we integrate these six complexity properties as an overarching framework to offer a complexitybased understanding of a viable EE.

\footnotetext{
${ }^{4}$ Unicorns are defined as high impact entrepreneurial firms valued at more than $\$ 1$ billion (e.g., Acs et al., 2017).
} 
Our study contributes to the current EE literature by providing a more nuanced understanding of the complexity properties of a viable EE. In line with Roundy et al. (2018), we confirm that a large number of self-organized agents and their nonlinear interactions build the foundation for viable EEs. We complement Roundy et al. (2018) study by showing that although EEs may be sensitive to initial conditions at early developmental stages that could cause evolutionary path dependence, viable EEs can avoid such sensitivity by improving their environmental adaptability. Moreover, our findings indicate that the emergence of successful entrepreneurial firms results from EE agents' collective endeavors, which in turn encourages EE agents to adjust their entrepreneurial activities. Finally, although EEs have open geographic boundaries; boundary openness should operate at multidimensional geographic scales.

Our study also extends CAS theory to the ecosystem level in two ways. First, the development and management of a viable EE depends on (1) nonlinear interactions among EE agents through positive feedback loops, (2) its environmental adaptability, and (3) diverse EE agents exchanging entrepreneurial resources and coevolving in multidimensional geographic boundaries. Second, a viable EE maintains a balanced level of complexity to produce successful entrepreneurial firms through the adaptive development process. Overall, our findings support the idea that CAS theory is a useful lens through which to understand the complexity properties of EEs and provide useful policy implications for entrepreneurship and innovation policies that enable viable EEs.

\subsection{LITERATURE REVIEW}

\subsubsection{Overview of EEs: main ideas and the challenges of complexity}

The value of the EE concept lies in its systemic features (Brown and Mason, 2017; Malecki, 2018; Stam, 2015), which help to explain how entrepreneurial actors-including individuals, organizations, and institutions-interact to produce various entrepreneurial activities in certain economic and institutional contexts (Acs et al., 2014; Autio et al., 2014; Garud et al., 2014). We observed that there are at least three schools consolidating EE's systemic features, discriminating them from the perspective of similar phenomena, such as national/regional innovation systems, innovation/industrial clusters, innovation milieu, and innovation ecosystems (cf. Autio et al., 2018). Specifically, systemic components indicate what participatory elements are included in a viable EE (Cohen, 2006; Isenberg, 2011; Spigel, 2015). Systemic processes help us understand how an EE develops over time (Auerswald and Dani, 2017; Mack and Mayer, 2016; Spigel and Harrison, 2018). And systemic governance structures 
explicate how an EE can be shaped to create successful entrepreneurship (Audretsch and Link, 2019; Colombo et al., 2019; Cumming et al., 2019).

Although fruitful, the current EE research faces several challenges (see Cavallo et al., 2018; Stam, 2015). In particular, there is a lack of a theoretical framework to simultaneously examine the systemic components, processes, and governance structures. As EEs are complex, variegated, and temporally discontinuous phenomena, such a framework is therefore warranted. In other words, current research frameworks in the EE literature fail to comprehend the full complexity of these organisms (Brown and Mason, 2017). A holistic guiding framework is important because "construing ecosystems as complex categories can allow for more conceptually robust and relevant applications” (Spigel and Harrison, 2018, p. 158). Specifically, we argue that holistic insights into the complexity nature of EEs will help clarify conceptual ambiguities, solve empirical problems, and, more importantly, facilitate policy.

\subsubsection{EEs as complex adaptive systems}

Complex adaptive system (CAS) theory (Anderson, 1999; Lewin, 1999) may be useful for shedding light on the conceptualization of EEs and addressing challenges related to comprehending the complexity nature of an EE (i.e., multicausality, discontinuity, and multidimensionality) for several reasons. First, as a subset of system and chaos theory, CAS theory is advantageous for explaining how complex causes can produce simple effects or how simple rules can have unpredictable consequences (Anderson, 1999), which is relevant to phenomena such as EEs (Ritala and Gustafsson, 2018). Second, EEs share patterns with general CAS in biology (e.g., a flock of birds or an ant colony) that include three fundamental elements: agents, interactions, and the environment (Acs et al., 2014; Dooley, 1997; Mitleton-Kelly, 2003). Third, recent work offers a complete set of complexity properties that a CAS shares with an EE (Aeeni and Saeedikiya, 2019; Roundy et al., 2018). Six properties are proposed to address problems, paradoxes, and ambiguities in EE research: emergence through "self-" organization, open-but-distinct boundaries, complex components, nonlinear dynamics, adaptability through dynamic interactions, and sensitivity to initial conditions (cf. Roundy et al., 2018).

\subsubsection{Emergence through "self-" organization}

According to CAS theory (e.g., Anderson, 1999), the complexity of CAS is largely attributed to numerous heterogeneous agents who interact with each other with different features and objectives. The agents in an EE are derived from six interdependent components: finance, 
markets, human capital, supports, culture, and policy (e.g., Isenberg, 2011). The six components can be further integrated into an analysis at the micro-, meso-, and macro levels (Berger and Kuckertz, 2016), that is, finance, markets, and human capital as microfoundations together with supports and policy at the meso level nurture new firm creation. Furthermore, EE components at the micro and meso levels communicate frequently, which in turn form the macro environment (level) including intangible schemata such as entrepreneurial climate, social/cultural norms, conventions, and advocated entrepreneurial spirits. The communication rules and principles influencing each agent are relatively coherent and change incrementally. During this process, EE agents and related entrepreneurial resources may enter or exit while the schemata remain stable, and new schemata may appear based on self-organized agents' interactions without any interventions by central organizer(s) (Feld, 2012; Isenberg, 2016; Spigel and Harrison, 2018).

\subsubsection{Open-but-distinct boundaries}

A CAS is not a stable and closed system but a dynamic and open system with fluid boundaries (Kauffman and Strohman, 1994). Mitleton-Kelly (2003, p. 32) stated that CASs are "open systems that exchange energy, matter, or information with their environment, and when pushed 'far-from-equilibrium', create new structures and order”. Similarly, an EE also has open-butdistinct boundaries. On the one hand, an EE's boundaries are open because the new entrepreneurial resources that flow into the EE can increase agent diversity, which produces more new entrepreneurial activities while driving redundant entrepreneurial resources out of the EE (Spigel and Harrison, 2018). On the other hand, an EE's sociocultural boundaries are clear and relatively stable. As noted earlier, both new and established agents share common intangible schemata (rule sets, logics, and values) that guide their respective entrepreneurial actions (Roundy, 2016). As such, agents who do not demonstrate certain sociocultural elements are treated as EE outsiders.

\subsubsection{Complex components}

To understand a CAS, we must consider its two opposing features: diversity and unity. Diversity in a CAS not only refers to the multiplicity of agents but also reflects their interactive relationships. For example, agents who randomly change their individual objectives and actions will have new interactive relationships with others. However, when examined at the system 
level, agents can be integrated into different components with relatively unified principles and attributes (Mitleton-Kelly, 2003).

In a viable EE, ecosystem agents can easily change their roles (for instance, investors become entrepreneurs) and may have multiple roles at one time (an incubator can simultaneously act as an entrepreneurial service provider and an angel investor). However, EE agents at different levels (micro, meso, and macro) (Berger and Kuckertz, 2016; Stam, 2015; Theodoraki and Messeghem, 2017) and as different components (governments, investors, and incubators) (Spigel, 2015) are relatively identifiable.

\subsubsection{Nonlinear dynamics}

Beyond linear causal models in mathematics, CAS is grounded in the mechanism by which inputs from interacting agents lead to disproportional outcomes (Morel and Ramanujam, 1999). Kauffman (1996) argued that the nonlinearity from inputs to outputs is determined by the degree of agents' diversity and connectedness. Brown and Mason (2017, p. 15) stated that "A key feature of ecosystems is nonlinearity". Considering the nature of nonlinearity, the process of combining all entrepreneurial resources is thus untraceable due to multidirectional causalities (Isenberg, 2016). Nevertheless, we can view EE performance through two different mechanisms: positive and negative feedback loops among (sub)components (McKelvey, 2004). Positive feedback loops suggest that changes in certain components amplify the benefits to others in a recursive fashion. Brown and Mason (2017) describe positive feedback loops as success breeding greater success. Instead of triggering infinite changes, negative feedback loops predict that interacting components move one or all components toward a steady state (Roundy et al., 2018; Stacey, 1995).

\subsubsection{Adaptability through dynamic interactions}

CASs, such as the human immune system, are stimulated to improve their adaptability, which is defined as a system's capacity to adjust to internal struggles and external threats without endangering its essential function (Chiva et al., 2010). For this purpose, a CAS will remain in a quasi-equilibrium state that helps it produce a better solution (new structures through agent entry, exit, and transformation) to survive (Anderson, 1999; Choi et al., 2001; Dooley, 1997).

In the EE context, "system-level adaptability emerges from behaviors at lower levels, even as the agents comprising those levels are themselves influenced by system-level changes” (Roundy et al., 2018, p. 4). The internal adaptation process refers to a small event caused by 
agent interactions that can trigger a cascade of changes and eventually cause system-level behavior. In turn, this process directs EE agents to modify their internal rules and evaluation criteria for fitness_ - at least temporarily (Kauffman and Strohman, 1994; McCarthy et al., 2006; Surana et al., 2005). The external adaptation process refers to external disturbances that cause adaptive reactions from EE agents, who accordingly readjust internal diversity and coherence in an accumulated way (e.g., Auerswald and Dani, 2017; Radinger-Peer et al., 2018).

\subsubsection{Sensitivity to initial conditions}

"The feedback loops and nonlinear relationships create a condition called sensitivity to initial conditions-which results in unpredictability” (Aydinoglu, 2013, p. 6). Sensitivity to initial conditions can help us understand how a CAS achieves its current state via evolutionary path dependence (i.e., new path creation is the result of new combinations based on, and limited by, historical system structures) (Neffke et al., 2011).

The extant EE research has confirmed this path-dependence feature (see Radinger-Peer et al., 2018). Early entrepreneurship success (especially well-known entrepreneurs) in EE offers experiences, role models, and entrepreneurial resources for prospective entrepreneurs who will make use of these advantages to promote more successes. In this respect, early entrepreneurial activities pass on genes to followers. Combinations of early entrepreneurs' previous ideas are further embedded into the $\mathrm{EE}$ and, as a whole, shape future entrepreneurial behaviors. As a result, the diversity of initial EE components can significantly impact its future state (Nylund and Cohen, 2017). By contrast, if past decisions by EE agents focus on a single type of entrepreneurship, these decisions might crowd out other ideas, and the EE might become susceptible to environmental shocks (Brown and Mason, 2017; Roundy et al., 2018). This holds especially true for EEs dominated by a single big firm (Bhawe and Zahra, 2019; Gray et al., 1996) or a single industry (Kenney et al., 1999; Spigel, 2015).

\subsection{METHODS}

We adopted the case study method based on two considerations. First, multiple qualitative data sources and theory-driven data analysis are preferable for studying CAS in different organizational forms (e.g., Brown and Eisenhardt, 1997; McCarthy et al., 2006; Roundy et al., 2018). Second, the case study method has a distinct advantage in situations in which "how" or “why” questions are being asked about events and activities over which the investigators have 
little to no control (Yin, 2013). Our research question was precisely driven by a retrospective, in-depth analysis of multiagent activities and critical events and development of a viable EE.

We selected the Zhongguancun EE located in Beijing as an appropriate research context for two reasons. First, the Zhongguancun EE has been transformed from an entrepreneurship policy-driven EE into a self-organized ecosystem. During this transformation process, the dispersed Zhongguancun EE agents have become more coherent and are specifically promoted by an inclusive entrepreneurship culture, high-quality human resources, supportive innovation policies, emerging markets, diverse financial agencies, and integrated digital infrastructures (Dong et al., 2019). As a result, the Zhongguancun EE changes from an environment that solely sells electronic products to one that nurtures innovative start-ups (Du et al., 2018). Additionally, such a transformational process features an increasing level of complexity (i.e., agent connectivity, diversity, ambiguity, and dynamicity) in the Zhongguancun EE, which supports our intention to apply CAS theory (de Toni and de Zan, 2016). Second, rich secondary data from various available sources, such as news on websites, newspapers, magazines, videos, books, and academic papers, can provide a holistic view of the Zhongguancun EE and hence be utilized to validate our research findings (van de Ven, 2007; Yin, 2013).

\subsubsection{Description of the Zhongguancun EE}

The Zhongguancun EE has been one of the most viable innovation centers in the world and has pioneered many disruptive innovations (KPMG, 2017). ${ }^{(5)}$ Over the last three decades, the Zhongguancun EE has been increasingly expanding its geographic boundary to cover approximately 500 square kilometers and has gathered over 20,000 high- and new-tech enterprises residing in 11 major industry sectors, such as mobile Internet, biomedicine, new energy and environmental protection, new materials, advanced intelligent manufacturing, aerospace engineering, and IT-related services (Dong et al., 2019). Moreover, according to the Zhongguancun Index 2018, the number of patents granted per ten thousand people soared from 1.4 in 2001 to 74.2 in 2017, indicating a trend of active entrepreneurial or innovative activities in the Zhongguancun EE. The EE has achieved the viability to produce high-growth entrepreneurial firms (76 unicorns from 2012 to 2018) through four developmental stages, where the diversity and coherence of Zhongguancun EE agents show periodical features. The four developmental stages are elaborated on in a chronological manner in Figure 5.1.

(5) See more research settings on Zhongguancun EE: http://zgcgw.beijing.gov.cn/; and https://assets.kpmg.com/content/dam/kpmg/tw/pdf/2017/04/changing-landscape-disruptive-tech-2017. 
Stage 1 is the period between 1980 and 1988 when the economic reforms proceeded in China. The initial entrepreneurs mainly came from leading universities, such as Peking University, Tsinghua University, and the Chinese Academy of Sciences and affiliates, from municipal governments and state-owned enterprises. Their entrepreneurial ambitions were deeply impelled by the central government's ambivalent attitudes toward new market-oriented companies and thus profit-oriented business practices. Many Internet-related markets (e.g., PC electronics) then boomed and were gradually clustered into "Zhongguancun Electronics Street", a prototype of the Zhongguancun EE, to better share information and resources. During this period, the diversity of EE agents was low. The social networks among agents within the Zhongguancun EE were fragile, as they were relatively closed academic networks involving only a few commercial agents, such as banks and business services providers.

Stage 2 is the period between 1988 and 1999 when most entrepreneurs aimed at creating high-tech Internet-based companies (e.g., Lenovo) but faced intense competition from multinational corporations (MNCs). In light of the massive number of entrepreneurial firms, the central government remained on the sidelines, whereas local Beijing municipalities played supportive roles. In so doing, in May 1988, the Beijing municipal government approved the rapid establishment of the "Beijing New Technology Industrial Development Trial Zone”, a significant step beyond selling electronic devices. During this period, diversified EE agents emerged, such as professional financial institutes, business service agencies, and talent service organizations. However, these agents operated separately and therefore lacked coherence in their entrepreneurial actions.

Stage 3 is the rapid development period between 1999 and 2009. A massive number of entrepreneurs faced problems regarding the shortage of business services, labor mobility restrictions, market monopoly and entry barriers, entrepreneurship information asymmetry, and intellectual property (IP) issues. Governments at different levels started to invest heavily into information/physical infrastructure, providing tax deductions, increasing public R\&D funding, and removing administrative obstacles. In June 2000, the first overseas liaison office was established in Silicon Valley in the U.S. to introduce international entrepreneurial resources. As a result, a community of returnee-initiated high-tech start-ups, related entrepreneurial service organizations (such as incubators and accelerators), and university spin-offs and established large MNCs thrived in the Zhongguancun EE. However, the fragility of mutual trust, scarce venture capital, and IP rights disputes endangered Zhongguancun EE’s sustainable development. 


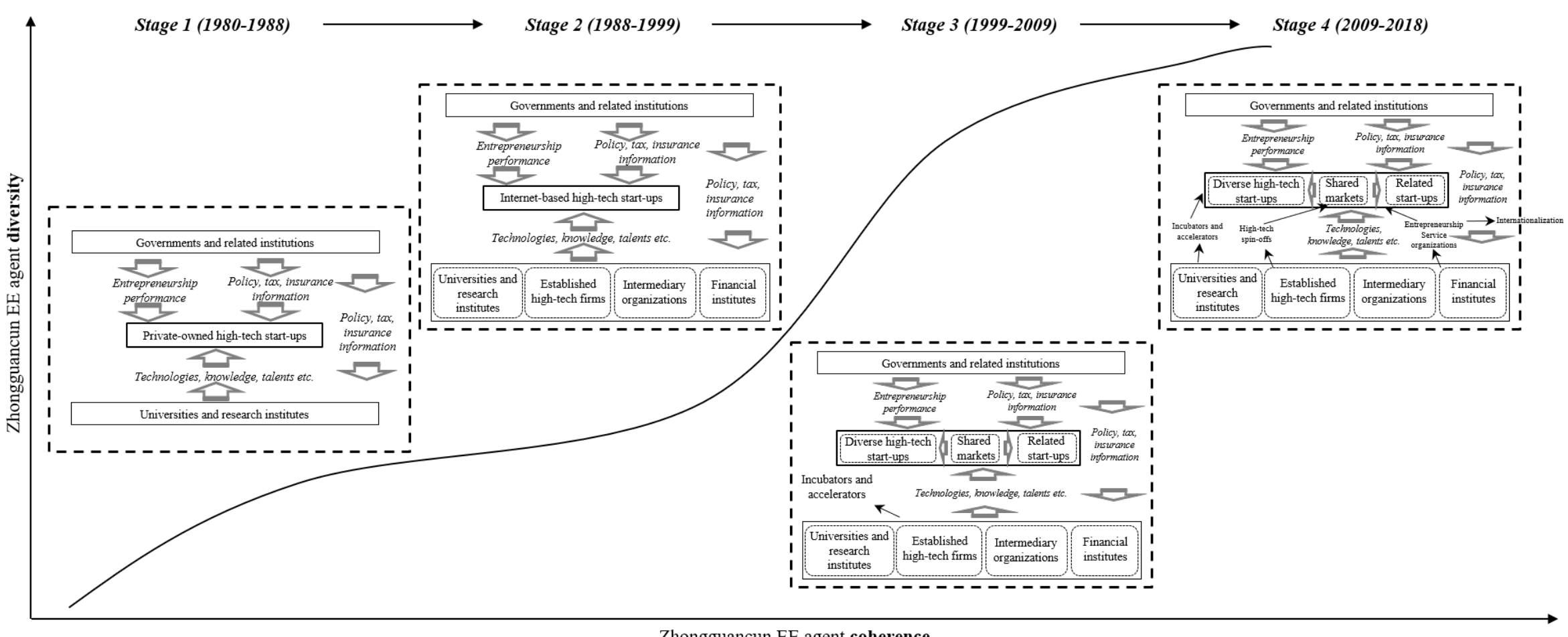

Figure 5.1: Developmental stages of the Zhongguancun EE (source: authors). 
Table 5.1: An overview of interviewees.

\begin{tabular}{|c|c|c|c|c|c|c|}
\hline Item & $\begin{array}{l}\text { Date } \\
\text { (2014-) }\end{array}$ & $\begin{array}{l}\text { Number of } \\
\text { Interviewers }\end{array}$ & $\begin{array}{l}\text { Interviewee Position } \\
\text { (Institution) }\end{array}$ & $\begin{array}{l}\text { Belonging to } \\
\text { EE } \\
\text { Components } \\
\end{array}$ & Code & $\begin{array}{l}\text { Duration } \\
\text { (Minutes) }\end{array}$ \\
\hline 1 & $05-15$ & 3 & $\begin{array}{l}\text { Co-founder } \\
\text { (Accelerator) }\end{array}$ & Culture & $\begin{array}{l}\text { co-founder, } \\
\text { Culture } 1\end{array}$ & $110 \mathrm{~min}$ \\
\hline 2 & $05-15$ & 5 & $\begin{array}{l}\text { Co-founder } \\
\text { (Incubator) }\end{array}$ & Culture & $\begin{array}{l}\text { co-founder, } \\
\text { Culture } 2\end{array}$ & $90 \min$ \\
\hline 3 & $05-15$ & 3 & $\begin{array}{l}\text { Co-founder } \\
\text { (Incubator) }\end{array}$ & Supports & $\begin{array}{l}\text { co-founder, } \\
\text { Supports } 1\end{array}$ & $100 \mathrm{~min}$ \\
\hline 4 & $05-27$ & 3 & $\begin{array}{l}\text { Co-founder (Venture } \\
\text { capital) }\end{array}$ & Finance & $\begin{array}{l}\text { co-founder, } \\
\text { Finance } 1\end{array}$ & $100 \mathrm{~min}$ \\
\hline 5 & $05-29$ & 3 & $\begin{array}{l}\text { Co-founder (Venture } \\
\text { capital) }\end{array}$ & Finance & $\begin{array}{l}\text { co-founder, } \\
\text { Finance } 2\end{array}$ & $80 \min$ \\
\hline 6 & 06-19 & 5 & Founder (Incubator) & Supports & $\begin{array}{l}\text { founder, Supports } \\
2\end{array}$ & $70 \mathrm{~min}$ \\
\hline 7 & 06-19 & 2 & $\begin{array}{l}\text { Director (Incubator \& } \\
\text { Accelerator) }\end{array}$ & Supports & director, Supports & $105 \mathrm{~min}$ \\
\hline 8 & 06-19 & 4 & $\begin{array}{l}\text { Co-founder } \\
\text { (Entrepreneurship } \\
\text { service provider and } \\
\text { incubator) }\end{array}$ & Supports & $\begin{array}{l}\text { co-founder, } \\
\text { Supports } 4\end{array}$ & $130 \mathrm{~min}$ \\
\hline 9 & $06-24$ & 5 & $\begin{array}{l}\text { Chairperson (Venture } \\
\text { capital) }\end{array}$ & Finance & $\begin{array}{l}\text { chairperson, } \\
\text { Finance } 3\end{array}$ & $130 \mathrm{~min}$ \\
\hline 10 & $06-24$ & 4 & $\begin{array}{l}\text { Co-founder (Mobile } \\
\text { Internet social app) }\end{array}$ & Markets & $\begin{array}{l}\text { co-founder, } \\
\text { Markets } 1\end{array}$ & $90 \min$ \\
\hline 11 & $06-24$ & 5 & $\begin{array}{l}\text { Founder (Car-sharing } \\
\text { service) }\end{array}$ & Markets & $\begin{array}{l}\text { founder, Markets } \\
2\end{array}$ & $80 \mathrm{~min}$ \\
\hline 12 & $07-04$ & 4 & $\begin{array}{l}\text { Co-founder (Venture } \\
\text { capital) }\end{array}$ & Finance & $\begin{array}{l}\text { co-founder, } \\
\text { Finance } 4\end{array}$ & $90 \mathrm{~min}$ \\
\hline 13 & $07-18$ & 2 & $\begin{array}{l}\text { Section Chief } \\
\text { (Zhongguancun } \\
\text { Administrative } \\
\text { Committee) }\end{array}$ & Policy & $\begin{array}{l}\text { section chief, } \\
\text { Policy } 1\end{array}$ & $80 \mathrm{~min}$ \\
\hline 14 & $07-24$ & 4 & $\begin{array}{l}\text { Senior Consultant } \\
\text { (Research institute) }\end{array}$ & Human Capital & $\begin{array}{l}\text { senior consultant, } \\
\text { Human Capital } 1\end{array}$ & $100 \mathrm{~min}$ \\
\hline 15 & $07-30$ & 4 & $\begin{array}{l}\text { CEO (Online } \\
\text { gaming) }\end{array}$ & Markets & CEO, Markets 3 & $80 \mathrm{~min}$ \\
\hline 16 & $07-30$ & 4 & CEO (Incubator) & Supports & CEO, Supports 5 & $120 \mathrm{~min}$ \\
\hline 17 & 08-01 & 4 & $\begin{array}{l}\text { Vice President } \\
\text { (Venture capital) }\end{array}$ & Finance & $\begin{array}{l}\text { vice president, } \\
\text { Finance } 5\end{array}$ & $100 \mathrm{~min}$ \\
\hline 18 & 08-01 & 4 & $\begin{array}{l}\text { Secretary General } \\
\text { (Chamber of } \\
\text { Commerce) }\end{array}$ & Supports & $\begin{array}{l}\text { secretary general, } \\
\text { Supports } 6\end{array}$ & $85 \mathrm{~min}$ \\
\hline 19 & $08-29$ & 3 & $\begin{array}{l}\text { President Assistant } \\
\text { (Commercial bank) }\end{array}$ & Finance & $\begin{array}{l}\text { president } \\
\text { assistant, Finance } \\
6\end{array}$ & $110 \mathrm{~min}$ \\
\hline 20 & $08-29$ & 2 & $\begin{array}{l}\text { Co-founder (Legal } \\
\text { service) }\end{array}$ & Supports & $\begin{array}{l}\text { co-founder, } \\
\text { Supports } 7\end{array}$ & $76 \mathrm{~min}$ \\
\hline 21 & $09-03$ & 3 & $\begin{array}{l}\text { CEO (Financing } \\
\text { guarantee/service) }\end{array}$ & Supports & CEO, Supports 8 & $70 \min$ \\
\hline 22 & $10-28$ & 3 & $\begin{array}{l}\text { CEO (High-tech } \\
\text { electrics) }\end{array}$ & Markets & CEO, Markets 4 & $90 \mathrm{~min}$ \\
\hline 23 & $11-05$ & 3 & $\begin{array}{l}\text { Executive Director } \\
\text { (University) }\end{array}$ & Human Capital & $\begin{array}{l}\text { executive } \\
\text { director, Human } \\
\text { Capital } 2 \\
\end{array}$ & $80 \min$ \\
\hline
\end{tabular}


Stage 4 is the period between 2009 and 2018, the viable stage in which high-growth startups in diverse industries increased exponentially and the connectedness of all $\mathrm{EE}$ agents became multilateral. For instance, on average, 1.5 start-ups were financed per day, and the average financing was 7 million dollars. One important reason behind the phenomenal change is that central governments transformed their dominant role into policy and service supporters. In particular, on March 13, 2009, the State Council approved the construction of the “Zhongguancun National Demonstration Zone”, which advanced the geographic layout of 16 major science parks. Later, on January 26, 2011, the introduction of the "Development Plan Outline for Zhongguancun National Demonstration Zone (2011-2020)” further accelerated the process of connecting the Zhongguancun EE to global innovation centers. Another important reason for the advance of the EE lies in the entrepreneurs' strong social networks and the formation of a conducive entrepreneurial culture by which the Zhongguancun EE established rules for entrepreneurial activities.

\subsubsection{Data collection}

Our data were drawn mainly from 23 group interviews complemented by six types of secondary data, namely, news/industrial articles, online audio and videos, public reports and yearbooks of the Zhongguancun EE, the corresponding author's participatory observations, extensive discussions with experts and practitioners, and industry meeting reports. These secondary data are helpful because they offer very accurate numbers as well as details that complement or contradict interviewees' narratives, thereby allowing for data triangulation (Jick, 1979). In total, we obtained 36.2 hours of recorded interviews and 1,443 pages of secondary data resources (excluding yearbooks and academic books).

Primary data was collected via face-to-face interviews with 23 entrepreneurs or senior managers/administrators at the Zhongguancun EE (see Table 5.1). These representative interviewees were conducted between May and November 2014 under the guidance of the Zhongguancun Administrative Committee (ZAC), a specialized quasi-political agency responsible for managing annual entrepreneurship and innovation information (Du et al., 2018). The 23 interviewees were distributed across six main EE components as categorized by Isenberg (2011). To anonymize our interviewees, we rename them following Isenberg's (2011) categorization of EE components. For example, among our interviewees, we have two agents from culture components who are coded as culture 1 and culture 2. In this way, we can offer a complete overview of the Zhongguancun EE by combining complementary perspectives from 
each component. In addition, such high-level interviewees with decades of entrepreneurial experience who have remained within the Zhongguancun EE ensured that we could capture the most informed qualitative data (especially at the policy level).

Each anonymously recorded interview involved multiple interviewers and was based on a standardized interview protocol to ensure data reliability (Strauss and Corbin, 1990). Multiple interviewers, including the corresponding author, senior ecosystem experts/scholars, and industrial practitioners, made it possible to collect answers from both academic and practical angles. The interview protocol, which consisted of three main sections, was frequently adjusted according to each interviewee's real-time responses. Specifically, the first section focused on the personal and organizational background of the interviewee. If the interviewee was an entrepreneur, he or she was asked to report on his or her entrepreneurial experience/history and his or her start-up's operating conditions. The second and key section focused on how the interviewees (and the organizations to which they belong) interacted with different EE agents to undertake entrepreneurial activities, on important changes in different industrial contexts in which they have been embedded in recent years, on critical entrepreneurial events or activities that have marked the development of the Zhongguancun EE, and on their evaluations of various agents' (finance, policy, and talent) roles in enabling the success of the Zhongguancun EE. The interview design for the second section allows us to keep a close eye on the three basic elements of a CAS: agents, their interactions, and environments in which multiple interactions occur (Dooley, 1997). The third section asked the interviewees to provide advice on how the Zhongguancun EE could better support future high-impact entrepreneurship.

Diverse secondary data were compiled by the first author to complement and triangulate the primary interview data. This approach further validated our research findings (Jick, 1979; Jonsen and Jehn, 2009). We stopped collecting secondary data when theoretical saturation was achieved (Eisenhardt, 1989; Yin, 2013). Finally, interview data, which were transcribed verbatim in Chinese, together with all secondary data were coded and analyzed using NVivo 11 software.

\subsubsection{Data analysis}

All four authors participated in the data analysis via multiple discussions, following the recommended procedures for qualitative research and grounded theory (Gioia et al., 2013; Strauss and Corbin, 1990). In this procedure, researchers are permitted to identify complexity properties to advance the data analysis process (Eisenhardt, 1989). Specifically, we adopted an 
iterative coding process that involved identifying emerging concepts, examining empirical evidence for supports, consolidating similar concepts to create refined themes, and collecting more data until reaching theoretical saturation. An overview of the data structure is illustrated in Figure 5.2.

The initial data analysis was based on three stages: open, axial, and selective coding (Strauss and Corbin, 1990). During the open coding stage, using the proposed complexity properties for guidance, the first and second author independently coded all the data sentenceby-sentence and remained open to what the qualitative materials suggested. This approach ensured that the coders interpreted the data in a similar fashion without missing any emergent information. Although acting independently, we regularly stopped and discussed the coding issues to arrive at a common set of codes. We initially identified 850 codes, each supported by two or more text segments. During the axial coding stage, three authors collated first-order codes that were conceptually similar and relevant to our themes. In addition, the corresponding author played the role of "censor" in group meetings to critically question or challenge the themes determined by the three open coders to improve data validity. Finally, during the selective coding process, conforming closely to the method suggested by Gioia et al. (2013), we strived to aggregate the identified themes into dimensions, thus formulating a coherent and insightful account of the complexity-based Zhongguancun EE. This stage was again guided by the established CAS literature, as we looked for matched empirical evidence in the data and new insights into the Zhongguancun EE using the six complexity properties (Roundy et al., 2018).

Additional coding and interviewing efforts were made in late 2018 until theoretical saturation was reached. We returned to the dataset in NVivo 11 to improve the consistency of the research results by addressing some information gaps. In cases of confusion or inconsistencies, we triangulated among all the interviewers and authors and, when necessary, checked factual information with key insiders at the Zhongguancun EE by email or phone call. We then began to develop our write-ups; the relevant parts of these were read and commented on by key interviewees and adjusted accordingly. Through this process, our analysis was grounded in qualitative data and internally consistent. Ultimately, we felt confident in the six revealed complexity properties as well as their integral relationships in the case of the Zhongguancun EE. 


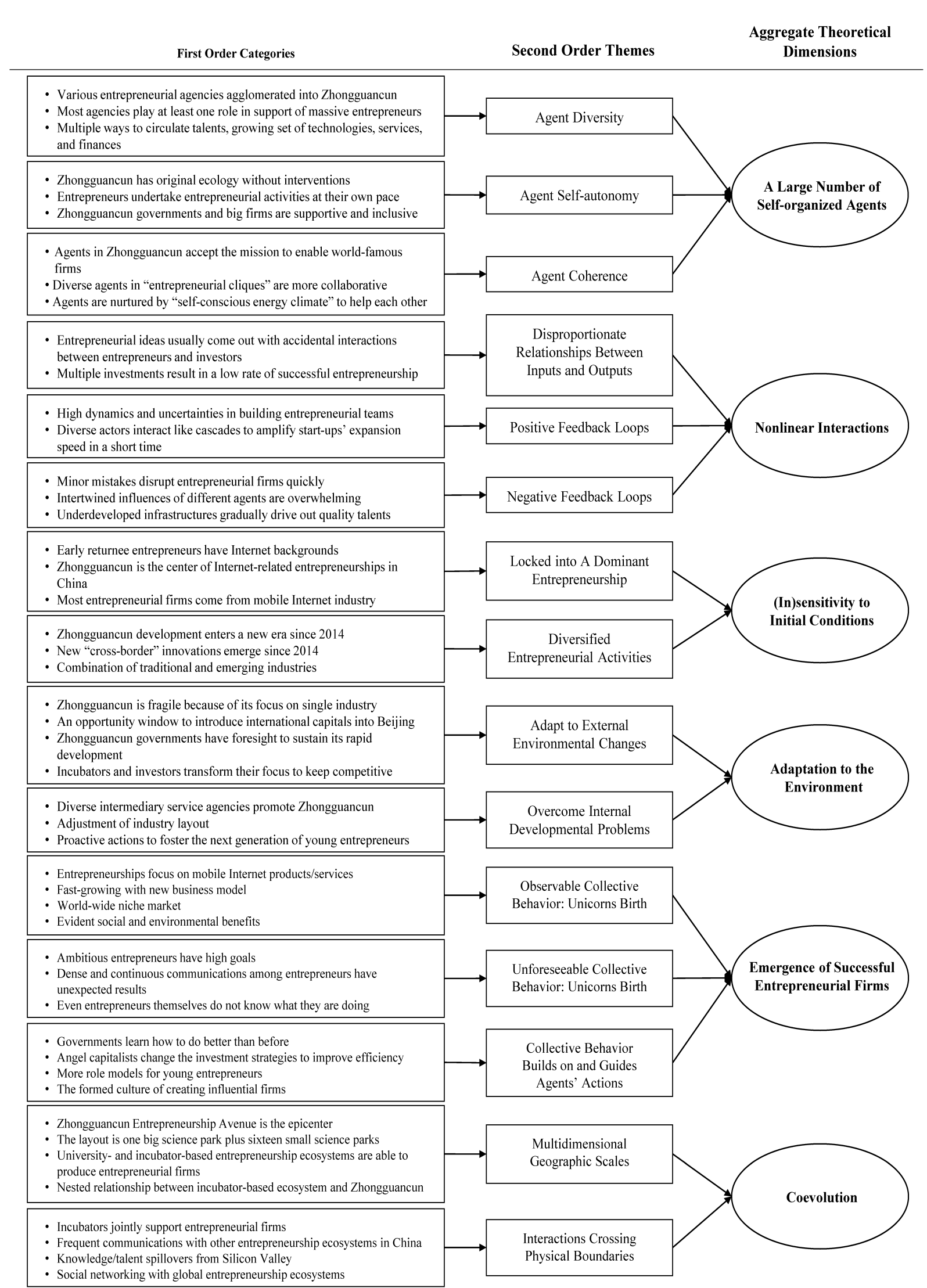

Figure 5.2: Data structure: the complexity-based Zhongguancun EE. 


\subsection{RESULTS}

Our analysis revealed six interrelated complexity properties that a viable EE exhibits: a large number of self-organized agents, nonlinear interactions, (in)sensitivity to initial conditions, adaptation to the environment, emergence of successful entrepreneurial firms, and coevolution. In the following section, we elaborate on each complexity property in more detail.

\subsubsection{A large number of self-organized agents}

Our data reveal that the viability of the Zhongguancun EE depends largely on eight dominant EE components (agents) that revolve around a large number of individual entrepreneurs. These agents comprise service-oriented governments, Internet-based industries, universities, dense research institutes, diversified investment agencies, entrepreneurship intermediaries, mass media, and many other entrepreneurial service agencies. Entrepreneurial resources, such as talents, technologies, finances, and services, circulate within and across the Zhongguancun EE and thus connect all EE agents (see Figure 5.3).

As shown in Figure 5.3, local (universities/research institutes, entrepreneurship intermediaries, and established firms) and overseas (returnees) talents are the two major sources of talent. Most talents choose to establish new firms with help from entrepreneurship intermediaries. To some extent, their entrepreneurial successes enhanced the Zhongguancun EE's attractiveness. Through supportive talent policies in particular, talents are stimulated to flock into the Zhongguancun EE. Regarding entrepreneurial resources of technologies, established ICT (Information and Communication Technology) firms (e.g., Baidu) as well as universities and research institutes are two major providers. These providers license technologies to or codevelop technologies with start-up firms. Additionally, diverse entrepreneurship intermediaries help entrepreneurial firms connect to (international) venture capital. The success of start-up firms and supportive government policies again encourages established ICT firms (e.g., Baidu) as well as universities and research institutes to continuously transfer technologies to start-up firms. Regarding financial resources, various finance agencies, established ICT firms, and governments offer financial support to entrepreneurs. To make the process effective, these financial agents either spend money on building incubators/accelerators given their direct roles in pinpointing high-growth new firms or engage in syndicated investment. As pointed out, "some entrepreneurial projects have risks...set the pooled funds with governments to improve investment effectiveness...” (co-founder, Finance 2). The 
successful entrepreneurs who are benefit from this process turn into new investors providing new streams of financial resources. Finally, the role of various entrepreneurship intermediaries is vital to entrepreneurial activities. Without their service, high transaction costs will result from the distrust among different agents and information asymmetry.
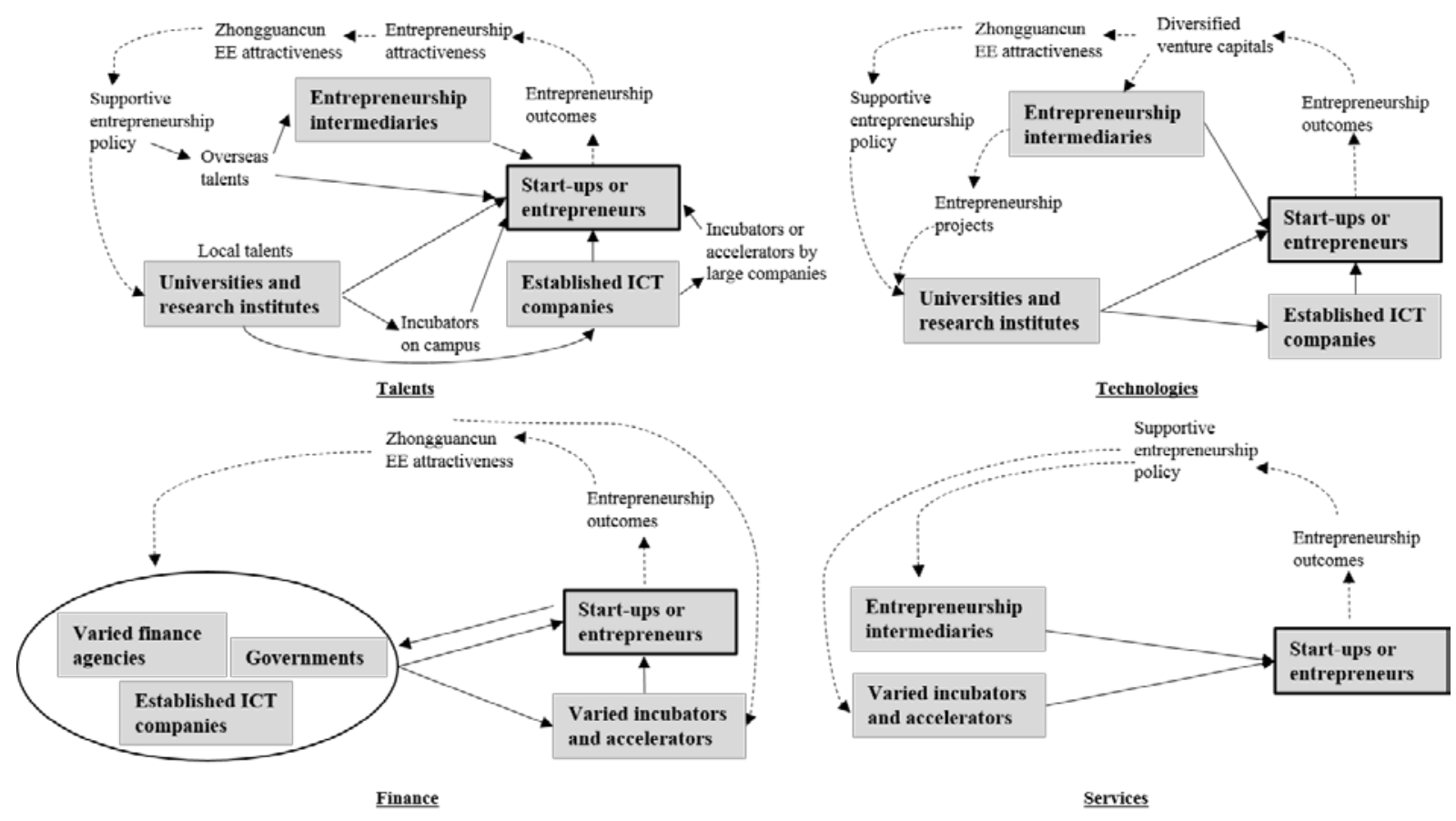

Figure 5.3: Circulation of entrepreneurial resources in the Zhongguancun EE (source: authors).

Our data also revealed that EE agents have three defining features. First, EE agents do not have clear role boundaries. In contrast with Silicon Valley, where angel investors and venture capitalists focus only on investment, finance agents in the Zhongguancun EE play additional roles to help entrepreneurs in other aspects, such as with management skills training, resource matchmaking, and even marketing. Similarly, incubators (and accelerators) support massive entrepreneurs with free office space, direct financial resources, and up-to-date entrepreneurial information. As such, these versatile investors and incubators cannot be easily differentiated.

Second, EE agents-especially entrepreneurs—are self-organized without any central controllers. Since 2009, a remarkable transition has occurred within the ZAC, a quasi-political agency. The committee changed its management focus from giving administrative commands ("What you are or are not permitted to do") to providing supportive entrepreneurship policies ("What or how can we help you") because it consciously realized that direct political interventions were disadvantageous to boosting high-quality entrepreneurial activities. Likewise, powerful agents such as investors and established firms also respect entrepreneurs' 
autonomy/ambition in developing innovations, as confirmed by the following quotes: "only entrepreneurs themselves know what they really want to offer. We usually do not give them operational support. We do not want to catalyze any start-ups but hope that they can grow at their own pace” (director, Supports 3). "If employees of big dotcom companies like Baidu want to try entrepreneurial ideas, they are always allowed to do so in our incubator while keeping their positions in Baidu” (co-founder, Supports 4).

Third, EE agents are inspired by a unique entrepreneurial culture that motivates and encourages innovation, risk bearing, failure tolerance, community building, and mentoring juniors/newcomers. Everyone who joins this community shares the common mission of building the most innovative EE in China or even the world. Driven by this mission, the agents of the Zhongguancun EE consciously innovate, take risks, help each other, and relay these shared values to the next generation of EE agents. As described, "Zhongguancun [EE] is a magical place and you cannot find another one elsewhere in China. Many entrepreneurs are attracted by its pleasant local entrepreneurship climate. The local climate formation is to the result of continual efforts by four generations of successful entrepreneurs, acknowledged entrepreneurial core values, and entrepreneurs' inner entrepreneurial passions. Once integrated into such a climate, entrepreneurs are motivated to develop world-famous companies instead of just creating a normal new company...” (CEO, Markets 4).

\subsubsection{Nonlinear interactions}

"As we often see several lucky ones from a thousand start-ups, there is a proverbial rule in terms of the emergence of successful entrepreneurship...It is not about the amount of money you invest but, to a large extent, about the entrepreneurs themselves, luck, and unforeseen factors..." (co-founder, Supports 7). "I always warn novice angel investors that they can obtain returns by continuously investing 20 times at least in different domains” (co-founder, Finance 1). These statement correspond to the nonlinear interactions among agents in the Zhongguancun EE, namely, that there is a disproportional relationship between entrepreneurial inputs (diverse entrepreneurial resources) and outputs (successful entrepreneurial firms). Despite the abundant local talent, supportive policies, diversified entrepreneurial services, and accessible financial resources provided by the Zhongguancun EE, only a small percentage of entrepreneurial projects will ultimately succeed.

Moreover, we found that nonlinear interactions exhibited two opposing patterns: positive and negative feedback loops. In positive feedback loops, dynamic interactions among EE agents 
accelerate new firm growth in a short time, which further promotes the development of the Zhongguancun EE. To illustrate the point, we draw on 245 news reports on the bike-sharing industry released by huxiu.com and 36kr.com, the two largest entrepreneurship information providers in China. The early success of two bike-sharing start-ups depended on government encouragement that allowed them to distribute sharing bikes on urban streets in Beijing in 2016. Due to the potential benefits to the environment and social welfare, many other closely connected EE agents, including mass media, NGOs, research institutes, and international investors, quickly became involved and offered entrepreneurial resources to the bike-sharing start-ups, which in turn accelerated their development. Eventually, 10 months later, these two start-ups became globally recognized unicorns in the bike-sharing industry. As such, these startups attracted many international entrepreneurial resources, which were injected into the Zhongguancun EE.

Negative feedback loops can be illustrated by two bankrupt bike-sharing ventures in the Zhongguancun EE. One new bike-sharing venture, founded by a returnee entrepreneur from the Silicon Valley in the U.S., occupied nearly 10 percent of its market share within 4 months of its foundation in late 2016. However, a badly managed marketing promotion by local operations managers induced a cascade of negative reactions from other EE agents. At the beginning, the mass media (especially We-media) propagated the marketing promotion's illegal elements, which aroused questions from the Beijing local security bureau. These questions again aroused mass media coverage, and then, several potential investors withdrew and upstream suppliers and end users started to lose confidence in the rapid development of the venture. The venture ceased business in October 2017. Another bike-sharing company experienced a similar incident when it began operating in late 2016. The venture claimed bankruptcy in late 2017 as it underestimated the importance of user deposits. The venture misused these deposits, which brought about sudden and widespread resistance from other EE agents (mass social media and end users).

Moreover, we also found that EE agent interactions through negative feedback loops blocked Zhongguancun EE development in a less obvious manner. For example, skilled talents are negatively impacted by the local infrastructure (i.e., high housing prices, traffic problems, and air pollution) surrounding the Zhongguancun EE. “...you can imagine that entrepreneurs have to pay for house rent with half of their salary. They are definitely demotivated to be innovative. And, they further spend hours on commuting, so I am sure they have no passion for creating big businesses” (vice president, Finance 5). This problem became intractable in 
approximately 2015 and 2016 when tens of thousands of entrepreneurs flooded into the Zhongguancun EE. However, “...the more entrepreneurs that live in Zhongguancun or nearby, the higher the housing prices are. Whereas fewer entrepreneurs will reduce Zhongguancun's viability. Zhongguancun is unable to solve this problem due to the limited living space. If solved improperly and not in timely manner, entrepreneurs will gradually move to Shanghai, Wuxi, or Shenzhen if their living environment worsens too much... this is disadvantageous to Zhongguancun [EE]” (vice president, Finance 5).

\subsection{3 (In)sensitivity to initial conditions}

The boom of Internet-related entrepreneurial activities has driven the rapid development of the Zhongguancun EE in the last two decades. Until 2014, we observed that most successful entrepreneurial start-ups came from the mobile Internet industry, such as Internet services, ecommerce, and online finance/education. The Zhongguancun EE followed such a pathdependent route for two historical reasons. First, the earliest entrepreneurs focused on electronics- or Internet-based industries. Their entrepreneurial successes resulted in rigid investment preferences, accumulated talents, a strong mobile Internet culture, and established social networks. In turn, this contributed to entrepreneurial activities in the mobile Internet industries. Second, early policymakers viewed Internet-related industries as a promising economic growth engine. As such, they released favorable entrepreneurship policies and invested heavily to build digital infrastructures (especially 2G, 3G, and 4G networks). To some extent, these efforts built a solid foundation for entrepreneurs to easily create niche markets in mobile Internet-related businesses. As stated, "Zhongguancun has become the epicenter of diverse mobile Internet industries. This means that entrepreneurs have to get close to Zhongguancun if their entrepreneurial projects relate closely to mobile Internet domains” (vice president, Finance 5). Despite the benefits, the downside of such industry concentration is also as stated, "Zhongguancun [EE] was rich in 'soft' things but short in 'hard' things... For cloud computing, semiconductors, integrated electronics systems, and electronic design, Shanghai and Shenzhen might be more competitive than Beijing Zhongguancun. For this reason, Zhongguancun began to make efforts to distribute new emerging industries. The old industrial layout will change a lot...” (co-founder, Finance 4).

The development of the Zhongguancun EE has been less sensitive to initial entrepreneurial conditions, particularly considering the recent developmental stages (2009-2018). Since 2014, a striking trend has been that many emerging industries, including biomedicine, smart robots, 
and aerospace, have sprung up in the Zhongguancun EE (Dong et al., 2019). As a result, synergies between newly introduced industries and the existing mobile Internet industry have produced many cross-border entrepreneurial firms. As analyzed by Greatwall Strategy Consultants in 2017, the success of cross-border innovations benefited much from emerging technologies, such as big data platforms and artificial intelligence technologies. This benefit was verified by one of our interviewees, “...2014 can be viewed as a new beginning for Zhongguancun. Many emerging entrepreneurial activities are focused on the integration between the mobile Internet industry and other emerging high-tech industries. A good example is the integration of the mobile Internet industry, automobile industry, and smart robot industry...” (online audio, academic entrepreneur).

\subsubsection{Adaptation to the environment}

Along with its insensitivity to initial conditions in the recent developmental stage, the Zhongguancun EE has increasingly improved its adaptability to environmental shocks. In general, the Zhongguancun EE, as a coherent entity, reacts quickly to economic, societal, and institutional environments. For instance, analyzed by Greatwall Strategy Consultants in 2011, the Zhongguancun EE treated U.S. subprime crisis in 2008 as a good opportunity to introduce diverse international venture capitalists to help new firms expand. As a consequence, 23 firms in 2009 and 39 entrepreneurial firms in 2010 successfully went public on the U.S. Nasdaq, though the number of IPO firms in 2007 and 2008 was just 2 and 8, respectively.

Moreover, at one time, a lack of diverse and robust entrepreneurial services, such as market information providers, legal consultants, IP rights protection, fund-raising guarantees, and specialized media propagation, curbed the development of the Zhongguancun EE. As was reported, “...before the maturity of various entrepreneurial services, around 2009, Zhongguancun did not seem to be a healthy entrepreneurial region” (chairperson, Finance 3). However, this situation has completely changed due to an ongoing trend in global innovative regions (cities), where diversified and coherent entrepreneurial services are expected to create successful entrepreneurial firms in an efficient way. The Zhongguancun EE's timely response to this trend transformed it into a much more friendly and healthy EE. By 2017, over 190 incubators and accelerators in the Zhongguancun EE collaborated closely to support entrepreneurs and make use of complementary entrepreneurial resources. As described, “...we introduced a nice entrepreneurial project to an accelerator because it is more suitable to providing specialized entrepreneurial services. In this way, they also collaborate with the others 
to provide entrepreneurial training to entrepreneurs within their incubators..." (co-founder, Culture 1).

Finally, the Chinese central government released a policy called "Mass Entrepreneurship and Innovation” in 2014 that required local governments to lower the entry barriers for entrepreneurship and to stimulate innovation. As a result, Zhongguancun local governments and bureaus reformed the lengthy administrative procedures for starting a new firm and set up special funds, such as the "Golden Seeds Fund", for grassroots entrepreneurs. Accordingly, investors proactively changed their investment focus, universities intentionally adjusted their educational orientations, and more entrepreneurs devoted themselves to technology-intensive domains. As underlined by one respondent, "unlike incubators or accelerators, we start exploring to build an 'aggregator' to nurture such [cross-border] firms. The 'aggregator' integrates the respective strengths of large firms, small films, service agencies, and relevant actors. Such resource integration can accelerate the breeding process of revolutionary products...” (CEO, Supports 5). These agile actions by EE agents guaranteed sustainable development of the Zhongguancun EE.

\subsubsection{Emergence of successful entrepreneurial firms}

Agents in the Zhongguancun EE demonstrate collective behavior, thereby creating influential companies. This collective behavior is unforeseeable as no one can predict what influential unicorns look like and thus intentionally create them. However, the emergence of such influential companies is observable due to shared general characteristics, such as mobile being Internet-related, having customer-driven products/services, being fast-growing, having new business models, having worldwide niche markets, and providing substantial social/environmental benefits. The emergence of such collective behavior in the Zhongguancun $\mathrm{EE}$ is the result of numerous ambitious entrepreneurs, coherent entrepreneurial actions among various EE agents, and the injection (elimination) of new (redundant) entrepreneurial resources.

First, entrepreneurs in the Zhongguancun EE are ambitious. Regardless of their educational background, gender, age, or social status, entrepreneurs are urged to commercialize innovative ideas that have social, economic, and environmental impacts. As stated, "Most of them [entrepreneurs] are pursuing self-actualization or showing a pure desire to change society...” (co-founder, Supports 1).

Second, nonlinear interactions between newly introduced entrepreneurial resources and established mobile Internet elements can produce cross-border entrepreneurs. The emergence 
of these entrepreneurs has had overarching guiding effects on EE agents. As demonstrated earlier, these effects include investors calibrating their investment strategies, governments reassessing previously introduced entrepreneurial policies and constructing infrastructure, and universities modifying their educational systems for qualified talents.

Third, the development of Zhongguancun EE has benefited from the Silicon Valley EE. According to two representative reports by Greatwall Strategy Consultants, since 1999, there has been a trend of overseas returnees moving from Silicon Valley to the Zhongguancun EE to explore entrepreneurial opportunities. These returnees were attracted by the availability of young talent, technology infrastructure, complete entrepreneurial services, supportive government agents, the closeness to mass markets, and energetic entrepreneurship networks in and surrounding the Zhongguancun EE. This injection of overseas returnees diversified EE components and accelerated EE evolution through heterogeneous technologies, concepts, and knowledge. Therefore, a senior official of ZAC confessed that "the growing emergence of "Haigui” [overseas returnee] entrepreneurship manifests the success of our talent policies". This trend has greatly helped the Zhongguancun EE avoid evolutionary path dependence connected to mobile Internet-related businesses.

\subsubsection{Coevolution}

Diverse EE agents interact and coevolve in different geographic areas. Zhongguancun Entrepreneurship Avenue, a geographic area with a complete set of EE components, including over 50 established dot-com firms, 45 entrepreneurship service agencies, 50 research institutes and universities, and nearly 2,000 investment agencies, is the Zhongguancun EE epicenter that breeds influential start-ups. Within this geographically bounded region, there are also many smaller EEs. These smaller EEs exchange advantageous entrepreneurial resources to nurture entrepreneurship. For example, 29 university-based EEs not only receive entrepreneurial services from incubator-based EEs but also supply qualified young entrepreneurs to them. Such ecosystem-level interactions contribute to the overall development of the Zhongguancun EE.

Our interviewees emphasized such nested geographic features. Tsinghua University is known as a small, viable research-based EE nested within the Zhongguancun EE because it internally offers necessary entrepreneurial conditions that give birth to new firms: “...First, as a world-famous technical university, Tsinghua is powerful in R\&D. This means that attracting entrepreneurs and investors is relatively easy for them. Second, they have a lot of alumni dispersed around the globe who have connected with other entrepreneurial resources outside of 
Zhongguancun [EE]. Third, dynamic interactions among CEOs from well-known firms and academia make Tsinghua look like a place producing innovative ideas...” (chairperson, Finance 3). Another interviewee confirmed this position, stating that “...Zhongguancun is a big ecosystem, while we are an embedded smaller one. We are able to produce influential entrepreneurships and innovations because we can provide start-ups with required entrepreneurial resources, such as angel funds, technicians, and management consulting services. Like us, I guess many other big incubators or accelerators in Zhongguancun [EE] can do so. We only share the same policies from governments and other entrepreneurial services...” (secretary general, Supports 6).

Moreover, these smaller EEs do not grow independently but interact frequently in various ways. To best serve Tsinghua graduate entrepreneurs, Tsinghua University launched “TusStar Accelerator” in 2001. In this way the university enhanced frequent collaborations with other incubator- or accelerator-based EEs to acquire complementary resources. “... we very often call to them. 'Hey, we here are an entrepreneurial team with a promising project that might be better incubated by your institutions, and then, we hand over the team ....we do not think this is a loss. Rather, many successful projects will in turn expand our brand influence” (founder, Supports 2). In addition to spontaneous interactions, many related social activities, such as forums, seminars, and conferences, are regularly coordinated by the ZAC, which also increases the interactions among EEs. "To sustain a dynamic entrepreneurship climate, we have a tradition of organizing around 150 Zhongguancun Entrepreneurship Forums since 2010, where we gather together various people, including famous entrepreneurs, investors, and experts, to give lectures... to make it continue, I think those incubators, innovation campuses, and various industrial associations play the key roles” (section chief, Policy 1).

However, the Zhongguancun EE is not a closed region of approximately 500 square kilometers. Paralleling Zhongguancun Entrepreneurship Avenue, there are approximately 16 other entrepreneurship epicenters in Beijing. Although spatially isolated, these regions with specific industries constantly exchange entrepreneurial resources with Zhongguancun Entrepreneurship Avenue. Moreover, such ecosystem-level interactions expand beyond Beijing to other regional EEs in China (e.g., Shenzhen, Shanghai, Hangzhou, and Nanjing). According to the Beijing Business Incubation Association, since 2012, almost 60 percent of the Zhongguancun EE representative incubators and accelerators (e.g., 3W Café and Legend Star) have set up branches or joint branches in these cities, which permits EE agents (and relevant entrepreneurial resources) to flow among these higher-scale regions. 
Finally, there are active ecosystem-level interactions between the Zhongguancun EE and regional ecosystems outside of China. Our data revealed that the ZAC has established 9 liaison offices in entrepreneurial regions and cities, including Silicon Valley, London, Paris, and New York. Returnee entrepreneurs have contributed significantly to the growth of the Zhongguancun EE since 1999. According to annual reports by the Zhongguancun Statistics Center and a talent report by LinkedIn.com in 2017, the number of returnee entrepreneurs in the Zhongguancun EE reached its peak at approximately 13,000 in 2013, compared to a mere 1,100 in 1999 . A relevant indicator released online by the ZAC in 2018 suggests that approximately 30 percent of the 76 unicorns were initiated or cofounded by Silicon Valley entrepreneurs. Typically, entrepreneur mobility between Silicon Valley in the U.S. and the Zhongguancun EE is the most evident. Many early successful entrepreneurs are from Silicon Valley, and they function as role models for followers. Due to the comprehensive cooperative relations between the two innovative regions, ranging from education, trade, capital, and business to governments, industrial associations, and chambers of commerce, "there is an identifiable clique of 'Silicon Valley’ entrepreneurs...” (chairperson, Finance 3).

In a sense, the attracted overseas talents, financial resources, emerging technologies, and leading management experiences has closely linked the Zhongguancun EE in a timely manner with other EEs so that the Zhongguancun EE could coevolve with them in various ways. This perspective is additionally supported by one of our interviewees, “...Tian [a returnee entrepreneur] considered collaborating with Beijing local governments and created six new companies ranging from cloud software to end cloud-computing marketing based specifically on the constructed cloud-computing platform. After these endeavors, Tian usually returned to Silicon Valley several times every year, attempting to absorb new knowledge, technologies, and concepts from there. Currently, the cloud-computing industry is beginning to take shape...” (CEO, Supports 5).

\subsubsection{A complexity-based framework for the Zhongguancun EE}

Taken together, we also observe that the six complexity properties demonstrated above do not act independently; rather, they work in an integrative manner to ensure the viability of the Zhongguancun EE. Specifically, the properties of a large number of self-organized agents and agents' nonlinear interaction illustrate what the fundamental constituents (and their interactive relationships) are in the Zhongguancun EE; the properties of (in)sensitivity to initial conditions and adaptation to the environment then indicate how the Zhongguancun EE develops/grows as 
a whole; the properties of emergence of successful entrepreneurial firms and coevolution are regarded as ecosystem governance structures that explain how the Zhongguancun EE can be shaped and, more importantly, the boundaries of the shaping effects.

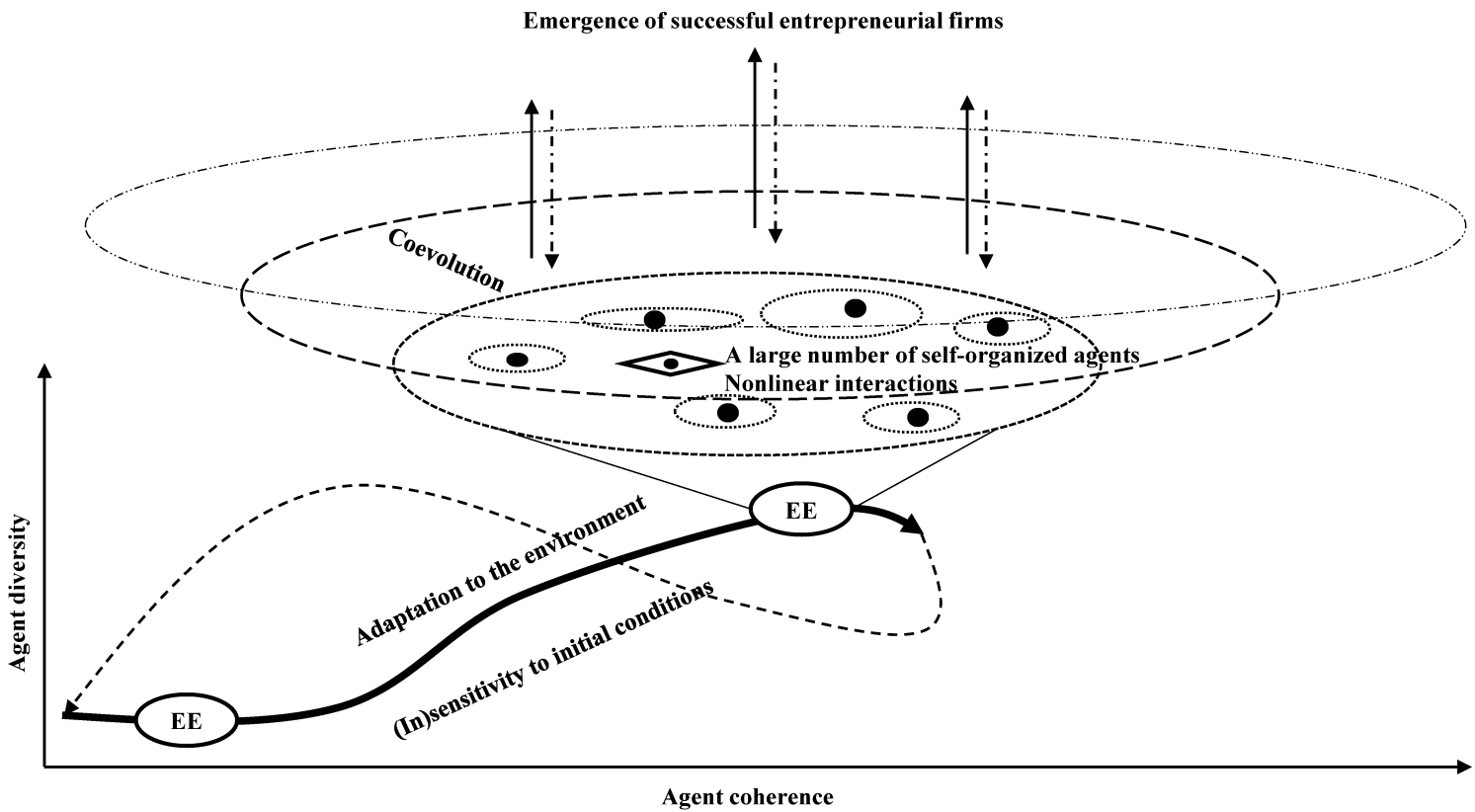

Figure 5.4: A complexity-based framework for the Zhongguancun EE.

Furthermore, as visualized by Figure 5.4, the six complexity properties are integrated into a coherent framework, which enables an overarching understanding of how the complexity nature of the Zhongguancun EE maintained and improved its viability over time. First, an increasing number of diversified $\mathrm{EE}$ agents (y-axis) and their increasingly coherent entrepreneurial actions/activities (x-axis) lay a solid foundation for EE viability that is typically embodied by the continuous emergence of high-impact new firms (e.g., unicorns). This result is caused by the fact that the emergence of successful entrepreneurial firms cannot be foreseen or intentionally planted by any individual agents but was a result of nonlinear interactions among them (see three paralleled dotted arrows). Although unforeseeable, the emergence of successful entrepreneurial firms as collective EE behavior can be observed and in turn motivates EE agents to adjust and even change their individual behaviors to (re)shape the Zhongguancun EE (see the parallel solid arrows). Second, the nonlinear interactions of selforganized agents in the early stage of the EE result in EE path-dependent development. However, by introducing heterogeneous and obsoleting redundant entrepreneurial resources in the EE and further promoting synergetic interactions between new and existing EE components, the EE becomes less sensitive to initial conditions. In addition, the EE develops sustainably as 
different EE agents coherently adapt themselves to withstand external shocks and solve internal developmental problems. Third, diverse EE agents exchange heterogeneous entrepreneurial resources and therefore coevolve on multidimensional (i.e., university, regional, national, and international) geographic scales (see dotted circles with different sizes in Figure 5.4).

\subsection{DISCUSSION}

Despite the increasing focus on EEs in the literature (e.g., Acs et al., 2017; Autio et al., 2018; Cohen, 2006; Feld, 2012; Isenberg, 2011; Stam, 2015), the complexity nature of EEs has been relatively underinvestigated (Autio and Levie, 2017; Brown and Mason, 2017; Goswami et al., 2018). To address this research gap, we examined a viable EE: the Zhongguancun EE in Beijing, China. Our study revealed six interrelated complexity properties of the Zhongguancun EE that are in line with the main properties that a CAS possesses (Aydinoglu, 2013; Choi et al., 2001; Peltoniemi, 2006; Russell and Smorodinskaya, 2018; Surie, 2017): a large number of selforganized agents, nonlinear interactions, (in)sensitivity to initial conditions, adaptation to the environment, emergence of successful entrepreneurial firms, and coevolution. Moreover, the synthesis of six interrelated complexity properties provides a better understanding of how the Zhongguancun EE maintains its viability through different developmental stages. Our findings make theoretical contributions to both the EE literature and CAS theory and provide useful policy implications.

\subsubsection{Theoretical contributions}

The first contribution of our study is that we extended the work by Roundy et al. (2018) that conceptualized EEs based on CAS theory. Roundy and colleagues proposed six main complexity properties that both a CAS and an EE share. Furthermore, the authors theorized that the birth of an EE is rooted in ambitious entrepreneurs and their adaptive intentions, EE agents' coherent actions, and new entrepreneurial resource injections. Based on our empirical findings, we offer a more nuanced complexity-based understanding of a viable EE. On the one hand, in line with Roundy et al. (2018), we argue that a large number of self-organized EE agents and their nonlinear interactions build the foundation for a complexity-based EE. On the other hand, our study complements their work in two ways: (1) EEs' sensitivity to initial development conditions is contingent on developmental stages. That is, this property is evident in early EE developmental stages, and then, viable EEs can improve their environmental adaptability to avoid path dependence with new resource injections and EE agents' coherent entrepreneurial 
actions. (2) EE governance has an "open” fluid boundary, and such boundary openness should be considered at multidimensional geographic scales. Overall, our study lends empirical support that CAS theory is an appropriate lens through which we can better understand EE development and management.

The second contribution of our paper is the integration of the EE literature and CAS theory, which provides three main theoretical implications. First, we showed that viable EEs depend on a large number of self-organized EE agents and their nonlinear interactions. Previous research has shown that diversified EE agents (Cohen, 2006; Isenberg, 2011; Mason and Brown, 2014) and their linear synergetic interactions (Ghio et al., 2019; Radinger-Peer et al., 2018; Spigel, 2015; Theodoraki et al., 2018) support a viable EE but paid less attention to nonlinear interactions. In line with recent conceptual studies on nonlinear relationships among EE agents (Brown and Mason, 2017; Roundy et al., 2018), our findings highlighted that, due to agents' fluid roles, the amplifying synergies (positive feedback loops) among EE agents accelerate the EE development process, whereas dampening synergies (negative feedback loops) restrain the process. Therefore, instead of focusing only on the individual and static functions of EE agents, future studies should adopt a complexity-based, more dynamic view to understand the interactive effects of EE agents on EE development.

Next, we showed that viable EEs are adaptive systems. Our study explained that the historical conditions of entrepreneurial resources in an EE's early development can determine its subsequent development. In other words, entrepreneurial activities and outputs in an EE's early developmental stage can lock the EE into limited industrial domains over time. This finding is consistent with the current literature suggesting that EEs follow a path-dependent evolutionary development process from birth to maturity (Colombelli et al., 2017; Letaifa and Rabeau, 2013; Mack and Mayer, 2016; Spigel and Harrison, 2018). Nonetheless, our study complements this literature by showing that viable EEs can avoid such path-dependent evolution by improving their environmental adaptability and, as a result, escaping the quick declining fate (Auerswald and Dani, 2017). To do so, EEs can intentionally introduce new EE agents, remove old ones, and strengthen their entrepreneurial actions' coherence. We thus suggest that future EE research should pay more attention to the adaptive evolutionary dynamics of the EE development process.

Finally, we showed that a viable EE's governance structure partially follows the "bottomup-top-down” approach. In contrast to extant scholars who consider the governance structure of an EE to be either "bottom-up” (Isenberg, 2011, 2016) or "top-down” (Bhawe and Zahra, 
2019; Spigel, 2015), our findings partly support the "bottom-up-top-down” approach proposed by Colombo et al. (2019) and Stam (2015). Specifically, a viable EE requires fewer direct, “topdown” interventions because the emergence of high-impact entrepreneurship is unmanageable by any single EE agent; rather, high-impact entrepreneurship emerges as a result of selforganized EE agents, the high fluidity of entrepreneurial resources, coherent entrepreneurial actions, and the introduction of new agents from outside. Additionally, such emergence is regarded as a collective behavior and, in turn, guides EE agents to adjust entrepreneurial actions to (re)shape the EE in the future. Although "top-down” tools such as policies can change, for example, infrastructure conditions, financial preferences, and human capital, they have difficulty in changing sociocultural elements, such as the local entrepreneurship climate, that formed in a "bottom-up" way. Therefore, a top-down approach is necessary but insufficient to shape viable EEs. Moreover, a top-down approach faces challenges because viable EEs are geographically nested phenomena with multidimensional scales. In our case, the Zhongguancun EE contains many smaller (university-based) EEs but is embedded within larger (inter)national EEs. These EEs do not develop separately but simultaneously coevolve. We thus argue that future studies should consider the interactive effects of policies at different geographic levels on EE development.

The third contribution is the extension of CAS theory to the ecosystem level. Most prior studies analyzing complexity management concentrated on effects at the individual firm level (Brown and Eisenhardt, 1997; McCarthy et al., 2006), the supply chain network level (Choi et al., 2001), or, recently, the innovation cluster level (Russell and Smorodinskaya, 2018; Surie, 2017). Comparatively less attention has been paid to the relationships between the level of complexity and EE performance. We argue that complexity management in the context of EEs comes down to EE agents' collective endeavors in an adaptive process instead of those of the individual agents. Specifically, as an EE evolves from its genesis, the level of complexity gradually increases until the point when the EE must avoid path dependence by introducing new (and ruling out old) EE agents and strengthening the interconnectedness of (new and existing) EE agents. Therefore, an EE can reduce the diversity and interconnectedness of pathdependent agents (complexity reduction) and simultaneously create new agent diversity and interconnectedness (complexity absorption) to maintain its viability. This adaptive process for sustaining the optimal level of complexity - that is, a manageable level of agent connectivity, diversity, ambiguity, and dynamicity (de Toni and de Zan, 2016) — in an EE does not depend on individual agents; rather, it is the result of various agents' collective endeavors. Our results 
are thus in line with the complexity management literature (Jacobs, 2013; Vasconcelos and Ramirez, 2011) and highlight that viable EEs can maintain a balanced level of complexity to produce numerous successful entrepreneurial firms.

\subsubsection{Policy implications}

This study offers three main policy implications. First, policymakers should recognize the limited effects of "top-down” policy tools on the emergence of high-impact entrepreneurial firms. Because encamped EE agents are self-organized, direct policy interventions might effectively shape hard things in EEs such as funds, infrastructure, and entrepreneurial services but may be relatively weak at shaping soft things such as the entrepreneurship culture that is expected to be formed and changed in a "bottom-up" way. Second, policymakers should update their policies during the different developmental stages of EEs. As indicated by our findings, an EE might fall into a path-dependent development process that will lock all the EE agents and, accordingly, entrepreneurial activities into a single domain. However, policymakers can mitigate such path-dependent evolution processes by introducing new entrepreneurial resources via new policies. As such, the continuity and coordination of various policies might pose a big challenge for policymakers being proactive and sometimes creative. Third, policymakers should shift their policy focus from promoting regional development to national and even international entrepreneurial resource exchanges. Specifically, policymakers should broaden their vision to different geographic levels and consider interconnections when designing entrepreneurship and innovation policies.

\subsubsection{Limitations and future directions}

This study has several limitations. First, we did not consider more nuanced complexity features. For example, we revealed nonlinear interactions among EE agents and distinguished two nonlinearity mechanisms, namely positive and negative feedback loops that promote and decelerate EE development. We found only economic outcomes of these two mechanisms. However, in the long run, both mechanisms might have a negative impact on social development (e.g., gender inequality, increased cost of living, and driving out other employment) in emerging economies (Berger and Kuckertz, 2016; Spigel and Harrison, 2018). Future research might consider the different types of outcomes resulting from EE components' nonlinear interactions and their effects on EE development. We also identified the adaptive life cycle from the "exploitation” to "conservation” phase (see Auerswald and Dani, 2017) of 
Zhongguancun EE when EE agent diversity and entrepreneurial coherence increase with a smooth curve (see Figure 5.4). Nevertheless, our results cannot provide robust evidence of how an EE reorients itself from the "release" to "reorganization" phase that is characterized by a sharp decrease in terms of the diversity and coherence of EE agents (Auerswald and Dani, 2017), as we did not observe any critical external shocks triggering the EE's adaptive process. Such EE evolutionary dynamics would be useful for uncovering the complexity nature of an EE's adaptability and discontinuity. A future longitudinal study could help to fill this gap.

Moreover, the use of a specific empirical setting may limit the generalizability of a theory (Yin, 2013). Whether our results can be applied to other productive EEs remains unknown. Future studies could enhance our findings' generalizability with a comparative case analysis involving two or more viable EEs in both emerging (e.g., Bangalore EE) and developed economies (e.g., Berlin EE).

\subsection{CONCLUSION}

How can an EE uncover its complexity properties across different development stages to maintain its viability? To date, scholars have not fully explored the complexity nature of EEs. In view of this gap, through borrowed insights from CAS theory and an in-depth qualitative study of the Zhongguancun EE in China, we identified six integrated complexity properties that were exhibited over time. Our findings provide new empirical insights into EE agents' nonlinear interactions, adaptive evolutionary dynamics, and multiscale governance boundaries. Additionally, our findings highlight an EE's adaptive process to sustain a balanced level of complexity to maintain its viability. By revealing the complexity nature of an EE from an emerging economy, our paper offers useful insights for policymakers to better promote and manage EE development.

\subsection{REFERENCES}

Acs, Z. J., Autio, E., \& Szerb, L. (2014). National systems of entrepreneurship: Measurement issues and policy implications. Research Policy, 43(3), 476-494.

Acs, Z. J., Stam, E., Audretsch, D. B., \& O’Connor, A. (2017). The lineages of the entrepreneurial ecosystem approach. Small Business Economics, 49(1), 1-10.

Aeeni, Z., \& Saeedikiya, M. (2019). Complexity theory in the advancement of entrepreneurship ecosystem research: Future research directions. In M. H. Bilgin, H. Danis, E. Demir, \& U. Can (Eds.), Eurasian business perspectives (pp. 19-37). New York, NY: Springer International Publishing. 
Alvedalen, J., \& Boschma, R. (2016). A critical review of entrepreneurial ecosystems research: Towards a future research agenda. European Planning Studies, 25(6), 887-903.

Anderson, P. (1999). Perspective: Complexity theory and organization science. Organization Science, 10(3), 216-232.

Audretsch, D. B., \& Link, A. N. (2019). Embracing an entrepreneurial ecosystem: An analysis of the governance of research joint ventures. Small Business Economics, 52(2), 429-436.

Auerswald, P. E., \& Dani, L. (2017). The adaptive life cycle of entrepreneurial ecosystems: The biotechnology cluster. Small Business Economics, 49(1), 97-117.

Autio, E., Kenney, M., Mustar, P., Siegel, D., \& Wright, M. (2014). Entrepreneurial innovation: The importance of context. Research Policy, 43(7), 1097-1108.

Autio, E., \& Levie, J. (2017). Management of entrepreneurial ecosystems. In M. Dodgson, D. M. Gann, \& N. Phillips (Eds.), The wiley handbook of entrepreneurship (pp. 423-449). Chichester, England: John Wiley \& Sons.

Autio, E., Nambisan, S., Thomas, L. D. W., \& Wright, M. (2018). Digital affordances, spatial affordances, and the genesis of entrepreneurial ecosystems. Strategic Entrepreneurship Journal, 12(1), 72-95.

Aydinoglu, A. U. (2013). Toward a new understanding of virtual research collaborations: Complex adaptive systems framework. SAGE Open, 3(4), 1-12.

Berger, E. S. C., \& Kuckertz, A. (2016). Female entrepreneurship in startup ecosystems worldwide. Journal of Business Research, 69(11), 5163-5168.

Bhawe, N., \& Zahra, S. A. (2019). Inducing heterogeneity in local entrepreneurial ecosystems: The role of MNEs. Small Business Economics, 52(2), 437-454.

Brown, R., \& Mason, C. (2017). Looking inside the spiky bits: A critical review and conceptualisation of entrepreneurial ecosystems. Small Business Economics, 49(1), 11-30.

Brown, S. L., \& Eisenhardt, K. M. (1997). The art of continuous change: Linking complexity theory and time-paced evolution in relentlessly shifting organizations. Administrative Science Quarterly, 42(1), 1-34.

Cavallo, A., Ghezzi, A., \& Balocco, R. (2018). Entrepreneurial ecosystem research: Present debates and future directions. International Entrepreneurship and Management Journal, 15(4), 1291-1321.

Chiva, R., Grandío, A., \& Alegre, J. (2010). Adaptive and generative learning: Implications from complexity theories. International Journal of Management Reviews, 12(2), 114-129.

Choi, T. Y., Dooley, K. J., \& Rungtusanatham, M. (2001). Supply networks and complex adaptive systems: Control versus emergence. Journal of Operations Management, 19(3), 351-366.

Cohen, B. (2006). Sustainable valley entrepreneurial ecosystems. Business Strategy and the Environment, 15(1), 1-14.

Colombelli, A., Paolucci, E., \& Ughetto, E. (2017). Hierarchical and relational governance and the life cycle of entrepreneurial ecosystems. Small Business Economics, 52(2), 505-521.

Colombo, M. G., Dagnino, G. B., Lehmann, E. E., \& Salmador, M. (2019). The governance of entrepreneurial ecosystems. Small Business Economics, 52(2), 419-428.

Cumming, D., Werth, J. C., \& Zhang, Y. (2019). Governance in entrepreneurial ecosystems: Venture capitalists vs. technology parks. Small Business Economics, 52(2), 455-484.

de Toni, A. F., \& de Zan, G. (2016). The complexity dilemma. Emergence: Complexity \& Organization, 18(3/4), 1-8. 
Dong, X., Hu, Y., Yin, W., \& Kuo, E. (2019). Zhongguancun model: Driving the dual engines of science \& technology and capital. Berlin, Germany: Springer.

Dooley, K. J. (1997). A complex adaptive systems model of organization change. Nonlinear Dynamics, Psychology, and Life Sciences, 1(1), 69-97.

Du, W., Pan, S. L., Zhou, N., \& Ouyang, T. (2018). From a marketplace of electronics to a digital entrepreneurial ecosystem (DEE): The emergence of a meta-organization in Zhongguancun, China. Information Systems Journal, 28(6), 1158-1175.

Eisenhardt, K. M. (1989). Building theories from case study research. Academy of Management Review, 14(4), 532-550.

Feld, B. (2012). Startup communities: Building an entrepreneurial ecosystem in your city. Hoboken, NJ: John Wiley \& Sons.

Garud, R., Gehman, J., \& Giuliani, A. P. (2014). Contextualizing entrepreneurial innovation: A narrative perspective. Research Policy, 43(7), 1177-1188.

Ghio, N., Guerini, M., \& Rossi-Lamastra, C. (2019). The creation of high-tech ventures in entrepreneurial ecosystems: Exploring the interactions among university knowledge, cooperative banks, and individual attitudes. Small Business Economics, 52(2), 523-543.

Gioia, D. A., Corley, K. G., \& Hamilton, A. L. (2013). Seeking qualitative rigor in inductive research: Notes on the gioia methodology. Organizational Research Methods, 16(1), 15-31.

Goswami, K., Mitchell, J. R., \& Bhagavatula, S. (2018). Accelerator expertise: Understanding the intermediary role of accelerators in the development of the Bangalore entrepreneurial ecosystem. Strategic Entrepreneurship Journal, 12(1), 117-150.

Gray, M., Golob, E., \& Markusen, A. (1996). Big firms, long arms, wide shoulders: The 'hub-andspoke' industrial district in the seattle region. Regional Studies, 30(7), 651-666.

Isenberg, D. (2014). What an entrepreneurship ecosystem actually is. Harvard Business Review, 5, $1-7$.

Isenberg, D. J. (2011). The entrepreneurship ecosystem strategy as a new paradigm for economic policy: Principles for cultivating entrepreneurship. In Paper presented at the institute of international and European affairs. Dublin, Ireland.

Isenberg, D. J. (2016). Applying the ecosystem metaphor to entrepreneurship: Uses and abuses. The Antitrust Bulletin, 61(4), 564-573.

Jacobs, M. A. (2013). Complexity: Toward an empirical measure. Technovation, 33(4), 111-118.

Jick, T. D. (1979). Mixing qualitative and quantitative methods: Triangulation in action. Administrative Science Quarterly, 24(4), 602-611.

Jonsen, K., \& Jehn, K. A. (2009). Using triangulation to validate themes in qualitative studies. Qualitative Research in Organizations and Management: An International Journal, 4(2), 123-150.

Kauffman, S. (1996). At home in the universe: The search for the laws of self-organization and complexity. New York, NY: Oxford University Press.

Kauffman, S. A., \& Strohman, R. C. (1994). The origins of order: Self-organization and selection in evolution. New York, NY: Oxford University Press.

Kenney, M., \& von Burg, U. (1999). Technology, entrepreneurship and path dependence: Industrial clustering in Silicon Valley and Route 128. Industrial and Corporate Change, 8(1), 67-103.

Letaifa, S. B., \& Rabeau, Y. (2013). Too close to collaborate? How geographic proximity could impede entrepreneurship and innovation. Journal of Business Research, 66(10), 2071-2078. 
Lewin, A. Y. (1999). Application of complexity theory to organization science. Organization Science, 10(3), 215, 233-236.

Li, W., Du, W., \& Yin, J. (2017). Digital entrepreneurship ecosystem as a new form of organizing: The case of Zhongguancun. Frontiers of Business Research in China, 11(1), 69-100.

Mack, E., \& Mayer, H. (2016). The evolutionary dynamics of entrepreneurial ecosystems. Urban Studies, 53(10), 2118-2133.

Malecki, E. J. (2018). Entrepreneurship and entrepreneurial ecosystems. Geography Compass, 12(3), e12359. https://doi.org/10.1111/gec3.12359.

Mason, C., \& Brown, R. Entrepreneurial ecosystems and growth oriented entrepreneurship. Final report to OECD, Paris. (2014). http://lib.davender.com/wpcontent/uploads/2015/03/Entrepreneurial-ecosystems-OECD.pdf.

McCarthy, I. P., Tsinopoulos, C., Allen, P., \& Rose-Anderssen, C. (2006). New product development as a complex adaptive system of decisions. Journal of Product Innovation Management, 23(5), 437-456.

McKelvey, B. (2004). Toward a complexity science of entrepreneurship. Journal of Business Venturing, 19(3), 313-341.

Mitleton-Kelly, E. (2003). Ten principles of complexity and enabling infrastructures. In E. Mitleton-Kelly (Ed.), Complex systems and evolutionary perspectives on organizations: The application of complexity theory to organizations (pp. 23-50). London, England: Elsevier.

Morel, B., \& Ramanujam, R. (1999). Through the looking glass of complexity: The dynamics of organizations as adaptive and evolving systems. Organization Science, 10(3), 278-293.

Neffke, F., Henning, M., \& Boschma, R. (2011). How do regions diversify over time? Industry relatedness and the development of new growth paths in regions. Economic Geography, 87(3), 237-265.

Nylund, P. A., \& Cohen, B. (2017). Collision density: Driving growth in urban entrepreneurial ecosystems. International Entrepreneurship and Management Journal, 13(3), 757-776.

O'Connor, A., Stam, E., Sussan, F., \& Audretsch, D. B. (2017). Entrepreneurial ecosystems: Placebased transformations and transitions. Berlin, Germany: Springer.

Peltoniemi, M. (2006). Preliminary theoretical framework for the study of business ecosystems. Emergence: Complexity and Organization, 8(1), 10-19.

Radinger-Peer, V., Sedlacek, S., \& Goldstein, H. (2018). The path-dependent evolution of the entrepreneurial ecosystem (EE) - Dynamics and region-specific assets of the case of Vienna (Austria). European Planning Studies, 26(8), 1499-1518.

Ritala, P., \& Gustafsson, R. (2018). Q\&A. Innovation and entrepreneurial ecosystem research: Where are we now and how do we move forward? Technology Innovation Management Review, 8(7), 52-57.

Roundy, P. T. (2016). Start-up community narratives: The discursive construction of entrepreneurial ecosystems. The Journal of Entrepreneurship, 25(2), 232-248.

Roundy, P. T., Bradshaw, M., \& Brockman, B. K. (2018). The emergence of entrepreneurial ecosystems: A complex adaptive systems approach. Journal of Business Research, 86, 110.

Roundy, P. T., Brockman, B. K., \& Bradshaw, M. (2017). The resilience of entrepreneurial ecosystems. Journal of Business Venturing Insights, 8, 99-104. 
Russell, M. G., \& Smorodinskaya, N. V. (2018). Leveraging complexity for ecosystemic innovation. Technological Forecasting and Social Change, 136, 114-131.

Spigel, B. (2015). The relational organization of entrepreneurial ecosystems. Entrepreneurship Theory and Practice, 41(1), 49-72.

Spigel, B., \& Harrison, R. (2018). Toward a process theory of entrepreneurial ecosystems. Strategic Entrepreneurship Journal, 12(1), 151-168.

Stacey, R. D. (1995). The science of complexity: An alternative perspective for strategic change processes. Strategic Management Journal, 16(6), 477-495.

Stam, E. (2015). Entrepreneurial ecosystems and regional policy: A sympathetic critique. European Planning Studies, 23(9), 1759-1769.

Strauss, A., \& Corbin, J. M. (1990). Basics of qualitative research: Grounded theory procedures and techniques. Newbury Park, CA: Sage Publications.

Surana, A., Kumara, S., Greaves, M., \& Raghavan, U. N. (2005). Supply-chain networks: A complex adaptive systems perspective. International Journal of Production Research, 43(20), 4235-4265.

Surie, G. (2017). Creating the innovation ecosystem for renewable energy via social entrepreneurship: Insights from India. Technological Forecasting and Social Change, 121, 184-195.

Sussan, F., \& Acs, Z. J. (2017). The digital entrepreneurial ecosystem. Small Business Economics, 49(1), 55-73.

Theodoraki, C., \& Messeghem, K. (2017). Exploring the entrepreneurial ecosystem in the field of entrepreneurial support: A multi-level approach. International Journal of Entrepreneurship and Small Business, 31(1), 47-66.

Theodoraki, C., Messeghem, K., \& Rice, M. P. (2018). A social capital approach to the development of sustainable entrepreneurial ecosystems: An explorative study. Small Business Economics, 51(1), 153-170.

van de Ven, A. H. (2007). Engaged scholarship: A guide for organizational and social research. New York, NY: Oxford University Press.

Vasconcelos, F. C., \& Ramirez, R. (2011). Complexity in business environments. Journal of Business Research, 64(3), 236-241.

Yin, R. K. (2013). Case study research: Design and methods. Thousand Oaks, CA: Sage Publications. 

CHAPTER 6

Discussion 


\subsection{INTRODUCTION}

This $\mathrm{PhD}$ research was motivated by the observation that ambitious new ventures desire to achieve high growth by building and sustaining a viable innovation ecosystem (Dattée et al., 2018; Hannah and Eisenhardt, 2018; Overholm, 2015). A viable innovation ecosystem suggests that all non-focal actors commit to and co-evolve towards shared vision(s) proposed by the new focal ventures (Moore, 1996; Adner 2006, 2012). However, achieving a viable innovation ecosystem requires ambitious new ventures to develop effective ecosystem-specific strategies (e.g., Adner, 2017; Autio and Thomas, 2014; Visscher et al., 2021) and sets of dynamic capabilities (Thomas and Autio, 2020; Velu, 2015). The existing literature provides incomplete cross-level mechanisms that underlie the innovation ecosystem's birth and viability. Therefore, the overall research question of the thesis is: how can new focal ventures develop capabilities and strategies to build and sustain a viable innovation ecosystem?

To address this research question, one systematic literature review and three empirical studies were conducted from 2016 to 2020, described respectively in Chapters 2 to 5. In this final chapter, the results from these chapters are integrated to address the research question. Further, more theoretical contributions and practical implications are discussed. Finally, the limitations of this $\mathrm{PhD}$ research are identified, and possible avenues for future research are recommended.

\subsection{ANSWERING THE OVERARCHING RESEARCH QUESTION}

Based on the results of Chapters 2 to 5, three cross-level mechanisms are generated to help address the overarching research question. The following sections start with discussions of strategy-based and capability-based cross-level mechanisms that underlie innovation ecosystem birth and viability, followed by the demonstration of the additional mechanisms that jointly account for the innovation ecosystem birth and viability.

\subsubsection{Strategy mechanisms: how to develop ecosystem-specific strategies}

As shown in Figure 6.1, new focal ventures should execute effective ecosystem-specific strategies to ensure various non-focal actors' long-term commitment to the newly-built innovation ecosystems. The study reported in Chapter 3 found that all four new focal ventures should develop four-dimensional (i.e., economic, coopetitive, social, and political) ecosystemspecific strategies. However, the viability of the innovation ecosystems relies on new focal ventures taking a systemic approach to strategy formulation and implementation. More 
specifically, via “strategy versatility”, new focal ventures seem to be more inclined to leverage the positive interactive effects between strategies. Doing so helps them compensate for any resource limitations and further improves their efforts to drive innovation ecosystems' birth and viability.

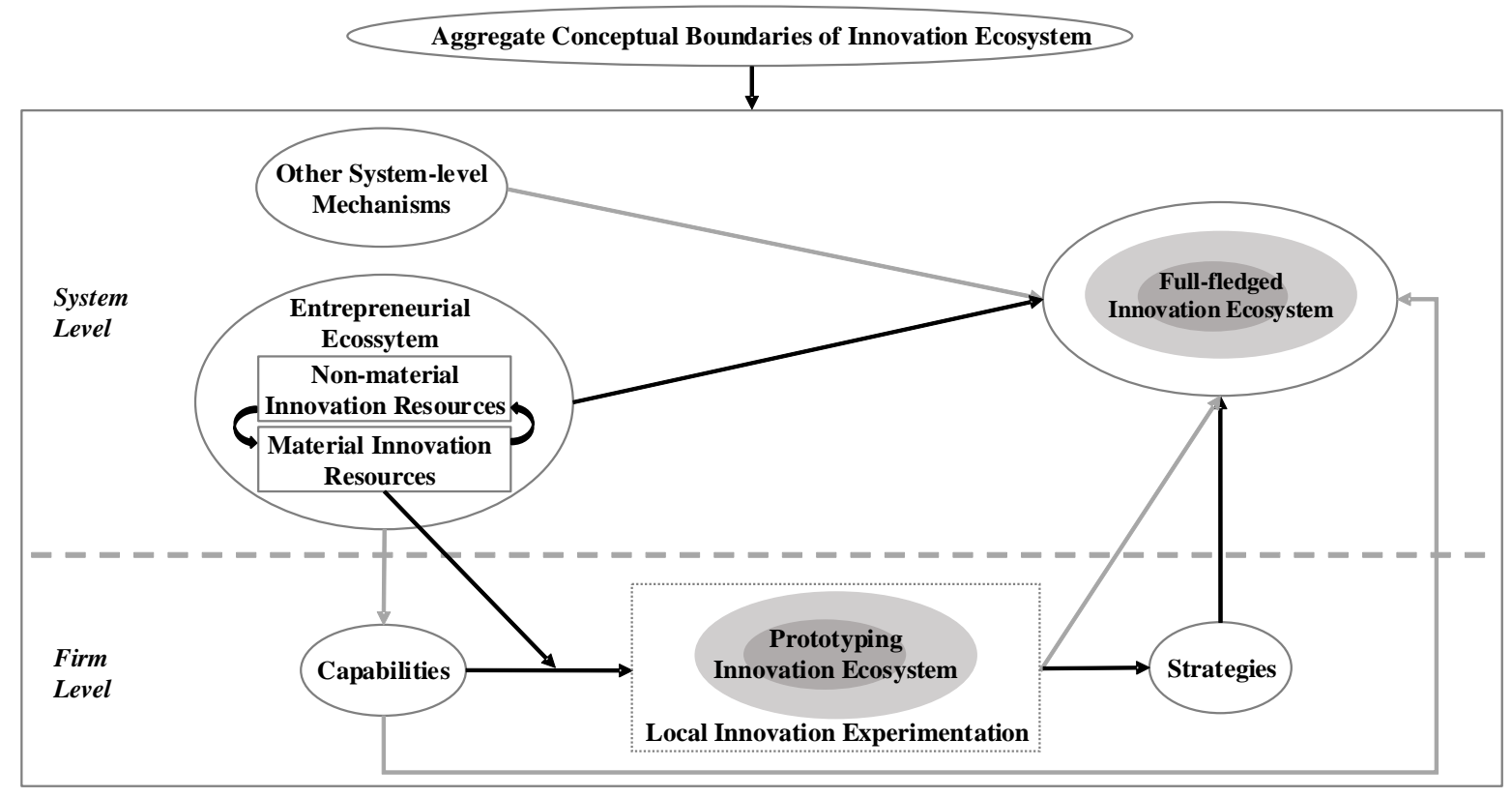

Figure 6.1: Concluding framework of the $\mathrm{PhD}$ thesis.

In addition to the strategy versatility seeking cross-sectional interactive effects among strategies, out-performed new focal ventures would take an intertemporal view of the strategies adopted. More specifically, via “strategy suboptimality”, they intentionally sacrifice strategies' short-term effectiveness to improve the efficacy of strategies implemented in the future. For instance, a case of new focal venture's proactive investment in new technologies leads them to lose the market share temporally. Such technological investment creates long-term benefits to align with the regulators who subsequently impose restrictions on their innovations. Hence, based on the above findings, it is claimed that those new focal ventures that create more crosssectional and intertemporal positive effects among strategies are more likely to build and sustain viable innovation ecosystems.

Why are outperformed new focal ventures better able to execute ecosystem-specific strategies creatively and effectively than others? Key findings from the Chapters 2 and 3 offer insights. First, results in Chapter 3 give a direct reason: outperformed ventures carried out the strategic innovation process of local innovation experimentation (LIE). LIE refers to a focal 
firm and its key partners testing the feasibility of innovative products (services, processes, or both) in a small-scale local society to make them mature enough to enter the mass societies. LIE conforms to Adner's (2012) notion that ecosystem builders before innovation ecosystems become full-fledged and must set an ecosystem boundary via a viable prototyping innovation ecosystem - the necessary actors they initially have to rely on to build the innovation ecosystems. LIE's high performance helps new focal ventures map out the innovation ecosystem boundary based on a viable prototyping innovation ecosystem. The innovation ecosystem boundary includes, for example, ecosystem structures (who are the direct and indirect contributors), actor dynamics (who in the future will impose restricting and enabling effects on innovation ecosystems), and interaction relationships (who affects who). Therefore, based on a clear innovation ecosystem boundary, new focal ventures gain a more holistic understanding of the co-evolution challenges posed by non-focal actors. Consequently, via LIE outperformed ventures would perform better the ecosystem-specific strategies than others not.

Second, as the findings in Chapter 2 show, an indirect reason is that new focal ventures have a deeper understanding of the innovation ecosystems' aggregated conceptual boundaries (i.e., key distinguishing features' structural relationships and temporal dynamics). That is, they recognize better how a full-fledged innovation ecosystem operates in its early stages. Accordingly, effective and creative ecosystem-specific strategies seem to be designed from three aspects:

1. The "roles" dimension (self-organization, non-linearity, shared vision) requires new focal ventures to align non-focal actors into shared visions. Since most self-organized actors are just as free to exit innovation ecosystems as they are to enter them, they should pay more attention to formulating emergent strategies than developing deliberate 'plan-and-execute' strategies. Next, actors' interactions are nonlinear. This points to the need to inspect implemented strategies, as poorly implemented ones could generate systemic, adverse effects on actors, possibly leading to the rapid failure of the ecosystem. Finally, shared visions might be subject to competition or compromise amongst non-focal actors. Thus, when designing strategies, ventures should shift the focus away from maximizing their own benefits towards the ecosystem-level competitiveness.

2. The "structures" dimension (complementarity, modularity, coupling) requires motivating non-focal actors to make unique contributions to the proposed innovations. The shortage of bargaining power and legitimacy makes new focal ventures difficult to exercise impacts on non-focal actors to invest unique complementary resources upfront. Managers should aim 
strategically for small-scale success by optimizing the use of limited resources. Next, new focal ventures lack established platforms for creating highly modular innovations quickly and directly. They are recommended to turn their strategic focus to open innovation activities (e.g., technology conferences) (Davis, 2016) and intermediary agencies (e.g., patent unions) (Moore, 2006). Such an indirect way also helps unify a variety of technological standards, designs, and requirements. Finally, in such open innovation activities, ventures should emphasize the cohesive innovation actions since tightly-coupled collaborations can help overcome innovation ecosystem fragility.

3. The "processes" dimension (emergence, co-opetition, co-evolution) requires new focal ventures to balance the innovation ecosystems' developmental momentum and stability. On the one hand, they should improve the attractiveness of the proposed innovations, so more contributors would like to join the newly-built innovation ecosystems. On the other hand, the emergence suggests that managers should be aware of the risks of moving too quickly by introducing many new participants within a short period since an early-stage innovation ecosystem might quickly collapse. Furthermore, managers should be more strategically proactive in analyzing the influences of newly introduced elements (e.g., new and uncommon actors or technologies). This is because newly introduced elements could trigger competitive tensions amongst non-focal actors, which could be detrimental to the innovation ecosystem's stability.

Summing up, innovation ecosystems' birth and viability rely on new focal ventures that systematically and intertemporally combine multidimensional strategies. The high performance of LIE and the aggregated conceptual boundaries of innovation ecosystems form solid preconditions for developing such winning ecosystem-specific strategies.

\subsubsection{Capability mechanisms: how to exploit ecosystem-related capabilities}

As shown in Figure 6.1, new focal ventures should exploit ecosystem-related capabilities to lead to a high LIE performance, which has been empirically found to increase the probability of successfully executing effective ecosystem-specific strategies. Chapter 4 identified three TMT-based capabilities that determine the high-level performance of the LIE:

1. Metacognitive capability refers to managers' higher-order cognitive ability to reflect on, understand, and consciously control their cognitive thinking related to a complicated task. According to the results, a high level of metacognitive capability suggests that managers can integrate better various feedback from actors, better manage value co-creation and value co- 
capture tension, and adapt themselves more easily to fast-changing contexts. Such holistic management and control result in multiple decision frameworks that maximize the likelihood of achieving challenging innovation goals (Haynie et al., 2010).

2. Networking capability reflects the stock of managers' social capital, which is critical for getting access to strategic resources or assets owned by other actors. As found, a high level of networking capability suggests that managers could maintain a "minimum but viable” set of key partners in the LIE. Through various social ties, managers could approach key-value complementors. Furthermore, superior partnership management skills and experiences assist in orchestrating key partners to co-develop innovations. Finally, high networking capability protects managers from innovation and appropriation risks by severing undesirable ties. Overall, high networking capability guarantees that new focal ventures can co-create unique value with the smallest, indispensable collection of key partners (Mitrega et al., 2012).

3. Learning agility is about managers' accumulated human capital, reflecting the extent to which managers' speed and flexibility to sense and solve emergent operational problems during LIE. As results have shown, a high level of learning agility helps new focal ventures maintain leadership in LIE. This is due to their high skills in acquiring new knowledge from experimentation activities and finding faster and higher quality solutions to problems than partners (Sambamurthy et al., 2003).

In addition to the above three capabilities that originated endogenously from top managers in new focal ventures (e.g., number, age/industry/education diversity), empirical results from Chapter 4 also highlight the exogenous origins that complement the stock of dynamic capabilities. Stated differently, the three dynamic capabilities pertaining to LIE are affected by regional innovation resources outside of the new focal ventures. It shows that two materialrelated local innovation resources in an EE complement significantly the two dynamic capabilities described above, thereby promoting the higher levels of the LIE:

1. Improved networking capability benefits most from diverse local networking activities arranged by local third-parties (e.g., industrial consortia). Specifically, new focal ventures could manage better "minimum but viable” key partners that LIE requires, if managers were to attend various networking activities (e.g., industrial standards-making meetings, academic conferences, technology transfers, and trade exhibitions) more frequently than others.

2. Enhanced learning agility benefits most from systemic local innovation facilities offered by local third parties (e.g., local universities). Specifically, to safeguard the leadership, new focal ventures could sense and respond to emerging problems more quickly and flexibly if 
managers leverage systemic innovation facilities more frequently. These enabling facilities include test centers, IT equipment, and specialized manufacturing facilities.

Taken together, the high performance of LIE has two significant origins. One origin is within new focal ventures, closely associated with top managers' stock of cognitions, social capital, and human capital. These three underpinning managerial dynamic capabilities are determined directly by the number of top managers, top managers' industry diversity, life experiences, and educational diversity (Adner and Helfat, 2003). The other origin is external to new focal ventures, relating primarily to regional structural, systemic innovation resources (Spigel, 2015).

\subsubsection{Additional cross-level mechanisms: how a viable EE matters}

Chapter 4 discusses how the high performance of LIE depends on dynamic capabilities within new focal ventures and "material-related" regional innovation resources external to them. Chapter 5 further explains how regional innovation resources could show positive, consistent impacts on new focal ventures. As revealed in Chapter 5, the positive and consistent impacts stem from the viability of the $\mathrm{EE}$ in which their newly-built innovation ecosystems are embedded. “Material-related” and “nonmaterial-related” regional innovation resources interact to ensure an EE's viability. Also, such interactions exhibit six significant complexity-based properties:

1. A large number of self-organized agencies signifies that regional innovation agencies and their resources (such as talents, finance, technologies, and services) are diverse. They have coherent intentions to create high-growth new ventures.

2. Nonlinear interactions refer to the effect that regional innovation agencies' resource inputs result in disproportionate outputs. Such an input-output process result in both positive and negative feedback loops.

3. (In)sensitivity to initial conditions suggests that regional innovation agencies would not fall into single types. On the contrary, they diversify themselves over time and promote cohesive interactions among themselves.

4. Adaptation to the environment suggests that regional innovation agencies would respond coherently to internal developmental problems, and to external threats and shocks.

5. Emergence of successful new ventures suggests that high-growth new ventures' births are unforeseeable for any single regional innovation agency. However, their emergence would 
positively impact innovation agencies that might (re)adjust their supporting strategies and entrepreneurs who might follow successful role models to show their own ambitions.

6. Coevolution suggests that innovation resources owned by various agencies are not limited to certain regional boundaries. Instead, they exist and free-flow across multi-scale (i.e., university, regional, national, and international) geographies.

Such six complexity properties illustrate the diverse, coherent regional innovation agencies have positive, consistent influences on new focal ventures and innovation ecosystems. The positive feedback loops suggest that new focal ventures could access required resources in an accelerated fashion to improve dynamic capabilities and develop innovation ecosystems faster than others not in the EE. Next, ecosystem-related dynamic capabilities could be sustainably strengthened since regional innovation agencies diversify themselves and promote interactions among each other. Finally, the accessible innovation resources range from local to international regions, thereby facilitating their ecosystem creation processes.

\subsection{THEORETICAL CONTRIBUTIONS}

Key findings set out above make theoretical contributions to the field. In Figure 6.1, darker arrows between boxes represent new theoretical knowledge, while lighter arrows between boxes represent previous knowledge. Next, each theoretical contribution is explained in greater detail.

\subsubsection{Theoretical contributions to the innovation ecosystem field}

6.3.1.1 Nuanced multi-level mechanisms involved in the innovation ecosystem birth and viability

The first contribution is to integrating the firm and system levels to explicate the innovation ecosystem's birth and viability. This contrasts significantly with previous literature focusing on either the system or the firm level. At the system level, scholars show the structural, descriptive, and deterministic perspectives to theorize the mechanisms of innovation ecosystem birth and viability. Specifically, studies taking the structural perspective discovered that geography-based knowledge ecosystems (Aksenova et al., 2019; Attour and Lazaric, 2020; Clarysse et al., 2014) and supply chains (Letaifa, 2014; Randhawa et al., 2020) could be transformed into innovation ecosystems. The descriptive perspective reveals what kinds of actors should be included in an innovation ecosystem's early stage (Dedehayir et al., 2018; Phillips and Srai, 2018) and what sub-stages the birth stage could be split into (Rong and Shi, 2014; Thomas and Autio, 2014). 
Profiting from big data (Basole, 2015) and simulation science (Ganco et al., 2020; Luo, 2018), the literature takes a deterministic perspective to underscore the number of ecosystem actors, structures, and dynamic interactions. Therefore, innovation ecosystem birth and viability follow a pure evolutionary (self-organized) way not maneuvered by any intentional actors. While the firm-level literature adopts top-down thinking, focusing on how particular agents design and shape the development of a viable innovation ecosystem (Baldwin, 2012; Gulati et al., 2012; Talmar et al., 2018). Taking factors existing at the system level as given, fruitful findings derived from this inquiry show how big firms exploit dynamic capabilities (Lütjen, 2019; Parente et al., 2019; Velu, 2015) and design effective strategies (Li, 2009; Zhang and Liang, 2011) to make innovation ecosystems viable.

Complementing the current ecosystems literature, this research integrates the system and firm levels and presents multi-level understandings of innovation ecosystem birth and viability. Research results led to the system-level insight that innovation ecosystem birth and viability benefit from viable EEs, which amplify the ecosystem creation process. In this vein, innovation ecosystem birth and development follows the bottom-up approach since nonlinear, emergent, and multi-level feedback, and impacts from local ecosystem actors are just out of the control of focal actors. Nuanced cross-level mechanisms are that: (1) viable EEs affect focal firms' dynamic capability levels and LIE; and (2) successful LIE and focal firms' effective strategic actions promote a viable innovation ecosystem. From this view, innovation ecosystem birth and viability reflect the top-down thinking as focal firms exert strategic design interventions.

The above insights are generally in accord with very recently published studies that innovation ecosystem birth results from the interplay of deliberate and unforeseen processes (Phillips and Ritala, 2019; Russo-Spena et al., 2020). As an extension, insights from this PhD research shed new light on the fact that such two interrelated processes can co-exist at two distinct levels. Thus, it is concluded that the evolutionary theory and design thinking should be simultaneously integrated to better unpack how innovation ecosystems (in new ventures contexts) even give birth and become viable. In all, the mechanisms driving innovation ecosystems' birth and viability are both complex and systemic, suggesting that future studies should apply multiple levels to better uncover the underlying mechanisms.

6.3.1.2 Integrating the capability and strategy literature into the innovation ecosystem birth and viability 
The second contribution is an integration of the capability and strategy perspectives into the current ecosystem literature. Extant scholars either study the effects of focal actors' dynamic capabilities (Cao et al., 2020; Feng et al., 2019; Kashan and Mohannak, 2017; Lütjen et al., 2019; Velu, 2015) or ecosystem-specific strategies (Ansari et al., 2016; Dattée et al., 2018; Hannah and Eisenhardt, 2018; Hedman and Henningsson, 2015; Snihur et al., 2018; Visscher et al., 2021) on innovation ecosystems. Such separation of research focus leads to limited insights into how the capabilities and strategies are related to each other, though both are rooted in the bundles of strategic resources owned by focal actors. Addressing this gap would drive scholars to integrate the resource-based view into the innovation ecosystem literature (Guo and Bouwman, 2016; Jacobides et al., 2018; Thomas and Autio, 2020).

The research results add nuanced knowledge about the cross-level mechanisms that underlie the innovation ecosystems' birth and viability. More specifically, higher-order and strategic dynamic capabilities lead to the high LIE performance, the foundation of viable prototyping innovation ecosystems (Chapter 4). Effective LIE facilitates the execution of ecosystem-specific strategies with the deployment of only limited resources (Chapter 3). Effective ecosystem-specific strategies consequently shape the viability of innovation ecosystems (Chapter 3). As a result, the interrelations between capabilities and strategies deepen the current understanding that prototyping innovation ecosystems evolve autonomously into (e.g., Adner, 2012), and capabilities result directly into (e.g., Kashan and Mohannak, 2017), viable innovation ecosystems. Overall, theoretical nuances uncovered by this $\mathrm{PhD}$ research suggest that scholars should take a more complex structural view when exploring the effects of focal actors’ capabilities and strategies on innovation ecosystems.

\subsubsection{The strategic role of LIE in the innovation ecosystem birth and viability}

The third contribution is to theorizing LIE's strategic role in an innovation ecosystem's birth and viability. Most previous studies argue that a viable innovation ecosystem relies only on aligning the economic and coopetitive actors, as the success of the proposed innovations are vulnerable to the co-evolution challenges caused by economic and coopetitive actors (e.g., see Adner and Kapoor, 2010, 2016; Hannah and Eisenhardt, 2018). However, when the proposed innovations are related to public goods, the social and political co-evolution challenges are equally critical for innovation ecosystems’ viability (Ma et al., 2018). Exposed to the criticality and multiplicity of co-evolution challenges, new focal ventures can conceive of the innovation ecosystem boundary with both economic and sociopolitical environments via effective LIE. 
Through experimentation activities in small-scale societies, they come to know how various actors treat the proposed innovations. Aimed with the collected on-site feedback (e.g., technical functions, customers' demands, and political/social stakeholders' attitudes) from local actors, they make better strategic actions to align non-focal actors. In all, LIE is a strategic choice for new focal ventures to enable the birth and viability of innovation ecosystems.

Based on this, LIE suggests that the spatial context is relevant to early-stage innovation ecosystems. Most studies have argued that innovation ecosystems are created around core value propositions (Adner, 2017) and digital platforms (e.g., Gawer and Cusumano, 2014; Li, 2009), and that non-focal actors are therefore aligned independently of geographic locations (Zahra and Nambisan, 2011). Thus, scholars often take for granted that there is little need to consider the spatial context in which innovation ecosystems take off. However, a competing argument, which LIE supports, posits that the "innovation ecosystem...involve[s] the logic of actor interdependence within a particular context (spatial dimension)” (Ritala and Almpanopoulou, 2017, p. 41) and that the "spatial context may have an influence on entrepreneurial and innovation ecosystem” (Clarysse et al., 2014, p. 1175). Put simply, the initial conditions in a spatial context, including key actors (e.g., local governments, pilot end-users), are critical for the birth of innovation ecosystems. Initial interactions with them facilitate the innovation ecosystems' birth and viability. Therefore, future studies on public-good related innovation ecosystems should consider LIE within spatial contexts as a critical factor in their analysis so as to better understand the innovation ecosystem's birth and viability.

\subsubsection{Structural and time-dependent ecosystem dynamics on innovation ecosystem birth and viability}

The fourth contribution relates to the knowledge about ecosystem dynamics. In general, ecosystem dynamics refers to the interactions between actors and how actor interactions impact the ecosystem-level outcomes (Davis, 2016). First, a nonlinear structure of ecosystem dynamics is added to the current literature. Most scholars have argued that focal actors must strategically manage (Snihur et al., 2018) or even control (Dattée et al., 2018) various ecosystem dynamics types to drive ecosystem birth and development. Their arguments draw on the assumption that focal actors' strategic actions have only direct linear effects on dyadic nonfocal actors (e.g., Gómez-Uranga et al., 2014; Kolloch and Dellermann, 2018; Leten et al., 2013; Liu and Rong, 2015). Findings in this $\mathrm{PhD}$ research stand in contrast to such hub-and-spoke structural ecosystem dynamics. The findings reported in Chapter 3 reveal that nonlinear ecosystem 
dynamics among non-focal actors result from new focal ventures' systemic combination of a set of positively reinforced strategies. Through strategic versatility, outperformed new focal ventures trigger actor dynamics simultaneously, and the positive actor dynamics promote the viability of innovation ecosystems more effectively. However, the ineffectiveness of managing ecosystem dynamics among the actors in an ecosystem's socio-political environment has overarching disadvantages for the viable economic environment and, as a result, for an innovation ecosystem's viability. These ecosystem environment dynamics answer recent calls by Jacobides et al. (2018) and Walrave et al. (2018) for a more nuanced understanding of ecosystem dynamics at various levels. Future studies should take a more dynamic and holistic view of ecosystem actor dynamics and their effects on innovation ecosystem birth and viability.

Second, the temporal understanding of ecosystem externalities in the innovation ecosystem birth has been advanced. Ecosystem externalities are ecosystem dynamics at the ecosystem level. They occur when pioneering focal actors' ecosystem creation efforts ease or impede the following focal actors' creation efforts. Scholars have found that negative externalities often prevent pioneers from building a more competitive innovation ecosystem. The benefit of pioneers' efforts is that followers might build innovation ecosystems effortlessly with the already known ecosystem structures (Hannah and Eisenhardt, 2018; Overholm, 2015). Findings reported in Chapter 3 extend the notion that such ecosystem-level negative externalities will gradually turn into positives for pioneers. This transition is closely related to pioneers' suboptimal strategic actions. Pioneers' proactiveness in sacrificing temporary economic benefits (short-term market share) brings them advantages in defending against the intertwined, overwhelming co-evolution challenges from socio-political actors, which matters in the long term. In contrast, followers focus on maximizing the short-term developmental benefits, overlooking the long-term sustainability by aligning socio-political actors upfront. Thus, future studies should pay special attention to temporal factors in analyzing ecosystemspecific strategies to explicate innovation ecosystem birth and viability.

\subsubsection{Theoretical contributions to the complexity management literature}

Another critical theoretical contribution is an extension of the complexity management literature to the ecosystem level. According to previous literature, the optimal level of complexity suggests that manageable connectivity, diversity, ambiguity, and dynamicity among actors lead to a system's high performance (de Toni and de Zan, 2016). Most prior studies analyzing complexity management concentrated on the effects at the individual firm level 
(Brown and Eisenhardt, 1997; McCarthy et al., 2006), the supply chain network level (Choi et al., 2001) or, more recently, the innovation cluster level (Russell and Smorodinskaya, 2018; Surie, 2017). Comparatively less attention has been paid to the relationships between the level of complexity and the performance of EEs. In line with the complexity management literature (Jacobs, 2013; Vasconcelos and Ramirez, 2011), findings from Chapter 5 argue that an optimal level of complexity in EEs comes down to regional innovation agents' collective endeavors in an adaptive process. More specifically, the level of complexity in an EE depends on whether new innovation agencies are introduced into (complexity absorption), and meanwhile old ones are ruled out (complexity reduction), the EEs. By way of such an adaptive process, a manageable level of complexity helps regional innovation agencies in EEs maintain viability to show sustainable impacts on new ventures' capability levels and their innovation ecosystem creation processes.

\subsection{PRACTICAL IMPLICATIONS}

\subsubsection{Implications for managers}

Key findings of this $\mathrm{PhD}$ research serve as practical guidelines for ambitious entrepreneurs to exploit dynamic capabilities and execute strategic actions more effectively, two cornerstones of viable innovation ecosystems. For ambitious entrepreneurs, the inward-to-outward entrepreneurial mindset becomes fundamental to innovation experimentation. This includes the traditional in-house lab experiments to test an innovation's technical feasibility as well as sociospatial experimentation with key local ecosystem actors to grasp the social fitness and political acceptability of an overall offering. To acquire high-quality feedback from local actors, it requires strategic managers to deal with the location selection dilemma properly before the implementation of LIE. On the one hand, the more complex the small-scale societies might be, the better performance the LIE activities might produce. On the other hand, it meanwhile requires managers to have a higher level of capabilities. Hence, managers should contemplate whether to select "unfriendly" or "friendly" small-scale societies to do LIE. "Friendly" smallscale societies relatively require less strong capabilities than "unfriendly" ones. But the downside should be noticed since managers probably receive incomplete feedbacks on complex innovations. Consider that if innovations relate to public safety (e.g., drones), going to "friendly" small-scale societies where the social and regulatory system is not grim might prevent managers from getting rich understanding of innovations’ nontechnical properties. In this way, managers are suggested not to start LIE unless their TMT members have shown sufficient capabilities 
and/or supports to face with multidimensional challenging feedbacks useful for innovations' adaptability in mass societies.

Next, to have higher-order, ecosystem-related capabilities that are directly related to TMT members, top managers of new focal ventures should improve their TMT members’ portfolios to ensure the TMT members' (age, education, and industry) diversity. They should attract new members with cross-industry working experiences, with rich track records in strategic departments or organizations, diverse educational backgrounds, diverse life experiences, and so on (Talke et al., 2011). In this way, they could improve their dynamic capabilities through the possession of sufficient social capital and human capital. Besides, they need specially designed training courses, programs, and practices to shape their cognitive habits, preferences, and deficits to improve metacognition to avoid big strategic errors in decision-making.

Moreover, superior absorptive capacity (skills and routines) transforms regional innovation resources into organization-level and even ecosystem-level advantages (Lowik et al., 2016). Regional innovation resources complement the established levels of organizational capabilities. However, such complementary effects between two different resources do not take place automatically. Instead, it is expected that managers should recognize, acquire, and transform diverse innovation resources effectively to overcome, for example, different operational problems during LIE (Morretta et al., 2020).

After obtaining decent results from LIE, managers need to develop strategic actions to align ecosystem actors. First, they should keep a certain level of strategic flexibility in the innovation ecosystem creation process. On the one hand, to best utilize the limited resources, they should shift their managerial attention away from a sole focus on separate effectiveness to dynamic, complex (positive) interplays between strategic actions. However, the effectiveness of deliberately planned strategies is predicated on considerable resource commitment and management teams' strategic adherence over time. To some extent, purely deliberative strategies may restrict strategic flexibility (Mintzberg and Waters, 1985). On the other hand, managers in most cases should take one-on-one strategic actions to address emergent problems. However, they still need to closely monitor such emergent responsive strategies because they might cause unforeseeable (negative) interactions among interdependent actors if strategies are not operated well. In this regard, keeping the strategic flexibility is closely associated with managers’ attention management (Brinckmann et al., 2019).

Second, managers should note that the ecosystem externalities during the innovation ecosystem creation process are double-edged swords. Pioneers who develop innovation 
ecosystems earlier should realize the positive effects of their ecosystem creation efforts for followers, who could ease their own ecosystem development by using a pioneer's clear ecosystem structures. However, this is inevitable because in a new market, it is necessary to allow some entrants into the market, attracting more non-focal actors to defend this new market collectively. In a short time, they can mitigate the negative effects by increasing market entry costs, such as strong IP protection and proprietary asset control (Leten et al., 2013). In the long term, they should take opportunities to turn such negative effects into positive effects with effective suboptimal strategic actions. For followers, although ecosystem externalities brought about by pioneers temporarily facilitate the innovation ecosystem creation process, they should have a long-term vision to forecast possible risks arising from their ecosystems. To do so, they might need a high level of learning capability to learn from pioneers' best practices and even from good examples in similar industries (Walrave et al., 2018). Knowledge and experiences from best practices/examples are indirect yet insightful for understanding the innovation ecosystem boundaries.

Finally, for those entrepreneurs who have little ecosystem building and governance experience before, the aggregated conceptual boundaries of ecosystems potentially offer guidelines to effectively design winning strategies and deploy strategic resources, which hence in turn likely increase the survivability of their newly-created innovation ecosystems. Given that shared visions that cannot be settled directly might be subject to fierce competition or compromise amongst non-focal actors, particularly if large commercial entities or noneconomic actors (e.g., regulators) play an important role in the shared vision, hence, when formulating strategies, managers should move away from maximizing the benefits for their own companies towards fostering broader competitiveness at the level of the ecosystem.

In addition, since managers often receive few incentives from complementors to make upfront investments in unproven market needs. Therefore, rather than starting the ecosystem on a large scale, which would require substantial strategic resources, new focal ventures should aim for early, small-scale success by optimizing the use of their limited resources. As the Redbike case in Chapter 3 illustrated, new focal ventures could develop prototypes of proposed innovations and then strive to test their market potential in small-scale markets. The tangible success from small-scale marketplaces could motivate key complementors to successfully kickstart innovation ecosystems (Ozcan and Eisenhardt, 2009). Moreover, unlike large commercial entities, whose established platforms or legitimacy can contribute to the co-creation of highly modularized ecosystem offerings by easily integrating a variety of technological standards, 
designs and requirements, new focal firms are advised either to undertake open innovation activities (e.g., technology conferences, co-designing, collective experiments) (Davis, 2016) or to rely on intermediary actors (e.g., anti-trust commissions and patent unions) (Moore, 2006). Over the course of such orchestration activities, new focal firms should inform all complementors within the ecosystem about the fact that the ecosystem is continuously vulnerable, thereby emphasizing the need for consistent cohesive innovative actions in response to external disruptors.

Based on the above, entrepreneurs should also balance out the developmental momentum of ecosystems with stability. They should enhance the attractiveness of the proposed offering for new actors, while, simultaneously, being cognizant of the risks associated with moving too quickly. More specifically, introducing a large number of new participants within a short time frame might increase the difficulty of achieving the relative schemes for co-capturing fair value, thereby triggering competitive tensions amongst actors, which, in turn, could be detrimental to ecosystem growth. To avoid this situation and realize the organic scaling of the ecosystem, new focal firms should firstly exploit their networking capabilities to maintain a manageable portfolio of ecosystem actors. For example, they could coerce explicit assumptions on proposed innovations as well as the behavioural rules of participation, thereby lowering opportunism and the appropriation of risks in ecosystems. Secondly, they should be more proactive in analyzing the possible influences of the newly introduced ecosystem elements (e.g., new and uncommon actors, rules, technologies, or institutions) or the modified core-value propositions concerning the overall development of the ecosystem. This could help new focal firms to translate small changes stemming from the non-linear interactions of ecosystem actors into valuable information, giving them a head start in converting these proactive understandings into highquality ideas or creative solutions. However, such first-mover advantages stemming from proactiveness and agility pose considerable challenges for new focal firms vis-à-vis the strengthening of their cognitive skills and learning capabilities.

\subsubsection{Implications for policymakers}

This PhD research also has three notable implications for regional policymakers to build viable EEs as its criticality to new focal ventures' capabilities and innovation ecosystem birth and viability. First, policymakers should recognize the limited effects of "top-down" policy tools on an EE's viability. Since the various innovation agencies in EEs are self-organized, direct policy interventions might effectively shape material innovation resources such as funds, 
infrastructure, and entrepreneurial services but may be relatively weak at shaping non-material resources such as the entrepreneurship culture that is expected to be formed and changed in a "bottom-up" way. Second, policymakers should update their innovation policies over time. This is because self-organized innovation agencies might fall into a path-dependent development process that will lock themselves and, accordingly, entrepreneurial activities into a single domain. Hence, to increase the diversity and cohesiveness of innovation agencies, policymakers should strategically introduce new entrepreneurial resources and rule out old-fashioned ones via innovation policies. As such, the continuity and coordination of various policies might pose a big challenge for policymakers being proactive and sometimes creative. Third, policymakers need to promote innovation resource exchanges at the regional, national, and even international levels. Specifically, policymakers should consider the interconnections of innovation policies at different geographical levels.

\subsection{LIMITATIONS}

This $\mathrm{PhD}$ research has two major limitations. The first limitation relates to the samples used in three empirical studies. Sampling in one country (China) might impact the generalizability of research findings to other countries because of the contextual variations in the innovation ecosystem birth and viability. In particular, In Chapter 3 research results suggest that four new focal ventures should take socio-political actors (regulators) as serious innovation uncertainties, because they will incrementally impose negative impacts on ecosystem birth and growth. Such property related to political actors propels managers to sacrifice the short-term benefits for longterm developmental momentum. However, as van Waes et al. (2018) noted, regulatory agencies in Amsterdam (also Paris, Melbourne, and San Francisco) are keeping an eye on new bikesharing new ventures from their genesis, rather than being positive bystanders, like most Chinese local governments. Thus, it is inferred that new bike-sharing ventures in such developed economics would take solving sociopolitical obstacles as their strategic priority. Therefore, it needs further research into whether new focal ventures would rely on suboptimal strategic actions to sustain innovation ecosystem development. Such a sampling consideration also exists in Chapter 5, where the biggest, most successful EE in mainland China is studied to look into complexity properties among various regional innovation agencies. To some extent, the so-called "Halo Effects" might bias the research results (Yin, 2013). Overall, considering the institutional difference, future studies should involve multiple, comparable cases from a variety of institutional settings to arrive at more robust conclusions. 
The second limitation comes down to the key research assumptions. Following prior literature and throughout the research, the focal actors were responsible for building and sustaining innovation ecosystems (Iansiti and Levien, 2004). Non-focal actors are assumed as passive actors during such process. In other words, non-focal actors' capabilities and strategies are not involved into the innovation ecosystem model. On the one hand, such an operation helps concentrate on the unit of analysis of the focal actors. On the other hand, it may be an oversimplification, particularly when studying early-stage innovation ecosystems fraught with high dynamism and complexity. As such, simultaneous consideration of strategies and capabilities from focal and non-focal actors would make for a great research opportunity. Considering such two sides at the same time comes with the methodological challenges. For example, when examining ecosystem (focal and non-focal) actors' strategies, researchers do not only need to find out what types of strategies they executed at different points in time, but also it requires them to clarify the complex interactions (tradeoff, reinforcing, or dampening) of strategies enacted by different actors. Especially they should find reliable methods to calculate the effects of complex strategy interactions on ecosystem-level results (birth and growth). It seems that to avoid possible research biases, multiple research methods should be adopted to capture such complex interactions, and further, to reasonably abstract the interactive effects beyond the dyadic level. Scholars could use rich longitudinal qualitative data to capture the types, directions, intensity, and effects of strategies' interactions. As these elements are more clear, agent-based simulation tools are then adopted to recheck the possible research inductions to draw reliable conclusions. Overall, adding influential factors (nonfocal actors) into the model might produce interesting research results. Yet researchers should take seriously the methodological challenges arising from increasing model complexity.

\subsection{FUTURE RESEARCH}

The PhD research prompts three key avenues for future studies. First, more scholarly work is needed to explore antecedents of LIE and contingent effects, considering its role in bridging focal actors' capabilities and strategies, although the present research has examined the three key capabilities' functions in the high level performance of LIE. However, the interesting question is that any other types of capabilities result in a high level of LIE, not limited to the three examined in this research. In Chapter 4, the individual effects of three capabilities on the LIE are tested quantitatively. Another interesting research question is whether there are intertemporal interactions among the three capabilities and how they act on the LIE? Based on 
the present framework and results, future studies have the possibility to address these new questions by adopting qualitative case studies and fuzzy-set qualitative comparative analysis (fs/QCA). More specifically, applying bottom-up knowledge from multiple qualitative cases, researchers could uncover a comprehensive portfolio of capabilities that play a positive role in the high performance of LIE, but come to understand further how capabilities interact with rich process data. Through fs/QCA analyzing techniques (Fiss, 2011), researchers have more profound insights regarding which bundles of capabilities have the most positive effects on LIE’s performance.

Besides, additional scholarly attention should be paid to what and how systemic innovation resources in an EE impact the capability-LIE relationships. As discussed in Chapter 4, systemic consultancy services in an EE shows an insignificant effect on the metacognition-LIE relationship. It is inferred that the level of metacognition is formed within TMTs, rather than being not affected by external factors. Another possible reason might be the cross-sectional data resources, as consultancy services take quite some time to present positive effects on metacognition. Furthermore, the metacognition level is likely to be related to the non-material resources (cultural or social elements) in the EE. Therefore, to explore how an EE impacts new focal ventures' capabilities and LIE processes, scholars are encouraged to: (1) examine the effects of both material and non-material innovation resources; and (2) combine survey data and longitudinal process data.

Furthermore, it warrants more scholarly care that some other non-capability factors might impact LIE. It is expected that the number of experimentation activities that new focal ventures undertake would cause a high level of LIE. In addition, new focal ventures simultaneously positioning experimentation activities in two or more separate small-scale societies would accelerate LIE. The institutional difference might be a possible contingency as the results of LIE show differences in two small-scale societies characterized by different cultures, social preferences, and legal systems. Some big firms as initial partners seem to influence LIE's final performance positively with strategic resources endowed by them. However, if managed improperly, LIE would prevent focal ventures from realizing their strategic aims as big firms with superior metacognition, networking capability, and learning skills might replace new focal ventures. It poses a new research question: how can new focal ventures deploy resources and design strategies proactively to avoid their replacement during LIE? Together, more empirical studies in the future are required to unpack additional antecedents and contingent effects critical to the LIE. 
Second, it is worth exploring how new focal ventures execute ecosystem-specific strategies beyond the early-stage of innovation ecosystems. The research focus of this $\mathrm{PhD}$ research is on innovation ecosystems' early developmental stage. That is rewarding because the innovation ecosystems' chaos and fragility allow observation of focal actors' active strategic actions (Dedehayir et al., 2018; Rong and Shi, 2014). As explained in Chapter 3, new focal ventures might, due to newness liabilities, would take suboptimal strategies to sustain the ecosystem-level competitiveness. An intriguing quest is whether (and in what forms) such counterintuitive strategies would take place in the renewal growth stages, and further offset the sustainability of innovation ecosystem growth? According to scholars, focal actors must reshape/reconfigure non-focal actors to offer new innovations during the innovation ecosystems' renewal stage (Autio and Thomas, 2018). Compared to the early stages, established institutions, systems, and beliefs between ecosystem actors are more rigid during the renewal stage, presenting difficulties for focal in implementing effective ecosystem-specific strategies (Ghazinoory et al., 2020). Thus, future longitudinal case studies on other periods beyond the growth stages might well improve the applicability of the present research's insights and, hopefully, unfold new properties of ecosystem-specific strategies.

Third, many complex and systemic cross-level mechanisms of innovation ecosystem birth need further development. Research results presented in Chapter 3 to 5 have uncovered how new focal ventures' capabilities and strategies relate to each other and impact innovation ecosystems' viability. Although encouraging, more theoretical details exist between new focal ventures and full-fledged innovation ecosystems. It is expected that for some innovation ecosystems aiming to achieve disruptive innovations, their birth and viability might involve more complex intermediary processes, not limited to the only LIE as revealed. The effectiveness of these higher-level intermediary processes would rely more on inter-organizational capabilities and strategies beyond the individual firm unit.

Besides, the reversed impacts of innovation ecosystems and prototyping innovation ecosystems on an EE's viability are possible. Testing such reversed impacts further addresses the increasing calls for more knowledge about the complex interactions between EEs and innovation ecosystems (see Thomas et al., 2018). Results presented in Chapter 5 suggest that a viable EE impacts significantly on new focal ventures and their innovation ecosystems. Ecosystem creation activities launched primarily by new focal ventures will magnetize new actors and resources outside of the EE where they are initially embedded. This, in turn, increases the number and diversity of innovation agencies, the foundations of an EE's viability. Even 
when innovation ecosystems finally collapse, specific strategic innovation resources would be circulated within the EEs, enabling the birth and viability of other innovation ecosystems (Spigel and Vinodrai, 2020). In conclusion, drawing on the framework in doctoral research, scholars have opportunities to unpack more nuanced cross-level mechanisms of innovation ecosystem birth and viability.

Considering the importance of a viable EE, an intriguing but under-investigated research question arises: how can traditional Marshallian districts such as science parks and innovation clusters transform successfully into viable entrepreneurial ecosystems? Addressing this issue can offer implications to underdeveloped regions that express considerable enthusiasm to (re)energize regional economic growth and competitiveness by applying EE approaches (Denney et al., 2021). However, doing so is challenging. First, it is time-consuming. As Chapter 5 suggests, the Zhongguancun EE produced system outputs (i.e., high-growth entrepreneurial firms) in 2013, while it started up in the 1990s. It requires regional innovation and entrepreneurship policies to be consistently coordinated over a long time horizon, thereby ensuring all EE components remain in place. Second, managing the mass of entrepreneurial agents is challenging because the functionality of traditional "top-down" policies might easily lose their original efficacy. Various political tools to be more creative necessitate than ever. Nevertheless, worldwide practices by diverse economies provide researchers great opportunities to explore this issue profoundly. Longitudinal qualitative cases, especially crossborder ones, await in the future.

\subsection{REFERENCES}

Adner, R. (2006). Match your innovation strategy to your innovation ecosystem. Harvard Business Review, 84(4), 98-108.

Adner, R. (2012). The wide lens: A new strategy for innovation. London: Penguin.

Adner, R. (2017). Ecosystem as structure: An actionable construct for strategy. Journal of Management, 43(1), 39-58.

Adner, R., \& Helfat, C. E. (2003). Corporate effects and dynamic managerial capabilities. Strategic Management Journal, 24(10), 1011-1025.

Adner, R., \& Kapoor, R. (2010). Value creation in innovation ecosystems: How the structure of technological interdependence affects firm performance in new technology generations. Strategic Management Journal, 31(3), 306-333.

Adner, R., \& Kapoor, R. (2016). Innovation ecosystems and the pace of substitution: Re-examining technology S-curves. Strategic Management Journal, 37(4), 625-648.

Aksenova, G., Kiviniemi, A., Kocaturk, T., \& Lejeune, A. (2019). From Finnish AEC knowledge ecosystem to business ecosystem: lessons learned from the national deployment of BIM. Construction Management and Economics, 37(6), 317-335. 
Ansari, S., Garud, R., \& Kumaraswamy, A. (2016). The disruptor's dilemma: TiVo and the US television ecosystem. Strategic Management Journal, 37(9), 1829-1853.

Attour, A., \& Lazaric, N. (2020). From knowledge to business ecosystems: emergence of an entrepreneurial activity during knowledge replication. Small Business Economics, 54(2), 575-587.

Autio, E., \& Thomas, L. (2014). Innovation ecosystems: Implication for innovation management. In M. Dodgson, D. M. Gann, \& N. Phillips (Eds.), The Oxford handbook of innovation management (pp. 204-288). Oxford: Oxford University Press.

Autio, E., \& Thomas, L. (2018). Tilting the Playing Field: Towards an Endogenous Strategic Action Theory of Ecosystem Creation. In World Scientific Reference on Innovation Volume 3: Open Innovation, Ecosystems and Entrepreneurship: Issues and Perspectives (pp. 111-140). New Jersey: World Scientific Publishing.

Baldwin, C. Y. (2012). Organization Design for Business Ecosystems. Journal of Organization Design, 1(1), 20-23.

Basole, R. C., Park, H., \& Barnett, B. C. (2015). Coopetition and convergence in the ICT ecosystem. Telecommunications Policy, 39(7), 537-552.

Brinckmann, J., Villanueva, J., Grichnik, D., \& Singh, L. (2019). Sources of strategic flexibility in new ventures: An analysis of the role of resource leveraging practices. Strategic Entrepreneurship Journal, 13(2), 154-178.

Brown, S. L., \& Eisenhardt, K. M. (1997). The art of continuous change: Linking complexity theory and time-paced evolution in relentlessly shifting organizations. Administrative Science Quarterly, 42(1), 1-34.

Cao, X., Ouyang, T., Balozian, P., \& Zhang, S. (2020). The Role of Managerial Cognitive Capability in Developing a Sustainable Innovation Ecosystem: A Case Study of Xiaomi. Sustainability, 12(17), 71-76.

Choi, T. Y., Dooley, K. J., \& Rungtusanatham, M. (2001). Supply networks and complex adaptive systems: Control versus emergence. Journal of Operations Management, 19(3), 351-366.

Clarysse, B., Wright, M., Bruneel, J., \& Mahajan, A. (2014). Creating value in ecosystems: Crossing the chasm between knowledge and business ecosystems. Research Policy, 43(7), 1164-1176.

Dattée, B., Alexy, O., \& Autio, E. (2018). Maneuvering in poor visibility: How firms play the ecosystem game when uncertainty is high. Academy of Management Journal, 61(2), 466498.

Davis, J. P. (2016). The group dynamics of interorganizational relationships collaborating with multiple partners in innovation ecosystems. Administrative Science Quarterly, 64, 621-661.

de Toni, A. F., \& de Zan, G. (2016). The complexity dilemma. Emergence: Complexity \& Organization, 18(3/4), 1-8.

Dedehayir, O., Mäkinen, S. J., \& Ortt, J. R. (2018). Roles during innovation ecosystem genesis: A literature review. Technological Forecasting and Social Change, 136, 18-29.

Denney, S., Southin, T., \& Wolfe, D. A. (2021). Entrepreneurs and cluster evolution: the transformation of Toronto's ICT cluster. Regional Studies, 55(2), 196-207.

Feng, N., Fu, C., Wei, F., Peng, Z., Zhang, Q., \& Zhang, K. H. (2019). The key role of dynamic capabilities in the evolutionary process for a startup to develop into an innovation ecosystem 
leader: An indepth case study. Journal of Engineering and Technology Management, 54, 81-96.

Ferreira, J. J., Fernandes, C. I., \& Raposo, M. L. (2017). The effects of location on firm innovation capacity. Journal of the Knowledge Economy, 8(1), 77-96.

Fiss, P. C. (2011). Building better causal theories: A fuzzy set approach to typologies in organization research. Academy of Management Journal, 54(2), 393-420.

Ganco, M., Kapoor, R., \& Lee, G. K. (2020). From rugged landscapes to rugged ecosystems: Structure of interdependencies and firms' innovative search. Academy of Management Review, 45(3), 646-674.

Gawer, A., \& Cusumano, M. A. (2014). Industry platforms and ecosystem innovation. Journal of Product Innovation Management, 31(3), 417-433.

Ghazinoory, S., Sarkissian, A., Farhanchi, M., \& Saghafi, F. (2020). Renewing a dysfunctional innovation ecosystem: The case of the Lalejin ceramics and pottery. Technovation, 96, 102122. https://doi.org/10.1016/j.technovation.2020.102122.

Gómez-Uranga, M., Miguel, J. C., \& Zabala-Iturriagagoitia, J. M. (2014). Epigenetic economic dynamics: The evolution of big internet business ecosystems, evidence for patents. Technovation, 34(3), 177-189.

Gulati, R., Puranam, P., \& Tushman, M. (2012). Meta-organization design: Rethinking design in interorganizational and community contexts. Strategic Management Journal, 33(6), 571586.

Guo, J., \& Bouwman, H. (2016). An analytical framework for an m-payment ecosystem: A merchants' perspective. Telecommunications Policy, 40(2-3), 147-167.

Hannah, D. P., \& Eisenhardt, K. M. (2018). How firms navigate cooperation and competition in nascent ecosystems. Strategic Management Journal, 39(12), 3163-3192.

Haynie, J. M., Shepherd, D. A., Mosakowski, E., \& Earley, P. C. (2010). A situated metacognitive model of the entrepreneurial mindset. Journal of Business Venturing, 25(2), 217-229.

Hedman, J., \& Henningsson, S. (2015). The new normal: Market cooperation in the mobile payments ecosystem. Electronic Commerce Research and Applications, 14(5), 305-318.

Iansiti, M., \& Levien, R. (2004). The keystone advantage: What the new dynamics of business ecosystems mean for strategy, innovation, and sustainability. Boston: Harvard Business School Press.

Jacobs, M. A. (2013). Complexity: Toward an empirical measure. Technovation, 33(4), 111-118.

Jacobides, M. G., Cennamo, C., \& Gawer, A. (2018). Towards a theory of ecosystems. Strategic Management Journal, 39(18), 2255-2276.

Kashan, A. J., \& Mohannak, K. (2017). The Role of Knowledge Integration in Capability Development and Emergence of Innovation Ecosystem. International Journal of Innovation and Technology Management, 14(5), 1-18.

Kolloch, M., \& Dellermann, D. (2018). Digital innovation in the energy industry: The impact of controversies on the evolution of innovation ecosystems. Technological Forecasting and Social Change, 136, 254-264.

Leten, B., Vanhaverbeke, W., Roijakkers, N., Clerix, A., \& Van Helleputte, J. (2013). IP models to orchestrate innovation ecosystems: IMEC, a public research institute in nano-electronics. California Management Review, 55(4), 51-64. 
Letaifa, S.B. (2014). The uneasy transition from supply chains to ecosystems: The valuecreation/value-capture dilemma. Management Decision, 52, 278-295.

Li, Y. R. (2009). The technological roadmap of Cisco's business ecosystem. Technovation, 29(5), 379-386.

Liu, G., \& Rong, K. (2015). The nature of the co-evolutionary process: Complex product development in the mobile computing industry's business ecosystem. Group \& Organization Management, 40(6), 809-842.

Lowik, S., Kraaijenbrink, J., \& Groen, A. (2016). The team absorptive capacity triad: a configurational study of individual, enabling, and motivating factors. Journal of Knowledge Management, 20, 1083-1103.

Lütjen, H., Schultz, C., Tietze, F., \& Urmetzer, F. (2019). Managing ecosystems for service innovation: A dynamic capability view. Journal of Business Research, 104, 506-519.

Luo, J. (2018). Architecture and evolvability of innovation ecosystems. Technological Forecasting and Social Change, 136, 132-144.

Ma, Y., Rong, K., Mangalagiu, D., Thornton, T. F., \& Zhu, D. (2018). Co-evolution between urban sustainability and business ecosystem innovation: Evidence from the sharing mobility sector in Shanghai. Journal of Cleaner Production, 188, 942-953.

McCarthy, I. P., Tsinopoulos, C., Allen, P., \& Rose-Anderssen, C. (2006). New product development as a complex adaptive system of decisions. Journal of Product Innovation Management, 23(5), 437-456.

Mintzberg, H., \& Waters, J. A. (1985). Of strategies, deliberate and emergent. Strategic Management Journal, 6(3), 257-272.

Mitrega, M., Forkmann, S., Ramos, C., \& Henneberg, S. C. (2012). Networking capability in business relationships-Concept and scale development. Industrial Marketing Management, 41(5), 739-751.

Moore, J. F. (1996). The death of competition: Leadership and strategy in the age of business ecosystems. New York: HarperBusiness.

Moore, J. F. (2006). Business ecosystems and the view from the firm. Antitrust Bull, 51, 31-75.

Morretta, V., Syrett, S., \& Ramirez, L. S. (2020). Territorial capital as a source of firm competitive advantage: evidence from the North and South of Italy. European Planning Studies, 28(12), 2390-2408.

Overholm, H. (2015). Collectively created opportunities in emerging ecosystems: the case of solar service ventures. Technovation, 39, 14-25.

Ozcan, P., \& Eisenhardt, K. M. (2009). Origin of alliance portfolios: Entrepreneurs, network strategies, and firm performance. Academy of Management Journal, 52(2), 246-279.

Parente, R., Rong, K., Geleilate, J. M. G., \& Misati, E. (2019). Adapting and sustaining operations in weak institutional environments: A business ecosystem assessment of a Chinese MNE in Central Africa. Journal of International Business Studies, 50(2), 275-291.

Phillips, M. A., \& Srai, J. S. (2018). Exploring emerging ecosystem boundaries: defining 'the game'. International Journal of Innovation Management, 22(08), 1840012. https://doi.org/10.1142/S1363919618400121.

Phillips, M. A., \& Ritala, P. (2019). A complex adaptive systems agenda for ecosystem research methodology. Technological Forecasting and Social Change, 148, 119739. https://doi.org/10.1016/j.techfore.2019.119739. 
Randhawa, K., West, J., Skellern, K., \& Josserand, E. (2020). Evolving a Value Chain to an Open Innovation Ecosystem: Cognitive Engagement of Stakeholders in Customizing Medical Implants. California Management Review. https://doi.org/10.1177/0008125620974435.

Ritala, P., \& Almpanopoulou, A. (2017). In defense of 'есо' in innovation ecosystem. Technovation, 60, 39-42.

Rong, K., \& Shi, Y. (2014). Business ecosystems: Constructs, configurations, and the nurturing process. London: Palgrave Macmillan.

Russell, M. G., \& Smorodinskaya, N. V. (2018). Leveraging complexity for ecosystemic innovation. Technological Forecasting and Social Change, 136, 114-131.

Russo-Spena, T., Tregua, M., Amitrano, C. C., \& Bifulco, F. (2020). Addressing Socio-Material Issues for an Emerging Innovation Ecosystem: Insights From Cultural Heritage. IEEE Transactions on Engineering Management. https://doi.org/10.1109/TEM.2020.3040746.

Sambamurthy, V., Bharadwaj, A., \& Grover, V. (2003). Shaping agility through digital options: Reconceptualizing the role of information technology in contemporary firms. MIS Quarterly, 237-263.

Snihur, Y., Thomas, L. D., \& Burgelman, R. A. (2018). An ecosystem-level process model of business model disruption: The disruptor's gambit. Journal of Management Studies, 55(7).1278-1316.

Spigel, B. (2015). The relational organization of entrepreneurial ecosystems. Entrepreneurship Theory and Practice, 41(1), 49-72.

Spigel, B., \& Vinodrai, T. (2020). Meeting its Waterloo? Recycling in entrepreneurial ecosystems after anchor firm collapse. Entrepreneurship \& Regional Development, 1-22.

Surie, G. (2017). Creating the innovation ecosystem for renewable energy via social entrepreneurship: Insights from India. Technological Forecasting and Social Change, 121, 184-195.

Talmar, M., Walrave, B., Podoynitsyna, K. S., Holmström, J., \& Romme, A. G. L. (2018). Mapping, analyzing and designing innovation ecosystems: The Ecosystem Pie Model. Long Range Planning, 101850. https://doi.org/10.1016/j.lrp.2018.09.002.

Talke, K., Salomo, S., \& Kock, A. (2011). Top management team diversity and strategic innovation orientation: The relationship and consequences for innovativeness and performance. Journal of Product Innovation Management, 28(6), 819-832.

Thomas, L. D., \& Autio, E. (2014). The processes of ecosystem emergence. In Working Paper, Imperial College Business School, University of London, July.

Thomas, L. D. W., \& Autio, E. (2020). Innovation ecosystems in management: An organizing typology. In Oxford Encyclopedia of Business and Management. Oxford University Press.

Thomas, L. D., Sharapov, D., \& Autio, E. (2018). Linking entrepreneurial and innovation ecosystems: The case of AppCampus. In Entrepreneurial ecosystems and the diffusion of startups. Edward Elgar Publishing.

van Waes, A., Farla, J., Frenken, K., de Jong, J. P., \& Raven, R. (2018). Business model innovation and socio-technical transitions. A new prospective framework with an application to bike sharing. Journal of Cleaner Production, 195, 1300-1312.

Vasconcelos, F. C., \& Ramirez, R. (2011). Complexity in business environments. Journal of Business Research, 64(3), 236-241. 
Velu, C. (2015). Knowledge management capabilities of lead firms in innovation ecosystems. AMS Review, 5(3-4), 123-141.

Visscher, K., Hahn, K., \& Konrad, K. (2021). Innovation ecosystem strategies of industrial firms: A multilayered approach to alignment and strategic positioning. Creativity and Innovation Management, 1-13. https://doi.org/10.1111/caim.12429.

Walrave, B., Talmar, M., Podoynitsyna, K. S., Romme, A. G. L., \& Verbong, G. P. (2018). A multilevel perspective on innovation ecosystems for path-breaking innovation. Technological Forecasting and Social Change, 136, 103-113.

Yin, R. K. (2013). Case study research: Design and methods (4th ed.). Thousand Oaks, CA: Sage Publications.

Zahra, S. A., \& Nambisan, S. (2011). Entrepreneurship in global innovation ecosystems. AMS Review, 1(1), 4-17.

Zhang, J., \& Liang, X.-J. (2011). Business ecosystem strategies of mobile network operators in the 3G era: The case of China Mobile. Telecommunications Policy, 35(2), 156-171. 
SUMMARY 


\section{Research problems}

Over recent decades, industrial firms have shifted to developing viable innovation ecosystems to co-create and co-capture value from innovations. It is increasingly observed that many new ventures show the ambition to build and sustain innovation ecosystems by aligning with various value complementors. Unfortunately, new ventures as leaders suffer a high rate of innovation ecosystem mortality. Among the reasons for the high mortality rate are that new ventures lack strategic resources and capabilities and ecosystem management experiences.

First, the insufficiency of strategic resources and capabilities prevents them from building innovation ecosystems quickly in a short time like big firms. Instead, they need to do so following a slow-staged process. However, the slow-staged process is usually accompanied by a proliferation of competitive innovation ecosystems, consequently leading them to the loss of first-mover advantage. New ventures should be replenished with rich resources and robust capabilities to solve a tension: the slow/ iterative ecosystem-building process and losing firstmover advantage. Second, the shortage of ecosystem management experiences makes new ventures feel laborious to keep key complementors' long-term commitment to innovation ecosystems, whose stay in and left to ecosystems are not subject to any contractual forces. Under these circumstances, on the one hand, leaving some key complementors out makes the ecosystem-level competitiveness less achievable. On the other hand, engaging complementors - especially big ones - runs the risk of losing ecosystem leadership. Therefore, they are required to execute effective ecosystem-specific strategies to solve another tension: maintaining individual leadership and ecosystem-level competitiveness.

The existing innovation ecosystem literature offers incomplete understandings of how new ventures as focal actors can exploit capabilities and implement strategies to build and sustain a viable innovation ecosystem. It is that research gap that has motivated this $\mathrm{PhD}$ research.

\section{Research perspectives}

In this $\mathrm{PhD}$ research, the cross-level research perspective is selected to address the research gap. This perspective is premised on the assumption that the ecosystem focal actors shoulder primary responsibilities for and benefit the most from viable innovation ecosystems. Therefore, it posits that ecosystem-related capabilities and ecosystem-specific strategies at the focal firm level could determine the viability of innovation ecosystems, which are at the system level. For this reason, the adoption of the cross-level perspective in this $\mathrm{PhD}$ research has opportunities to 
open the black-box of how new focal ventures' ecosystem-related capabilities form and create impacts, how new focal ventures' ecosystem-specific strategies are implemented and yield ecosystem-level effects, and how the capabilities and strategies are related to each other. Beyond the insights from the focal firm to system levels, further insights from the system to focal firm levels could be enriched.

\section{Research approach and findings}

One literature review and three empirical studies were designed to present cross-level mechanisms of how new focal ventures exploit capabilities and implement strategies to build and sustain a viable innovation ecosystem. All three empirical studies were set in the context of mainland China. One multiple-case study relied on two surviving and two failed innovation ecosystems in the Chinese bike-sharing industry, aiming to answer how the four biking ventures formulated and implemented effective ecosystem-specific strategies to obtain ecosystem-level results. With 111 respondents from Chinese innovation hubs, one PLS-SEM-based study quantitatively examined how three dynamic capabilities and systemic innovation supports act at the performance level of the "local innovation experimentation", considered as the prototypical innovation ecosystem. The third empirical study was a single case study on the background of the Zhongguancun entrepreneurship ecosystem (EE) located in Beijing. This study was conducted to show how viable entrepreneurship ecosystems impact the new ventures and their innovation ecosystem creation processes.

In terms of how new focal ventures develop effective ecosystem-specific strategies, the research has provided three key insights. First, outperformed ventures leverage the interplays of four dimensional (i.e., economic, coopetitive, social, and political) strategies. Through "strategy versatility", they seek cross-sectional interactive effects among ecosystem-specific strategies, instead of implementing them individually. Doing so helps them compensate for the resource limitation and further enhances their efforts to drive the innovation ecosystems’ birth and viability. Through “strategy suboptimality”, they intentionally sacrifice strategies' shortterm effectiveness to enhance future implemented strategies’ efficacy. As a result, individual leadership and long-term ecosystem-level competitiveness are guaranteed simultaneously.

Second, such two ecosystem-level strategies are grounded in cognitive preconditions. Outperformed ventures carried out the local innovation experimentation (LIE) effectively. During LIE, key complementors rally around new focal ventures to collectively experiment with immature innovations and form a prototypical innovation ecosystem. As a result, LIE's 
high performance helps new focal ventures map out the innovation ecosystem boundary, through which new ventures could proactively design and implement ecosystem-level strategies.

Furthermore, though not examined empirically, new focal ventures are thought to have a deeper understanding of the innovation ecosystems' aggregated conceptual boundaries (i.e., key distinguishing features' structural relationships and temporal dynamics). That is, they recognize better how a full-fledged innovation ecosystem operates during its early stages. Such clarified conceptual boundaries assist ventures in making winning ecosystem-level strategies.

In terms of how new focal ventures exploit ecosystem-related capabilities, the research has provided two key insights. On the whole, they need a set of dynamic capabilities to acquire the high LIE performance, the foundation for a full-fledged innovation ecosystem. First, these dynamic capabilities are firm-internal, reflecting top managers' cognition, social capital, and human capital. Metacognitive capability refers to managers' higher-order cognitive ability, helping new ventures better integrate various feedback from actors, manage better value cocreation and value co-capture tension, and adapt themselves easier to fast-changing contexts. Networking capability is a strategic collaborative capability, reflecting the stock of managers' social capital. This capability is critical for maintaining a "minimum but viable" set of key complementors in LIE. Learning agility is about managers' accumulated human capital, reflecting the extent to which managers' speed and flexibility to detect and solve emergent operational problems during LIE.

Second, findings show that two material-related, systemic local innovation supports in EE complement significantly two dynamic capabilities, thereby promoting the higher levels of LIE. Improved networking capability benefits most from diverse local networking activities arranged by local third-parties (e.g., industrial consortia). Improved learning agility benefits most from systemic local innovation facilities offered by local third-parties (e.g., local universities).

Findings also illustrate how regional innovation resources in an EE can show positive, consistent impacts on new focal ventures and their newly-created innovation ecosystems. That is explicated by six significant complexity-based properties that a viable EE exhibits over time. More specifically, the positive feedback loops suggest that new ventures could access the required resources in an accelerated fashion to enhance their dynamic capabilities and develop innovation ecosystems faster than others not in the EE. Next, ecosystem-related dynamic capabilities could be sustainably strengthened since regional innovation agencies are diversifying themselves and promote interactions among each other. Finally, the accessible 
innovation resources range from those in local to international regions, thereby facilitating their ecosystem creation process in a consistent way.

\section{Theoretical contributions}

The findings revealed by this research contribute to the innovation ecosystem literature and the complexity management literature. First, this research shed new light on that the "bottom-up" evolutionary approach and top-down” design thinking are two interrelated processes that coexist distinctly at two levels. Thus, future studies should apply multiple levels to uncover the underlying mechanisms of innovation ecosystems' birth and viability. Second, this research bridges the gap between the separate research focus on focal firms' ecosystem-related capabilities and ecosystem-specific strategies. Scholars should take a more complex structural view when exploring the effects of focal actors' capabilities and strategies on innovation ecosystems. Third, LIE suggests that the spatial context is relevant to early-stage innovation ecosystems. Fourth, the structural and time-based ecosystem dynamics are added to the current innovation ecosystem literature. Finally, this research extends the complexity management literature to the ecosystem level.

\section{Practical implications}

For managers, four guidelines are provided. They should note that ecosystem-related dynamic capabilities are directly related to TMT members. Therefore, for managers, they should have the inward-to-outward entrepreneurial mindsets which becomes fundamental to innovation experimentation. To this end, managers should improve TMT members' portfolios to ensure the TMT members' diversity in terms of age, education, and industry. Furthermore, they require a high-level absorptive capacity to transform regional innovation resources into organizationlevel and even ecosystem-level advantages. They should keep a certain level of strategic flexibility as either pure deliberate strategies or pure emergent strategies would hamper the innovation ecosystem creation process. Meanwhile, managers should note that the ecosystem externalities during the innovation ecosystem creation process are double-edged. Both ecosystem pioneers and followers should proactively take actions to cope with both the negative and positive effects of their ecosystem creation efforts. Finally, for those entrepreneurs who have little ecosystem building and governance experience before, the aggregated conceptual boundaries of ecosystems potentially offer guidelines to effectively design winning strategies 
and deploy strategic resources, which hence in turn likely increase the survivability of their newly-created innovation ecosystems.

For regional policymakers, this research offers three suggestions. First, policymakers should recognize the limited effects of "top-down" policy tools. This is because non-material innovation resources are expected to be formed and changed in a "bottom-up” way. Second, they should update their innovation policies over time so that the whole EE might not fall into a path-dependent development process. Third, they should consider interconnections of innovation policies on different geographical levels. So innovation resources crossing the regional, national, and even international levels are connected cohesively, thereby facilitating new ventures and the development of newly-created innovation ecosystems. 
SAMENVATTING 
De laatste decennia is het steeds belangrijker geworden voor nieuwe ondernemingen om als expliciete ambitie en in een leidende rol (als zgn focal firm) innovatie-ecosystemen te bouwen, die levensvatbaar zijn en blijven door met de partners in het ecosysteem die aanvullende waarde leveren voor de onderneming ((value complementors) gezamenlijk te innoveren en co-creëren. Helaas zien we dat deze nieuwe ondernemingen daar vaak niet in slagen en zien we een hoog 'sterftecijfer' van innovatie-ecosystemen rondom deze focal firms, onder meer te wijten aan het ontbreken van strategische middelen en capaciteiten en aan ervaring met het managen (bouwen én in standhouden) van ecosystemen.

Het gebrek aan strategische middelen en capaciteiten zorgt ervoor dat de slagkracht van de nieuwe onderneming niet snel genoeg is in het opbouwen van het innovatie-ecosysteem. Het trage, gefaseerde proces wat zij doorlopen zorgt voor verlies van het pioneersvoordeel en proliferatie van concurrerende innovatie-ecosystemen. Het proces van ecosysteemopbouw is te langzaam en het voordeel van de first mover verdwijnt. Weinig of geen ervaring in het bouwen en in standhouden van ecosystemen bemoeilijkt het bestendigen van lange termijnverbindingen met value complementors die immers niet door enige vorm van contract verbonden zijn. Het weglaten of wegvallen van sleutelpartners vermindert het concurrentievermogen op ecosysteemniveau. Het opnemen van te grote partners als value complementors heeft daarentegen ook het risico in zich dat de nieuwe onderneming het leiderschap in het ecosysteem kwijtraakt. Het is daarom belangrijk dat nieuwkomers doeltreffende ecosysteem gerichte strategieën toepassen om het spanningsveld van behoud van zowel hun individueel leiderschap in als het concurrentievermogen van hun innovatieecosysteem succesvol te kunnen managen.

De bestaande literatuur over innovatie-ecosystemen biedt onvolledige inzichten in de manier waarop nieuwe ondernemingen als centrale actoren capaciteiten kunnen benutten en strategieën toepassen om een levensvatbaar innovatie-ecosysteem op te bouwen en in stand te houden. In dit onderzoek is gekozen voor een cross-level onderzoeksperspectief om deze leemte te adresseren. We gaan ervanuit dat ecosysteem-gerelateerde capaciteiten en ecosysteemspecifieke strategieën op het niveau van de focal firm bepalend zijn voor de levensvatbaarheid van innovatie-ecosystemen, die zich op systeemniveau bevinden. De toepassing van dit crosslevel perspectief bied te mogelijkheid om de black box te openen van hoe de ecosysteemgerelateerde capaciteiten van nieuwe focal firms zich vormen en effecten creëren, hoe hun ecosysteem-specifieke strategieën worden geïmplementeerd en effecten op ecosysteem-niveau opleveren, en hoe de capaciteiten en strategieën aan elkaar gerelateerd zijn. 
Een literatuurstudie en drie empirische studies werden opgezet. Alle drie de empirische studies werden uitgevoerd in de context van het Chinese vasteland:

- een kwalitatief uitgevoerde meervoudige case study van twee overlevende en twee mislukte innovatie-ecosystemen opgebouwd door focal firms in de Chinese deelfietsenindustrie leverde rijke en diepgaande inzichten op in de formulering en implementatie innovatie-ecosystemen gericht op resultaten op ecosysteem-niveau

- een kwantitatieve PLS-SEM studie met data van 111 respondenten uit Chinese innovatie-hubs leidde tot kennis over hoe drie soorten dynamische capaciteiten en systemische innovatie-ondersteunings activiteiten uitwerken op de prestaties van zogenaamde 'locale innovatie-experimenten' die wij beschouwen als prototypische innovatie-ecosystemen.

- de derde empirische studie was een single case study van het Zhongguancum entrepreneurship ecosysteem (EE) in Beijing. Deze studie werd uitgevoerd om aan te tonen hoe levensvatbare ecosystemen een impact hebben op nieuwe ondernemingen en op hun processen voor het creëren van innovatie-ecosystemen.

Het onderzoek heeft de volgende belangrijke inzichten opgeleverd:

1. Succesvolle focal firms maken bij het bouwen van hun innovatie-ecosystemen beter gebruik van de wisselwerking tussen economische, coöperatieve, sociale en politieke ecosysteem strategieën door deze niet individueel te implementeren maar met oog voor interactieve effecten, zgn. strategic versatility. Op die manier compenseren zij hun beperkte middelen. Door een bepaalde mate van strategische suboptimaliteit offeren zij opzettelijk de korte-termijneffectiviteit op ten gunste van de effectiviteit van de toekomstige optimale situatie, waarmee hun individueel leiderschap wordt geborgd naast het concurrentie-vermogen op ecosysteemniveau.

2. Deze ecosysteem-niveau strategieën zijn gebaseerd op cognitieve randvoorwaarden die zich manifesteren in het effectief uitvoeren van lokale innovatie-experimenten (LIE). Belangrijke value complementors scharen zich rond de nieuwe onderneming om gezamenlijk te experimenteren met onrijpe/vroege innovaties en vormen zo een prototypisch innovatie-ecosysteem. Hiermee worden de grenzen van het innovatieecosysteem in kaart gebracht, waardoor de focal firm proactief en in leidende rol strategieën op ecosysteem-niveau kan ontwerpen en implementeren.

3. Voorts wordt aangenomen, hoewel dit niet empirisch is onderzocht, dat (goed presterende) nieuwe focal firms dieper inzicht hebben in de geaggreggeerde conceptuele 
grenzen van de innovatie-ecosystemen: de structurele relaties en de tijdsdynamiek. Zij zien beter (en eerder) in hoe een volwaardig innovatie-ecosysteem in zijn beginstadium functioneert. Dergelijke verduidelijkte conceptuele grenzen helpen ondernemingen om winnende strategieën op ecosysteem-niveau te ontwikkelen.

4. Last but not least nog twee belangrijke samenhangende inzichten over de manier waarop nieuwe focal firms ecosysteemgerelateerde capaciteiten benutten. Ten eerste hebben zij een reeks dynamische capaciteiten nodig om hun hoge LIE-prestaties te leveren, de basis van een (toekomstig) volwaardig innovatie-ecosysteem. Deze dynamic capabilities zijn bedrijfsintern en weerspiegelen de kennis, het sociaal kapitaal en het menselijk kapitaal van tomanagers. Metacognitief vermogen verwijst naar het hogereorde cognitieve vermogen van topmanagers waardoor zij voor hun nieuwe ondernemingen de feedback van diverse actoren beter kunnen integreren, het spanningsveld tussen waardecreatie en het vastleggen van waarde beter kunnen managen, en zich gemakkelijker kunnen aanpassen aan de snel veranderende dynamiek in de omgeving. Het vermogen om te netwerken is van strategisch belang voor de voorraad sociaal kapitaal en het behoud van de minimale set van value complementors in het LIE. Learning agility verwijst naar wendbaarheid en veerkracht, geaccumuleerd in menselijk kapitaal, daarmee ook de mate waarin managers snel en flexibel kunnen optreden bij operationele problemen gedurende het LIE. Ten tweede laten de resultaten zien dat het opbouwen en verbeteren van netwerkcapaciteit het meest baat heeft bij activiteiten georganiseerd door derden zoals industriële consortia (denk ook aan kennisparken) en dat learning agility het meest heeft aan innovatie-activiteiten geïnitieerd door kennispartners zoals locale universiteiten of onderzoeksinstituten.

Aanvullend zien we dus dat ook regionale innovatiestimulering in een EE (ondernemerschapsecosysteem) positieve, consistente effecten hebben op nieuwe focal firms en hun nieuw-gecreëerde innovatie-ecosystemen. Positieve feedback-loops zorgen voor snellere toegang tot middelen om dynamische capaciteiten te verbeteren en sneller het innovatie-ecosysteem te ontwikkelen, ecosysteemgerelateerde dynamische capaciteiten worden duurzaam versterkt door het interactie-bevorderende optreden van regionale innovatieagentschappen, en tenslotte wordt het proces van ecosysteemvorming vergemakkelijkt door de link tussen lokale en internationale regio's en de daarvoor toegankelijke innovatie-stimulering. 
De resultaten van dit proefschrift hebben zowel theoretische bijdragen als praktische implicaties. De theoretische bijdragen zijn aan de innovatie-ecosystemen literatuur en de literatuur over complexiteitsmanagement. Het onderzoek werpt ten eerste een nieuw licht op het feit dat 'bottom-up' evolutionaire benadering en het 'top-down' ontwerp-denken twee onderling gerelateerde processen zijn, die ook op twee verschillende niveaus naast elkaar bestaan, wat betekent dat multi-level onderzoek cruciaal is om de onderliggende mechanismen van het ontstaan en de levensvatbaarheid van innovatie-ecosystemen bloot te leggen. Ten tweede overbruggen we de kloof tussen de afzonderlijke onderzoeksfocus op ecosysteemgerelateerde capaciteiten van focal firms en ecosysteem-specifieke strategieën, wat pleit voor het hanteren van een meer complexe structurele visie bij toekomstig onderzoek. Ten derde suggereren de resultaten rondom LIE hoe relevant de locale context is voor innovatieecosystemen in een vroeg stadium. Ten vierde worden de structurele en op tijd gebaseerde ecosysteem dynamics toegevoegd aan de huidige innovatie-ecosysteemliteratuur. Last but not least breiden we de complexiteitsmanagement literatuur uit naar het ecosysteemniveau.

In praktische zin worden voor (top) managers een viertal richtlijnen gegeven gericht op de verhoging van de diversiteit van de portefeuilles en samenstelling van het managementteam, het belang van een hoog niveau van wat wel absorptive capacity wordt genoemd om regionale innovatie- 'bronnen' om te kunnen zetten in voordelen op het eigen organisatieniveau en waar nodig op ecosysteem niveau. De juiste mate van strategische flexibiliteit is daarnaast cruciaal. Topmanagers moeten er ook rekening mee houden dat de externe effecten van het ecosysteem tijdens het proces van innovatie-ecosysteem creatie tweesnijdend zijn: zowel volgers als pioniers moeten positieve en negatieve effecten goed kunnen opvangen.

Afsluitend volgen ook een drietal suggesties voor regionale beleidsmakers op basis van het onderzoek. Het is van belang om de bekeringen van 'top down' beleidseffecten te herkennen, omdat niet-materiele innovatiemiddelen naar verwachting juist op een 'bottom-up' manier worden gevormd en veranderd. Ten tweede moet het innovatiebeleid regelmatig worden bijgesteld om te voorkomen dat het hele EE in een padafhankelijk ontwikkelingsproces vervalt. Ten derde: het is belangrijk om rekening te houden met de onderlinge verbanden tussen innovatiebeleidsmaatregelen op verschillende niveaus, en de innovatiemiddelen die het regionale, nationale en zelfs internationale niveau overschrijden op coherente wijze met elkaar verbinden, waardoor voor nieuwe focal firms het ontwikkelen van innovatie-ecosystemen optimaal wordt gefaciliteerd. 

ACKNOWLEDGEMENT 


\section{Acknowledgement}

Like many other PhD students, I took over a whole year to decide exactly what to research. That was torturing because I had to read, read, and read during throughout first year of my PhD life. After forming an overview of a certain research topic, I decided to join the relevant academic conversations. To make my voices heard by peer scholars, I pinpointed the research problems, constructed research models, executed data collection, analyzed data, and arrived at new insights. It then continued with confrontations in which my promotor, daily supervisors, peers, reviewers, and colleagues brought something new and unexpected to my research. Finally, my first research paper was finished. Despite numerous challenges, I repeated these steps again and again throughout my whole $\mathrm{PhD}$ journey. Four papers were finally compiled into this $\mathrm{PhD}$ thesis. However, I could never have complete that alone. Instead, its completion relied on many agencies and people to whom I wish to thank at this final stage of this journey.

First of all, I would like to thank the Chinese Scholarship Council (CSC) and the University of Twente (UT). The financial support from CSC and the inclusive research environment created by UT laid the solid material foundations for my PhD journey, and made it less daunting.

Second, I want to express thanks to my team of supervisors: my promotor Petra de WeerdNederhof, and my two daily supervisors, Sandor Lowik and Haibo Zhou. I could not have come so far and achieved so such without your supervision. You turned me into a qualified researcher.

Petra, while you have stayed in academia for over three decades, in my opinion you would be an excellent strategic investor if you went into industry. I still remember that you were the first one saying 'yes' to going to Beijing to collect the bike-sharing industry data. Even though there were many uncertainties and risks since the Chinese bike-sharing industry was undergoing much turbulence at that time, you still encouraged me to make a plan and approved my travel budget. I still remembered you created various opportunities for me to attend courses, seminars, and conferences where I met new people and gained new insights. Besides, the weekly meetings and spontaneous communications in your office always inspired me as you would always suggest novel ideas. Your rich experience of paper writing, case-study conducting, paper presenting promote the finish of the $\mathrm{PhD}$ thesis. Importantly, your inclusive attitudes to my impulsiveness and many kindness made me feel at home in Netherlands. Thanks for your consistent support, financially, academically, and mentally. 
Sandor, I am glad that you did not convince me of selecting the innovation campus as my major topic though that is also a promising research topic. During the past five years, we had many interesting discussions though emails, in the office, on the road and in the train. Especially in the campus office, I cannot remember how many times we disagree with each other on various research topics. Even though sometimes the fierce disagreements made you uncomfortable, you continued to offer useful advice and tips to encourage me to think further. I have never met any supervisor who is so critical, dedicated, stimulating, and enthusiastic as you have been during the PhD supervision sessions. You always had good comments; you always showed patience while listening to my foolish ideas and tolerance of my 'stubbornness'; you always made things structured and challenged existing academic authorities. These qualities from you and your work will be highly beneficial for me and my work in the future. Thank you for supervising me.

Haibo, it perhaps the best decision I ever made during my PhD lifetime to invite you to be my daily supervisor. Your participation in my daily supervisions advanced my research enormously. You could easily understood what I meant in writing and in conversation because we share the same culture and language. So you were the bridge in the supervisor team, connecting Sandor, Petra, and me. Throughout the past four years, you have imparted to me many pragmatic tactics regarding writing a paper, a response letter, a formal request, an application for an award, and even a greeting email. What impressed me the most were the days we spent in Groningen in the summer of 2018. You taught me how to address reviewers' comments, hand by hand, word by word. You kept asking me to narrow my focus, to be more concrete and specific in formulating specific argumentations when to open the dialogue with peer scholars. Working with well-experienced researchers such as you reminds me how fortunate and honored I am! Thank you for supervising me so well.

Third, I have to thank people who also contributed to my research directly, since the accomplishment of this $\mathrm{PhD}$ project also involving them. Hoping not to painfully forget anybody, I take the risk of mentioning their names.

I would like to thank my close colleagues at the NIKOS. Agata, Isabella, Niina, Tijs, thank you for never tiring of replying to my emails. I still remember Isabella made great efforts to completely reviewing the bike-sharing paper. Your constructive comments and compliments gave me the confidence to continue the research. Annemarie, Ariane, Bart, Björn, Efthymios, Jeroen, Marlies, Michel, Patrick, Rainer, and Raymond, thank you for sharing your experiences and offering useful advice, which helped my research a great deal. Anna, Carolina, Hanna, Igors, 
Koen, Lisa, Martin, Timo, Xander, and Yasin, thanks for chatting with me during work breaks, and always being ready to listen to my complaints. I will never forget those good memories of you during lunches, seminars, conferences, and home parties. Andres, Ari, and Shuijing, thank you for being my good roommates, and making it pleasant for me to go to the office each day. Last but not least, I am grateful to Liqin: thank you for accompanying me along this long march. Your consistent encouragement helped me survive the most stressful periods.

There are more people at NIKOS as well as at TMS that contributed to my research. I would like to particularly thank the NIKOS secretarial staff: Danielle, Hester, Joyce, Marieke, and Monique. Your supporting work provided much convenience to my research, travel, and applications. I really appreciate your contributions. TMS members such as Erwin, Frederik, Holger, Klaas, Matthias, Remco, Vincent helped me in many ways. Thank you for spending the time listening to my research stories, and importantly, giving me much inspiration.

In addition to my colleagues at the UT, I would like to say thanks to my friends at the UT: Ben, Changqing Lu, Chenxiao Tang, Guorui Huang, Jinyao Tang, Minghao Yu, Pengyu Xu, Qi Wang, Shu Zhang, Tao Tian, Wei Liu, Wenyi Wang, Xiaochen Liu, Yang Wang, Yifei Yu, Yuan Lin, Yuntao Zhu, Zheqian Yuan, Zhen Jiao, Zhicheng Yang. During the past four years, the precious moments of cooking, shopping, playing basketball, cycling, and traveling with you guys made the whole $\mathrm{PhD}$ lifetime less stressful.

Outside UT, I would like to mention others and thank them. My four co-authors, Peter Ping Li, Yanghong Tu, Yanmin Wang, and Yi Ruan, thanks for your great collaborations in finishing papers in English or Chinese. Without your input, these published papers would have been impossible. During the collaborations, I learnt a lot in terms of how to perform a good research. Four senior researchers - Aki Harima, Christina Theodoraki, Erik Stam, Ke Rong thank you for guiding my studies. Communicating with you always makes me well-enlightened. I hope to cooperate with you in the future if suitable opportunities arise.

I have my special thanks to qualifier committee: prof. Jörg Henseler, prof. Georges Romme, and dr. Klaasjan Visscher. Your constructive feedback on my doctoral framework inspired me a lot, and gave me much confidence to move forward. Definitely, I see you as excellent scholars that I should follow in my future academic career.

Finally, I want to show my gratitude, respect, and love to my family. The most important person in my life, Yiqian (Mrs. Hu), my wife, thanks for regularly pulling me away from the sometimes stressful academic world and keeping me in touch with the real community life, 
thank you for marrying to me and being my only reason to come back China and come home every day; also, thanks for creating the favorable environment for my $\mathrm{PhD}$ work. I keep in mind our plans about what to do and where to go. I hope these plans will become realities in future. My own parents, my mother-in-law, my father-in-law, thanks for your consistent love, trust, support, encouragement, and patience. I love you more than you can imagine.

Jin Han

Changsha, 09 March 2021

\section{致谢 (Acknowledgement in Chinese)}

在过去的五年博士生涯里, 我从未体验过如此纯粹而又漫长的科研生活。说纯粹, 是因为 没有任何外在干扰，得以静下心来思考科研问题; 说漫长，则是思考的过程及其缓慢而又复杂， 容不得半点急功近利。在过去的五年里, 值得高兴的是自己的科研能力得到显著提升, 能够独 立自主的承担一项科研课题; 而比较失望的地方在于, 与顶尖的科研工作者相比, 自己在研究 素养上还存在相当大的差距。能够一路坚持下来并走到论文答辩讲台上, 这并非一人之功, 而 是多方帮助与鼓励的结果。这令人心存感激, 特以致谢。

首先需要感谢国家公派留学基金委员会、荷兰大使馆教育处和特温特大学。留学基金委员 会不仅给予了雄厚的生活补助, 在科研管理上也出处体现人文主义关怀。与此相关的荷兰大使 馆教育处也时刻关注中国留学生的个人健康、生活和学习。2020 年春天, 新冠肺炎肆虐荷兰境 内, 教育处迅速给留学生派发充足的防护用品, 就是最好的例证。而特温特大学为我提供了宽 松的科研环境。我十分感激特温特大学在科研上的包容态度, 不以论文数量来评判一个科研工 作者的绩效好坏。而是着眼于未来, 关注博士生的科研基础和挖掘科研潜力。这令我能潜心阅 读英文文献、著作, 安心地思考学术问题。

其次需要感谢我的导师团队: Petra、Sandor 和周海波老师。导师们对待科研工作充满敬畏、 始终秉承着严谨细致的科研态度, 使我获益颇丰。在过去的五年时间里, 他们的辛勤指导使我 在学术思辨、数据收集分析、论文写作与修改等方面的能力得到了质的飞跃。

再次需要感谢我的同事和荷兰的朋友们。我亲密的同事们：Anna、Carolina、Hanna, Igors、 Koen、Lisa、Martin、Timo、Xander、Yasin。感谢你们无微不至的关怀, 令我快速地适应了荷 兰文化, 并感受到了荷兰文化的独特鬼力。我的荷兰小伙伴们: 陆长青、黄国锐、徐鹏宇、王 启、张舒、刘威、王洋、呼逸非、林远、朱云涛、焦振、杨志成。感谢你们! 与你们一起吃火 锅、打篮球、骑车、旅行的时光, 令我终生难忘。 
还需要感谢我的论文合作作者：李平老师、涂艳红师姐、王彦敏老师、阮奕老师。能够与 你们一起开展论文合作, 令我倍感营幸。在论文合作过程中, 你们身上所散发的独特的人格鬼 力, 令我敬仰。

还需要特别感谢我的高中好友们：陈志辉、陈卓、程成、戴钧、焦赞、李文、秦梧斌、汪 浩、谢长春、徐沶、严成、易超、易鹏; 本科好友们: 曹志明、崔禄健、贺靖、何畅、贺泽芳、 洪礼敏、黄程、李红、李忠杰、罗孝、王胜、伍翕婷、钟雅至; 硕士好友们: 边慧东、胡星野、 黄小宝、李嗓、李招来、刘杰、刘金洋、刘佩、龙腾、欧阳妮、苏亚、田可、王珂、谢芳、谢 康、张丹丹、张帆、朱天箭。如果没有你们一直以来的帮助与支持, 我无法坚持走到现在。与 你们在一起的时光，始终能令我身心舒畅。衰心期盼我们的友谊长存！

最后我想对我的爱人和亲人表达我最真挚的感谢。移倩，从恋爱到结婚，四年异国、两万 多公里, 感谢你一直以来的包容、耐心和爱。你的存在始终能给枯燥无味的学术生活添上勃勃 生机。爸、妈, 感谢你们对儿子长达 25 年的教育投资。在过去 25 年的求学生涯里, 你们一以 贯之的信任、鼓励、呵护，使我成为社会可用之材。这份恩情和爱，超越了世界上一切可加修 饰的语言。我爱你们! 请时间慢慢走, 请你们慢慢变老。 
Building and sustaining an innovation ecosystem is more like developing a whole residential district: more complex than other forms, more players to coordinate, more layers of interaction, and unintended emergent outcomes. Dosing so is challenging for most ambitious new ventures. With four studies, this $\mathrm{PhD}$ research offers rich new insights into how new ventures as ecosystem navigators can increase the sustainability of their innovation ecosystems by effectively designing and executing strategies, and exploiting organizational dynamic capabilities. 